Universidade Federal do Paraná

\author{
Anderson Leão Frigo
}

\title{
Two-dimensional vessel-current interaction model for inland waterways assessment
}




\author{
Anderson Leão Frigo
}

\title{
Two-dimensional vessel-current interaction model for inland waterways assessment
}

Tese apresentada como requisito parcial à obtenção do grau de Doutor, Programa de Pós-Graduação em Engenharia de Recursos Hídricos e Ambiental, Setor de Tecnologia, Universidade Federal do Paraná.

Supervisor: Prof. Dr. Ing. Tobias Bernward Bleninger 
Catalogação na Fonte: Sistema de Bibliotecas, UFPR Biblioteca de Ciência e Tecnologia

\section{F899t Frigo, Anderson Leão}

Two-dimensional vessel-current interaction model for inland waterways assessment / Anderson Leão Frigo . - Curitiba, 2018.

$$
153 \mathrm{f} \text {. : il. color. ; } 30 \mathrm{~cm}
$$

Tese - Universidade Federal do Paraná, Setor de Tecnologia, Programa de Pós-Graduação em Engenharia de Recursos Hídricos e Ambiental, 2018.

Orientador: Tobias Bernward Bleninger Bibliografia: p. 132-141.

1. Hidrovias. 2. Navios - Hidrodinâmica. 3. Engenharia hidráulica. 4. Mecânica dos fluidos. 5. Paraguai, Rio - Navegação. I. Universidade Federa do Paraná. II. Bleninger , Tobias Bernward. III. Título.

CDD: 627.1

Bibliotecário: Elias Barbosa da Silva CRB-9/1894 


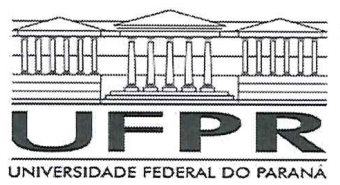

MINISTÉRIO DA EDUCAÇÃO

SETOR TECNOLOGIA

UNIVERSIDADE FEDERAL DO PARANÁ

PRÓ-REITORIA DE PESQUISA E PÓS-GRADUAÇÃO

PROGRAMA DE PÓS-GRADUAÇÃO ENGENHARIA DE

RECURSOS HÍDRICOS E AMBIENTAL

\section{TERMO DE APROVAÇÃO}

Os membros da Banca Examinadora designada pelo Colegiado do Programa de Pós-Graduação em ENGENHARIA DE RECURSOS HIDRICOS E AMBIENTAL da Universidade Federal do Paraná foram convocados para realizar a arguição da Tese de Doutorado de ANDERSON LEÃO FRIGO, intitulada: \&NBSP; TWO-DIMENSIONAL VESSEL-CURRENT INTERACTION MODEL \&NBSP;WATERWAYS ASSESSMENT, após terem inquirido a aluna e realizado a avaliação do trabalho, são de parecer pela sua a provaguz defesa. no rito de

A outorga do título de Doutor está sujeita à homologação pelo colegiado, ao atendimento de todas as indicações e correções solicitadas pela banca e ao pleno atendimento das demandas regimentais do Programa de PósGraduação.

Curitiba, 26 de Fevereiro de 2018

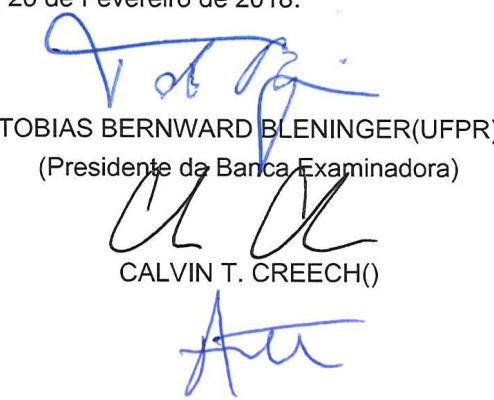

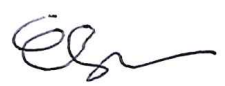

ELOY KAVISKI(UFPR)

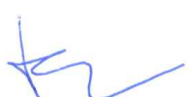

FERNANDO OLIVEIRA ANDRADE(UFPR)

EDUARDO RATTON(UFPR) 


\section{Acknowledgments}

First and foremost I would like to acknowledge my advisor Prof. Dr. Ing. Tobias Bernward Bleninger (Federal University of Paraná). I appreciate all his contributions, ideas and discussions to make my D.Sc. experience productive and stimulating. I am also grateful to Prof. Bleninger for the opportunity and encouragement to work abroad under the supervision of highly skilled researchers.

I am grateful to all the Professors and colleagues of the Post-Graduate Program in Water Resources and Environmental Engineering (Federal University of Paraná) for their support during my work. I am especially grateful to the Researchers and Professors who directly took part in the evaluation of my research: Calvin Creech, Cristovão Fernandes, Eduardo Ratton, Eloy Kaviski, Fernando Andrade, and Heinz Fill.

I also would like to acknowledge the excellent support provided by DNIT, ITTI, and the Brazilian Navy within the project of the Paraguay River EVTEA. The field campaigns, data gathering, and analysis were very important activities in the development of my studies. Furthermore, the cooperation provided by the colleagues at ITTI made possible the Paraguay River analysis.

I am grateful to the researchers of the Bundesanstalt Für Wasserbau in Karlsruhe, Germany. The shared data were fundamental for this research. I am especially grateful to Rolf Zentgraf, Dennis Harlacher and Markus Scherer for the precious opportunity of researching different models and approaches to enrich my D.Sc. experience.

Finally, I would like to thank CAPES for the fellowship that supported my graduate studies since 2011. This funding is very important in my career and I am very grateful to them. 
The public must retain control of the great waterways. It is essential that any permit to obstruct them for reasons and on conditions that seem good at the moment should be subject to revision when changed conditions demand. 


\section{Resumo}

As hidrovias brasileiras conectam o interior da América do Sul a polos industriais e a portos costeiros de águas profundas no Brasil, Argentina e Uruguai, possibilitando o escoamento de matérias primas, como grãos e minérios. Entretanto, o potencial do transporte aquaviário interior no país não é totalmente explorado. Um dos principais fatores que contribuem para este cenário é a falta de pesquisas específicas, levantamentos de campo e métodos operacionais próprios. É comum que a navegação ocorra com poucas informações (e.g. dados batimétricos), o que não é consistente com hidrovias modernas, competitivas e seguras. Neste trabalho foram analisados processos de modelagem hidrodinâmica e métodos operacionais utilizados mundialmente e aplicados à navegação. Foi identificado que pesquisas sobre avaliação de hidrovias internas são escassas no Brasil, relacionadas a problemas específicos e os métodos muitas vezes são inerentes à navegação marinha e de canais de aproximação. Esta tese apresenta uma abordagem para avaliar a capacidade de navegação dos rios através de um modelo 2D fast-time, que analisa a interação entre navios e o escoamento fluvial. O modelo utiliza escoamentos Eulerianos e uma abordagem Lagrangeana para o ship-tracking, integrando as principais características dos rios (e.g. campo de velocidade) e das embarcações (e.g. dimensão, manobrabilidade), calculando os momentos lineares e angulares resultantes, determinando o movimento dos navios em pontos considerados críticos para a navegação. A parte alemã do rio Reno foi utilizada para a verificação do modelo e o trecho brasileiro do rio Paraguai foi utilizado como estudo de caso. Medições de campo foram necessárias como dados de entrada e para auxiliar na avaliação da capacidade de navegação dos rios. De acordo com os resultados, o modelo conseguiu reproduzir satisfatoriamente a navegação de navios no rio Reno. Em seguida, foram realizados estudos em regiões críticas para a navegação no rio Paraguai. Foi possível analisar a influência dos parâmetros dos navios e canais que mais impactam a capacidade de navegação, como a velocidade, massa e o raio de curvatura. Portanto, pode-se usar os resultados do modelo para para otimizar o design e o gerenciamento de hidrovias interiores.

Palavras-chaves: Hidrovias. Modelagem. Piloto automático. Transporte fluvial. 


\section{Abstract}

Brazilian waterways link the interior of South America to industrial regions and coastal deep-water ports in Brazil, Argentina, and Uruguay, enabling the efficient flow of raw material as grain and ore. Nevertheless, the potential of the inland waterborne transport in the country is not fully explored. One of the main factors contributing to this scenario is the lack of specific research, field surveys, and operational methods. The navigation is mostly performed using few data (e.g. bathymetric data), which is not consistent with modern, competitive and safe waterways. This work analyzes hydrodynamic modeling and operational methods used worldwide and applied to navigation. It was identified that few methods for inland waterway navigability assessment in Brazil are used; they are sparse on specific problems and the methods used are often concepts of marine navigation and approach channels. This thesis presents a survey in how to assess the navigability capacity of rivers by a 2D fast-time vessel-current interaction model. The developed model uses Eulerian flows and a Lagrangian ship tracking approach, coupling river features (e.g. velocity field) and ship characteristics (e.g. dimension, maneuverability), calculating the resultant linear and angular momentum, thus measuring the ship motion at critical points for navigation. The German section of the Rhine River was used for the model verification and the Brazilian stretch of the Paraguay River as case study. Field measurements are necessary as input data and were processed to determine the navigation potential of rivers. According to the results, the model was able to reproduce satisfactorily the navigation of ships on the Rhine River. Then, studies of critical regions for navigation in the Paraguay River were carried out. It was possible to analyze the influence of parameters of vessels and channels that most impact the navigation capacity, such as the velocity, mass, and curvature radius. Therefore, one can use the model results for decision making policies to optimize the design and management of inland waterways.

Keywords: Waterways. Modeling. Auto-pilot. River transportation. 


\section{List of Tables}

1.1 Comparison between transport main modes. . . . . . . . . . . . . . . . . 21

2.1 Brazilian main waterways length and transported cargo. . . . . . . . . . 25

2.2 Locks in Brazilians main waterways. . . . . . . . . . . . . . . . . . 27

2.3 Key aspects for assessment of cargo vessels on inland waterways. . . . . . . 31

2.4 Survey on the largest convoys currently allowed in the main Brazilian waterways. . . . . . . . . . . . . . . . . . . 31

4.1 Fast-time and real-time computer models to evaluate navigability capacity of vessels and waterways. . . . . . . . . . . . . . . . . . . . . 72

5.1 Summary of initial results simulations. . . . . . . . . . . . . . . 80

5.2 Ship parameters setup for scenario simulations. . . . . . . . . . . . . 103

5.3 RMSE results of scenario I. . . . . . . . . . . . . . . . . . . 105

6.1 Ship parameters setup for Paraguay River simulations. . . . . . . . . . . 121

6.2 Summary of ship parameters for scenario III . . . . . . . . . . . . . . . 127

A.1 Additional width due to the ship maneuverability capacity. . . . . . . . . . 142

A.2 Additional width due to the ship velocity. . . . . . . . . . . . . . . . 142

A.3 Additional width due to the wind intensity. . . . . . . . . . . . . . . . . . 142

A.4 Additional width due to the transversal current velocity. . . . . . . . . . 143

A.5 Additional width due to the longitudinal current velocity. . . . . . . . . . 143

A.6 Additional width due to aid to navigation. . . . . . . . . . . . . . . 143

A.7 Additional width due to cargo risk. . . . . . . . . . . . . . . . 143

A.8 Additional width due to the channel bottom surface. . . . . . . . . . . . 143

A.9 Additional width due to the depth-draft ratio. . . . . . . . . . . . . . . 144

A.10 Additional width due to effects of proximity to existing structures. . . . . . 144

B.1 Vessel-current model parameters. . . . . . . . . . . . . . . . . . 145

C.1 Simulation I parameters setup. . . . . . . . . . . . . . . 146

C.2 Simulation II parameters setup. . . . . . . . . . . . . . . . 147 
C.3 Simulation III parameters setup. . . . . . . . . . . . . . . . . . . 147

C.4 Simulation IV parameters setup. . . . . . . . . . . . . . . . . . . . . 148

C.5 Simulation V parameters setup. . . . . . . . . . . . . . . . . . 148

D.1 Setup parameters used to calibrate a Paraguay type vessel. . . . . . . . . . 149

D.2 Setup parameters used to calibrate the Rhine River vessel. . . . . . . . . . 149

E.1 Description of used scripts. . . . . . . . . . . . . . . . . 151 


\section{List of Figures}

1.1 Brazilian transport matrix. . . . . . . . . . . . . . . . . . 21

1.2 Freight modal split for BRICS countries. . . . . . . . . . . . . . . 22

2.1 The Brazilian rivers and main waterways. . . . . . . . . . . 26

2.2 Dependence of the gross tonnage capacity to the ship draft and length. . . 29

2.3 Dependence of the gross tonnage capacity to the ship width and the relation between the ship width and length. . . . . . . . . . . . 30

2.4 Representation of a $n \bullet m$ convoy composition. . . . . . . . . . 32

3.1 Boat angular movements and general shipboard directions. . . . . . . . . 48

3.2 Inertial and vessel two-dimensional reference system and ship discretization in $P_{N}$ points. . . . . . . . . . . . . . . . . . . . . . . . . . . 49

3.3 Coordinate system representation of a river. . . . . . . . . . . . . 49

4.1 Sample of a bathymetric analysis. . . . . . . . . . . . . . . . 59

4.2 Sample of a cross-section longitudinal velocity magnitude. . . . . . . . . . 61

4.3 Drag force due to pressure (form) and shear stress (skin-friction). . . . . . 63

4.4 Drag force due to pressure (form) and shear stress (skin-friction) for a rectangular ship. . . . . . . . . . . . . . . . 65

4.5 Skin-friction drag coefficient for a plate. . . . . . . . . . . 66

5.1 Model main input data. . . . . . . . . . . . . . . . . . . 74

5.2 Example of the model GUI to setup and evaluate results. . . . . . . . . . 75

5.3 Model spatial data input. . . . . . . . . . . . . . . . 76

5.4 Velocity points mesh in the Rhine River. . . . . . . . . . . . . . . 78

5.5 Summarized algorithm diagram of the vessel-current interaction model. . . 79

5.6 Auto-pilot detection of the navigation path. . . . . . . . . . . 80

5.7 Ship motion results for scenario I. . . . . . . . . . . . . . . . . 81

5.8 Scenario I results for ship velocities and resultant forces. . . . . . . . . . 82

5.9 Scenario I results for the Froude number and angle. . . . . . . . . . . . 83

5.10 Drag force quadratic relation with the ship velocity. . . . . . . . . . . 84

5.11 Ship motion results for scenario II. . . . . . . . . . . . . . . . 85 
5.12 Scenario II results for the velocities and forces. . . . . . . . . . . . . . . 86

5.13 Scenario II results for the Froude number and angle. . . . . . . . . . . . . . 87

5.14 Ship motion results for scenario III. . . . . . . . . . . . . . . . . . . . . 88

5.15 Scenario III results for velocities and forces. . . . . . . . . . . . . . . . . 89

5.16 Scenario III results for the Froude number and angle. . . . . . . . . . . . . 90

5.17 Ship motion results for scenario IV . . . . . . . . . . . . . . . . . . . 91

5.18 Scenario IV results for velocities and forces. . . . . . . . . . . . . . . . 92

5.19 Scenario IV results for the Froude number and angle. . . . . . . . . . . . . 93

5.20 Ship motion results for scenario V . . . . . . . . . . . . . . . . . 94

5.21 Scenario V results for velocities and forces. . . . . . . . . . . . . . . . . 95

5.22 Scenario V results for the Froude number and angle. . . . . . . . . . . . . . 96

5.23 Stability analysis of the model. . . . . . . . . . . . . . . . . 98

5.24 Drag force distribution in the ship port and bow. . . . . . . . . . . . . 99

5.25 Ship maneuverability analysis example. . . . . . . . . . . . . . . . . . 99

5.26 Example of the vessel-current model result. . . . . . . . . . . . . . . . 100

5.27 Data sample shared by the BAW . . . . . . . . . . . . . . . 102

5.28 Downstream and upstream results of a ship following real data path for different maneuver forces. . . . . . . . . . . . . . . . . . . . . . . . . . 104

5.29 Downstream navigation telemetry and simulation results using $50 \%$ and $100 \%$ of possible maneuver force. . . . . . . . . . . . . . . . 106

5.30 Upstream navigation telemetry and simulation results using 50\% and $100 \%$ of possible maneuver force. . . . . . . . . . . . . . . . . 107

5.31 Correlation analysis for velocity and angle for downstream navigation of the model result and measured ship. . . . . . . . . . . . . . . . . . . 108

5.32 Downstream and upstream results of a ship using the potential path as orientation line. . . . . . . . . . . . . . . . . . . . . . 109

5.33 Unlimited and limited speed influence on the ship motion for different mass values.

6.1 Restriction of the maximum width and length of barges composition in the northern stretch of the Paraguay River waterway. . . . . . . . . . . . . . 115

6.2 Paraguay River critical sections for navigation. . . . . . . . . . . . . 116

6.3 Field surveys region. . . . . . . . . . . . . . . . . . . 117

6.4 Sample of Paraguay River input data. . . . . . . . . . . . . . . . 120

6.5 Flow velocity magnitude in the study section of the Paraguay River. . . . . 121

6.6 Scenario I results: downstream navigation at Santana Pass. . . . . . . . . . 122

6.7 Scenario I results: downstream navigation at Miguel Henrique Pass. . . . . 123 
6.8 Scenario I results: downstream navigation at Mucunã Pass. . . . . . . . . . . 124

6.9 Scenario I results: downstream navigation at Abobral Pass. . . . . . . . . . . 124

6.10 Scenario I results: downstream navigation at Caraguatá Pass. . . . . . . . 125

6.11 Scenario I results: downstream navigation at Jacaré Pass. . . . . . . . . . . 125

6.12 Scenario II results: navigation performance comparison of vessels with different lengths. . . . . . . . . . . . . . . . . . . . . . 126

6.13 Scenario III results: navigation performance of vessels with different characteristics. . . . . . . . . . . . . . . . . . . 127

D.1 Setup parameters used to calibrate the Paraguay River vessel. . . . . . . . 150

D.2 Setup parameters used to calibrate the Rhine River vessel. . . . . . . . . . 150 


\section{Acronyms}

ADCP Acoustic Doppler Current Profiler.

ANA Brazilian National Agency for Water.

ANEEL Brazilian Electricity Agency.

ANTAQ Brazilian Agency for Waterway Transportation.

BAW German Federal Agency for Waterways.

BRICS Group of five major emerging economies: Brazil, Russia, India, China and South Africa.

CFD Computational Fluid Dynamics.

DNIT Brazilian National Bureau of Infrastructure and Transportation.

EVTEA Study of Technical, Economic and Socio-Environmental Feasibility.

GIS Geographic Information System.

GNP Gross national product.

GUI Graphical User Interface.

HPP Hydro Power Plant.

IHO International Hydrographic Organization.

ITTC International Towing Tank Conference.

ITTI Technological Institute of Transport and Infrastructure of the Federal University of Paraná.

MMC Method of Monte Carlo. 
NACA National Advisory Committee for Aeronautics.

NASA National Aeronautics and Space Administration.

PIANC Permanent International Association of Navigation Congresses.

RMSE Root Mean Square Error.

TKM Ton-kilometer unit.

UFPR Federal University of Paraná.

USGS U.S. Geological Survey. 


\section{List of Symbols}

$C_{D}$ Drag coefficient ( ).

$C$ Curvature radius $(m)$.

Fr Froude number ( ).

Gt Gross tonnage ( ).

$R^{2}$ Pearson coefficient of determination ( ).

Re Reynolds number ( ).

$\alpha_{L}$ Angle of attack $(\mathrm{rad})$.

$\alpha$ Angular acceleration $\left(\mathrm{rad} / \mathrm{s}^{2}\right)$.

$\mu$ Fluid cinematic viscosity $(\mathrm{kg} / \mathrm{s} \times \mathrm{m})$.

$\rho$ Fluid density $\left(\mathrm{kg} / \mathrm{m}^{3}\right)$.

$\theta$ Angle formed between a vector and the axis of a coordinate system $(\mathrm{rad})$.

$\vec{F}$ Force vector $(N)$.

$\vec{L}$ Angular momentum vector $\left(K g \bullet \mathrm{m}^{2} / \mathrm{s}\right)$.

$\vec{P}$ Linear momentum vector $(K g \bullet m / s)$.

$\vec{\tau}$ Torque vector $(N \bullet m)$.

$\vec{w}$ Angular velocity $(\mathrm{rad} / \mathrm{s})$. 


\section{Contents}

1 Introduction $\quad 20$

2 The Brazilian waterway system and navigability assessment methods 25

2.1 Brazilian inland waterways . . . . . . . . . . . . . . . 25

2.2 Brazilian fleet . . . . . . . . . . . . . . . . . . . . 28

2.3 Research and standards for waterways . . . . . . . . . . . . . . 32

2.4 Navigation channel design for Brazilian inland waterways . . . . . . . . . . 34

2.4.1 Channel width for meander sections . . . . . . . . . . . . . . . . . . 35

2.4.2 Channel width for straight sections . . . . . . . . . . . . . . . . 35

2.4.3 Channel curvature radius . . . . . . . . . . . . . . . . . . . 37

2.4.4 Channel depth . . . . . . . . . . . . . . . . . . . . . . 37

2.5 Chapter closure . . . . . . . . . . . . . . . . . . . . . 37

3 Rigid body dynamics applied to a vessel 38

3.1 Kinematic equations . . . . . . . . . . . . . . . . 38

3.2 Equations of motion . . . . . . . . . . . . . . . . . . 40

3.3 General system of equations of motion . . . . . . . . . . . . . . . 42

3.4 Characterization of vessels as rigid bodies . . . . . . . . . . . . . 47

3.5 Chapter closure . . . . . . . . . . . . . . . . . . . . 49

4 Fluid mechanics for river hydraulics and immersed rigid bodies $\quad 50$

4.1 Governing equations for fluid flow . . . . . . . . . . . . . . . 50

4.1 .1 Continuity equation . . . . . . . . . . . . . . . 51

4.1 .2 Momentum equation . . . . . . . . . . . . . . . . . . . 52

4.1 .3 Navier Stokes equations _ . . . . . . . . . . . . . . . . . . 53

4.2 Fluvial hydraulics and river modeling . . . . . . . . . . . . . . . . . 54

4.2.1 Open channel hydraulics . . . . . . . . . . . . . . . . . . . . 56

4.2 .2 River bends . . . . . . . . . . . . . . . . . . . . . . . . 58

4.2 .3 Bathymetry . . . . . . . . . . . . . . . . . . . . . . 58

4.2 .4 Velocity field . . . . . . . . . . . . . . . . . . . 60 
4.3 Fluid flow around immersed bodies . . . . . . . . . . . . . . . . 61

4.3 .1 Drag force . . . . . . . . . . . . . . . . . . . . . . 62

4.3 .2 Lift forces . . . . . . . . . . . . . . . . . . . . . . . . . . 68

4.3 .3 Added mass . . . . . . . . . . . . . . . . . . . . . . . . . . . . . . . 69

4.4 Modeling ship motion . . . . . . . . . . . . . . . . . . . 70

4.5 Chapter closure . . . . . . . . . . . . . . . . . . . . 72

5 Vessel-current interaction model $\quad 73$

5.1 Input data . . . . . . . . . . . . . . . . . . . . . . 74

5.2 Main algorithm . . . . . . . . . . . . . . . . . 77

5.3 Auto-pilot algorithm . . . . . . . . . . . . . . . . . 77

5.4 Model testing . . . . . . . . . . . . . . . . . . . . 80

5.4 .1 Scenario I: engine force response . . . . . . . . . . . . . . . . . . . . 81

5.4 .2 Scenario II: longitudinal flow response . . . . . . . . . . . . . . . . . . . . 85

5.4 .3 Scenario III: transversal flow response . . . . . . . . . . . . . . . . . . . . 88

5.4 .4 Scenario IV: maneuverability analysis . . . . . . . . . . . . . . . . . . . . 91

5.4.5 Scenario V: auto-pilot analysis . . . . . . . . . . . . . . . . . . . 94

5.4 .6 General analysis . . . . . . . . . . . . . . . . . . . . . 97

5.5 Model verification . . . . . . . . . . . . . . . . . . . . . . . 100

5.5 .1 Field data . . . . . . . . . . . . . . . . . . . . . . 101

5.5 .2 Verification results . . . . . . . . . . . . . . . . . . 103

5.6 Chapter closure . . . . . . . . . . . . . . . . . . . . . 110

6 Case study - Paraguay River 112

6.1 Area of study . . . . . . . . . . . . . . . . . . . . . . . 112

6.2 Characterization of the Paraguay River navigation channel . . . . . . . . . . . 114

6.3 Field data . . . . . . . . . . . . . . . . . . . . . . 116

6.3 .1 Flow velocity . . . . . . . . . . . . . . . . . . . 118

6.3 .2 Bathymetry . . . . . . . . . . . . . . . . . . . 118

6.3.3 Discharge . . . . . . . . . . . . . . . . . . . . . . . 119

6.3.4 Sediment transport . . . . . . . . . . . . . . . . . . . . . . . 119

6.4 Navigation modeling . . . . . . . . . . . . . . . . . . . 119

6.4 .1 Simulation setup . . . . . . . . . . . . . . . . . . 120

6.4 .2 Scenario I . . . . . . . . . . . . . . . . . . . . . . . . . . . . 122

6.4 .3 Scenario II . . . . . . . . . . . . . . . . . . . . . . . . . 126

6.4 .4 Scenario III . . . . . . . . . . . . . . . . . . . . . . . . 127

6.5 Chapter closure . . . . . . . . . . . . . . . . . . . . . 128 
7 Conclusions

Bibliography

Appendix

A PIANC navigation channel width calculation

B Model parameters

C Model simulation parameters

D Ship calibration relations

E Description of developed scripts

F Publications 


\section{Chapter 1}

\section{Introduction}

The study of waterways and the maintenance of its navigability is not a recent topic. Haupt $(1890,1908)$ discussed the importance of investment in the waterborne transport, stating the necessary measures to relieve the country infrastructure (USA) from inadequate facilities to transport the high tonnage produced. The author also researched various fields related to the waterborne transportation, highlighting the analysis of economic viability due to dredging and also political impediments. Even after a century of this publication these topics and discussions are still relevant abroad and even more in Brazil.

According to the Brazilian National Agency of Waterway Transportation, (ANTAQ, 2012) Brazil has one of the largest waterway networks in the world: about $27,000 \mathrm{~km}$ in navigation conditions with potential for expansion of over $15,000 \mathrm{~km}$, resulting in a total estimated navigable mesh of 42,000 km. Thus, deployment, maintenance, and improvement of waterways are factors of great importance for the expansion and diversification of the transport matrix, a strategic long-term planning for the country economy and infrastructure.

Costa (2001) described the major characteristics of the most used transportation, modes, presented in Table 1.1. The waterborne transport is considered the most efficient mode to shift large volumes of cargo with low unit value (e.g. grain and ore), which corresponds to a great portion of the production of wealth in Brazil (Ministério do Desenvolvimento, 2015), reinforcing the need for investment and research in this mode.

The Brazilian freight matrix of products transported within the country is summarized in Fig. $1.1^{1}$. A total of $16 \%$ of the cargo was moved by waterborne mode, where $11 \%$ by ocean navigation and $5 \%$ by inland waterways. The road transport accounted for $65 \%$,

\footnotetext{
${ }^{1}$ Values are presented in Ton-kilometer unit (TKM), a measurement equivalent to the weight of material transported in tonnes multiplied by the number of useful kilometers of the transport mode.
} 
Table 1.1: Comparison between transport main modes. Data provided by Costa (2001).

\begin{tabular}{ccc}
\hline Waterways & Railroads & Highways \\
\hline Carrying capacity ${ }^{1}:$ & 22 wagons bulk & 39 bulk trucks \\
1 barge & 132 wagons bulk & 234 bulk trucks \\
Life span: & 1 train $=30$ years & 1 truck $=10$ years \\
1 barge $=50$ years & & \\
$\frac{\text { Implementation cost: }}{1 \mathrm{~km}=\text { US } \$ 34,000}$ & $1 \mathrm{~km}=$ US $\$ 1.4$ million & $1 \mathrm{~km}=$ US $\$ 440,000$ \\
$\frac{\text { Social and environmental cost }{ }^{2}:}{\text { US } \$ 0.23 / 100 \text { ton } / \mathrm{km}^{2}}$ & US $\$ 0.74 / 100$ ton $/ \mathrm{km}$ & US $\$ 3.20 / 100$ ton $/ \mathrm{km}$ \\
\hline
\end{tabular}

${ }^{1}$ Capacity: 1 barge $=1,100$ tons, 1 wagon bulk $=50$ tons and 1 grain truck $=28$ tons.

${ }^{2}$ Accidents, noise and environmental pollution, water consumption, and land occupied.

$15 \%$ by railroads, $4 \%$ by pipelines, and $0.02 \%$ by air (EPL, 2016).

Germany has an economically efficient network of waterways and may be used as a benchmark. The inland waterway transport is up to 240 million tons per year (Eurostat, 2007), equivalent to $75 \%$ of transport capacity by rail. The German Federal waterways accumulate a total of $7,350 \mathrm{~km}$ (WSV, 2016) and are an important part of the European waterways network. According to ANTAQ (2016), the Brazilian transportation of cargo in water channels was of 83.8 million of tons. Germany moves approximately 3 times this amount in a country with approximately a quarter of navigable rivers extension.
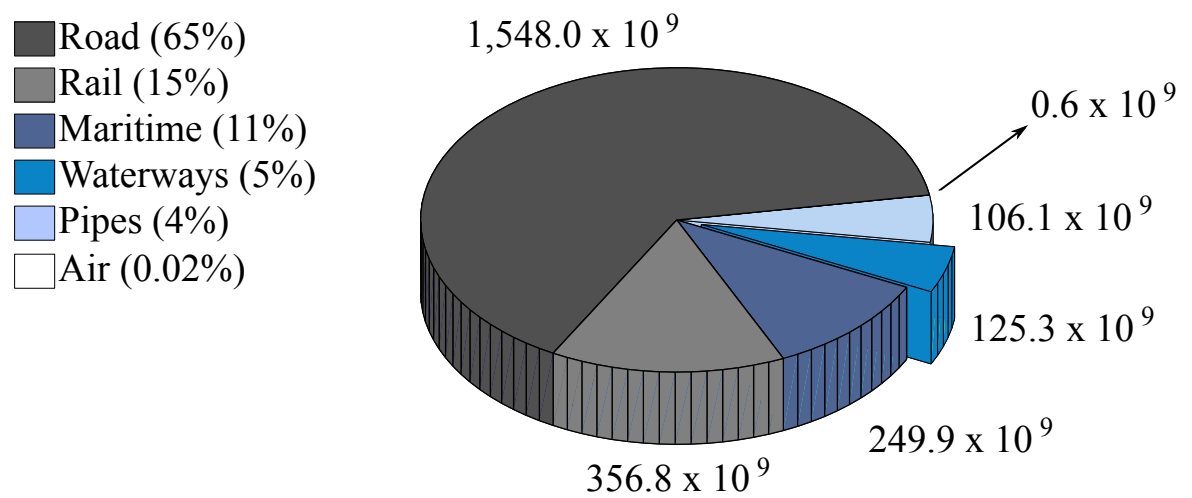

Figure 1.1: Brazilian transport matrix (EPL, 2016). The freight data are in ton-kilometer.

Comparing the Brazilian situation with other emerging countries can be considered more suitable to evaluate the actual situation and future prospects for the country transport planning. Figure 1.2 presents the freight modal split in ton-kilometer for BRICS ${ }^{1}$,

\footnotetext{
${ }^{1}$ Group of five major emerging economies: Brazil, Russia, India, China and South Africa (BRICS).
} 
where only inland transportation accounts as waterways. Among these countries, Brazil has the greatest dependence on road transportation. China, however, has a balanced modal split, where waterways are responsible for almost $30 \%$ of the total cargo transportation. Another important aspect is that, except Brazil, in all countries, railways are responsible for over a third of the freight.

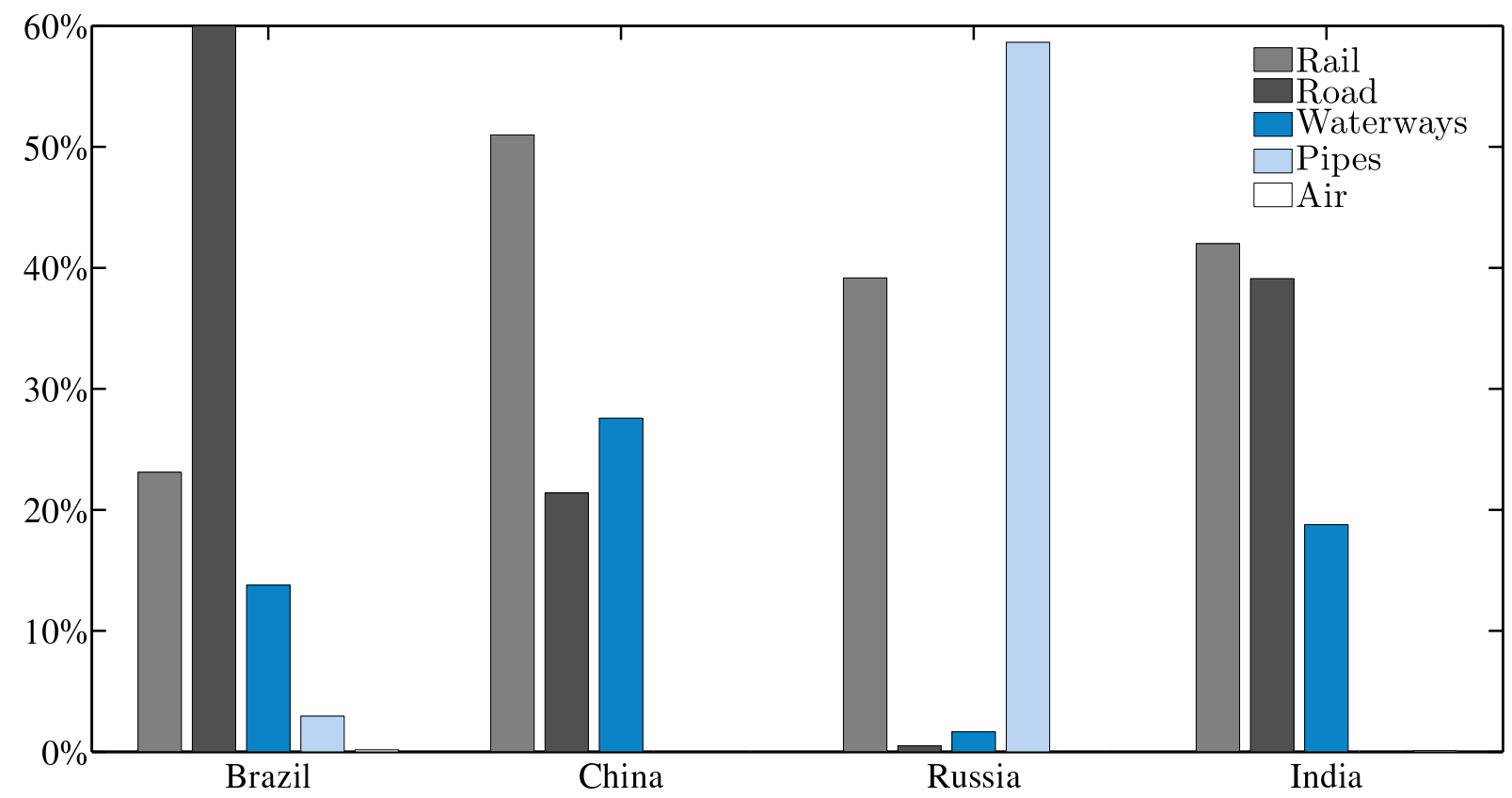

Figure 1.2: Freight modal split for BRICS countries, considering only inland modes and in percentage values of ton-kilometer. Data provided by the World Bank (2010).

According to several official reports (PNLT, 2012; Ministério dos Transportes, 2013; EPL, 2016) the expansion of Brazilian waterways is necessary to diversify the country transport matrix. Thus, federal and private investments are being applied to develop this transport mode. These studies are discussed in the following chapter.

Even though river systems are common in Brazil, few watercourses under natural conditions present features that allow safe and continuous navigation, capable of carrying out commercial transport of cargo (Almeida and Brigghetti, 1997). However, even these waterways require frequent follow-up studies and maintenance to support navigation.

The study of inland waterways is a multidisciplinary task, related to areas of geotechnics, hydrology, hydraulic and hydrodynamic modeling, and general issues of planning and logistics. The management becomes even more complex when adjustments to increase safety are necessary, which are usually due to natural conditions of watercourses and require detailed surveys, analysis, and modeling. Furthermore, engineering measures to improve navigability are planned to optimize the hydraulic system and to preserve its natural morphology, i.e. environmental impacts mitigation. 
The analysis of the navigability potential of waterways should not be evaluated solely for the morphological characteristics of these systems, such as width and depth of the channel, the same way that the simple determination of the flow velocity cannot ensure safe navigation conditions. Navigation safety is one of the key issues for any channel design (Briggs et al., 2003). This can only be guaranteed by detailed studies of the river system (Horritt and Bates, 2002), ship motion (Varyani, 2006; Lataire et al., 2012; von Graefe et al., 2015) and traffic management (Ince and Topuz, 2004). Nowadays attention should also be given to the multiple uses of water resources, such as urban supply and hydroelectric generation, which reinforces the need for studies to seek optimized use of rivers.

Currently, there is no global approach for the navigability capacity evaluation of waterways. In addition to general standards and guidelines, detailed in the next chapter, specific studies for navigation may be required, as small-scale models and computer models.

Small-scale studies are used for several analyzes, as the assessment of maneuvers in ports (e.g. Gerent and Alfredini, 2010) and the optimization of vessels (e.g. Hüsing et al., 2000). However, for large river sections this approach may be considered expensive and complex, thus a great variation of parameters is usually unfeasible. Computer models are an advanced approach for the analysis of river flow (e.g. Horritt and Bates, 2002) and simulation of ship motion (e.g. Linke et al., 2015). It has the advantage of the easy variation of several parameters and results analysis. Meanwhile, as disadvantages are the need for a large set of input data, calibration, computational effort and complexity for the model implementation. Therefore, both cited approaches are more suitable for the analysis of small river stretches.

This research found a knowledge gap in the high complexity and expense for the assessment of inland waterways projects, especially during early stages. It is proposed a fast-time model that, by few parameters of rivers and vessels and using semi-empirical analytic equations, evaluates the capacity of inland waterways to provide commercial navigation. Thus, given the main characteristics of rivers, flow and vessels, the twodimensional model calculates the vessel-current interaction, providing relevant information to design and management of waterways. The river velocity field is analyzed using a Eulerian approach, while for the ship-tracking a Lagrangian frame of reference is applied. The model is open source and has been built so that new features can be easily added or modified.

In this study, several works related to hydrodynamic modeling of vessels and rivers were investigated. Then, a large data set for the river characterization and modeling was 
collected during field surveys in the area of study. Finally, the developed vessel-current interaction model is described and its results are presented.

The thesis hypothesis is that the interaction occurring between vessels and river velocity fields is a key parameter to ensure navigation conditions for inland waterways and this interaction can be obtained through a two-dimensional analytical model.

The general objective of this research is the development of a model to evaluate the interaction between the river flow and vessels, thus characterizing the navigability potential of waterways. The specific objectives can be summarized as:

$\leq$ Review of the latest research on river navigation and inland waterways assessment.

$\leq$ Develop of a computational method to evaluate the vessel-current interaction.

$\leq$ Use the vessel-current interaction model to assess the navigability condition in sections of the Rhine and Paraguay River.

$\leq$ Evaluate the most relevant parameters to ensure navigability conditions.

This document is structured in seven chapters. In the first chapter the study introduction, objectives and hypothesis are presented. Chapter two is dedicated to a detailed survey on the situation and technical standards for Brazilian waterways. The third chapter presents an investigation of rigid bodies dynamics applied to vessel motion. In chapter four a review of fluid mechanics for river hydraulics and immersed bodies is presented. The fifth chapter presents the vessel-current model. The sixth chapter presents the model application in the Paraguay River. Finally, in the last chapter, the study conclusions and perspectives are presented. 


\section{Chapter 2}

\section{The Brazilian waterway system and navigability assessment methods}

This chapter initially presents an analysis of the Brazilian waterway system, where the characteristics and problems of its main rivers are discussed. Then, a description of the vessel cargo fleet operating in Brazil is presented. Finally, a survey of researches and standards for the construction and operation of waterways is analyzed.

\subsection{Brazilian inland waterways}

Currently, 13,000 km of the Brazilian rivers are extensively used for commercial navigation. Nevertheless, due to low water levels, only 6,500 km are continuously explored. Table 2.1 summarizes the extension and the transported cargo of the most important waterways in the country: Madeira-Amazonas, Tocantins-Araguáia, São Francisco, ParaguayParaná, and Tietê-Paraná rivers. Figure 2.1 highlights the aforementioned waterways.

Table 2.1: Brazilian main waterways length and transported cargo (ANTAQ, 2016).

\begin{tabular}{ccc}
\hline Waterway & Length $(\mathrm{km})$ & Transported cargo (ton/year) \\
\hline Madeira-Amazonas & 1,056 & $46.6 \bullet 10^{6}$ \\
Tocantins-Araguaia & 3,000 & $25.4 \bullet 10^{6}$ \\
São Francisco & 1,579 & $49.5 \bullet 10^{3}$ \\
Parana-Tietê & 1,258 & $6.3 \bullet 10^{6}$ \\
Paraguay-Paraná & 1,270 & $3.3 \bullet 10^{6}$ \\
\hline Total & 6,584 & $81.6 \bullet 10^{6}$ \\
\hline
\end{tabular}

The Strategic Plan for Waterways (Ministério dos Transportes, 2013) presents a set 


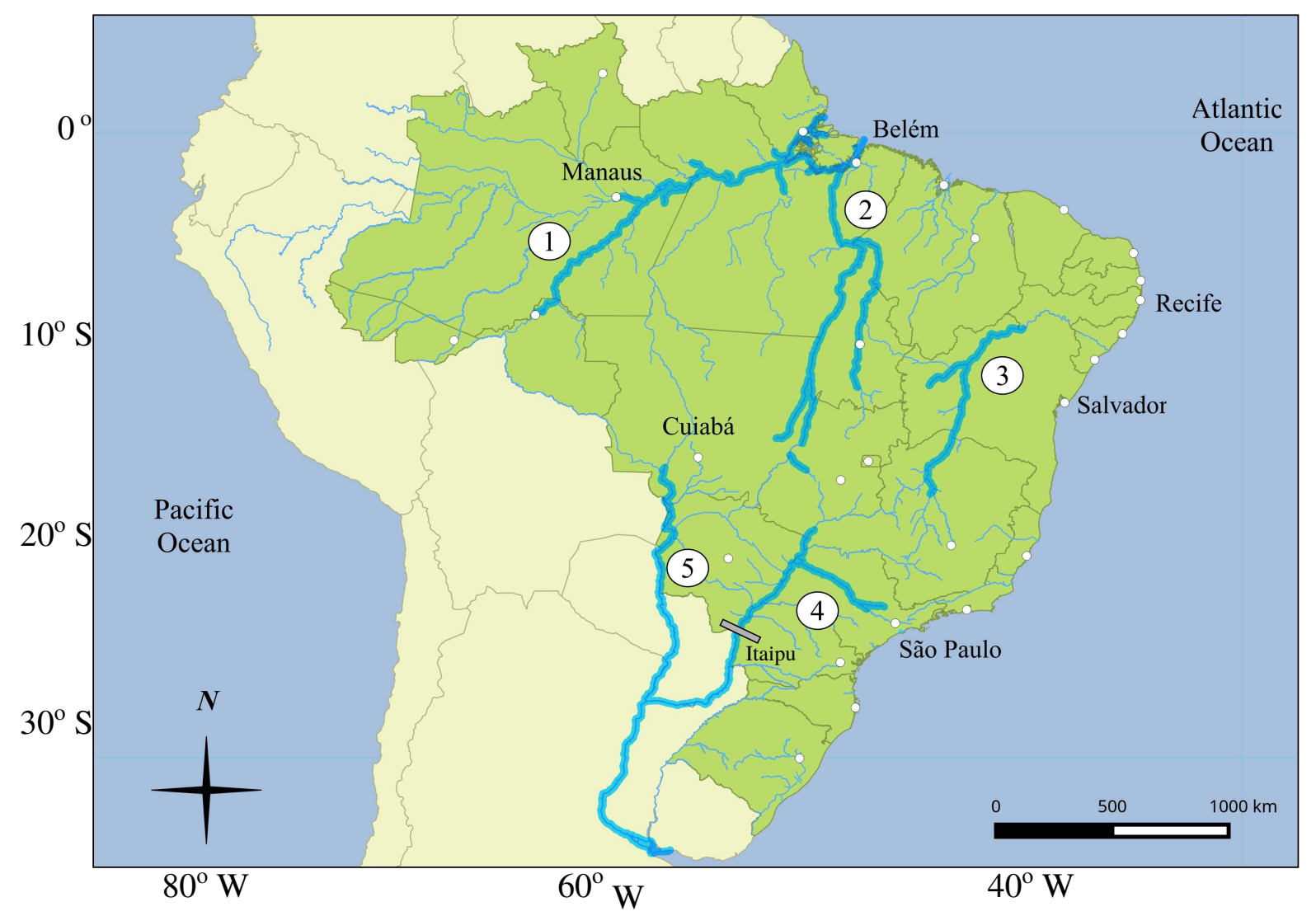

Figure 2.1: The Brazilian rivers are presented in blue and the main waterways are highlighted: 1) Madeira-Amazonas; 2) Tocantins-Araguaia; 3) São Francisco; 4) Tietê-Paraná, and 5) Paraguay-Paraná waterway. The Brazilian state capitals are shown by small white circles and the Brazilian territory is presented in dark green.

of measures to accelerate the development of inland navigation in Brazil. Despite the initiative to promote the waterborne transportation, there are several technical issues to be solved for Brazilian rivers, as the low density of monitoring stations, conflict of interest in the water use (e.g. human consumption, hydroelectric sector, waterways), and the absence of locks in dams (e.g. Itaipu in Fig. 2.1) and a traffic management system.

Padovezi (2003) listed some of the most important aspects for the analysis of Brazilian waterways. The author listed the navigation channel depth; flow velocity; curvature radius; presence of critical points or restrictions (e.g. locks, bridges, and narrow channels); presence of strong winds and wave formation; susceptibility to environmental changes due to vessels passage (e.g. banks destabilization); temporal variation in navigation conditions due to the water system, and the necessity of maintenance (e.g. dredging due to sedimentation).

Regarding the availability of river data, the Brazilian section of the Paraguay River has one station every $100 \mathrm{~km}$, while the German stretch of the Rhine River, for example, has an average density of one gauge station every $32 \mathrm{~km}$ (WSV, 2016). The remoteness 
of Brazilian waterways is another challenge for data collection and waterways assessment.

The rivers in Brazil share its navigation potential with energy generation. The Brazilian electric grid relies approximately $85 \%$ of its energy on hydroelectric power generation (ANEEL, 2014). Hydro Power Plant (HPP) locks, in the best scenario, delay the waterborne transportation and increase the overall operational costs. Even for major rivers, several HPPs were built without locks, thus making navigation impossible. Table 2.2 presents the number of locks in Brazilian official inland waterways.

Table 2.2: Locks in Brazilians main waterways. Data provided by ANEEL (2014).

\begin{tabular}{ccc}
\hline Waterway & Number of dams & Dams with locks \\
\hline Madeira-Amazonas & 3 & 1 \\
Tocantins-Araguaia & 9 & 1 \\
São Francisco & 8 & 1 \\
Parana-Tietê & 15 & 8 \\
Paraguay-Paraná & 4 & 2 \\
\hline
\end{tabular}

Another difficulty in waterways operation in Brazil is the lack of a co-management of water resources. The Brazilian Electricity Agency (ANEEL) controls the HPPs locks, hence the water level of rivers and reservoirs. This aspect increases the uncertainty over waterways condition, as the ANEEL responsibility is solely for the energy demand, which could lead to impending the minimal water levels necessary for navigation. In the years of 2014-2015, the Brazilian South East region faced a severe drought. During this time regional locks almost dried up, leaving major Brazilian waterways without barge traffic for 22 months. The co-management of water resources is a key point for the optimal use of the waterborne transport and should be part of the national power planning and policies.

In summary, the modernization of inland waterways in Brazil implies the standardization of several aspects, including: (1) definition of a survey datum; (2) analysis of backwater effects due to dams; (3) identification of critical meanders; (4) definition of optimal periods for dredging; (5) identification of morphological changing rates; (6) characterization of dunes and its morphologies (velocity, amplitude and period); (7) characterization of sediments; (8) optimal vessels and path definition; (9) coordination of HPPs energy generation with navigation minimal depth; (10) optimization of traffic; (11) maneuverability modelling; (12) identification of critical depth stretches and (13) reduction of environmental impacts. All these aspects will require further detailed investigation and must be provided by private and public stakeholders. 


\subsection{Brazilian fleet}

The Brazilian Agency for Waterway Transportation (ANTAQ) keeps an extensive data set of vessels characteristics operating in Brazilian inland waterways, as the ship name, class, gross tonnage capacity, length, beam, and the draft. These parameters can be used to analyze the current state of the Brazilian fleet (details are presented in chapter 3 ). It is also possible to evaluate general relations between load capacity and vessel dimensions, parameters that directly affect the navigability capacity of rivers.

Various parametric relations of ship characteristics arise from the data provided by ANTAQ (2012), summarized in Figs. 2.2 and 2.3. The relations between the parameters are enhanced by Pearson coefficient of correlation $\left(R^{2}\right)$. The vessel gross tonnage (see section 3.4) is the ship cargo capacity, presenting an expected dependence on barges dimensions. As shown in Fig. 2.2 (a), the higher the cargo capacity, higher the required draft and the necessary waterway depth $\left(R^{2}=0.72\right)$. The gross tonnage is also positively related to the barge length $\left(R^{2}=0.78\right)$ and width $\left(R^{2}=0.54\right)$, Figs. 2.2 (b) and 2.3 (a) respectively. Thus, any improvement on the cargo capacity would also require increasing the vessel dimension and modify the ship lenght-width relation (Fig. $2.3 \mathrm{~b}, R^{2}=0.73$ ).

The search for efficiency in waterborne transportation seeks a balance between the low velocity (typical in cargo vessels) and the transported volume, increasing economic pressures for ships with higher cargo capacity. However, according to Figs 2.2 and 2.3, higher load capacity leads to a greater requirement for space in waterways, not only by the vessel space constraint but because the maneuverability is also affected by the weight and dimension of ships. Therefore, adaptation works (e.g. widening and dredging) may be necessary.

Historically, due to the advance of the inland navigation and technological resources, rivers are receiving several interventions to improve its navigability condition (e.g. Rhine, Mississipi, and Paraguay River). In Brazil, until the Strategic Waterways Plan (Ministério dos Transportes, 2013), the waterway transportation received little attention from government policies. In the U.S, however, these discussions were promoted by the Inland Waterways Commission (Haupt, 1908, 1909) a century ago.

The river modeling and navigability analysis process in Brazil is not fully established. There are many questions to be standardized for general inland navigation, such as the definition of critical points and navigability conditions, how to proof navigability, and when model applications are required. Another aspect is that without stimulating the naval industry the majority of the Brazilian inland waterway fleet was not developed in the country, but imported from different river systems that have different characteristics 

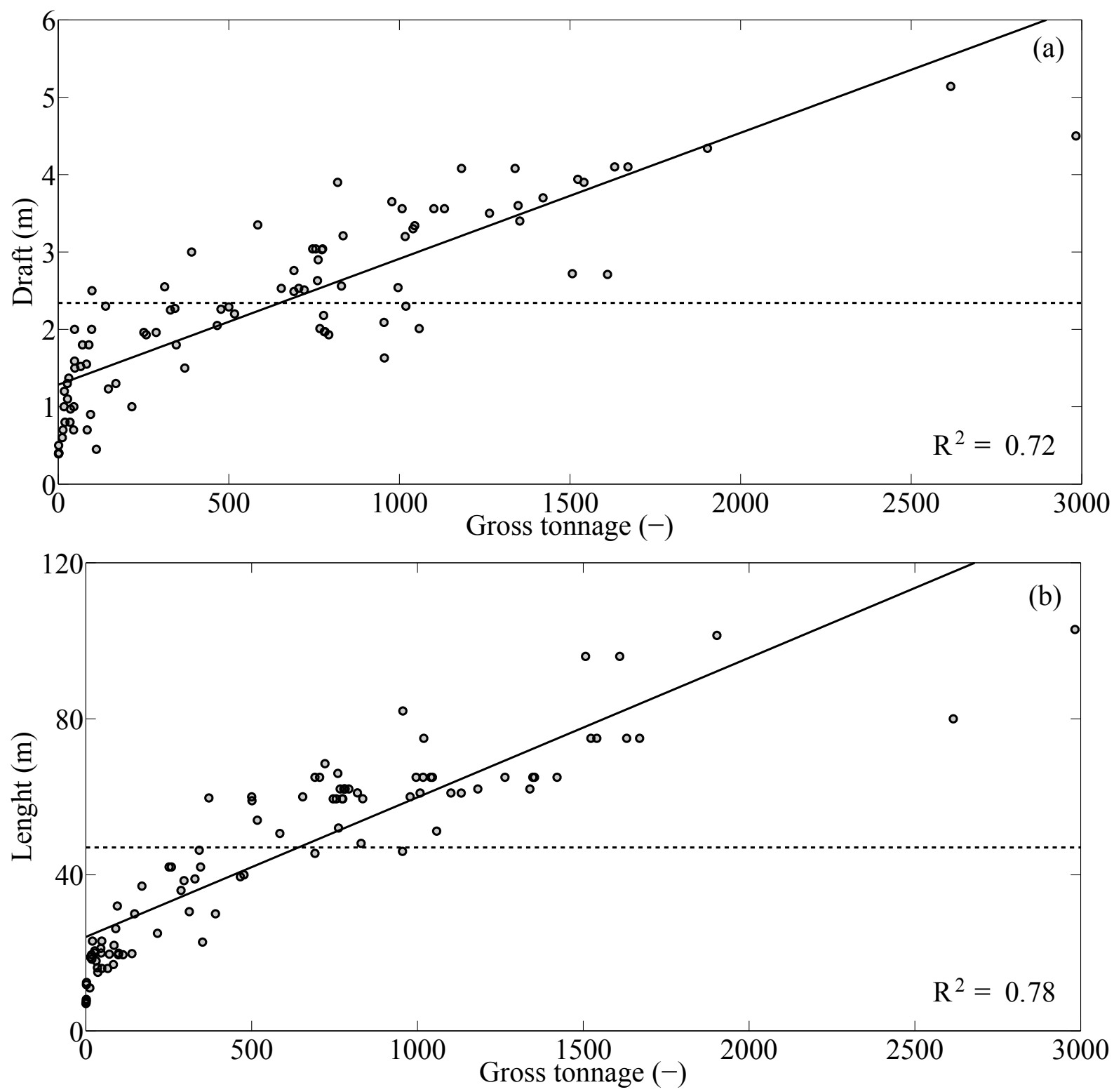

Figure 2.2: Dependence of the gross tonnage capacity to the ship (a) draft and (b) length. The black line is a linear correlation and the dashed line presents mean values.

and demands. Thus, the use of ships that are not specifically designed for Brazilian rivers features may face physical constraints. Moreover, the Brazilian rivers are being adapted to acquired ships and not the opposite, where vessels should be optimized for these waterways.

The increasing importance of environmental impact mitigation and the development of a more rigorous environmental legislation leads to a change in the concept of waterborne transportation. The vessels must be adapted to the natural conditions of rivers, seeking greater efficiency, security, and less harm to the environment. The vessel characteristics depend on the physical restrictions of the river and also on the operation of waterways. 

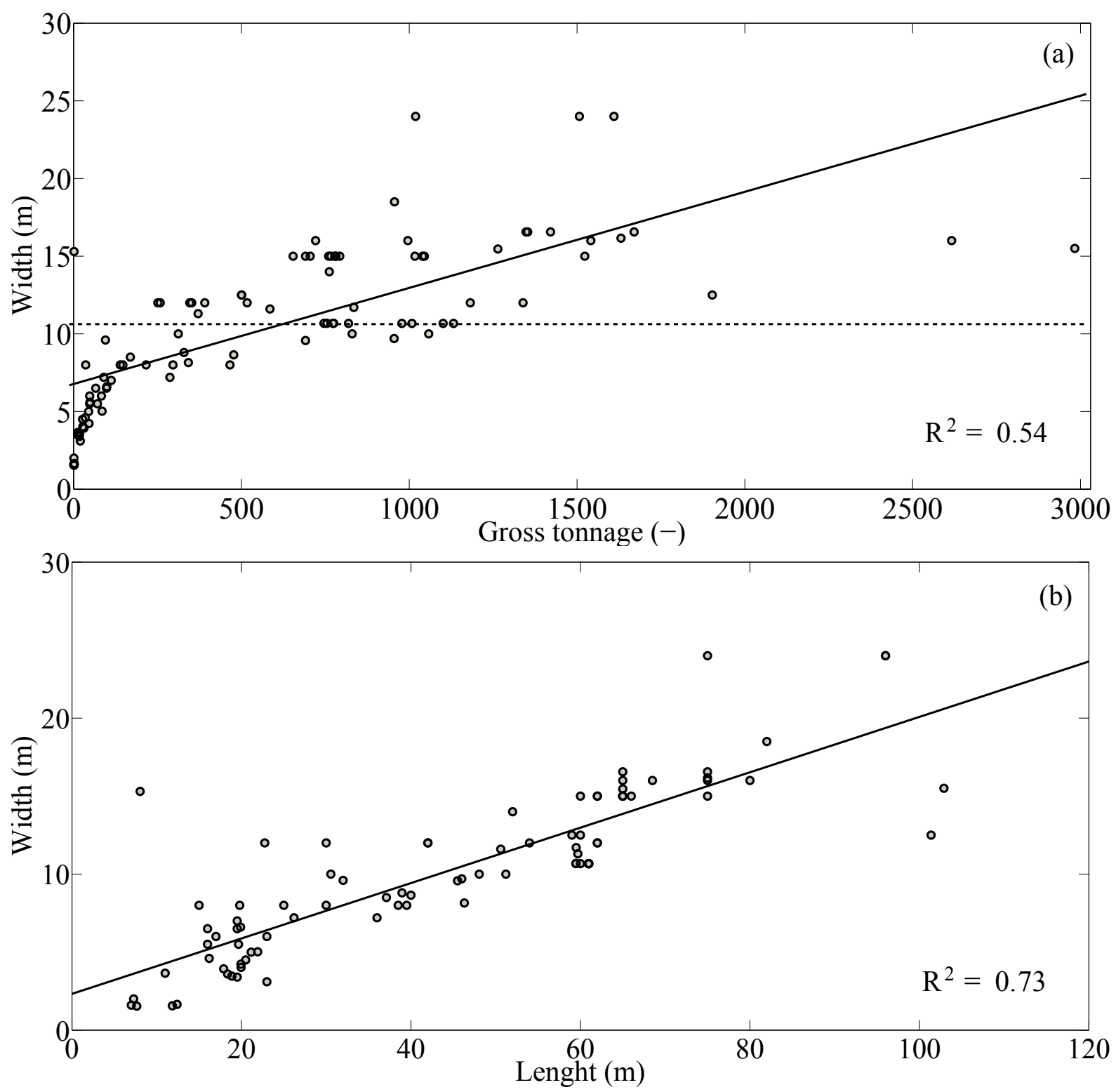

Figure 2.3: Dependence of the gross tonnage capacity to the ship (a) width and the relation between the ship width and length (b). The black line is a linear correlation and the dashed line presents the mean value.

Padovezi (2003) presented a simplified description of the main features concerning the determination of an optimal vessel for inland waterways (Table 2.3).

In Brazilian rivers, the most common cargo vessels are barge convoys propelled by pushers, as presented in Fig. 2.4. The number of barges and its arrangement may vary according to several parameters arising from the relation between vessels and rivers. Among these parameters, we highlight the towboat power to overcome the flow and the overall convoy length and width to navigate around bends with different curvature radius.

Currently, there are no published studies with guidelines on the arrangement of barges to be used in Brazilian rivers, which is determined by the expertise of professionals. The 
Table 2.3: Key aspects for assessment of cargo vessels on inland waterways. Adapted from Padovezi (2003).

\begin{tabular}{cl}
\hline Features & \multicolumn{1}{c}{ Description } \\
\hline Hull structure & $\begin{array}{l}\text { Optimize structural weight and buoyancy (draft). Relates the mate- } \\
\text { rial to be used and the dimensions of each barge, seeking increased } \\
\text { cargo. }\end{array}$ \\
\hline Arrange & $\begin{array}{l}\text { Set of barges for transport in the waterway, with the organization } \\
\text { and the number of barges carried by the pusher. Must respect the } \\
\text { physical characteristics of the waterway and the dimensions of the } \\
\text { approved convoy by the Brazilian Navy. }\end{array}$ \\
\hline Propulsion & $\begin{array}{l}\text { Must support existing river currents and present the motor capacity } \\
\text { to perform the transport of barges within the speed limit set in the }\end{array}$ \\
& waterway (upstream or downstream). \\
\hline Maneuverability & $\begin{array}{l}\text { Ensures the navigability of barges in waterway curves. Azimuth } \\
\text { thruster can be used to increase the maneuverability conditions. }\end{array}$ \\
\hline Stability & $\begin{array}{l}\text { Must meet propulsion needs and required maneuvers, with adequate } \\
\text { depth and weight, low noise, low emission of pollutants, and econom- } \\
\text { ically viable. }\end{array}$ \\
& $\begin{array}{l}\text { Capacity to restore its original equilibrium after a disturbance what- } \\
\text { soever. Should withstand the waves generated by the passage of } \\
\text { other vessels and meet specific standards. }\end{array}$ \\
\hline Operation & $\begin{array}{l}\text { Control of the operation velocity, load and unload of the barges, pe- } \\
\text { riodic maintenance of the vessels, and the analysis of the operational } \\
\text { feasibility. }\end{array}$ \\
\hline
\end{tabular}

Strategic Waterways Plan (Ministério dos Transportes, 2013) presents a survey regarding the maximum arrangement of barges, reproduced in Table 2.4. Nevertheless, the results are only for high water condition and no study or method describes how these results were obtained, which reinforces the need to develop guidelines and specific vessel maneuverability models for Brazilian rivers.

Table 2.4: Survey on the largest convoys currently allowed in the main Brazilian waterways (Ministério dos Transportes, 2013). The data are related to a high water level and not considering pushers dimension.

\begin{tabular}{ccccc}
\hline Waterway & Arrangement & Barge size $(\mathrm{m} \bullet \mathrm{m})$ & Total size $(\mathrm{m} \bullet \mathrm{m})$ & Draft $(\mathrm{m})$ \\
\hline Madeira-Amazonas & $4 \bullet 5$ & $60 \bullet 11$ & $240 \bullet 55$ & 4.0 \\
Tocantins-Araguaia & $3 \bullet 3$ & $60 \bullet 11$ & $180 \bullet 33$ & 2.1 \\
São Francisco & $2 \bullet 2$ & $60 \bullet 8$ & $120 \bullet 16$ & 1.8 \\
Parana-Tietê & $3 \bullet 2$ & $60 \bullet 11$ & $180 \bullet 22$ & 2.5 \\
Paraguay-Paraná & $4 \bullet 4$ & $60 \bullet 12$ & $240 \bullet 48$ & 2.6 \\
\hline
\end{tabular}




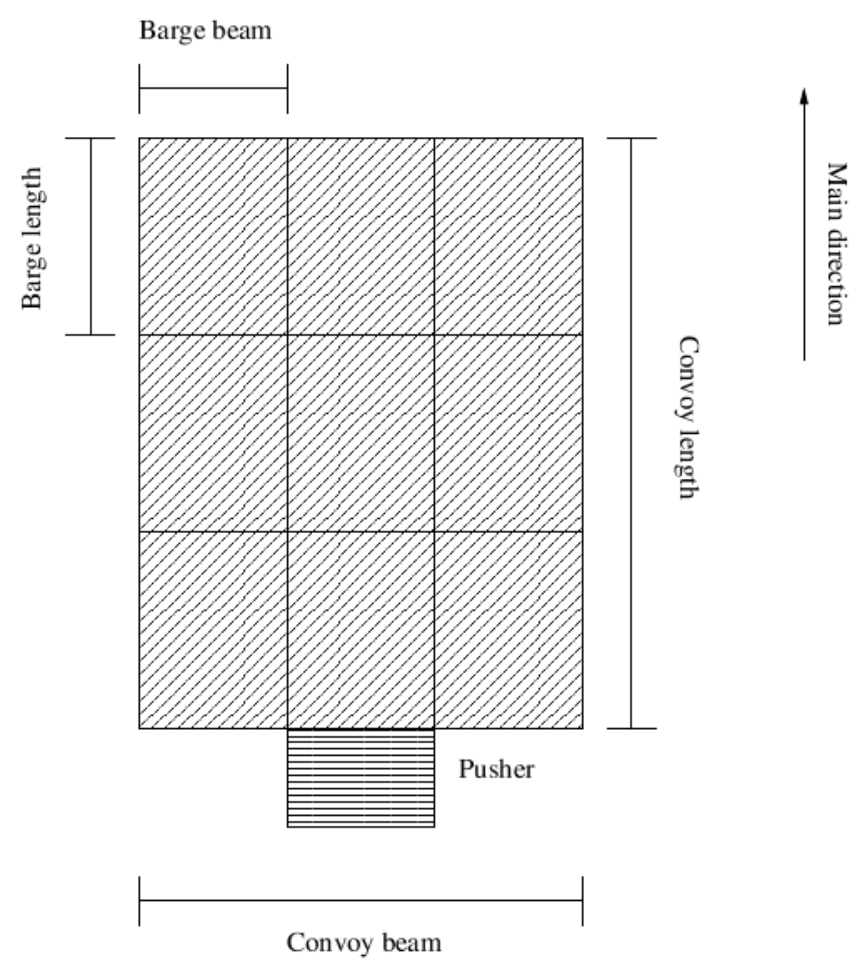

Figure 2.4: Representation of a $n \bullet m$ convoy composition, where $n$ barges are arranged in the longitudinal direction (length) and $m$ barges are used as the base of the convoy and are arranged transversely to the navigation axis (width).

\subsection{Research and standards for waterways}

Navigation-related researches are broad. The studies can be specific to ships, as movements during navigation (e.g. squat effects and stability problems) or general guidelines for the construction and operation of waterways, which parameterize the main relations between ships and rivers. Generally, the standards are not specific and must be used only as an initial indication, not to be considered as optimized values for the design and operation of waterways. A brief review of studies and standards is described in the following.

Blaauw and Verhey (1983) proposed a design technique for inland navigation fairways. It consists of three phases in the design process of waterways: economic studies, initial design, and final design. This study presented a qualitative overview of the strategies related to the setup of inland fairways. However, the cited methods are too broad and more suited to European rivers, mostly already adapted to navigation. Currently, the Brazilian waterways are at an early stage of development and the river systems have not been properly studied and modeled. Thus, previous analysis of the physical processes is essential for the assessment, since there are no established standards for the construction and management of Brazilian inland waterways. 
McCartney (1986) summarized a set of procedures used by the U.S. Army Corps of Engineers to develop inland fairways for commercial navigation. The study shows an extensive review of the main technical aspects related to the planning and management of waterways. According to the author, among the principal characteristics affecting the design and operation are: climate weather (wind, waves, visibility); site characteristics (bathymetry, currents, sediment movement); tow characteristics (geometry, maneuverability, traffic); environmental conditions (ecology, water quality) and social aspects (recreation, safety). These aspects were well described; nevertheless, the detailed quantification of parameters that affect the navigability condition was not in the scope of the study.

The U.S. Geological Survey (USGS), in cooperation with the Washington State Department of Natural Resources, published a scientific report (Magirl and Olsen, 2009) presenting an approach to assess the navigability potential of rivers. The authors used to discharge and channel geometry measurements from the USGS streamflow-gaging stations and data from a geographic information system. Regression curves were derived to predict depth, top width, and bottom width as a function of the mean annual discharge. The predictions of hydraulic geometry were then compared to thresholds established by the Washington State Department of Natural Resources to determine navigability potential. Then, using the values of average annual discharges, the rivers were labeled as "probably navigable" and "probably not navigable". However, this method can only represent an initial and partial analysis of the navigation conditions of rivers, since the temporal variation of discharge, spatial and temporal variations in the flow velocity field and other important features to navigation (e.g. velocity field, obstacles, and curvature radius) were not addressed by this study.

Waterway feasibility projects can be managed by different approaches, as there are no universal methods for the design and maintenance process. Several agencies are designated to research and publish technical reports and scientific papers on the standardization of operations in waterways, determining its navigability condition. Nevertheless, those guidelines are usually set for specific cases and its application for different regions may be restricted.

Among the most important research agencies for navigation are the Permanent International Association of Navigation Congresses (PIANC) and the German Federal Agency for Waterways (BAW). In Brazil, waterways are under Brazilian National Bureau of Infrastructure and Transportation (DNIT) and ANTAQ responsibility, departments linked to the Brazilian Ministry of Transportation.

PIANC is an international organization that research topics on standards in the field of waterway traffic on channels, rivers, and ports. The institution periodically provides 
technical reports related to waterborne transportation, e.g. standardization of ships and inland waterways for river and sea navigation (PIANC, 1996), approach channel construction (PIANC, 1995), vessel traffic and transport management for inland waterways (PIANC, 2002), and performance indicators for inland waterways transport (PIANC, 2011).

The German agency BAW is another important research institute in the field of waterways, supporting the German Federal Ministry of Transport. It is the central provider of consultancy and expert services related to waterways engineering tasks, construction supervision, safety, and regulations. The BAW also publishes periodically studies on navigation channels, as an overview of researches and construction works on German waterways (BAW, 2007), automatic water level control system for waterways (BAW, 2012) and even the impacts of climate change on waterways and navigation in Germany (BAW, 2009).

In Brazil, a specific regulation exists to deal with the dimensioning of channels and other nautical aspects for harbor planning (ABNT, 1995). However, this guideline is not specific and optimized for inland waterway projects and currently is not being applied. Nowadays Brazilian authorities are using PIANC regulatory standards (PIANC, 1995) to design and operate inland waterways. This standard is considered rather restrictive (ITTI, 2014) and not optimized for Brazilian rivers. Even though several sections are not considered safe by the used guideline, commercial navigation is occurring. Frequently rivers systems have many characteristics that are not measured by broad standards, requiring specific studies as small-scale models and computer models.

Beside guidelines, the assessment of waterways can be carried out through empirical small-scale studies and computational models. As already mentioned, scale models may have great limitations for studies of extense regions and when a large variation of parameters is required, where the computational approach is recommended. The navigation representation trough computer models can occur for real-time or fast-time simulators, where either analytical and numerical equations can be used. In section 4.4 a review on modeling of ship motion is presented.

\subsection{Navigation channel design for Brazilian inland waterways}

This section reviews the set of methods used to design navigation channels for Brazilian rivers, where currently the PIANC approach channel guideline (PIANC, 1995) is being 
applied.

The used standard does not establish rigid specifications and presents approaches in how to design navigation channels. This guideline deals with several technical aspects related to river morphology, vessel characteristics and velocity fields (e.g. river current and wind intensity). Each analyzed parameter provides coefficients that can increase the navigation channel width in meander and straight sections, the curvature radius, and the depth. The higher the safety issues, the greater the navigation channel coefficient and dimensions. A brief summary of this guideline is presented in the following.

\subsubsection{Channel width for meander sections}

For the determination of the navigation channel width for curves, PIANC (1995) guideline suggest the analysis of the channel over-width in these sections and the tangent distance between bends.

It is preferable that the navigation path is located on the inside region of curves, with dimensions varying according to the radius of curvature and length of the vessel-type, as presented by Eq. (2.1),

$$
\Delta W=\frac{L v^{2}}{8 C}
$$

where $\Delta W$ is the curve over-width, $L v$ is the vessel-type length and $C$ is the river curvature radius.

The minimum length of a tangent between curves $(T)$ only depends on the ship-type length:

$$
T \approx 5 L v
$$

\subsubsection{Channel width for straight sections}

The recommended navigation channel width for straight sections is given by several parameters affecting the ship navigability. These parameters are represented by specific coefficients that are related to the largest vessel beam $(B)$ specified in the waterway project. The coefficients are summed, resulting in the recommended width for the navigation channel. Some parameters are related to the vessel and flow velocities and either are given in $\operatorname{knots}^{1}(k n)$. These parameters are detailed in Tables A.1 to A.10 in the appendix section.

\footnotetext{
${ }^{1}$ The knot unit is defined as 1 nautical mile per hour, approximately $0.515 \mathrm{~m} / \mathrm{s}$ and $1.85 \mathrm{~km} / \mathrm{h}$.
} 
The maneuverability parameter relates the capacity of a ship to perform maneuvers during navigation, i.e, agility in changing course. Table A.1 classifies various types of vessels due to its maneuverability capacity defined by relations presented in PIANC (1995). From this, the maneuverability coefficients are used to calculate the additional width of the fairway project.

The ship average velocity is a major factor to calculate the navigation channel dimension, the higher the velocity the higher the necessary maneuver area. The width increase due to this parameter can be verified in Table A.2.

The wind velocity field affects the motion of ships. It generates lateral acceleration and moments of rotation, resulting in sudden changes of direction. Thus, an increase in the channel width may be necessary. The influence of this parameter is presented in Table A.3.

Transversal and longitudinal currents directly impact the ship navigation. Tables A.4 and A.5 describe the additional width coefficients for transversal and longitudinal currents respectively. It can be observed that the current effect is considered greater for ships navigating at low speed.

Navigational aid is related to all nautical signaling within the river and is fundamental for safe navigation. The additional width due this coefficients is presented in Table A.6. PIANC standards also consider a parameter related to the transported cargo risk, summarized in Table A.7.

In shallow water regions, several hydrodynamic effects that compromise navigation may occur. Then, safety coefficients must be adopted according to the channel depth $(H)$ and ship draft $(d)$ ratio. Table A.8 presents coefficients for additional width due to the channel bottom surface morphology and Table A.9 regards coefficients due the overall depth-draft ratio.

The Influence of asymmetric pressures generated by the proximity of structures nearby vessels (e.g. banks and groins) is also an important factor. This effect is a function of the ship velocity and the structure type, described in Table A.10.

The navigation channel calculation takes into account the sum of all aforementioned parameters, which are related to the maximum vessel beam considered in the waterway project. Equation (2.3) is used to calculate the navigation channel width:

$$
L=M c+V c+W c+F t c+F l c+N c+R c+S c+D c+2 \bullet E c .
$$

The additional width is given by the described coefficients: maneuverability $(M c)$, average vessel velocity $(V c)$, wind intensity $(W c)$, transversal currents $(F t c)$, longitudinal currents 
$(F l c)$, navigation aid $(N c)$, cargo risk $(R c)$, channel botom $(S c)$, depth-draft ratio $(D c)$, and structures proximity effect $(E c)$.

\subsubsection{Channel curvature radius}

The minimum curvature radius for the navigation channel is determined by two main factors: (I) maximum steering angle of ships and (II) the ratio between the river depth and the vessel draft. Usually, the depth-draft ratio is calculated for a low water scenario, therefore obtaining more conservative safety parameters. With both steering angle and depth-draft ratio determined, one must observe the radius of curvature relation presented in PIANC (1995).

\subsubsection{Channel depth}

The navigation channel depth is defined according to several parameters, as the vessel draft, effects of tides, squat movement, and water density (PIANC, 1995).

In the absence of further information, one must use the depth-draft ratio, where the value 1.1 regards sheltered waters (e.g. rivers), 1.3 in cases of waves up to a meter high and 1.5 in situations of higher waves and unfavorable directions. Also, the Froude number ${ }^{1}$ must be lower than 0.7 . Then, the channel depth can be determined to fulfill the requirements.

\subsection{Chapter closure}

In this chapter a broad analysis of the Brazilian waterway system was presented, from the main characteristics of rivers to the description of the operating cargo fleet in the country. A survey of researchers and standards for the design and operation of inland fairways was also described and in the last section, the used method for navigation channel design in Brazil was discussed. The current approach can be useful for initial stages for waterways projects. However, studies (ITTI, 2015) indicate that this guideline is not sufficient to optimize the navigation channel and the inland water transportation in the country and specific studies for Brazilian rivers are required. The next chapter presents an overview on dynamics of rigid bodies, a necessary topic for the development of the fast-time vessel-current interaction model to be applied in waterways assessment.

\footnotetext{
${ }^{1}$ See section 4.2 .1 for further details.
} 


\section{Chapter 3}

\section{Rigid body dynamics applied to a vessel}

Rigid body dynamics analyzes the movement of bodies under the action of external forces. The assumption that the system is rigid implies that no deformations occur. This premise simplifies the system evaluation, reducing the problem to the analysis of translation and rotation of the body within a specified reference system.

The dynamics of a rigid body system can be assessed by equations of motion, which are derived using either Newton's laws of motion or Lagrangian mechanics (MacMillan, 1936). The solution of these equations defines how the system formed by rigid bodies changes as a function of time and is an important tool in the computer simulation of mechanical systems (Salençon, 2001).

This chapter presents a review of rigid body studies, initially by kinematics and motion equations. The main objective is to research the necessary theoretical background to describe the vessel motion as a free rigid body subjected to external forces (e.g. flow velocity field). Finally, the last section of the chapter is dedicated to present specific concepts and researches related to inland waterway vessels.

\subsection{Kinematic equations}

The ship-current interaction can be modeled using the forces applied on the vessel and its resultant trajectories. In this section, a review of the kinematics equations based on Feynman lectures (Feynman et al., 1964) is presented, as the analysis of the position, velocity, acceleration, and trajectory of a rigid body.

In classical mechanics, the kinematic equations describe the motion of objects without 
considering the forces that may have caused the motion. The first approach of the model will consider two dimensions: longitudinal $(y)$ and transversal $(x)$, ignoring variations in the vertical component $(z)$. Thus, the system can be considered as a planar rigid body case under holonomic constraints (Timoshenko and Young, 1948). However, in this study, the equations will be demonstrated for three-dimensional general cases and will be further reduced to a two-dimensional condition.

The components of position, velocity, and acceleration of a body are given by its vector relation formed between the body center of gravity and the reference system. The position vector of a body is a vector drawn from the reference system origin to the body and expresses both the distance and direction of the point from the origin. For any given three-dimensional vector $\vec{s}$, in this case, the position, the component in each direction is presented in equation (3.1):

$$
\vec{s}=s_{x} \hat{i}+s_{y} \hat{j}+s_{z} \hat{k}
$$

where $x, y$ and $z$ are references to the adopted coordinate system and $\hat{i}, \hat{j}$ and $\hat{k}$ are the orthogonal unit vectors indicating the directions.

The magnitude of a vector $\vec{s}$ is defined by:

$$
\vec{s} \overline{\sqrt{ }} \sqrt{s_{x}^{2}+s_{y}^{2}+s_{z}^{2}}
$$

The angles between the coordinate system axis and the direction of $\vec{s}$ are represented by $\theta_{x}, \theta_{y}$ and $\theta_{z}$. The vector module in a given direction is represented by its projection of the directional components:

$$
\begin{aligned}
& s_{x}=\vec{g} \cos \left(\theta_{x}, \vec{s}\right), \\
& s_{y}=\vec{g} \cos \left(\theta_{y}, \vec{s}\right), \\
& s_{z}=\vec{g} \cos \left(\theta_{z}, \vec{s}\right) .
\end{aligned}
$$

The position variation in a limited amount of time gives the body an instantaneous velocity (3.4) and acceleration vector (3.5):

$$
\begin{gathered}
\vec{v}=\frac{d \vec{s}}{d t} \\
\left.\vec{a}=\frac{d \vec{v}}{d t}=\frac{d}{d t}\right) \frac{d \vec{s}}{d t}\left[=\frac{d^{2} \vec{s}}{d t^{2}} .\right.
\end{gathered}
$$

By the integration of Eq. (3.5) it is possible to obtain the velocity after a $\Delta t$ period, 


$$
\begin{gathered}
\int_{v_{o}}^{v} d \vec{v}=V_{0}^{\Delta t} \vec{a} d t, \\
\vec{v}=\overrightarrow{v_{0}}+\vec{a} \Delta t .
\end{gathered}
$$

Finally, the vector for the trajectory can be determined integrating equation (3.6):

$$
\begin{array}{r}
\int_{s_{0}}^{s} d \vec{s}=\sqrt{0}_{0}^{\Delta t} \vec{v} d t, \\
\vec{s}=\overrightarrow{s_{0}}+\overrightarrow{v_{0}} \Delta t+\frac{1}{2} \vec{a} \Delta t^{2} .
\end{array}
$$

Analogous to Eq. (3.7), one can calculate the angular motion $(\theta)$ in relation to the angular velocity $(\omega)$ and acceleration $(\alpha)$. The angular acceleration is given by the angular variation in the time,

$$
\frac{d^{2} \theta}{d t^{2}}=\alpha
$$

Integrating Eq. (3.8) in time one obtain the angular velocity,

$$
\omega=\alpha \Delta t+\omega_{0}
$$

The angular motion is obtained by the integration of Eq. (3.9),

$$
\theta=\theta_{0}+\omega_{0} \Delta t+\frac{1}{2} \alpha \Delta t^{2}
$$

The presented equations provide the linear and angular velocity and trajectory of rigid bodies. However, the movement is always related to forces, thus it is necessary to review the equations of motion that are presented in the following section.

\subsection{Equations of motion}

The kinematic equations define the velocity and trajectory, while the equations of motions describe the external forces that generate translational and rotational acceleration.

The linear momentum $(\vec{P})$ is a physical quantity used to determine the tendency of bodies to remain in motion. It is necessary to evaluate the body translation since its derivation with respect to time can provide the forces that act on the body, therefore the movement, 


$$
\vec{P}=m \vec{v}
$$

The force $(\vec{F})$ is obtained by deriving the linear momentum and represents its variation in time:

$$
\vec{F}=\frac{d \vec{P}}{d t}=\frac{d}{d t}(m \vec{v}) .
$$

Considering the body mass constant in time, we obtain the classical force representation:

$$
\vec{F}=m \frac{d}{d t}(\vec{v})=m \vec{a}
$$

The resulting force $\left(\vec{F}_{r}\right)$ and acceleration $\left(\vec{a}_{r}\right)$ are due to $n$ force components acting on a rigid body and are given by a vectorial sum. In this study the subscript $r$ refers to all resultant vectors,

$$
\begin{gathered}
\vec{F}_{r}=\int_{j=1}^{n} \vec{F}_{i}=m \vec{a}_{r}, \\
\vec{a}_{r}=\frac{1}{m} \int_{j=1}^{n} \vec{F}_{i} .
\end{gathered}
$$

The force terms are the major unknowns for this research. The calculation of these important components is difficult and will be covered in detail in the following chapters.

The angular momentum $(\vec{L})$ is the rotational analog of linear momentum and represents the tendency of a body to rotate. The magnitude depends on the angular velocity $(\vec{w})$ and the body mass distribution, given by the moment of inertia $(I)$ :

$$
\vec{L}=I \vec{w}
$$

This relation can also be obtained using the vector product of the linear momentum and a position vector:

$$
\vec{L}=\vec{s} \bullet \vec{P}
$$

The moment of inertia of a rigid body depends on its mass distribution. It determines the necessary torque to variate the angular velocity around a rotational axis. The torque $(\vec{\tau})$ is a vector obtained by the angular momentum variation in time. Thus, 


$$
\vec{\tau}=\frac{d \vec{L}}{d t}=\frac{d(I \vec{\omega})}{d t}=\frac{d(\vec{s} \bullet \vec{P})}{d t},
$$

Deriving equation (3.16) and considering the body mass distribution constant in time, the torque can be obtained by the Newton second law of rotation:

$$
\vec{\tau}=I \alpha
$$

where $\alpha$ is the rigid body angular acceleration. Another approach to obtain the torque is by deriving equation (3.17) in time,

$$
\vec{\tau}=\vec{s} \bullet \vec{F}
$$

The rigid body can be discretized into $k$ points. Then, the translation and rotational motion is due to the $n$ forces and torques acting on all discrete points of the rigid body:

$$
\begin{aligned}
\vec{F}_{r} & =\int_{j=1}^{n} \int_{=1}^{k} \vec{F}_{i, j} \\
\vec{\tau}_{r} & =\int_{j=1}^{n} \int_{j=1}^{k} \vec{\tau}_{i, j} .
\end{aligned}
$$

The formal definitions of linear and angular momentum allow the description of the forces and torques which a rigid body is subjected. A system of equations coupling these quantities in all directions is described in the next section.

\subsection{General system of equations of motion}

This section presents an approach to derive the equations of motion for a rigid body within a flow field. It was based on the works published by Kirchhoff (1869) and Kornev (2013). The method consists of a general system describing the six degrees of freedom $(6 \mathrm{DOF})$ of a three-dimensional rigid body motion in a fixed reference system.

The linear and angular momentum may also be derived using the kinetic energy equation $(E k)$ :

$$
E k=\frac{1}{2} m \vec{V}^{2} \sqrt{ }
$$

where $(\vec{V})$ is the total velocity of a rigid body, described by a linear $(\vec{v})$ and a rotational 
component $(\vec{w})$ :

$$
\vec{V}=\vec{v}+(\vec{\omega} \bullet \vec{s})
$$

where,

$$
\begin{aligned}
& \vec{v}=v_{x} \hat{i}+v_{y} \hat{j}+v_{z} \hat{k}, \\
& \vec{w}=w_{x} \hat{i}+w_{y} \hat{j}+w_{z} \hat{k}, \\
& \vec{w} \bullet \vec{s}=\left[\begin{array}{ll}
w_{y} s_{z} & w_{z} s_{y}
\end{array}\right] \hat{i}+\left[\begin{array}{ll}
w_{z} s_{x} & w_{x} s_{z}
\end{array}\right] \hat{j}+\left[\begin{array}{ll}
w_{x} s_{y} & w_{y} s_{x}
\end{array}\right] \hat{k} .
\end{aligned}
$$

Then, deriving equation (3.22) with respect to the velocities one obtain the linear and angular momentum:

$$
\begin{aligned}
& \vec{P}=\frac{d E k}{d \vec{v}}=\frac{\partial E k}{\partial v_{x}} \hat{i}+\frac{\partial E k}{\partial v_{y}} \hat{j}+\frac{\partial E k}{\partial v_{z}} \hat{k}, \\
& \vec{L}=\frac{d E k}{d \vec{w}}=\frac{\partial E k_{\hat{w}}}{\partial w_{x}}+\frac{\partial E k}{\partial w_{y}} \hat{j}+\frac{\partial E k}{\partial w_{z}} \hat{k} .
\end{aligned}
$$

Determining the equation of kinetic energy through the velocity integration and applying the relation described in (3.24), several body parameters arise, as the inertia moments, which are the products of inertia and static moments of inertia:

$$
\begin{aligned}
E k & =\frac{1}{2} \sqrt{m}_{m} \vec{V}^{2} d m \\
& =\frac{1}{2} \sqrt{m}_{m}(\vec{v}+\vec{\omega} \bullet \vec{s}) \cdot(\vec{v}+\vec{\omega} \bullet \vec{s}) d m \\
& =\frac{1}{2} \sqrt{m}_{m}\left[\vec{v}^{2}+2 \vec{v}(\vec{\omega} \bullet \vec{s})+\vec{\omega} \bullet \vec{s}^{2}\right] d m \\
& \left.=\frac{1}{2}\right] \vec{v}^{2} V_{m} d m+2 \vec{v} V_{m}(\vec{\omega} \bullet \vec{s}) d m+V_{m} \vec{\omega} \bullet \vec{s}^{2} d m(.
\end{aligned}
$$

Considering equation (3.27) for the three-dimensional case, 


$$
\begin{aligned}
& E k=\frac{1}{2} m\left(v_{x}^{2}+v_{y}^{2}+v_{z}^{2}\right) \\
& +v_{x} w_{y} ل_{m} z d m \quad v_{x} w_{z} V_{m} y d m \\
& +v_{y} w_{z} V_{m} x d m \quad v_{y} w_{x} V_{m} z d m \\
& +v_{z} w_{x} V_{m}^{y d m} \quad v_{z} w_{y} V_{m} x d m \\
& \left.+\frac{1}{2}\right) w_{x}^{2} V_{m} y^{2} d m \quad 2 w_{x} w_{y} V_{m} x y d m+w_{y}^{2} V_{m} x^{2} d m[ \\
& \left.+\frac{1}{2}\right)+w_{y}^{2} V_{m} z^{2} d m \quad 2 w_{y} w_{z} V_{m} y z d m+w_{z}^{2} V_{m} y^{2} d m[ \\
& \left.+\frac{1}{2}\right)+w_{z}^{2} V_{m} x^{2} d m \quad 2 w_{z} w_{x} V_{m} x z d m+w_{x}^{2} V_{m} z^{2} d m[.
\end{aligned}
$$

The inertia moments are defined as:

$$
\begin{aligned}
& I_{x x}=V_{m}\left(y^{2}+z^{2}\right) d m, \\
& I_{y y}=V_{m}\left(x^{2}+z^{2}\right) d m,
\end{aligned}
$$

and

$$
I_{z z}=V_{m}\left(x^{2}+y^{2}\right) d m .
$$

The products of inertia are defined as:

$$
\begin{aligned}
& I_{x y}=\sqrt{m}_{m} x y d m, \\
& I_{x z}=\sqrt{m}_{m} x z d m,
\end{aligned}
$$

and

$$
I_{y z}=\sqrt{m}_{m} y z d m .
$$

The static moments of inertia are defined as:

$$
\begin{aligned}
& S_{x}=V_{m} x d m, \\
& S_{y}=V_{m} y d m,
\end{aligned}
$$


and

$$
S_{z}=\sqrt{m}_{m} z d m
$$

Applying the previous inertia relations in equation (3.28),

$$
\begin{aligned}
& E k=\frac{1}{2} m\left(v_{x}^{2}+v_{y}^{2}+v_{z}^{2}\right) \\
& +v_{x} w_{y} S_{z} \quad v_{x} w_{z} S_{y} \\
& +v_{y} w_{z} S_{x} \quad v_{y} w_{x} S_{z} \\
& +v_{z} w_{x} S_{y} \quad v_{z} w_{y} S_{x} \\
& +\frac{1}{2} w_{x}^{2} I_{x x}+w_{y}^{2} I_{y y}+w_{z}^{2} I_{z z}( \\
& \quad \frac{1}{2}\left(w_{x} w_{y} I_{x y}+w_{z} w_{x} I_{x z}+w_{y} w_{z} I_{y z} .\right.
\end{aligned}
$$

Equation (3.38) is derived in relation of linear $(\vec{v})$ and angular $(\vec{w})$ velocities, thus providing the linear $(\vec{P})$ and angular $(\vec{L})$ momenta. Three-dimensional forces $(\vec{F})$ and torques $(\vec{\tau})$ applied to the body arise from the derivation of the linear and angular momenta in time and are the six degrees of freedom equations, which describe the rigid body dynamics. Thus, the forces are given by:

$$
\begin{array}{lcc}
F_{x}=m \frac{d v_{x}}{d t}+S_{z} \frac{d \omega_{y}}{d t} & S_{y} \frac{d \omega_{z}}{d t}+\omega_{y} \frac{d S_{z}}{d t} & \omega_{z} \frac{d S_{y}}{d t} \\
F_{y}=m \frac{d v_{y}}{d t}+S_{x} \frac{d \omega_{z}}{d t} & S_{z} \frac{d \omega_{x}}{d t}+\omega_{z} \frac{d S_{x}}{d t} & \omega_{x} \frac{d S_{z}}{d t} \\
F_{z}=m \frac{d v_{z}}{d t}+S_{y} \frac{d \omega_{x}}{d t} & S_{x} \frac{d \omega_{y}}{d t}+\omega_{x} \frac{d S_{y}}{d t} & \omega_{y} \frac{d S_{x}}{d t}
\end{array}
$$

The torques are given by:

$$
\begin{aligned}
& \tau_{x}=I_{x x} \frac{d \omega_{x}}{d t}+S_{y} \frac{d v_{z}}{d t} \\
& S_{z} \frac{d v_{y}}{d t} \\
& I_{x y} \frac{d \omega_{y}}{d t} \\
& I_{x z} \frac{d \omega_{z}}{d t} \\
& +\omega_{x} \frac{I_{x x}}{d t}+v_{z} \frac{d S_{y}}{d t} \\
& v_{y} \frac{d S_{z}}{d t} \\
& \omega_{y} \frac{d I_{x y}}{d t} \\
& \omega_{z} \frac{d I_{x z}}{d t}, \\
& \tau_{y}=I_{y y} \frac{d \omega_{y}}{d t}+S_{z} \frac{d v_{x}}{d t} \\
& S_{x} \frac{d v_{x}}{d t} \\
& I_{x y} \frac{d \omega_{x}}{d t} \\
& I_{y z} \frac{d \omega_{z}}{d t} \\
& +\omega_{y} \frac{I_{y y}}{d t}+v_{x} \frac{d S_{z}}{d t} \\
& v_{z} \frac{d S_{x}}{d t} \\
& \omega_{x} \frac{d I_{x y}}{d t} \\
& \omega_{z} \frac{d I_{y z}}{d t}, \\
& \tau_{z}=I_{z z} \frac{d \omega_{z}}{d t}+S_{x} \frac{d v_{y}}{d t} \\
& S_{y} \frac{d v_{x}}{d t} \\
& I_{x z} \frac{d \omega_{x}}{d t} \\
& I_{y z} \frac{d \omega_{y}}{d t} \\
& +\omega_{z} \frac{I_{z z}}{d t}+v_{y} \frac{d S_{x}}{d t}
\end{aligned}
$$


Several inertia related parameters in equations (3.39) and (3.40) are necessary for the earth-fixed reference system. However, when a ship-fixed reference system is used, the inertia moments, products of inertia and static moments are constant in time. Kirchhoff (1869) derived the linear (3.11) and angular (3.16) momentum equations for the shipfixed frame system, describing the motion of any rigid body within an ideal fluid. This approach simplifies the force and torque equation to:

$$
\begin{aligned}
& \vec{F}=\frac{d \vec{P}}{d t}+\vec{\omega} \bullet \vec{P} \\
& \vec{\tau}=\frac{d \vec{L}}{d t}+\vec{v} \bullet \vec{P}+\vec{\omega} \bullet \vec{L}
\end{aligned}
$$

Despite the change in the reference system, another hypothesis can be used to simplify the ship motion equation: (I) the ship mass distribution is symmetrical and (II) the offdiagonal elements of the inertia matrix and static moments are zero. This hypothesis can be satisfied by a special choice of the location of origin and direction of the coordinate system axes, as presented by Kornev (2013).

Using the previous simplifications, the $6 \mathrm{DOF}$ equations arise for the forces,

$$
\begin{aligned}
& \left.F_{x}=m\right) \frac{d v_{x}}{d t}+v_{z} \omega_{y} \quad v_{y} \omega_{z}[, \\
& \left.F_{y}=m\right) \frac{d v_{y}}{d t}+v_{x} \omega_{z} \quad v_{z} \omega_{x}[, \\
& \left.F_{z}=m\right) \frac{d v_{z}}{d t}+v_{y} \omega_{x} \quad v_{x} \omega_{y}[.
\end{aligned}
$$

and torques,

$$
\begin{aligned}
& \tau_{x}=I_{x x} \frac{d \omega_{x}}{d t}+\omega_{y} \omega_{z}\left(I_{z z} \quad I_{y y}\right), \\
& \tau_{y}=I_{y y} \frac{d \omega_{y}}{d t}+\omega_{x} \omega_{z}\left(\begin{array}{ll}
I_{x x} & I_{z z}
\end{array}\right), \\
& \tau_{z}=I_{z z} \frac{d \omega_{z}}{d t}+\omega_{x} \omega_{y}\left(\begin{array}{ll}
I_{y y} & I_{x x}
\end{array}\right) .
\end{aligned}
$$

For the rigid body dynamics in a plane $\left(\begin{array}{ll}x & y\end{array}\right)$ the terms regarding a third dimension $(z)$ are not considered, then: 


$$
\begin{aligned}
& v_{z}=0, \\
& \omega_{y}=0, \\
& \omega_{x}=0 .
\end{aligned}
$$

Finally, the resultant force and torque for a two-dimensional rigid body is given in equation (3.45). $F_{x}$ and $F_{y}$ are the sum of all forces in $x$ and $y$ direction respectively and $\tau_{z}$ is the resultant torque around the vertical ( $\mathrm{z}$ ) axis ( $\mathrm{x}-\mathrm{y}$ plane).

$$
\begin{aligned}
& \left.F_{x}=m\right) \frac{d v_{x}}{d t} \quad v_{y} \omega_{z}[ \\
& \left.F_{y}=m\right) \frac{d v_{y}}{d t}+v_{x} \omega_{z}[ \\
& \tau_{z}=I_{z z} \frac{d \omega_{z}}{d t}
\end{aligned}
$$

The previously presented equations describe the rigid body motion in a plane and are obtained when the forces acting on all points of the body are known. To characterize a vessel as a rigid body, the main parameters of these systems are described in the following.

\subsection{Characterization of vessels as rigid bodies}

The parameters describing vessel characteristics are usually specific to nautical terms and navigation research. A review of the main aspects of ships is necessary and will be briefly described in this section.

A vessel capacity of cargo is usually defined by its gross tonnage $(G t)$, a dimensionless index related to the ship overall volume. The gross tonnage is calculated based on the volume of all enclosed spaces of the ship and is used to determine its cargo capacity, safety rules, and general fees. This index was worldwide adopted after the publication of standards methods on waterborne transport tonnage (International Convention on Tonnage Measurements of Ships, 1969).

The ship length, beam, and draft are parameters of major importance for any waterway assessment, as they define the need for adaptation works in rivers. The length parameter relates two values: (I) the overall length, defined as the maximum length of the ship; and (II) length at waterline, the ship length measured at the waterline. The beam is the vessel width at its widest point and the draft is the necessary water depth to 
float a ship.

The ship directions and angles also have its own nautical nomenclatures, summarized in Fig. 3.1. Port (red beacon) and starboard (green beacon) refers respectively to the left and right side of a vessel on board facing the front part of the craft, the bow. The back side of the ship is the stern. During navigation, the craft is subjected to angular variations in its three axes of movement: (I) roll, when the angular movement occurs on its longitudinal axis; (II) yaw, the rotation about its vertical axis; (III) pitch, the rotation about its transverse axis.

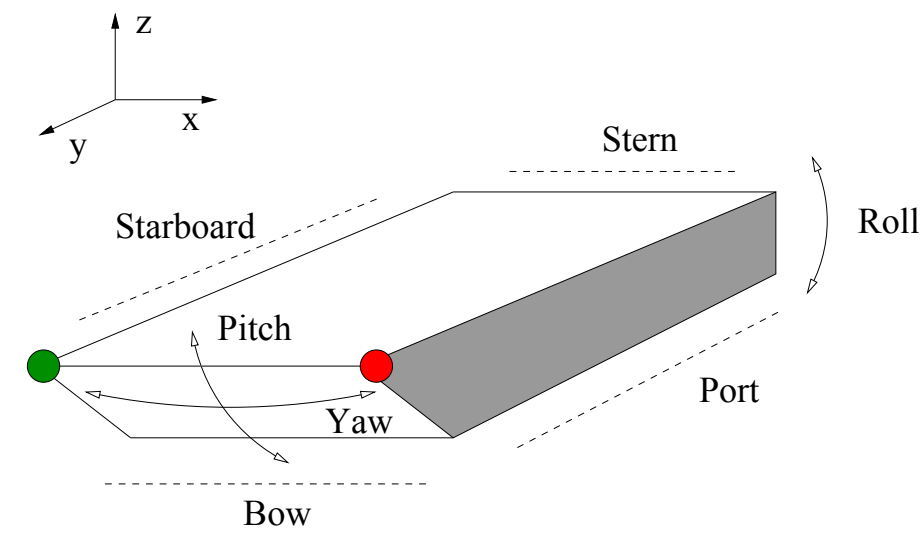

Figure 3.1: Representation of boat angular movements (arrows) and general shipboard directions (dotted lines).

Figure 3.2 (left) shows hypothetical reference systems. The earth-fixed reference system $(\mathrm{x}-\mathrm{y})$ is inertial and is linked to the description of the river and vessel overall position. The vessel reference system $\left(\mathrm{x}^{\prime}-\mathrm{y}\right.$ ') describe the relative motion within the waterway. As presented by Kornev (2013), adopting a relative reference system is necessary to simplify several parameters related to the body inertia.

For rigid bodies, the analysis of resultant forces and torques usually occurs by the discretization of the system in a finite number of sections or points. The overall force on the body is the sum of all forces and torques acting in each one of the discrete points. Figure 3.2 (right) presents a vessel hypothetically described by $N$ discrete points. The resultant force and torque on the rigid body are given by equation (3.21).

The coordinate system representation of rivers to be used in this research is given in Fig. 3.3, where $S t$ is related to the river transversal distance (between margins), $S l$ is the longitudinal distance (flow main direction), and $S v$ the vertical distances (water depth). 

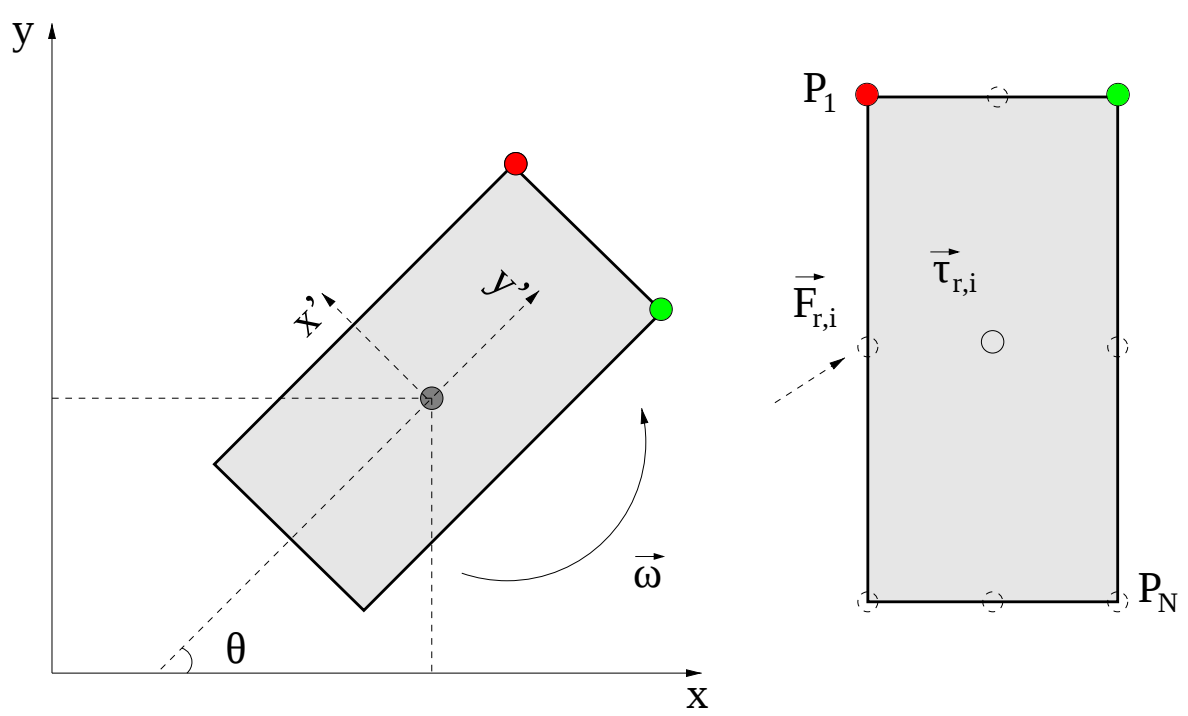

Figure 3.2: Inertial (x-y plane) and vessel ( $\left.\mathrm{x}^{\prime}-\mathrm{y}^{\prime}\right)$ two-dimensional reference system (left). The ship angle with the inertial reference system is $\theta$ and $\vec{\omega}$ is the angular acceleration. Ship discretization in $P_{N}$ points (right), where $\vec{F}_{r}$ and $\vec{\tau}_{r}$ are the resultant force and torque applied in the point $i$.

(a)<smiles>CC(C)CC(C)CC(C)C</smiles>

(b)

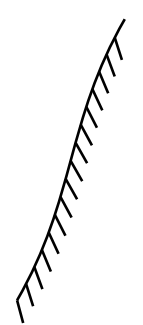

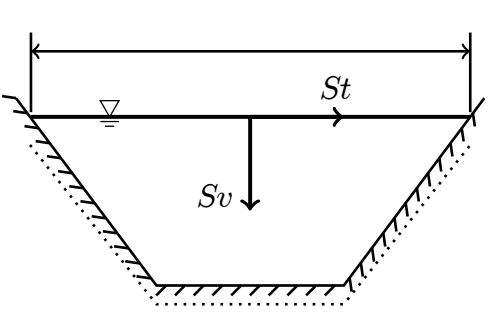

(c)

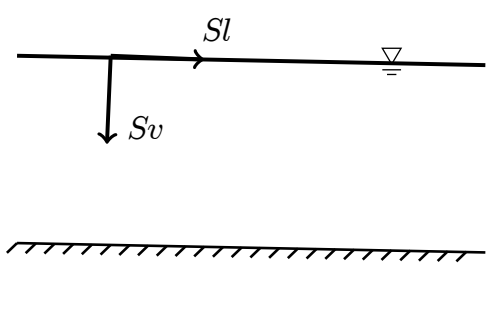

Figure 3.3: Coordinate system representation of a river: (a) top, (b) cross-section, and (c) longitudinal view. $S t$ is the river transversal distance, $S l$ is the longitudinal distance, and $S v$ the vertical distances.

\subsection{Chapter closure}

In this chapter, basic concepts of kinematics and motion equations were reviewed. Then, by deriving the Kinetic Energy Equation the theoretical background necessary to represent the resultant forces and torques acting in a rigid body subjected to external forces was presented, where Eq. (3.45) defines the vessel linear and angular motion in the model. The last section of the chapter characterized vessels as rigid bodies, presenting the main features and parameters necessary for the elaboration of the computational model.

As long as the forces are known, the representation of vessel movement is possible. These forces arise from the interaction between the ship and the river flow. The following chapter presents a survey on fluid mechanics for river hydraulics and immersed rigid bodies, necessary to model the velocity field that generates the forces affecting the motion. 


\section{Chapter 4}

\section{Fluid mechanics for river hydraulics and immersed rigid bodies}

Fluid mechanics studies are necessary to the analysis of hydraulic and hydrodynamic characteristics of fluvial systems. It is also fundamental to evaluate the motion of rigid bodies within flow fields. This chapter presents concepts of fluid mechanics, river hydraulics and hydrodynamic modeling that are important for the vessel-current model development.

\subsection{Governing equations for fluid flow}

The flow velocity is a primary concern for most engineering problems in fluid mechanics. The velocity field distribution relates several parameters necessary to describe the flow characteristics and its implications, as pressure, forces, and turbulence.

The Navier-Stokes equations are the most advanced mathematical approach to describe viscous fluid motion, relating the acceleration of the velocity field with pressure, gravity, and viscous forces. These equations establish that changes in momentum and acceleration of fluid particles are given by the product of changes in pressure, dissipative viscous forces acting on the fluid, and external forces.

The derivation of the Navier-Stokes equations presented in this study is based on the work developed by Schlichting (1966). The equations can be determined starting from a set of assumptions and preliminary equations. The fluid medium must be continuous and all variables of interest differentiable. Also, Coriolis effects and surface tension are disregarded. The Navier-Stokes derivation arise by a momentum-force balance and continuity equilibrium, described in the following sections. 


\subsubsection{Continuity equation}

Considering a control volume $\Omega$ and its boundary surface $\partial \Omega$, the continuity equation can describe the change of an intensive property $\beta$ within a control volume $\Omega$ by the Reynolds Transport Theorem (Greenberg, 1998):

$$
\frac{\partial}{\partial t} \sqrt{\Omega}_{\Omega} \beta d V=\sqrt{\partial \Omega}_{\beta} \beta \vec{v} \times \vec{n} d A \quad V_{\Omega} Q d V
$$

where $\vec{v}$ is the flow velocity, $\vec{n}$ is the surface normal versor, and $Q$ is the representation of sources or sinks of $\beta$ within the control volume $(V)$.

The first term of equation (4.1) describes the variation of property $\beta$ in time, the second indicates the amount of $\beta$ flowing through the boundary $\partial \Omega$ and the last term describes how much of the property is leaving the volume due to sinks or sources inside the boundary.

Greenberg (1998) describes how the Divergence Theorem relates the flow of a vector field through a closed surface $(\partial \Omega)$ to a control volume $(\Omega)$ :

$$
\sqrt{\partial \Omega}_{\beta} \beta \vec{v} \times \vec{\imath} d A=ل_{\Omega} \times(\beta \vec{v}) d V
$$

where the divergence of the velocity vector is given by:

$$
\times \vec{v}=\frac{\partial v_{x}}{\partial x}+\frac{\partial v_{y}}{\partial y}+\frac{\partial v_{z}}{\partial z} .
$$

Thus, the flux term of equation (4.1) can be expressed as a volume integral:

$$
\frac{d}{d t} V_{\Omega} \beta d V=V_{\Omega} \times(\beta \vec{v})+Q d V
$$

and since the control volume is fixed in space, the previous equation can be writen as:

$$
\sqrt{\Omega}_{\Omega} \frac{\partial \beta}{\partial t}+\times(\beta \vec{v})+Q d V=0
$$

Then, the general form of the continuity equation is presented in equation (4.6):

$$
\frac{\partial \beta}{\partial t}+\quad x(\beta \vec{v})+Q=0
$$

The mass conservation can be obtained by replacing the intensive property $\beta$ by the specific mass $(\rho)$ in equation (4.6): 


$$
\frac{\partial \rho}{\partial t}+\quad x(\rho \vec{v})+Q=0
$$

when no source or sink within the control volume is present $Q=0$,

$$
\frac{\partial \rho}{\partial t}+\quad \times(\rho \vec{v})=0
$$

Rearranging equation (4.6) we verify that it corresponds to a material derivative of the intensive property $\beta$, which is the rate of change of the intensive property in a velocity field in time and direction, then:

$$
\frac{D \beta}{D t}=\frac{\partial \beta}{\partial t}+\beta(\quad \times \vec{v})
$$

\subsubsection{Momentum equation}

The momentum conservation equations arise from Newton second law, already presented by equation (3.12). Replacing the expression of mass $(m)$ by density $(\rho)$ and considering $\vec{b}$ as the force $\vec{F}$ by the control volume $\Omega$, the equation can be rewritten as:

$$
\vec{b}=\rho] \frac{d}{d t} \vec{v}(x, y, z, t) /
$$

Applying the chain rule to the velocity derivative:

$$
\vec{b}=\rho) \frac{\partial \vec{v}}{\partial t}+\frac{\partial \vec{v}}{\partial x} \frac{\partial x}{\partial t}+\frac{\partial \vec{v}}{\partial y} \frac{\partial y}{\partial t}+\frac{\partial \vec{v}}{\partial z} \frac{\partial z}{\partial t}[
$$

which can be rearranged as:

$$
\vec{b}=\rho) \frac{\partial \vec{v}}{\partial t}+\vec{v} \times \vec{v}[
$$

Applying the definition of material derivative,

$$
\vec{b}=\rho \frac{D \vec{v}}{D t}
$$

Assuming that the forces acting on the fluid is due to fluid stresses $(\overline{\bar{\sigma}})$ and external forces $(\vec{F})$, the momentum equation is given by:

$$
\vec{b}=\times \overline{\bar{\sigma}}+\vec{F}
$$




\subsubsection{Navier Stokes equations}

To obtain the Navier-Stokes equations it is necessary to evaluate the stress tensor $(\overline{\bar{\sigma}})$, where $\sigma_{i, j}$ is the stress in the plane perpendicular to $i$ in direction of $j$ :

$$
\overline{\bar{\sigma}}=\left\{\begin{array}{ccc}
\sigma_{x x} & \tau_{x y} & \tau_{x z} \\
\tau_{y x} & \sigma_{y y} & \tau_{y z} \\
\tau_{z x} & \tau_{z y} & \sigma_{z z}
\end{array}\right.
$$

The stress tensor $\overline{\bar{\sigma}}$ can be divided into two terms in the general form of Navier-Stokes equation:

$$
\overline{\bar{\sigma}}=p \delta_{i, j}+T
$$

where $\delta_{i, j}$ is the Kronecker delta, $p$ is the pressure and the term $T$ is presented in equation (4.17). In the following we are assuming that $p=p \delta_{i, j}$.

$$
T=\left\{\begin{array}{ccc}
\sigma_{x x}+p & \tau_{x y} & \tau_{x z} \\
\tau_{y x} & \sigma_{y y}+p & \tau_{y z} \\
\tau_{z x} & \tau_{z y} & \sigma_{z z}+p
\end{array}\right.
$$

Using Eqs. (4.17) and (4.16), the Cauchy momentum equation is obtained:

$$
\rho \frac{D \vec{v}}{D t}=\quad p+\quad \times T+\vec{F}
$$

The first term of the previous equations $\left(\rho \frac{D \vec{v}}{D t}\right)$ is the force on each fluid particle, which is composed by three components: a pressure term $(p)$ related to normal stresses; a stress term that causes motion due to shear stresses $(x T)$, and the external force term acting on the fluid particles $(\vec{F})$.

To obtain the general form of Navier-Stokes equation from Eq. (4.18), one must analyze some characteristics of the fluid. Thus, an expression for the stress tensor $(T)$ must be evaluated. Also, if the fluid is compressible, equations of the energy state and conservation are also necessary.

For a Newtonian and incompressible fluid the stress is proportional to the rate of deformation and to the fluid viscosity $(\mu)$, thus the shear stress is given by:

$$
\left.\tau_{i j}=\mu\right) \frac{\partial v_{i}}{\partial x_{j}}+\frac{\partial v_{j}}{\partial x_{i}}[
$$

and 


$$
\times \sigma=\mu \times\left\{\begin{array}{lll}
\sigma_{x x} & \tau_{x y} & \tau_{x z} \\
\tau_{y x} & \sigma_{y y} & \tau_{y z} \\
\tau_{z x} & \tau_{z y} & \sigma_{z z}
\end{array}\right.
$$

Applying (4.19) in (4.20) it is possible to obtain the shear stress relation:

$$
\times T=\mu^{2} \vec{v}
$$

Finally, the Navier-Stokes equations for Newtonian and incompressible fluid is obtained,

$$
\rho \frac{D \vec{v}}{D t}=\quad p+\mu^{2} \vec{v}+\vec{F}
$$

Applying indicial notation for Navier-Stokes equation, for $i$ and $j=1,2,3$ :

$$
\rho] \frac{\partial v_{i}}{\partial t}+v_{j} \frac{\partial v_{i}}{\partial x_{j}}\left(=\frac{\partial P}{\partial x_{i}}+\mu \frac{\partial^{2} v_{i}}{\delta x_{j}^{2}}+F_{i} .\right.
$$

The complete Navier-Stokes equations are still not solved analytically. The models based on these equations, as Telemac (EDF, 2014) and Delft3D (Deltares, 2014), use treatments and simplifications for the numerical solution, which directly affects the results. Sequera (1994) presented several studies discussing Navier-Stokes equations and related non-linear problems approach. Those numerical methods are not in the scope of this research and are not addressed in this study.

\subsection{Fluvial hydraulics and river modeling}

River modeling is a key point for navigability assessment. The modeling approach must be thorough, especially given the complex characteristics of the regions and the necessity of vast gathering of data to be obtained during field surveys. The river model can provide information on the water level and velocity fields along the channel, which is the main input data for the ship-tracking analysis.

The modeling of river systems depends on some preliminary considerations to be analyzed: (I) will it be concentrated with information in the measured sections or distributed by modeled data? (II) which is the required model dimension to assess ship motion? (III) do the simulations occurs for permanent or transient flow condition? These are some of the most important questions to be analyzed to determine the strategy in the waterways modeling. 
Numerical models are widely used to simulate flow in open channels and assess rivers hydrodynamic characteristics. Among the most used models highlights HEC-RAS and Delft3D. Each one has its advantages, features, and limitations of use.

Flow processes in rivers are naturally three-dimensional. Nevertheless, in some cases, it is possible to ignore the velocity spatial variation in relation to the channel depth and width. Thus, the flow process may be approximated as varying in only one space dimension, along the longitudinal direction of the flow. This approach suits a large number of studies, especially when the vertical and lateral velocities are considered to be much lower than the longitudinal velocity.

For one-dimensional analysis of open channel flow, HEC-RAS (US Army Corps of Engineers, 2006) is a software extensively used worldwide. It is designed to be applicable in a wide range of geographic areas, solving several different problems, as the prediction of river flow inundation and damage (Horritt and Bates, 2002), dam brake (Xiong, 2011), sediment transport (Brunner and Gibson, 2005), and water quality (Fan et al., 2009).

The Delft3d model stands out when a three-dimensional analysis is required. The program is a fully integrated computer software suited for a multi-disciplinary approach and three-dimensional computations for coastal, river and estuarine areas. It can carry out simulations of river flows (Macmahan and Reniers, 2010), sediment transports (Hu et al., 2009), waves (Elias et al., 2001), water quality (Chen and Mynett, 2006), and morphological developments (Lesser et al., 2004). Delft3D is composed of several modules, grouped around a mutual interface. The FLOW module is used for rivers analysis. It is a multi-dimensional (2D or $3 \mathrm{D}$ ) hydrodynamic simulation program which computes unsteady flow and transport phenomena (Deltares, 2014).

Regarding the river model dimension, the traditional approach to study flow patterns in channels is through one-dimensional models that take information in the form of crosssections. Although the normal flow in rivers can be assumed to be one-dimensional in the main channel, this assumption becomes invalid at heterogeneous boundaries, thus requiring the use of two and three-dimensional hydrodynamic models (Merwade, 2009).

Horritt and Bates (2002) discussed the use of one-dimensional or two-dimensional approach for river analysis. The authors presented the performance of several models and analyzed the ability to predict a particular discharge and inundation extent. The research indicated that the one-dimensional model suited better for the studied reach. Nevertheless, these results may be linked to local parameters and study area characteristics, especially given the low transversal flow rate on site.

Lane et al. (1994) also evaluated predictive ability and prediction utility for two and 
three-dimensional models. The authors compared the predictions of models using highquality field data and identical boundary conditions. The evaluation of the 3D model suggests that there is a fundamental limitation upon model predictive ability due to problems of specifying topographic complexity. However, comparison with the 2D model shows that the 3D model has a higher predictive ability, particularly if the 2D model is not corrected for the effects of secondary circulation.

For the Brazilian waterways, sensitivity studies among the different possible models should be tested and the results compared. Before determining which strategy is the best to simulate the rivers, basic channel hydraulics are necessary for a first outlook of the flow system. Input data gathering is also necessary, which usually consist of bathymetry, velocity field, discharge, and sediment transport.

\subsubsection{Open channel hydraulics}

The classical approach for initial assessments of river occur by the analysis of several hydraulic parameters, as described by diverse authors (Henderson, 1966, Graf, 1984, Cardoso, 1998, Fox et al., 2011). These parameters are essential to characterize the dynamics occurring in rivers.

In channel hydraulics, the Reynolds number $(R e)$ is widely used to describe the flow as a laminar or turbulent regime. This dimensionless number is the relation of inertial and viscous forces and is used to determine various other characteristics of the flow. For rivers, the flow regime is considered laminar for Reynolds Numbers lower than 500 and turbulent for values over 2,000. Values between these levels configure a system flow in transition (Chow et al., 1988). The Reynolds Number equation is given by:

$$
R e=\frac{\rho R \bar{v}}{\mu},
$$

where $\rho$ is the fluid density, $\mu$ the fluid dynamic viscosity and $\bar{v}$ the fluid mean velocity. The value $R$ defines a typical length scale in the system, usually hydraulic radius for open channels. The hydraulic radius is defined by the ratio of the cross-sectional area $(A)$ and the wet perimeter $(p w)$ :

$$
R=\frac{A}{p w} .
$$

A widely used simplification is to consider the cross-section of the channels as rectangular, then: 


$$
R=\frac{H L}{2 H+L}=\frac{H}{1+2 H L^{-1}},
$$

where $H$ and $L$ are the cross-section depth and width respectively. A valid approximation for shallow rivers is that $R / H$. However, numerical models use algorithms that perform a precise integration of the area and perimeter of the sections, reducing errors in simulations.

The Froude number $(F r)$ is another essential dimensionless parameter in the characterization of rivers, relating the inertial and gravity forces, describing events like hydraulic jumps and backwater effects. The parameter is given by:

$$
F r=\nabla_{\overline{g R}}^{\bar{v}}
$$

The numerator part of the Froude number equation is the fluid mean velocity $(\bar{v})$ and is related to the inertial force. The denominator represents the gravity force in the flow and is given by the gravity $(g)$ and hydraulic radius $(R)$. The Froude number classifies the flow regime as subcritical $(F r<1)$, critical $(F r=1)$ and supercritical $(F r>1)$.

The river flow can also be assayed for its flow variation in time (Eq. 4.28). Channels in steady flows regime are associated with little variations on the discharge values, considered approximately constant in a certain period. If this condition is not valid, the flow regime is transient, usually associated with flood waves, dams operations and rainfall events, hence:

$$
\begin{aligned}
& \frac{d}{d t}=0 \text {, steady flow condition, } \\
& \frac{d}{d t} \models 0 \text {, unsteady flow condition. }
\end{aligned}
$$

The velocity field in natural channels is three-dimensional. Usually, velocities occurring in the longitudinal direction, parallel to rivers margins, predominates over the lateral flow (transverse direction, perpendicular to the margins) and vertical flow (vertical direction, perpendicular to the river bottom). The analysis of velocities is important in the process of river modeling, defining the need for more dimensions.

Rivers with much larger longitudinal than transversal and vertical velocities can be evaluated by a one-dimensional approach (Horritt and Bates, 2002). However, for rivers with a non-homogeneous channel morphology as bedrock formation (Venditti et al., 2014) or strong tributaries channels (Zhao et al., 1994), the transversal and vertical velocities are higher and the flow should be treated by a two or three-dimensional approach.

The flow vorticity is another important characteristics. This quantity may define rotational patterns within the flow field, which could affect the motion of rigid bodies. 
Kundu (1990) described the vorticity of a fluid element as a function of the velocity field:

$$
\vec{\Omega}=\bullet \vec{v}
$$

A fluid motion is called irrotational if $\overrightarrow{\omega v}=0$, thus:

$$
\frac{\partial v_{i}}{d x_{j}}=\frac{\partial v_{j}}{d x_{i}}, i \models j
$$

\subsubsection{River bends}

The curvature radius $(C)$ is a parameter that can characterize meandering stretches of rivers and is widely used in navigation research. Combined with parameters of the flow (e.g. velocity), river (e.g. width), and ships (e.g. velocity, length and, rudder) is used in the determination of risks to navigation and the need of improvement works.

Graewe (1971) published a study regarding dimensioning and widening of waterways. The author establishes the relation between the radius of curvature and width of channels with geometric features of vessels. Then, it was possible to determine the minimum width values of the navigation channels (or maximum width of a vessel) for the safe passage of ships.

Guarneri et al. (2016) also presented an approach for the characterization of the radius of curvature of rivers that have commercial navigation. The authors applied the method to analyze two stretches of the Paraguay River waterway. Then compared the results with the standards used in the region. These methods and results will be further applied in this research.

\subsubsection{Bathymetry}

The main objective of bathymetric measurements is to obtain the channel depth and main features. Regardless of the used hydrodynamic model, bathymetry data are essential in the process of adjusting computer models to represent river hydrodynamics, sediment transport, and geomorphologic assessment (Merwade, 2009).

Currently, there are several types of equipment and methodologies for obtaining bathymetric data: satellite imagery, aerial photography, acoustic bathymetry survey, and laser technology. In Brazil, multifrequency acoustic profiling is the most used approach for hydrographic surveys and is a proven method for bathymetry and sedimentation measurements. These devices have many similarities with the acoustic velocity profilers and 
its operation is briefly explained in the following.
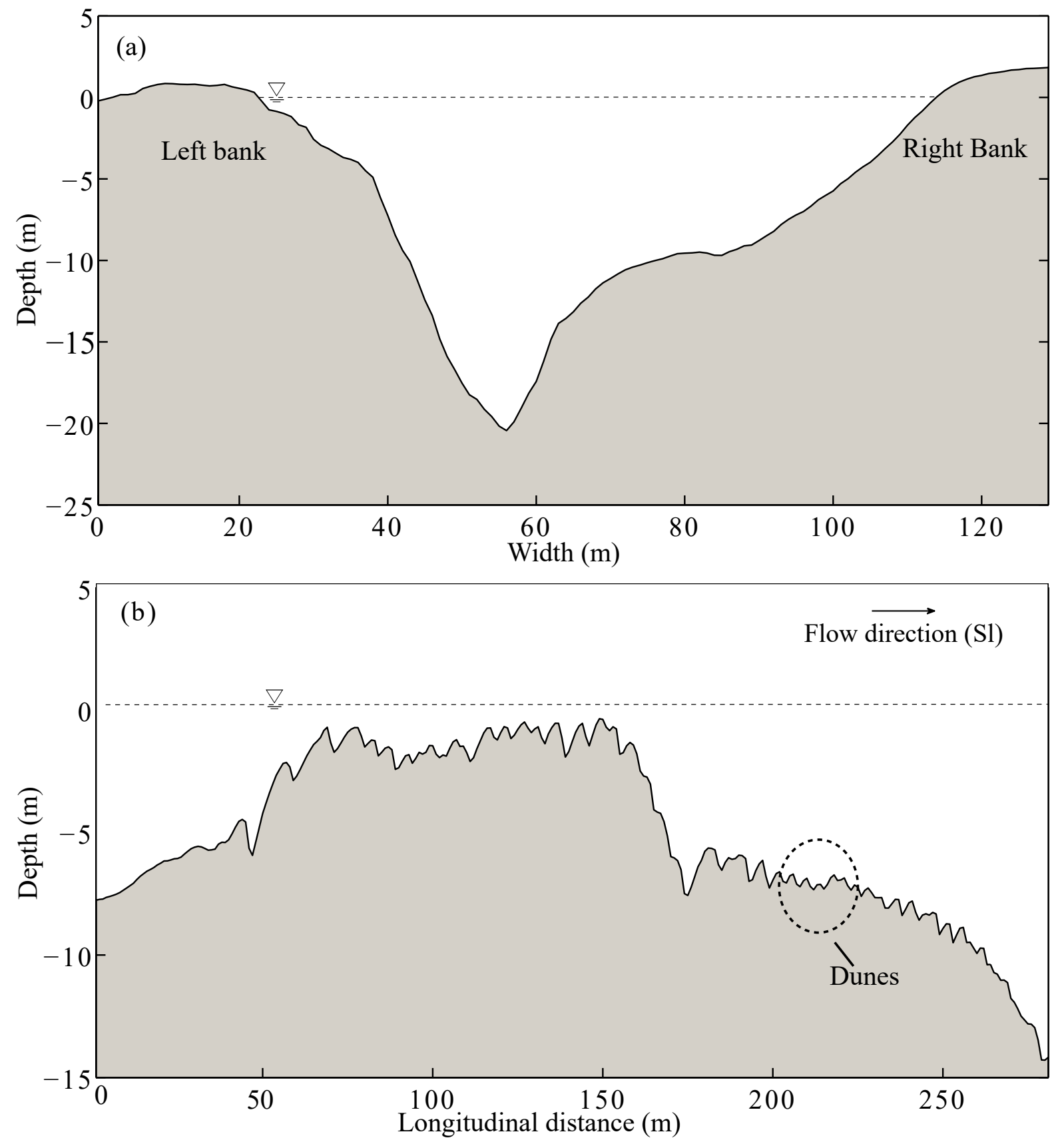

Figure 4.1: Sample of a bathymetric analysis: (a) cross-section and (b) longitudinal view of a river stretch. Measurement performed on a field survey in the Paraguay River.

A conventional way to measure the river bathymetry is by cross-sectional surveys, shown in Fig. 4.1 (a), where ground profiles are collected transverse to the river flow main direction, presenting the channel depth along its covered width. The cross-sections can provide information of the section area, perimeter and the hydraulic radius. Combining this information with the river flow velocity one can calculate the discharge.

The river bed can also be analyzed by bathymetric sampling along the flow direction, 
as presented in Fig. 4.1 (b). These measurements allow the analysis of the river bed level variations due to the river slope and to the presence of sediment dunes. Sediment transport is a major challenge in the maintenance of inland waterways. It is related to erosion and sedimentation processes, which are the main causes of the formation of sandbanks along the navigation channel, thus detailed bathymetric surveys are important for sediment transport analysis.

\subsubsection{Velocity field}

The velocity field is one of the most important parameters in the study of rivers. It can be obtained by field measurements and by modeling of the channel flow. Several types of research recognized the importance of flow patterns in open channel analysis, where the velocity field is particularly relevant for navigability assessments since it can induce sinkage effects, angular rotation, and translation motion on vessels.

For the river flow modeling, extrapolation of field measurements to numerical modeling makes the data gathering even more sensible, given that three-dimensional models need three-dimensional data for verification purposes (Lane et al., 1998).

More traditional methods of flow measurements only provide average values for the flow velocity, which is not sufficient for a detailed analysis of the river. The use of Doppler technology for measuring river flows was a major breakthrough in the research of fluvial hydrodynamics. The devices based on this technology are known as Acoustic Doppler Current Profiler (ADCP) and have application in various areas, e.g. hydrodynamic models calibration, current monitoring, velocity profiles in a section, and general hydraulic studies (Gamaro, 2012).

The use of ADCP equipment provides data of complex hydrodynamic processes, especially those involving three-dimensional current speed, such as the analysis of hydrodynamic effects on rivers junctions (Lane et al., 2008), braided rivers flow (Williams et al., 2013), and hydrodynamic of rivers in bedrock canyons (Venditti et al., 2014).

In general, the acoustic equipment emits sound waves that are reflected by suspended particles and by the river bed (Gamaro, 2012). As the floating particles are expected to be at the same velocity of the flow, the river three-dimensional velocity can be measured by the Doppler effect.

The latest equipment for velocity mapping allows a wide range of settings, increasing the data detailing in the surveys, as frequent calibration of the compasses, correction on the local magnetic declination and setting the salinity of the measured fluid. The measurements shall be carried out carefully to avoid the accumulation of errors. 
The ADCP divides the cross-section into several cells, each with a respective position coordinate and a value for velocity in the longitudinal, transversal and vertical direction. Also, the equipment provides a linear bathymetry, usually depth along the cross-section width. Figure 4.2 presents resultant current velocity profile for a measured cross-section. The river bed is presented in gray and the velocity by a normalized color map. The space with no data are left in white and usually is filled with interpolation results provided by several algorithms. Although data post-processing is critical to the analysis, there are few programs dedicated to it. Therefore, to assist this research a post-processing tool was developed (see Tomas et al., 2016).

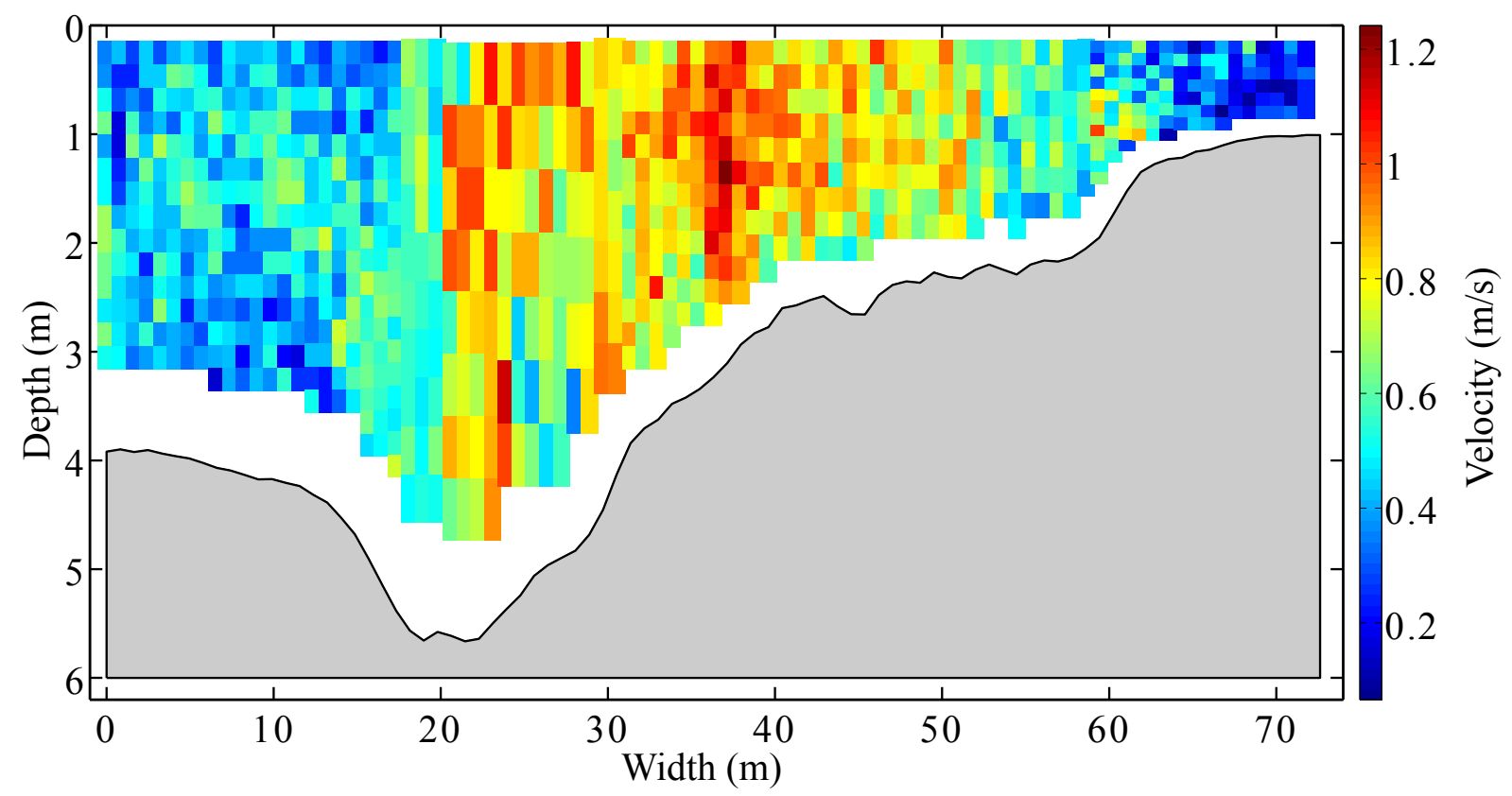

Figure 4.2: Sample of a cross-section longitudinal velocity magnitude given by an acoustic profiler. Measurement performed on a field survey in Paraguay River.

The Paraguay River is the main area of study for this research, thus to better characterize this fluvial system several cross-sections were analyzed with the ADCP. The field survey and measurements are detailed in chapter 6 .

For sake of brevity, only an introduction of the equipment and its methodology were described, more details are presented by Lane et al. (1998), Szupiany et al. (2007) and Gamaro (2012).

\subsection{Fluid flow around immersed bodies}

This section regards the analysis of the motion of bodies immersed in a fluid field. The rotational and translational movement of bodies in the fluid may cause several resistance 
forces to the movement, as drag and lift. The analysis of these forces is fundamental to model the interaction between vessels and the river flow.

\subsubsection{Drag force}

Whenever there is relative motion between a rigid body and a viscous fluid that surrounds it, a net force $\vec{F}$ will affect the immersed body. The magnitude of this force depends on many factors, as the fluid-body relative velocity, the fluid properties, and the body morphology. The flow around the body generates tension on each surface element and this is what induces the resultant force. The surface tensions are composed of tangential stresses due to viscous action and normal stresses due to local pressure (Fox et al., 2011). The viscous action, resulting in the surface resistance from shear forces, is often called skin-friction drag and the resistance resulting from pressure forces is called form drag (Roberson and Crowe, 1993).

Drag is the force component on a body that acts parallel to the direction of a relative motion. Figure 4.3 presents the drag for a two-dimensional body, where the drag resultant is due to a pressure $(p)$ and shear stress $(\tau)$ component acting in a differential area $(d A s)$ :

$$
d \vec{F}_{D}=p \cos _{\theta} d \vec{A} s+\tau \sin _{\theta} d \vec{A} s
$$

The resultant force is obtained by the integration of the pressure and shear stress for the body area:

$$
\vec{F}_{D}=\sqrt{ }\left(p \cos _{\theta}+\tau \sin _{\theta}\right) d \vec{A} s
$$

The difficulties in determining the drag force arise in the calculation of pressure and shear stress components, as these terms are related to the shape of the body. Currently the state-of-art for these analyzes is related to the use of Computational Fluid Dynamics (CFD), usually applied in the optimization process of immersed rigid structures, e.g. ships (Moctar et al., 2012). These algorithms divide the body surface into a high spatial resolution computational mesh, calculating the pressure variation in each node to obtain resultant forces and pressures.

Despite the good representation provided by CFD software, the analysis of the pressure distribution in rigid bodies requires a great amount of data, which is not always possible during initial stages of waterways projects assessment. It is important to emphasize that for this research the perspective is not of the optimization of the structure of ships or its maneuverability, but in obtaining the average navigation displacement. For these cases, 


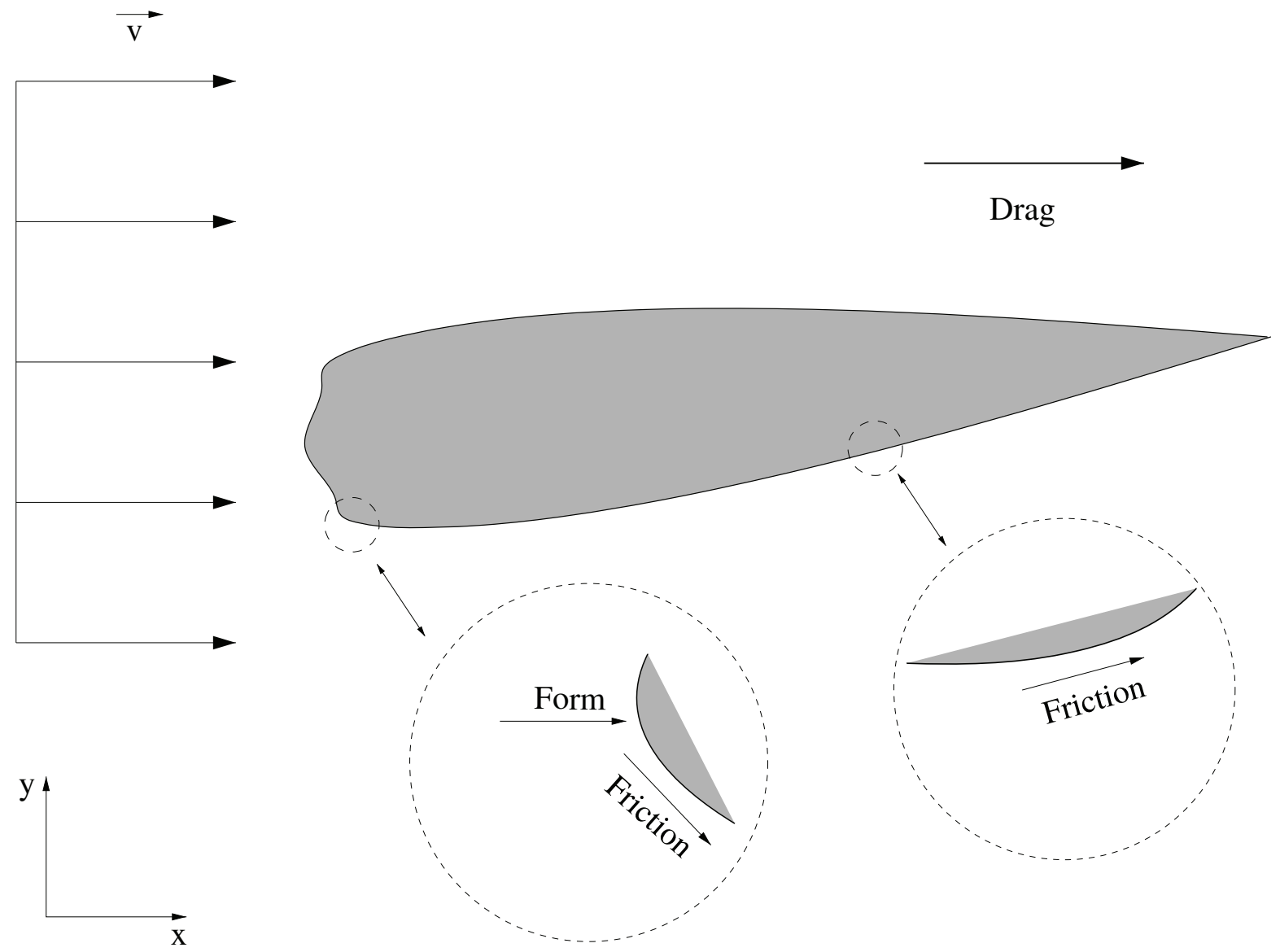

Figure 4.3: Drag force due to pressure (form) and shear stress (skin-friction) on a body moving within a fluid field. The drag force direction is always parallel to the fluid motion, where the form drag component is normal and the skin-friction component is tangential to the body surface.

another possible solution is through the use of analytical semi-empirical equations, which although simpler can provide relevant information to the modeling process.

Fox et al. (2011) presents a relation for the drag forces using the $\pi$-Buckingham theorem. In the case of a body with dimensions proportional to $L$, immersed in a viscous and incompressible fluid and with a certain relative velocity $(\vec{v})$, density $(\rho)$, and viscosity $(\mu)$, the drag force $\left(\vec{F}_{D}\right)$ can described in functional form as:

$$
F_{D}=f_{1}(L, v, \mu, \rho)
$$

The application of the $\pi$-Buckingham theorem results in two dimensionless parameters $\pi$ :

$$
\left.\frac{F_{D}}{\rho v^{2} L^{2}}=f_{2}\right) \frac{\rho v L}{\mu}[
$$

As $L^{2}$ is proportional to a surface area (As): 


$$
\left.\frac{F_{D}}{\rho v^{2} A s}=f_{3}\right) \frac{\rho v L}{\mu}[
$$

The relation obtained is valid for incompressible flow and the characteristic length used in the Reynolds number depends on the shape of the body. For the adopted considerations of incompressibility, the drag coefficient is only a function of the Reynolds number.

The drag coefficient $C_{D}$ is defined as:

$$
C_{D}=\frac{F_{D}}{\frac{1}{2} \rho v^{2} A s},
$$

and the drag force acting on a submerged body is given by:

$$
F_{D}=\frac{1}{2} \rho v^{2} C_{D} A s
$$

The drag force depends on the magnitude and direction of the relative velocity. If the body speed is greater than the flow, the drag decelerates the body independent of the displacement direction. If the body velocity is lower, the drag accelerates the ship for the direction of the flow and decelerates for movements in the opposite direction.

As presented, the drag forces in two and three-dimensional bodies occur by skinfriction and pressure components. Equation (4.37) is applied using separate or composite drag coefficients $\left(C_{D}\right)$ of each drag force component, thus:

$$
C_{D}=C_{\mathrm{D}, \mathrm{p}}+C_{\mathrm{D}, \mathrm{f}}
$$

where $C_{\mathrm{D}, \mathrm{p}}$ is the form drag coefficient and $C_{\mathrm{D}, \mathrm{f}}$ is the frictional drag coefficient. The methods for determining the coefficients are described in the following. One used simplification is that the drag force vector $\left(F_{D}\right)$ formed between the flow and the ship area is fully decomposed as a normal (form drag) and tangential component (friction drag), shown in Fig. 4.4.

\section{Frictional drag coefficient}

The analytical determination of the total drag coefficient is very complex and has not yet been solved for a general case, where usually towing tank experiments are necessary for each ship project. In these experiments, the total drag coefficient can be empirically estimated. However, the determination of the skin-friction drag coefficient can be achieved by the analysis of the flow speed distribution in a field near the surface of a rigid body, approach known as the Boundary Layer Theory, initially proposed by Prandtl (1904) and 


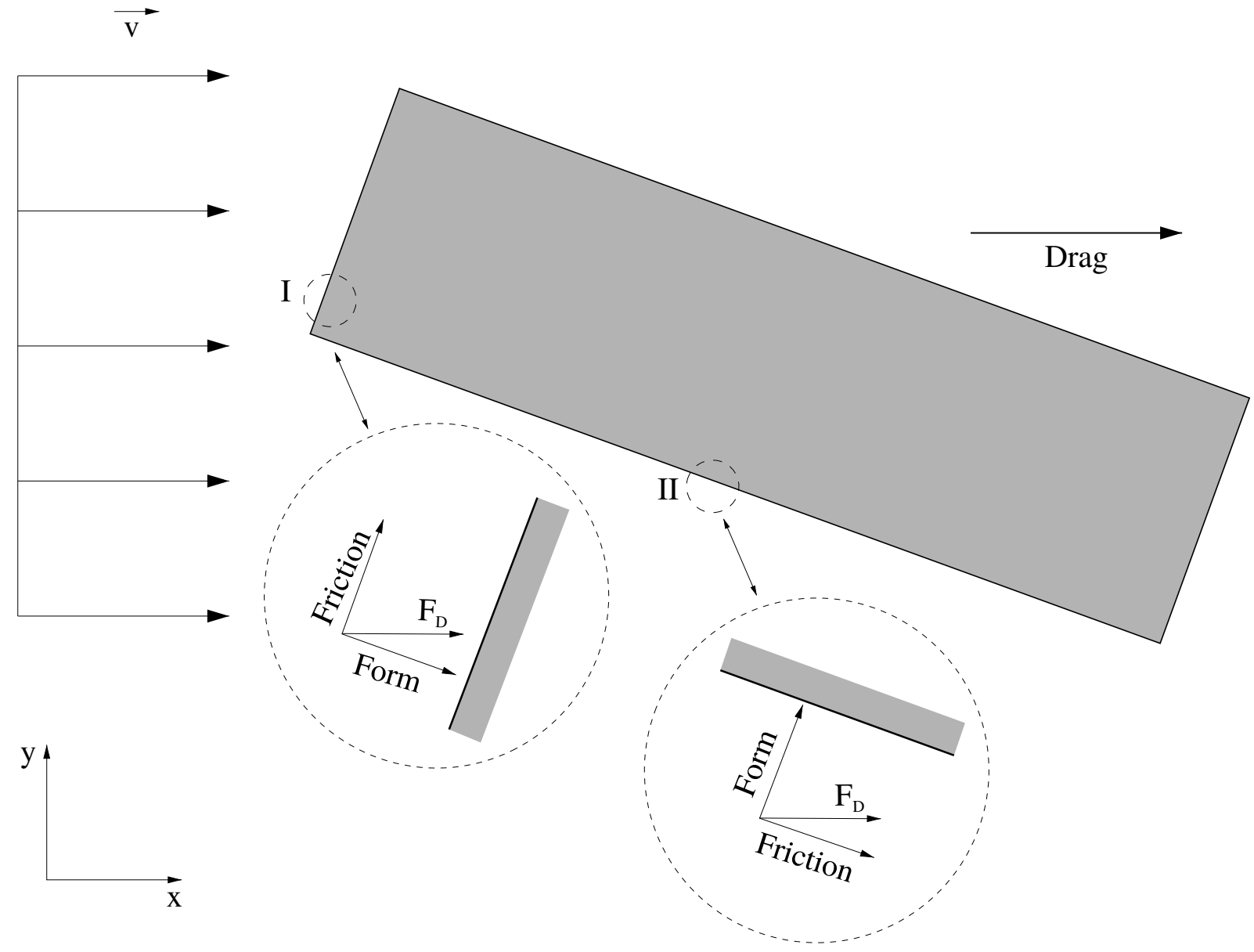

Figure 4.4: Drag force due to pressure (form) and shear stress (skin-friction) for a rectangular ship.

widely described by Schlichting (1966).

The hypothesis of the vessel-river interaction as a parallel flow over a plate is considered a good approximation by engineers and naval architects (Milgram, 1998, Kodama et al., 2000, Usta and Korkut, 2013). Then, it is possible to use this method to estimate the vessel skin-friction drag coefficient, where only the tangential component of the velocity vector formed between the ship surface and the flow is considered (see Fig. 4.4).

The determination of the drag coefficient for a laminar and turbulent boundary layer was presented in Fox et al. (2011). For the laminar case,

$$
C_{D, f}=\frac{1}{\overline{R e}}
$$

where the Reynolds Number is related to a characteristic dimension of the plate. Assuming that the boundary layer is turbulent from the plate leading edge, the coefficient can be obtained by equation (4.40), valid for the interval $10^{5}<R e<10^{7}$, 


$$
C_{D, f}=\frac{0.0742}{R e^{\frac{1}{5}}}
$$

Schlichting (1966) has developed experimental works to adjust the drag coefficient in relation to the Reynolds number. The proposed equation is valid for $R e<10^{9}$ and properly adjusted to the experimental data,

$$
C_{D, f}=\frac{0.455}{(\log R e)^{2.58}}
$$

The friction drag coefficient adjusted by equations (4.39), (4.40) and (4.41) are presented in Fig. 4.5. Thus, knowing the established boundary layer regime on the plate and the Reynolds number, it is possible estimate the skin-friction drag coefficient.

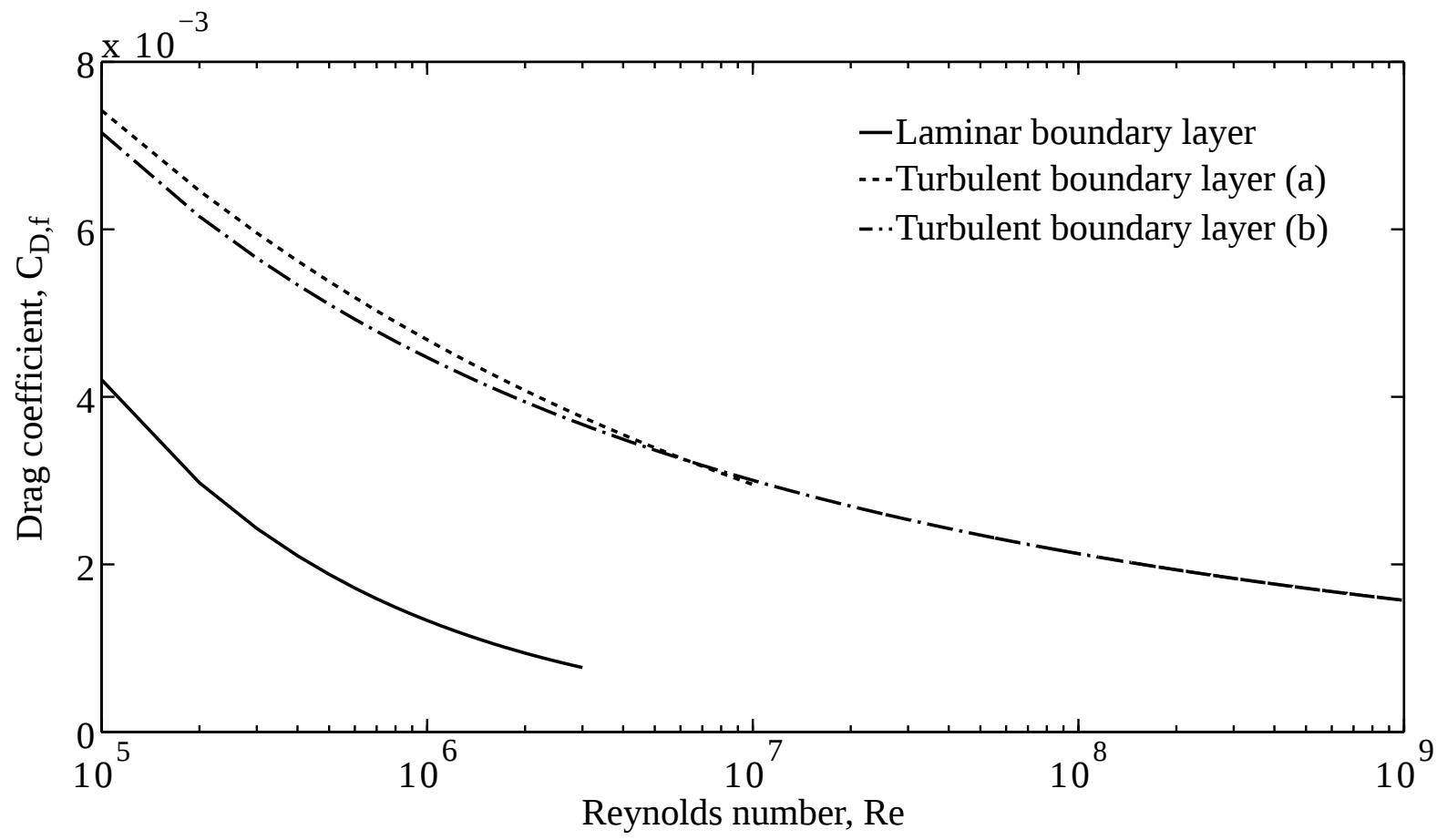

Figure 4.5: Skin-friction drag coefficient for a plate with different values of Reynolds number. The drag coefficient for a laminar boundary layer is determined by equation (4.39) and for a turbulent boundary layer by equations (a) (4.40) and (b) (4.41).

Another widely used expression for the skin-friction drag coefficient for ships is the presented by the International Towing Tank Conference (ITTC) guidelines (ITTC, 1957):

$$
C_{D, f}=\frac{0.075}{(\log \operatorname{Re} 2)^{2}}
$$

Therefore, using the previous equations one can also estimate the skin-friction coefficient of ships with the Reynolds number of the vessel-current interaction. 


\section{Form drag coefficient}

Figure 4.4 (I) presents a component of the flow perpendicular to the body surface, where the shear stress does not contribute to the drag force, only given by the pressure component. For this scenario, the flow separates from the plate edges, where backflow occurs. Although the pressure on the surface of the plate is essentially constant, its magnitude cannot be determined analytically or by numerical highly resolved studies (Fox et al., 2011).

As aforementioned, the pressure and the total drag coefficient can be determined by scale models experiments, which usually require investments in laboratories and equipment. This subject is very important for aerodynamics and hydrodynamics problems. Therefore, several authors researched and published experimental data of form drag coefficients for different bodies morphologies and Reynolds numbers (e.g. Hoerner, 1965).

The National Advisory Committee for Aeronautics (NACA) ${ }^{1}$ was a U.S. federal agency founded in 1915, responsible to research fluid mechanics. The study of the form drag coefficient was essential in the optimization process of early aircrafts and this agency became a reference in this field. The experiments mostly consisted of the analysis of forces and torques arising from the interaction of rigid bodies and flows, as the reaction on streamlining bodies (Abbot, 1932), aircraft scale model (Freeman, 1932), anemometers (Brevoort and Joyner, 1935), and cylinders (Lindsey, 1938). However, these studies were not specifically designed for ships and its application may not be feasible.

According to ITTC guidelines (ITTC, 1957), the form factor, i.e. form drag coefficient, can be estimated by a relation between the ship total resistance and the frictional drag coefficient:

$$
C_{T}=(1+k) C_{D, f}
$$

where $C_{T}$ is the total resistance coefficient, $k$ is the form factor and $C_{D, f}$ is the frictional resistance coefficient. For this equation, additional terms regarding waves, roughness and wind resistance were not considered and are presented in the guideline. Thus, one can observe by comparing equations 4.43 and 4.38 that $k \bullet C_{D, f}=C_{D, p}$ and $C_{T}=C_{D}$.

Min and Kang (2010) presents a detailed review of the form factor of different ships designs, thus whenever data of the total drag is not available one can estimate the form drag coefficient published for a similar vessel.

\footnotetext{
${ }^{1}$ In 1958 the agency was dissolved and the researchers were transferred to the newly created National Aeronautics and Space Administration (NASA).
} 


\subsubsection{Lift forces}

The lift is a component of the hydrodynamic force whose direction is perpendicular to the flow. The lift equation is defined as,

$$
F_{L}=\frac{1}{2} \rho v^{2} C_{L} A s .
$$

where except for $C_{L}$, the remaining parameters are analogous to the presented in Eq. (4.37), velocity vector $(\vec{v})$, fluid density $(\rho)$, and surface area $(A s)$.

Rearranging the terms for the lift coefficient,

$$
C_{L}=\frac{F_{L}}{\frac{1}{2} \rho v^{2} A s}
$$

This coefficient depends on the Reynolds number and the angle of attack $\left(\alpha_{L}\right)$, which is the angle formed between the body axis of symmetry and the free stream velocity vector (Fox et al., 2011).

The study of lift is important for researchers related to flight aerodynamic of aircrafts (Goett and Bullivant, 1938; Lissaman, 1983) and even animals (Tucker, 1993; Ellignton et al., 1996). However, also plays a major role in hydrodynamics of vessels (PIANC, 1992).

The lift phenomenon is widely discussed by many researchers (Milgram, 1998; Kundu, 1990; Fox et al., 2011). These forces are usually associated with the increase (decrease) of the velocity and pressure along the surface of bodies. Due to the pressure differences of the flow, the surface with higher flow velocity (lower pressure) is the suction surface, while the surface with lower flow velocity (higher pressure) is the pressure surface.

A great challenge for this research is to present simplified solution of complex problems, and the determination of the lift coefficient is not different. Given the unavailability of data and the discretization of the rigid body as a rectangular and simple body, this coefficient will be defined by the thin airfoil theory, then:

$$
C_{L}=2 \pi \alpha_{L}
$$

where this relation is valid for small angles of attack $\left(\alpha_{L}\right)$ in radians. Further details are presented by Morris and Rusak (2013). 


\subsubsection{Added mass}

In fluid mechanics, the added mass is the inertia added to a system due to an accelerating body within a flow, shifting some volume of surrounding fluid as it moves through it. Added mass or virtual mass is a common issue given that immersed bodies and surrounding fluid cannot occupy the same physical space simultaneously. A detailed overall description and necessary hypothesis are described by several authors (Brennen, 1982; Kornev, 2013; Sen and Vinh, 2016).

The added mass can reach a considerable percentage of the ship mass and therefore its inertia. This additional hydrodynamic force acting on the vessel is calculated as an increase in the total system mass and inertia moment and can be obtained by experiments or theoretical approaches. The added mass coefficients are usually described by a $m_{i j}$ matrix, where its elements can vary with the body directions.

Considering a generic direction $i$, the resultant hydrodynamic force is given by:

$$
F_{i}=\frac{d V_{i}}{d t}\left(m+m_{i}\right)
$$

where the fluid inertia increases the real mass $(m)$ by the additional virtual mass $\left(m_{i}\right)$. The total mass becomes greater and that is why the mass $m_{i}$ is known as additional or hydrodynamic mass. The fluid inertia effect reduces the ship overall acceleration, if the body speed increases $\left(\frac{d V}{d t}>0\right)$ the fluid inertia decelerates it and if reduces the speed $\left(\frac{d V}{d t}<0\right)$ the added mass effect accelerates the body.

The methods to calculate the added mass are not discussed in this work but are detailed by Kornev (2013). Analytical solutions for the added mass are possible for bodies with simple geometries. Thus, given the consideration of a two-dimensional rigid body to represent a ship, this study uses the solution for an elliptical cylinder to calculate the added mass. The coefficients for the longitudinal $\left(m_{11}\right)$ and transversal direction $\left(m_{22}\right)$ and to the vertical rotation axis $\left(m_{66}\right)$ depends on the water density $(\rho)$ and the ellipse geometry, where $a$ and $b$ are half the width and length of the ellipse, respectively,

$$
\begin{aligned}
& m_{11}=\rho \pi b^{2}, \\
& m_{22}=\rho \pi a^{2},
\end{aligned}
$$

and

$$
m_{66}=\frac{\rho \pi}{8}\left(\begin{array}{ll}
a^{2} & b^{2}
\end{array}\right)^{2}
$$




\subsection{Modeling ship motion}

Even if a model performs a good representation of the river system, the simple understanding of the channel geometry and flow are not sufficient to ensure safe and optimal navigation. Skaggs and Bastian (1986) published a review of studies that used hydrodynamic modeling to assess cargo transport in rivers and maritime fairways. Most articles emphasized the relevance of the interactions analysis between vessels and the velocity field for waterways projects, i.e. the modeling of vessel movement.

According to Constantine (1960), navigation in restricted waterways (e.g. rivers) has several aspects that are different from the marine environment. Initially, inland waterways are usually limited in depth and width. Therefore, the river bathymetry and sediment transport patterns must be periodically studied (Assine, 2005; Henning et al., 2007; Rijn, 2007). The curvature radius analysis is also essential to ensure navigability condition. Graewe (1971) described the relation of this parameter with ships dimensions, velocity and maneuverability capacity. In order to improve the navigability conditions, rivers receive artificial interventions, like groins and locks. These hydraulic constructions impact the flow and must also be analyzed.

Several authors are researching and modeling ship motion and hydrodynamic features, as squat effect and ship stability. Vessel traffic systems and navigation simulators are also being developed, these studies are essential to optimize and improve the overall security and logistic aspects of operations.

The squat effect is a very important hydrodynamic phenomenon to be considered for shallow water condition (e.g. approaching channels). It occurs whenever a vessel is moving quickly through a low depth region, creating an area of lower pressure that causes the ship to be closer to the seabed than would otherwise be expected (Varyani, 2006; Delefortrie et al., 2010; Lataire et al., 2012).

Ship stability problems may arise due to many aspects, as the cargo distribution or even the craft project itself. Vessel traffic management systems (Ince and Topuz, 2004) is important in waterways operation, reducing the effect of the traffic in the ship stability (Gourlay, 2009). Complementarily, Briggs et al. (2003) developed a method for assessing the probability of a ship accident for various channel geometries and depths for different environmental conditions of wind, waves, and currents.

As presented in chapter 2, several studies can be used as reference to assess waterways projects, as the proposed by Blaauw and Verhey (1983), McCartney (1986), Magirl and Olsen (2009), and PIANC guidelines (e.g. PIANC, 1995, 2011). However, rivers systems can have characteristics that are not measured by guidelines. Then, specific studies for 
navigation are necessary, as small-scale physical models and numerical computer models.

A physical model for navigation is usually a small-scale experiment, where a large range of parameters is analyzed during the ship movement. The experimental configuration is carefully set using dimensional analysis, like Froude and Reynolds number. The results of these tests are important to evaluate, for example, hydrodynamic forces on ships (Kume et al., 2006), effects of currents (Hüsing et al., 2000; Kolarov, 2006), and overall ship stability (Fitriadhy et al., 2013). However, for large river sections this approach may be considered expensive and complex, thus a great variation of parameters and scenarios may be unfeasible.

Numerical models are an advanced approach for ship navigation studies. They have the advantage of the easy variation and analysis of several parameters. However, the validity of these models is limited by the data availability and to the mathematical approach, it's based on (Linke et al., 2015).

According to Benedict et al. (2017), numerical motion simulators can be used as research tools for waterway investigations and design, studies for maneuvering capabilities of new ships and overall decision making. Navigation simulators are models that couple environmental characteristics (e.g. velocity field), physical aspects of the region (e.g. depth, width, curvature radius) and vessel features (e.g. dimension, power, maneuverability) to evaluate the ship motion within a defined fairway. These models can run real-time or fast-time simulations

Usually, real-time simulators have a control room (ship bridge) with all the equipment and controls necessary to enhance tests (Harlacher et al., 2015) and are used for specific situations and regions, as crew training for difficult operations. Fast-time simulators are mostly used to evaluate and optimize general parameters related to navigation (Linke et al., 2015; Benedict et al., 2017). The main objective of these programs is the maneuverability prediction of a ship, by simulating a specified set of standard maneuverer within a short time frame (Toxopeus, 2006).

Table 4.1 presents several models used for the analysis of waterways and navigation. The motion simulators can be considered the most sophisticated tools for the analysis of the movement of vessels. Nevertheless, these numerical models require as input data a large amount of detailed information of the river system, flow and ships, which may not be available for large-scale projects (e.g. long river stretches) at initial periods of assessment. Another important aspect to be emphasized is that the algorithms of these models also require a large amount of processing capacity and calibration.

The greatest difference between the cited models and the one proposed in this research 
Table 4.1: Fast-time and real-time computer models to evaluate the navigability capacity of vessels and waterways.

\begin{tabular}{|c|c|c|}
\hline Model & Company & Main features \\
\hline PeTra & BAW & Fairway routing in river as function of the water level. \\
\hline TRASSE & BAW & $\begin{array}{l}\text { Navigation channel design for a non-flowing water con- } \\
\text { dition. }\end{array}$ \\
\hline FaRAO & BAW & $\begin{array}{l}\text { Fast-time simulator to find optimal ship controls in terms } \\
\text { of fuel consumption, safety concerns and arrival time (see } \\
\text { Linke et al., 2015). }\end{array}$ \\
\hline SAMMON & ISSIMS & $\begin{array}{l}\text { Ship dynamic models for rudder, thruster or engine ma- } \\
\text { noeuvre simulation under different environmental condi- } \\
\text { tions (see Benedict et al., 2017). }\end{array}$ \\
\hline Lockfill & Deltares & $\begin{array}{l}\text { Fast-time simulator enabling the analysis of shipping mo- } \\
\text { tion within a lock. }\end{array}$ \\
\hline ANS 6000 & Rheinmetall & Real-time ship handling simulator. \\
\hline NTPRO 5000 & Transas & Real-time ship handling simulator. \\
\hline
\end{tabular}

is that the main movements of vessels in a velocity field are calculated through analytical equations. By this approach, a smaller number of parameters to be calibrated are required. Thus, the model could be used more easily during the initial stage of evaluation of inland waterways, for decision making, design, and management.

\subsection{Chapter closure}

In this chapter, a review of the necessary concepts of fluid mechanics, river hydraulics, hydrodynamic and ship motion modeling was described. All the presented bibliographic survey was necessary for the development of the vessel-current model, presented in the next chapter, followed by initial results and the model verification process. 


\section{Chapter 5}

\section{Vessel-current interaction model}

This chapter presents the developed model, the adopted hypothesis, the necessary input database, the main algorithm, initial verification results, and verification approach using data from the Rhine River.

The method proposed by this research seeks to easily implement and analyze any force affecting the vessel motion. Then, it will be possible to define the path of the ship for any set of parameters, estimating those that optimize navigation. The most important feature is that the model evaluates the river navigability condition for any vessel, river flow, and fairway project.

The model is a fast-time simulator that calculates the movement of barges for a given flow. The movements considered in this model are two-dimensional, transversal and longitudinal directions. The vertical direction is ignored, given the premise that in rivers the effect of waves can be generally disregarded, especially for vessels that carry heavy loads and present low-speed navigation. Among major drag components of such ships, the free-surface wave component is very small due to the low speed, where the skin frictional drag component occupies approximately $80 \%$ of the total drag (Kodama et al., 2000). The rotational movements occurring due to the resulting torques are also evaluated. For this model, the river velocity field is constant and is not affected by the movement of ships.

As presented in chapter 3, a typical vessel can be discretized as a rigid body (see Fig. 3.2), where the main parameters of real ships can be applied. For each discrete point, the resultant forces and torques due to hydrodynamic forces are evaluated. Then, resultant values of force and torque for the whole body and for each time-step is obtained. Hence, one can determine the accelerations, velocities, and the overall resulting ship motion.

The physical basis of this model relies on the conservation of linear and angular momenta, on the 6DOF Kirchoff equations, and hydrodynamic forces, already presented 
in chapter 4. The computer algorithm was written using Matlab and Python programming languages. The necessary parameters to run the model and the main algorithm are detailed in the following sections.

\section{$5.1 \quad$ Input data}

The model input data are related to general characteristics of the simulation, to the flow, physical aspects of the river and vessels. Figure 5.1 presents a diagram summarizing these parameters. This information can be obtained by database or specific field surveys.

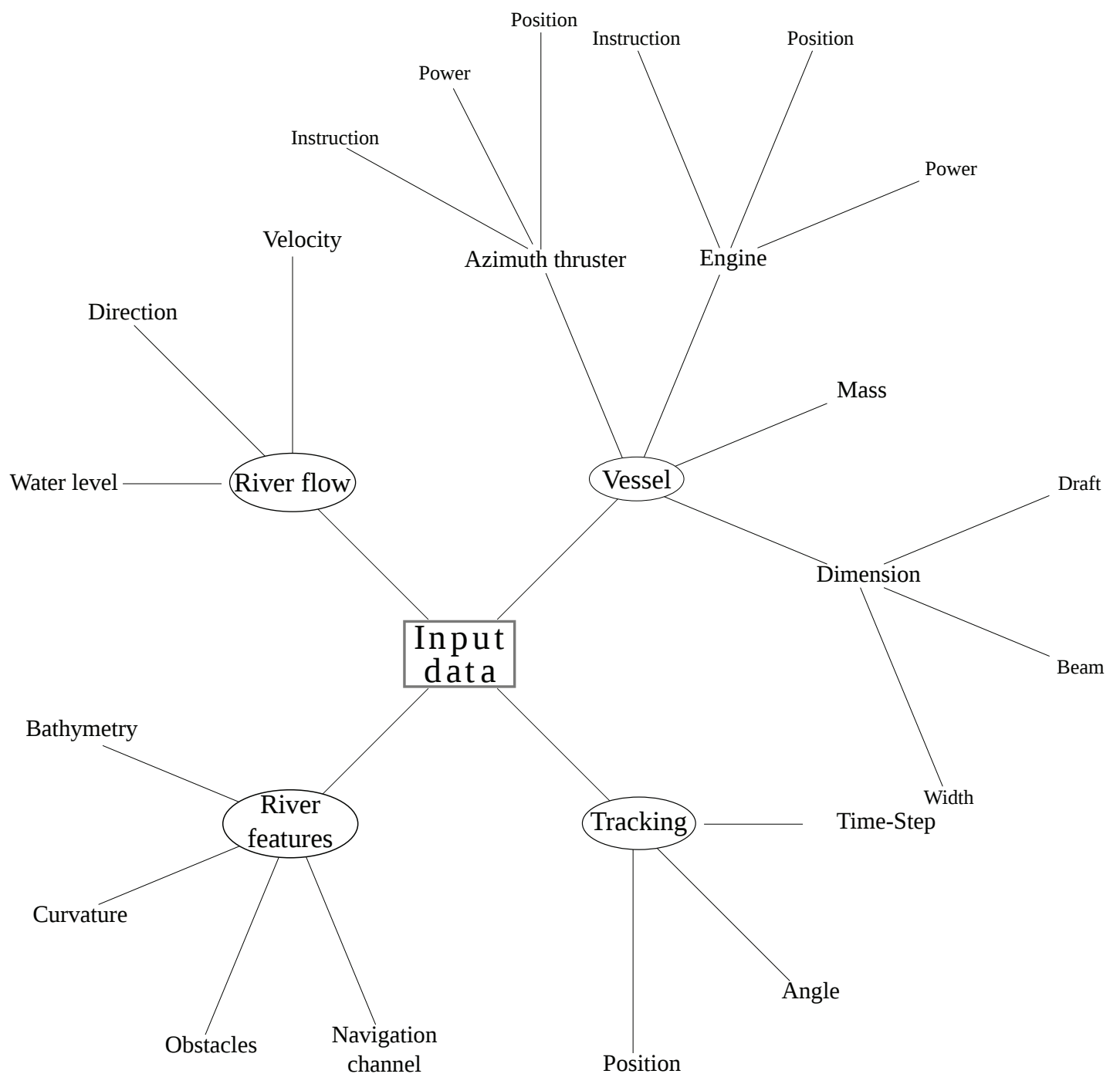

Figure 5.1: Model main input data.

For each simulation, it is necessary to configure the model parameters. This can be easily set by the use of a Graphical User Interface (GUI) framework developed within the main program. The data matrix is stored for simulation, analysis, and post-processing. Figure 5.2 illustrates the model GUI to configure and evaluate simulation results. 
(a)
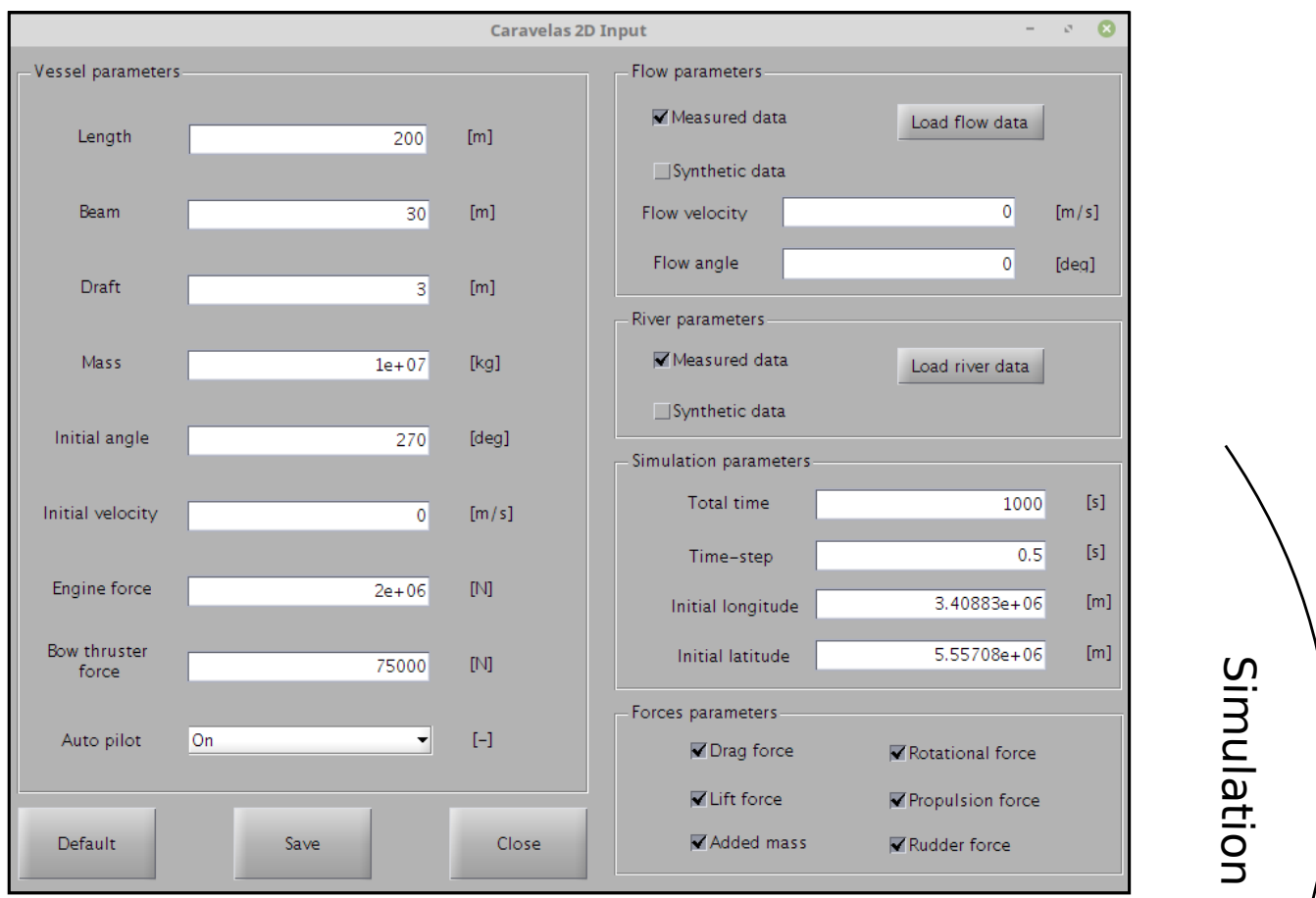

(b)

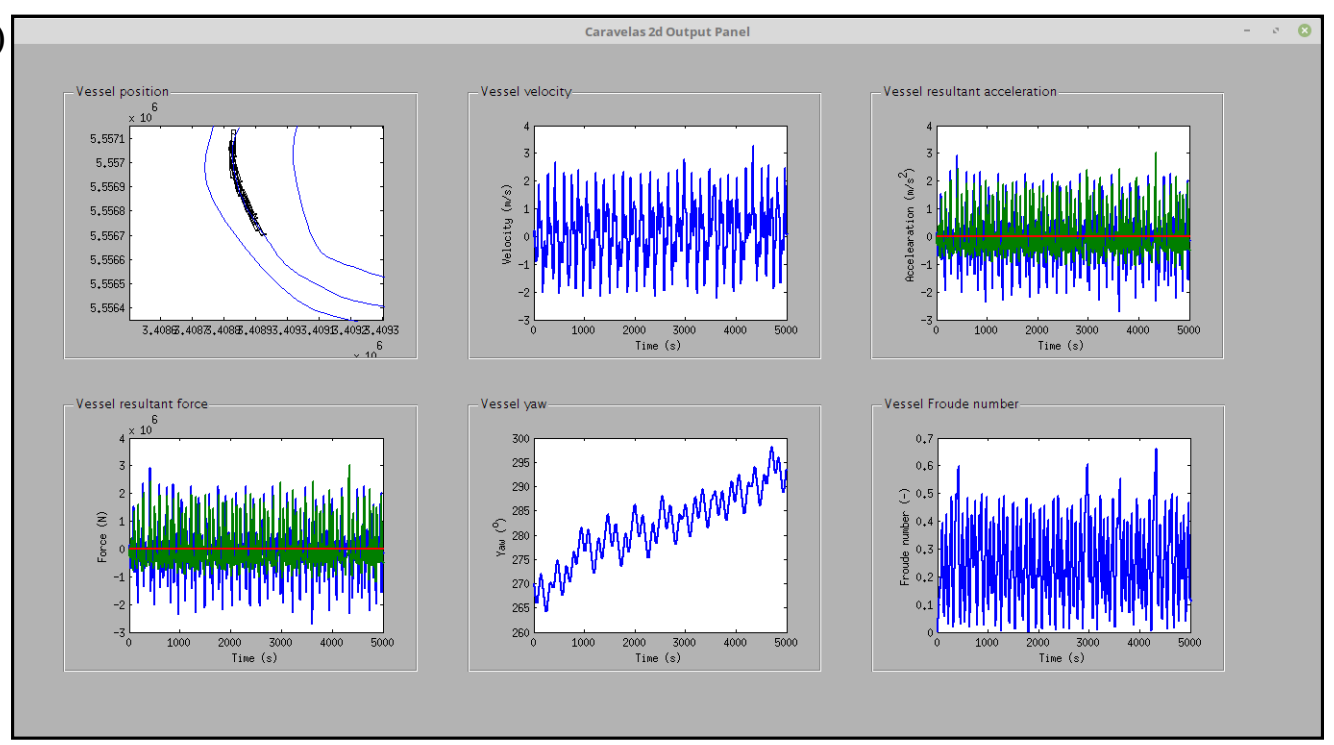

Figure 5.2: Example of the model GUI to setup (a) and evaluate results (b).

The data resolution may vary according to the availability of information to be simulated. Each position operates as a vector, storing the necessary data for the modeling process, as presented in Fig. 5.3. All geospatial information can be loaded as Shapefiles ${ }^{1}$. The simulation time and time-step are also necessary to be set, where the latter is important to keep the model stable, which is discussed in the next section.

The geospatial data are the river and flow information. The river data are the bathymetry, navigation path, the margin coordinates (latitude and longitude), and the position and size of obstacles for navigation (e.g. bridges and groins). The flow data are

\footnotetext{
${ }^{1}$ ESRI vector data storage format for storing the location, shape, and attributes of geographic features.
} 


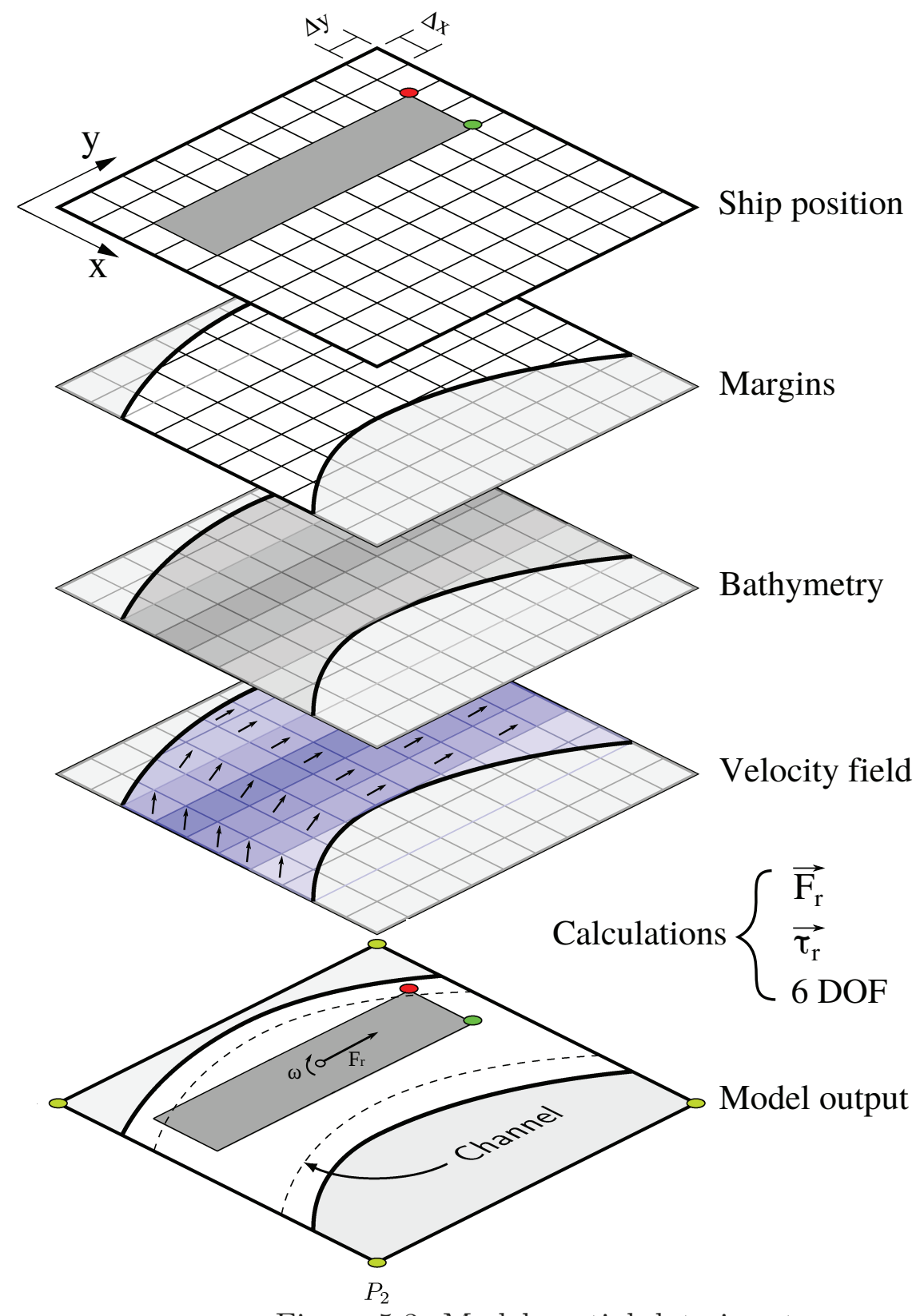

Figure 5.3: Model spatial data input.

the velocity field magnitude and direction. This information can be obtained using one and two-dimensional models of rivers or direct measurements on the field. The vertical direction is not considered, only the longitudinal and transversal components are used.

The navigation paths are designed lines within the river to be followed by the ships. Usually, the vessels maintain close to its right margin of the river (starboard). However, this varies according to river conditions in specific stretches, such as flow or bathymetry. In these regions, there is signaling so that the vessels stay in the center of the navigation channel or that even change to the other margin.

Regarding vessel characteristics, the model loads the convoy (pusher and barges) draft, length and width. The total weight, center of mass, thrust power and azimuth thruster 
angles are also required. By default, the drag and lift coefficients are determined using the methods described in chapter 4 , but specific values may also be set.

\subsection{Main algorithm}

The concepts of rigid body dynamics are used in the discretization of the vessel in a finite number of sections, i.e. ship discrete point. The number of sections can be previously set and each discrete point has a proportional and constant amount of the total mass and surface area of the ship. During navigation, the vessel $k$ points present distinct physical responses to the forces and torques. The sum of these responses gives the resultant force and torque vectors for the entire ship. Both the engine and rudder or azimuth thruster are placed on the vessel stern, in the transverse axis of symmetry.

As shown in Fig. 5.3, each vessel section will occupy a certain area. Each position on the grid has an array of necessary data for calculations, as the direction and intensity of the velocity field. When a ship section occupies more than one grid cell, the parameters values are weighted by an average.

Initially, the software loads the described input data. Besides the engine thrust, the forces affecting the vessel are due to its interaction with the river velocity field, i.e. drag (Eq. 4.37), lift (Eq. 4.44), and added mass (Eq. 4.47). As detailed in Fig. 5.4, for each time interval the algorithm identifies data points (blue circles) within the vessel area (rectangles). The magnitude and direction average is calculated and this velocity vector is used in the estimation of the hydrodynamic forces interacting with the ship.

Then, for a determined interval $(\Delta t)$ the forces (e.g. drag, thrust, rudder) acting on each section are calculated. It is possible to determine for each $\Delta t$ the resulting force $(\vec{F})$, linear acceleration $(\vec{a})$, torque $(\vec{\tau})$, angular velocity $(\vec{\omega})$ and acceleration $(\vec{\alpha})$, overall velocity $(\vec{V})$ and position $(\vec{s})$ of the vessel.

The calculations occur until a simulation constraint is reached. These constraints may be the simulation time or impediments to the vessel movement, such as contact with obstacles, bed or channel banks, and the occurrence of excessive velocity. A summary of the model algorithm is presented in Fig. 5.5.

\subsection{Auto-pilot algorithm}

An auto-pilot system was developed to simulate the ship maneuvers within waterways. This feature is required for the model verification with real data. The auto-pilot tries to 


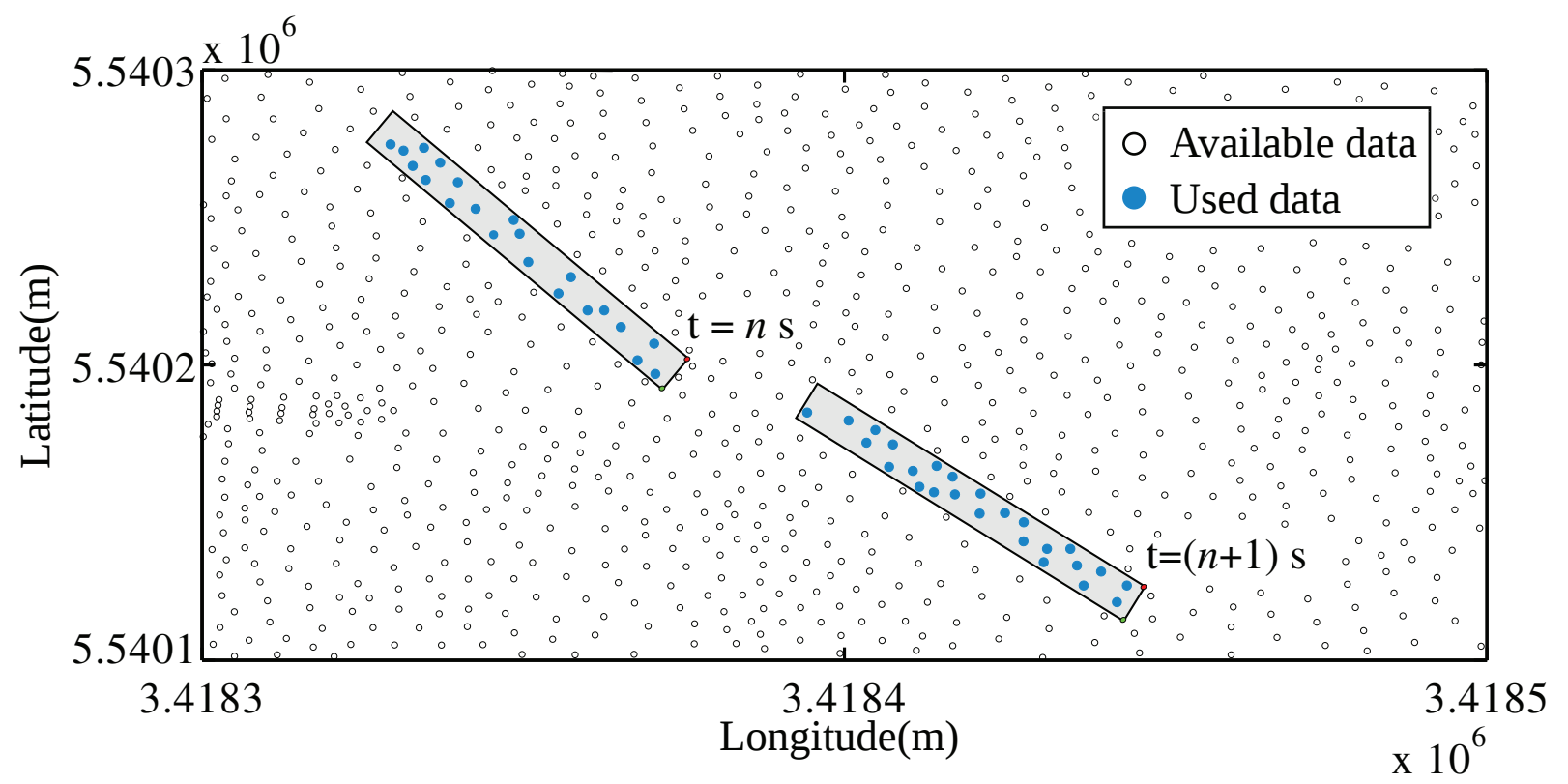

Figure 5.4: Velocity points mesh in the Rhine River (black circles). The blue circles are inside the vessel influence area and are used to calculate the vessel-current interaction.

keep the vessel following a navigation line, usually the river navigation channel. It rotates the ships through the activation of the rudder or azimuthal thrusters. The auto-pilot also requires calibration regarding angles, forces and response time.

A set of points defining a navigation channel is necessary for the auto-pilot, where the maximum distance between two points must not be greater than a defined detection distance (Fig. 5.6, blue area). When this requirement is not met, it is recommended an interpolation operation to fill the gap distance between these points.

For each time-step, the closest point within the auto-pilot detection region is used for the ship orientation. The detection radius is set by a maximum distance $(L r)$ and angle $(\theta r)$, these parameters are necessary to avoid the ship being locked in loops (e.g. return to a previous navigated point). Then, the angle formed between the ship bow and a target point $(\theta P n)$ is calculated and used to define rudder maneuvers. If the ship is in the left side of the navigation channel $\left(0^{\circ}<\theta P n<90^{\circ}\right.$ and $\left.90^{\circ}<\theta P n<180^{\circ}\right)$ the rudder maneuvers to starboard. If the ship is in the right side of the navigation channel $\left(180^{\circ}<\theta P n<270^{\circ}\right.$ and $\left.270^{\circ}<\theta P n<360^{\circ}\right)$ the rudder maneuvers to port.

Other rules were also necessary and implemented for the system, such as tolerance values of the ship-channel distance and the angle of the ship regarding the ideal route of navigation. As a result, excessive maneuvers can be avoided, especially since heavy vessels have a higher moment of inertia and their maneuverability is complex. One can easily add or modify current maneuver rules by accessing the algorithm code. 


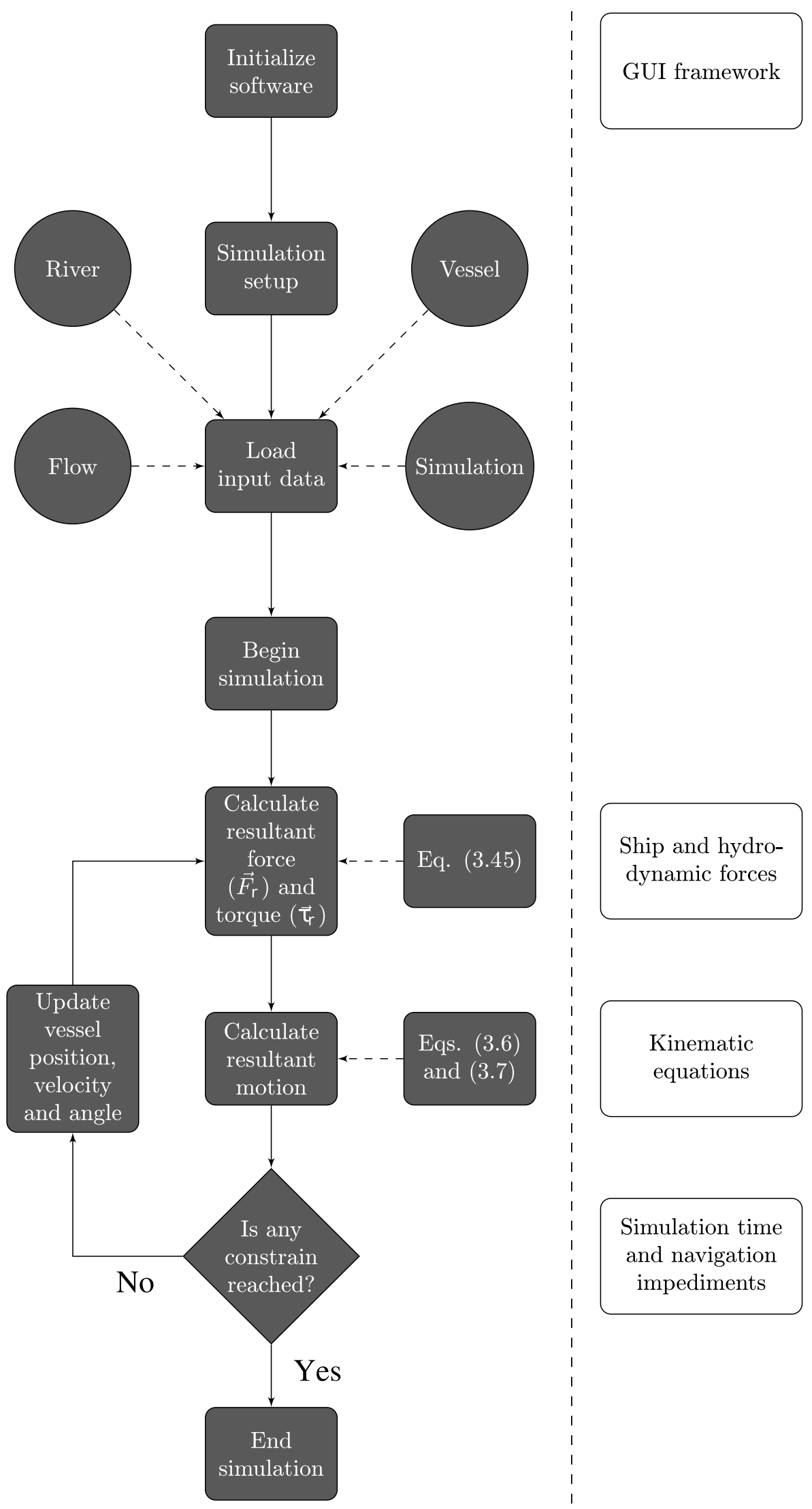

Figure 5.5: Summarized algorithm diagram of the vessel-current interaction model. 


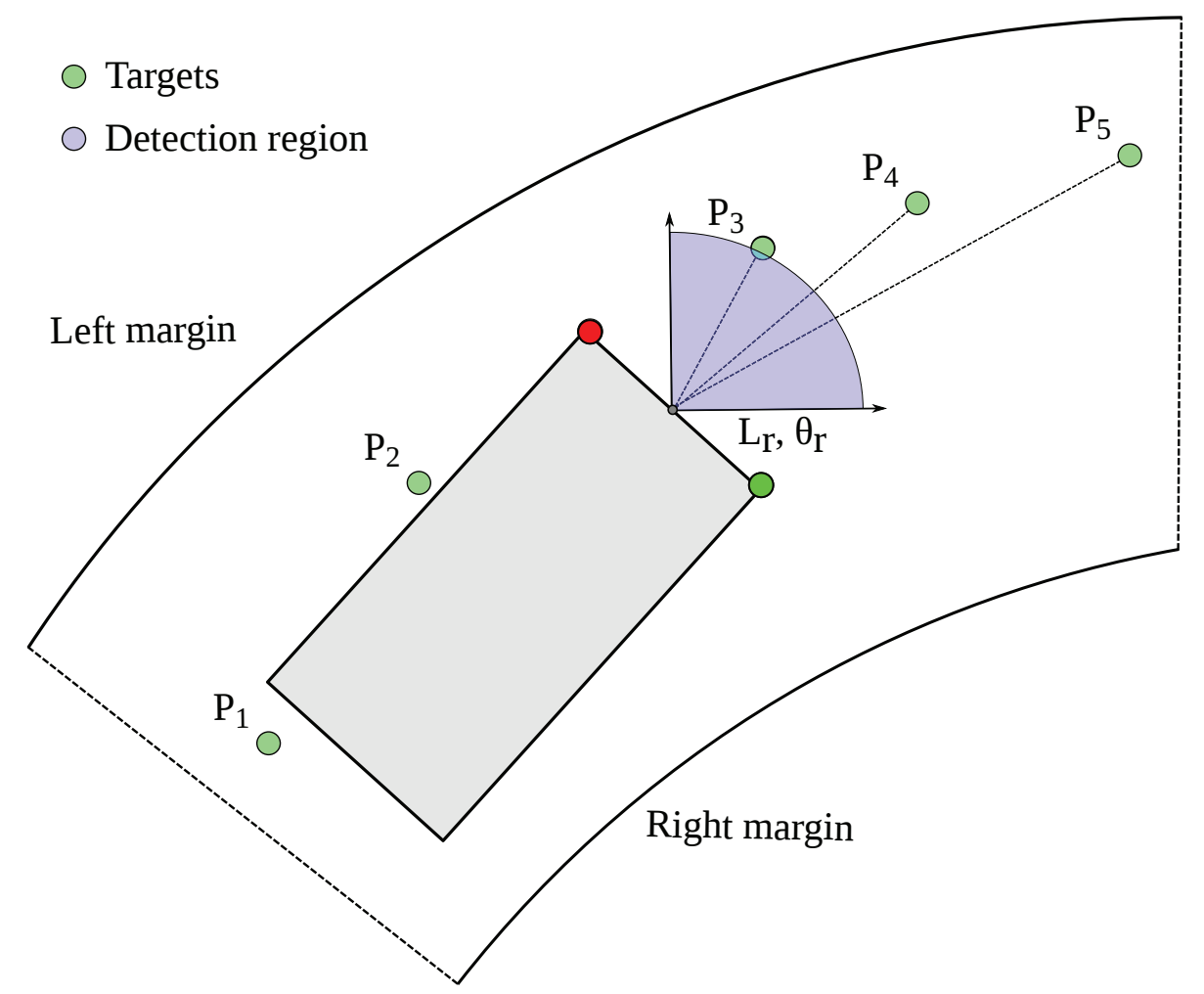

Figure 5.6: Auto-pilot detection of the navigation path(targets P1-P5). The detection region is shown in light blue and is defined by a maximum distance $(L r)$ and angle $(\theta r)$.

\subsection{Model testing}

To verify the model physical consistency, i.e. coherence with the used equations, initial simulations were performed to analyze the model performance for different scenarios of velocity fields and navigation channel. These simulations are summarized in Table 5.1.

For these simulations, several aspects were studied, as the ship motion, maneuverability, velocity, forces, angle variation, Froude number, the model stability and the auto-pilot performance. The characteristics of the river and velocity field were hypothetical and constant during simulations, varying only for each scenario.

Table 5.1: Summary of initial results simulations.

\begin{tabular}{ll}
\hline Simulation & \multicolumn{1}{c}{ Description } \\
\hline Scenario I & $\begin{array}{l}\text { Ship response for different engine forces configuration within a null and } \\
\text { steady flow. }\end{array}$ \\
Scenario II & $\begin{array}{l}\text { Ship response for an upstream and downstream one-dimensional longitu- } \\
\text { dinal flow navigation and constant engine force. }\end{array}$ \\
Scenario III & $\begin{array}{l}\text { Ship response for a one-dimensional transversal flow navigation and con- } \\
\text { stant engine force. }\end{array}$ \\
Scenario IV & Ship maneuverability response for a straight channel. \\
Scenario V & Ship maneuverability response for a circular channel.
\end{tabular}

The forces components considered in these simulations are due to the (I) drag, (II) ro- 
tation, (III) engine propulsion, and (IV) azimuth thruster. The vessel being simulated has a constant self-propulsion defined by the engine power. The vessel rudder operates according to the auto-pilot system, where the rudder angles varied in the range of $\left[45^{\circ},+45^{\circ}\right]$. The forces are applied and evaluated for all time-steps.

Each simulation scenario has a table presenting its main parameters and is shown in the appendix section. The simulated ship dimension is related to the overall convoy size (barges and pusher). The drag coefficients (friction and pressure) were considered unitary and the inertia moment was set as $10^{6} \mathrm{~kg} / \mathrm{m}^{2}$. Although these values are not a realistic physical representation, this choice facilitates the detection of inconsistencies in the model. It was used a hypothetical reference system in meters and for these results the subscript $x$ is related to variations in the longitude, while $y$ refers to the latitude direction.

\subsubsection{Scenario I: engine force response}

This scenario simulates a ship within a null and steady flow (e.g. lakes). This simplifications allow the analysis of the simulator with a smaller number of parameters. For this case the auto-pilot and azimuth thruster maneuvers were not used. The adopted parameters for this simulation are described in Table C.1 in the appendix.

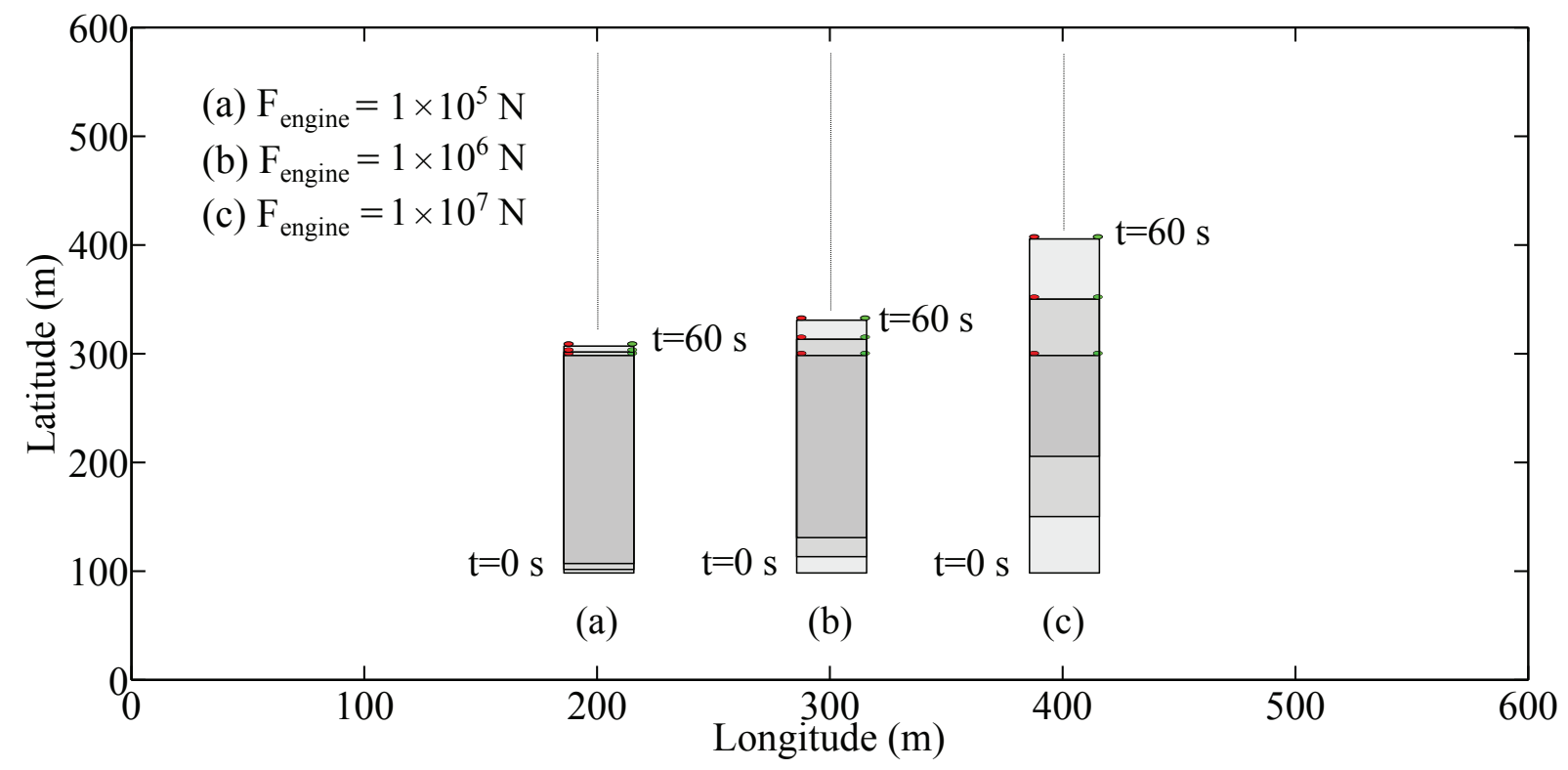

Figure 5.7: Ship motion results for scenario I for different engine forces setup: $1 \bullet 10^{5} \mathrm{~N}$ $(\mathrm{a}), 1 \bullet 10^{6} \mathrm{~N}(\mathrm{~b})$ and $1 \bullet 10^{7} \mathrm{~N}(\mathrm{c})$. 

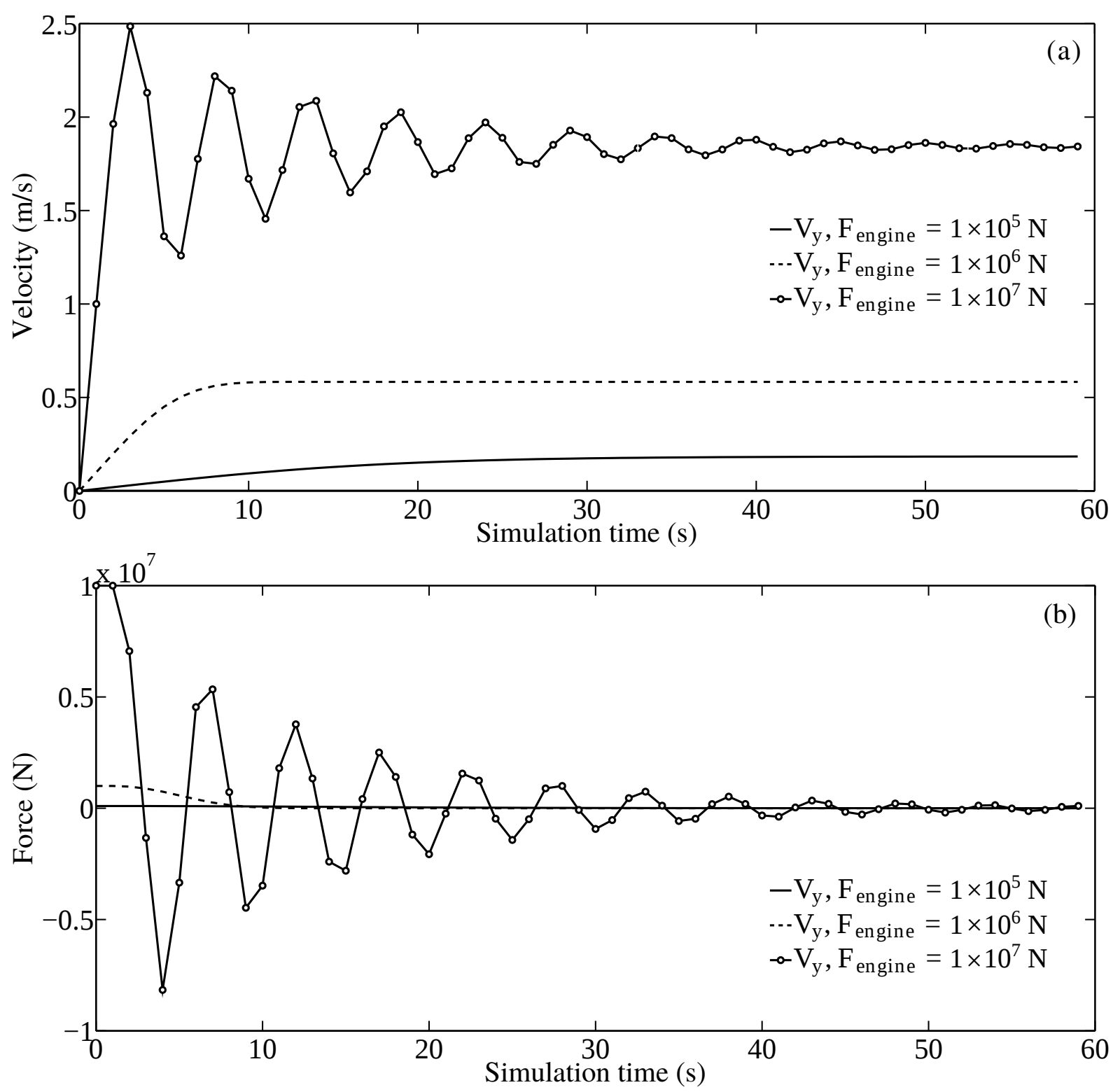

Figure 5.8: Scenario I results for ship velocities (a) and resultant forces (b) for different configurations of engine forces. 

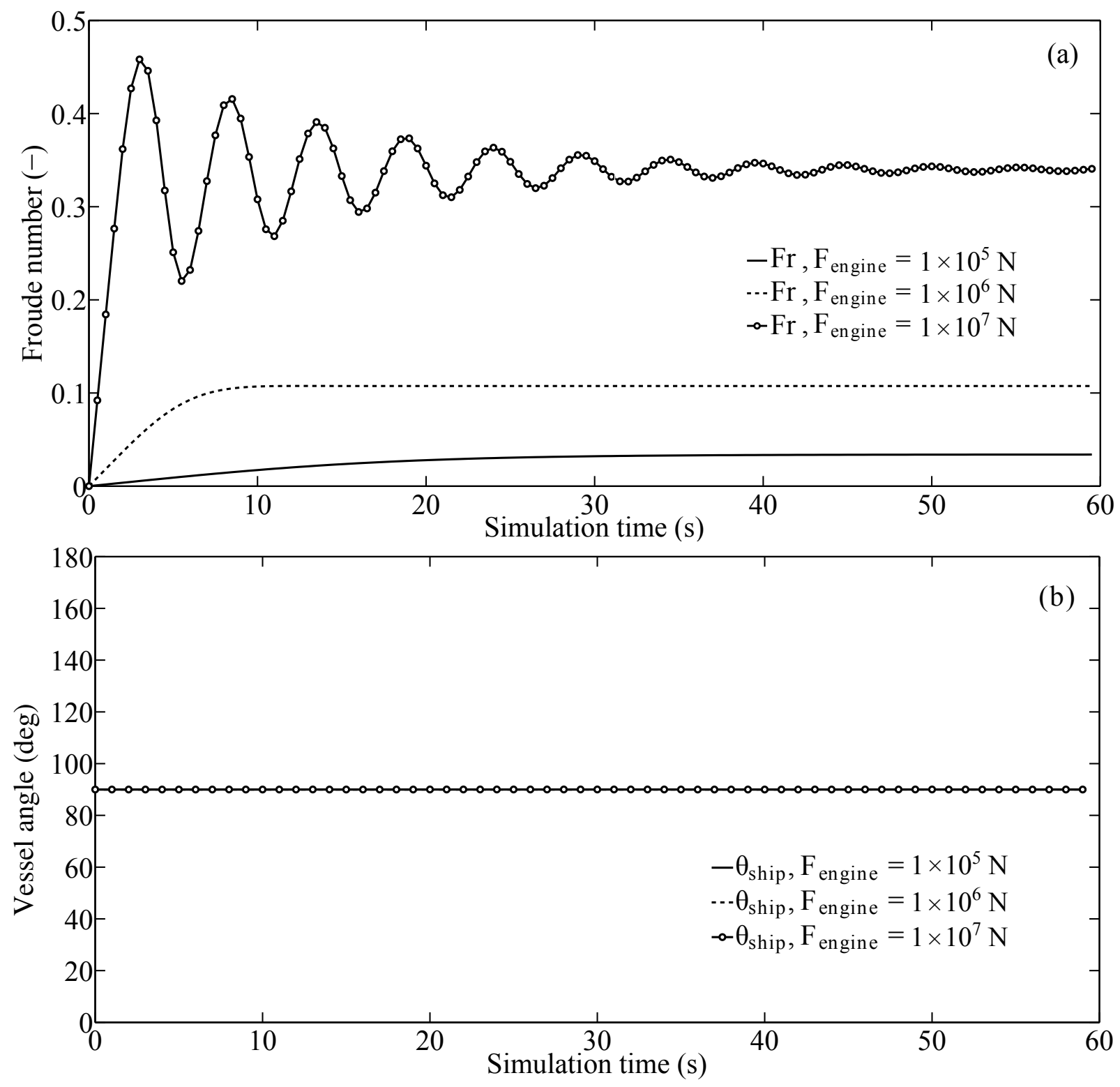

Figure 5.9: Scenario I results for the Froude number (a) and angle (b) for different configurations of engine forces. 
The vessel motion for scenario I is presented in Fig. 5.7, where both azimuth thruster maneuvers and the auto-pilot system were not considered. Also, due to the null and steady flow condition, the movement occurred only in the longitudinal direction. One can observe that the greater the engine force, greater the vessel displacement for the simulated time.

The ship velocity in the longitude $(x)$ and latitude $(y)$ directions are presented in Fig. 5.8 (a), where the motion and velocity occurs only by the ship propulsion ( $y$ direction). Figure 5.8 (b) present the vessel resultant force, given by the sum of all forces in the ship discrete points. Initially, the ship was steady and the only force acting was due to its engine. Then, the vessel begins to accelerate and gains speed. The drag force acting against the ship motion grows according to equation (4.37), the higher the vessel-flow velocity difference, higher the drag force resistance. This result may also be observed in Fig. 5.10, which relates the vessel overall drag force with the velocity magnitude. The resultant force varies until an equilibrium is reached, where neither the engine force increase or the resistance force restrains the ship acceleration (i.e. stationary state). The results oscillations were also analyzed and are described in the following section.

The Froude number is shown in Fig. 5.9 (a), where the vessel-flow relation is subcritical $(F r<1)$ for all simulated engine force. The ship yaw variation is the angle formed with the reference system and is presented in Fig. 5.9 (b). For this scenarios, the yaw has not varied, which was expected given that the azimuth thruster was not used and the flow velocity field along the vessel was homogeneous and constant.

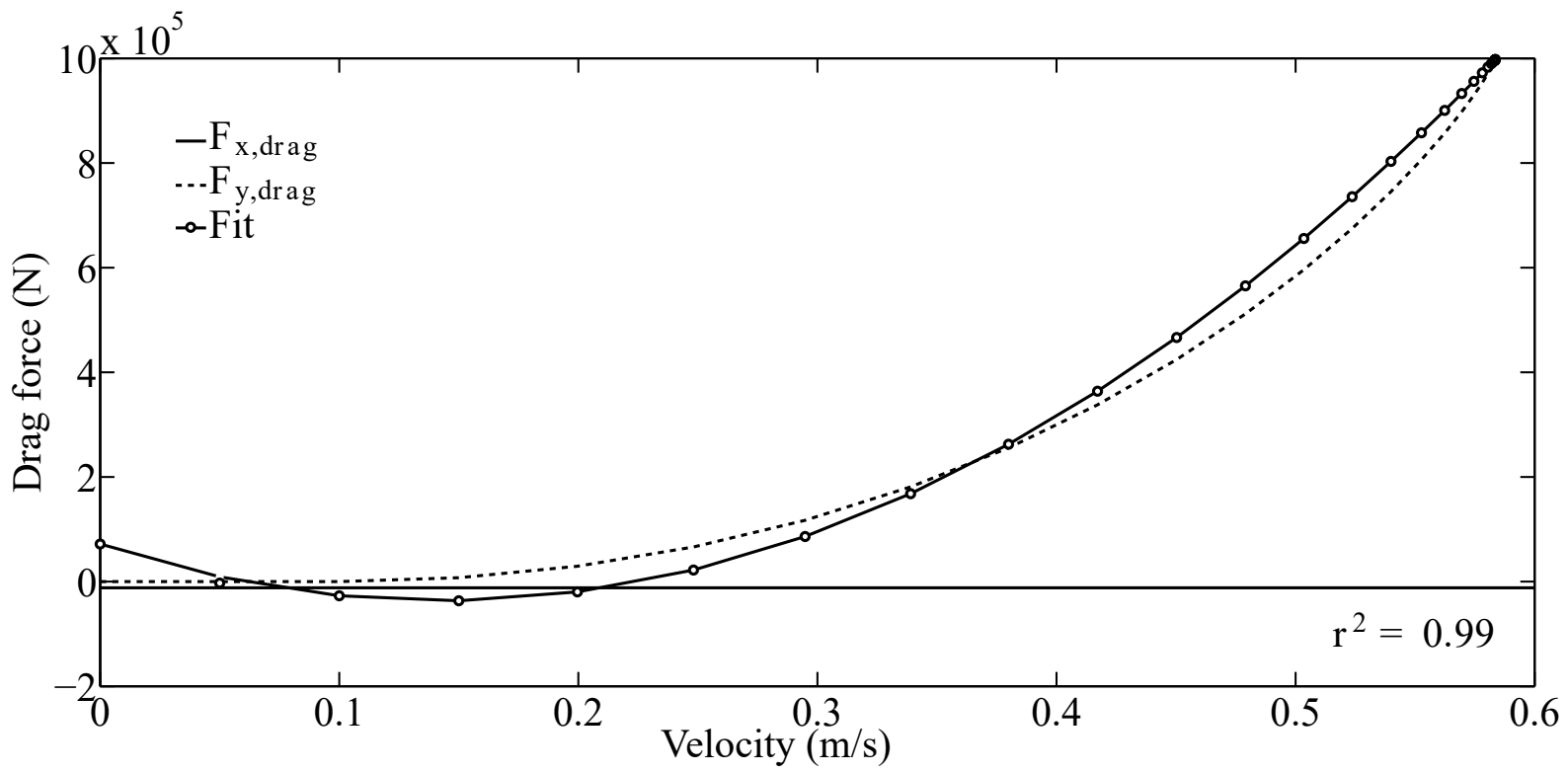

Figure 5.10: Drag force quadratic relation with the ship velocity for scenario I (b). The higher the ship velocity, higher the resistance force due to the drag. 


\subsubsection{Scenario II: longitudinal flow response}

This scenario simulated a ship navigating upstream and downstream a $0.1 \mathrm{~m} / \mathrm{s}$ onedimensional longitudinal flow. For this case, the auto-pilot and azimuth thruster maneuvers were not used. The adopted parameters for this simulation are described in Table C.2 in the appendix.

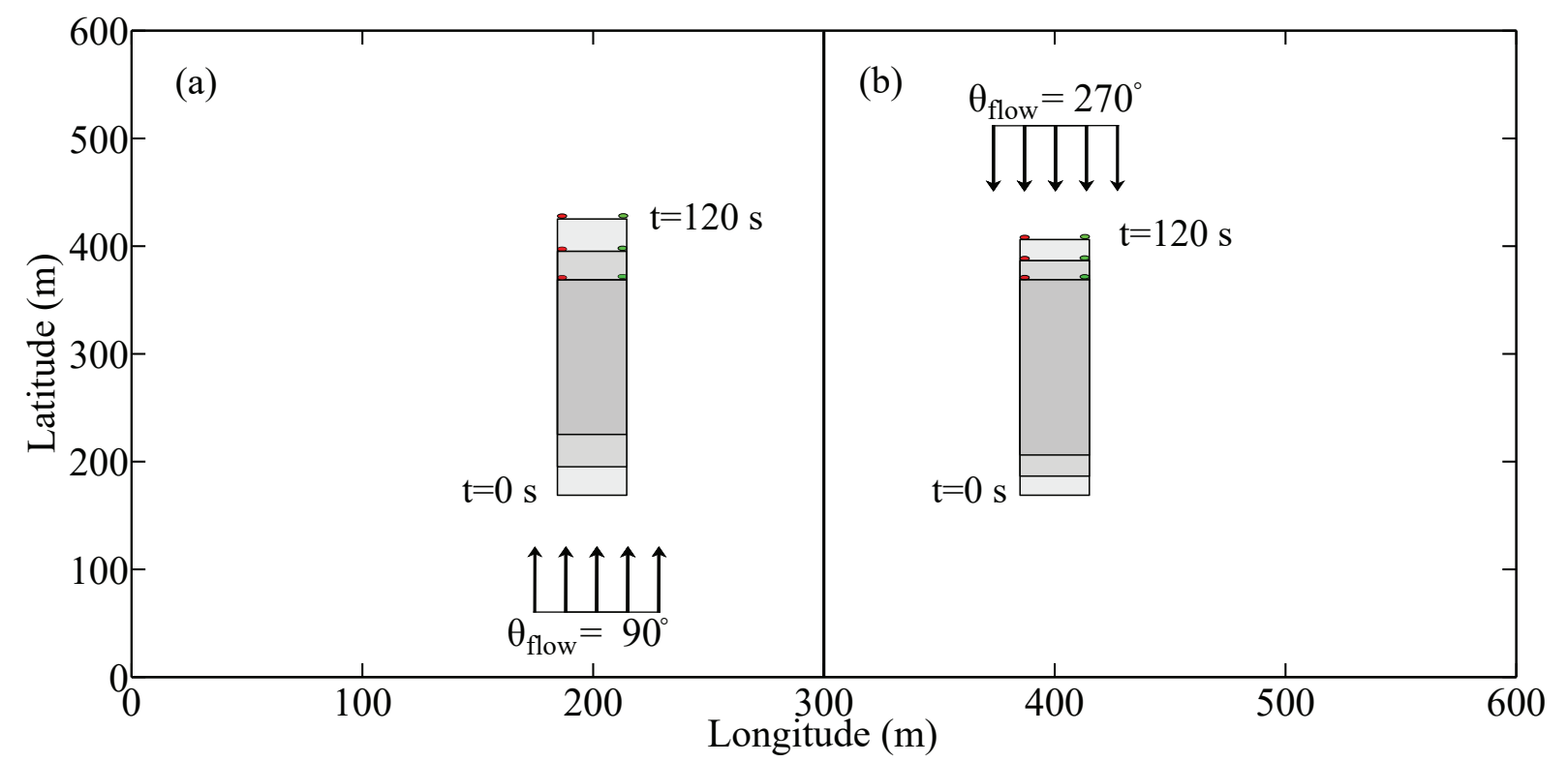

Figure 5.11: Ship motion results for scenario II for downstream (a) and upstream (b) directions in a river with a $0.1 \mathrm{~m} / \mathrm{s}$ one-dimensional longitudinal flow.

The vessel motion for scenario II is shown in Fig. 5.11. The results are similar to the last scenario, where the ship moved only in the longitudinal direction. However, it is possible to observe the effect of the river flow, accelerating the vessel for downstream navigation and slowing it for upstream navigation.

The effect of the current in the velocity and resultant force is also shown in Fig. 5.12 (a) and 5.12 (b) respectively. The final velocity, i.e. terminal velocity, converges to different values, higher for $\theta_{\text {flow }}=90^{\circ}$, when the current push the vessel to the same direction of the engine force (downstream). Regarding the resultant forces, it is possible to observe that for both upstream and downstream navigation the values quickly converge to zero.

The Froude number relation depends on the velocity, therefore the result for the downstream ship navigation was also higher, Fig. 5.13 (a). As in the previous scenario, no angular variation occurred, given that neither the auto-pilot or azimuth thruster maneuvers were used, as shown in Fig. 5.13 (b). 

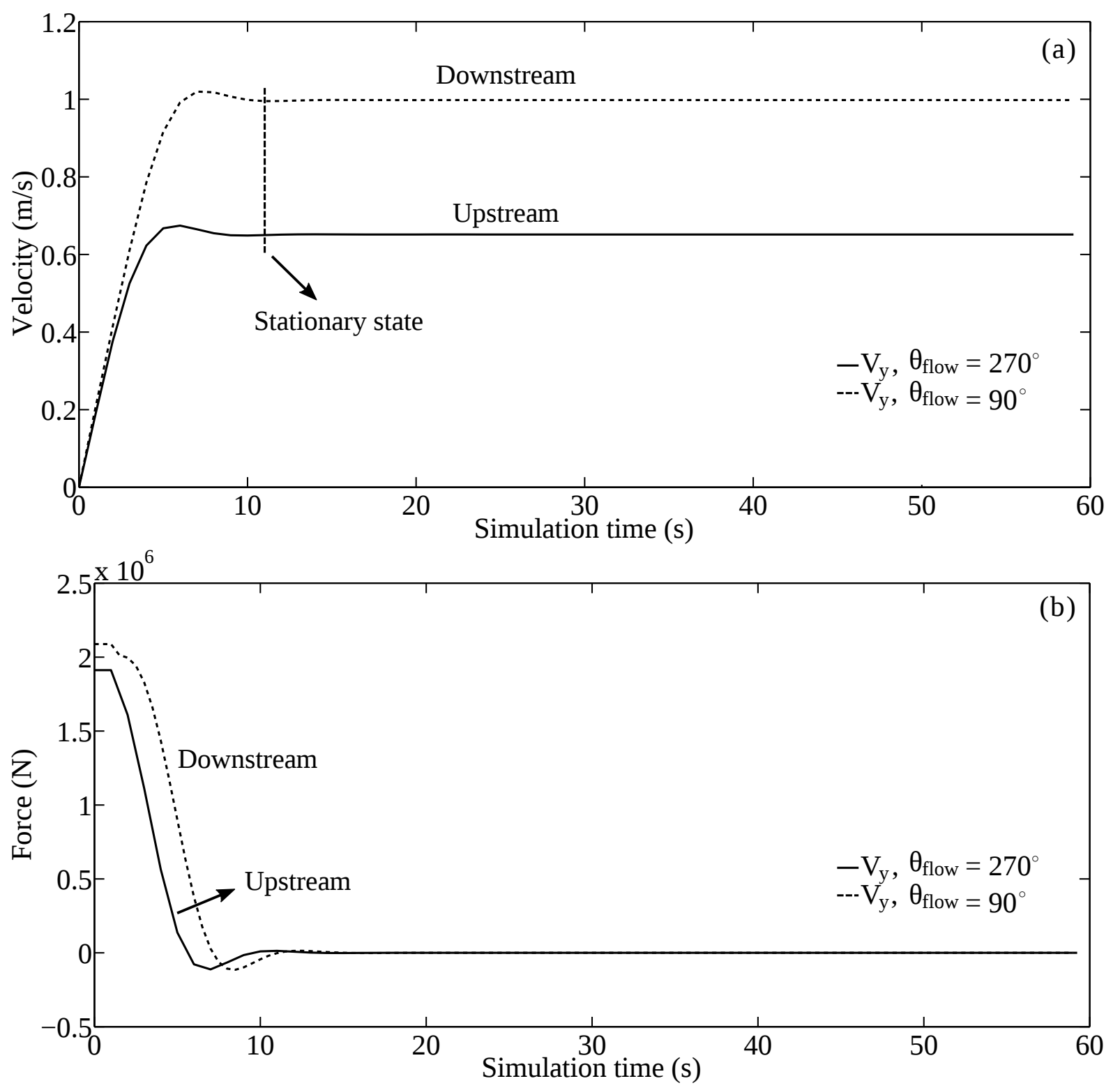

Figure 5.12: Scenario II results for velocities (a) and forces (b) of a ship navigating upstream and downstream a $0.1 \mathrm{~m} / \mathrm{s}$ one-dimensional longitudinal flow. 

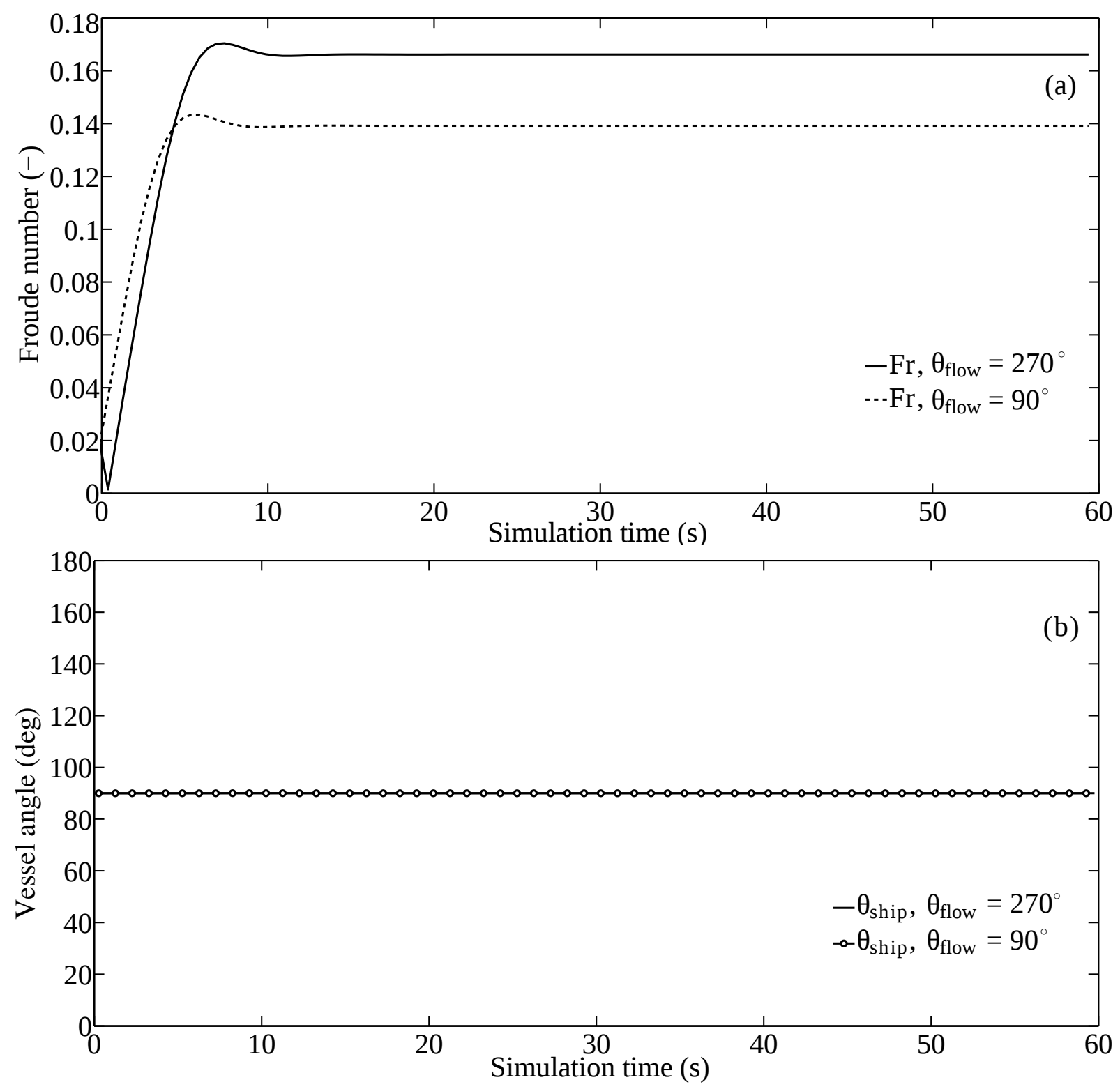

Figure 5.13: Scenario II results for the Froude number (a) and angle (b) of a ship navigating upstream and downstream a $0.1 \mathrm{~m} / \mathrm{s}$ one-dimensional longitudinal flow. 


\subsubsection{Scenario III: transversal flow response}

This case simulated a vessel navigating within a $0.5 \mathrm{~m} / \mathrm{s}$ one-dimensional transversal flow, where the auto-pilot and azimuth thruster maneuvers were not used. The adopted parameters for this simulation are described in Table C.3 in the appendix.

The ship displacement is presented in Fig. 5.14. As occurred in previous simulations, the ship motion occurred in the longitudinal direction $(\Delta S l)$ due to its propulsion. However, given the velocity field, there was also a transversal component, where the vessel moved along its starboard side $(\Delta S t)$.

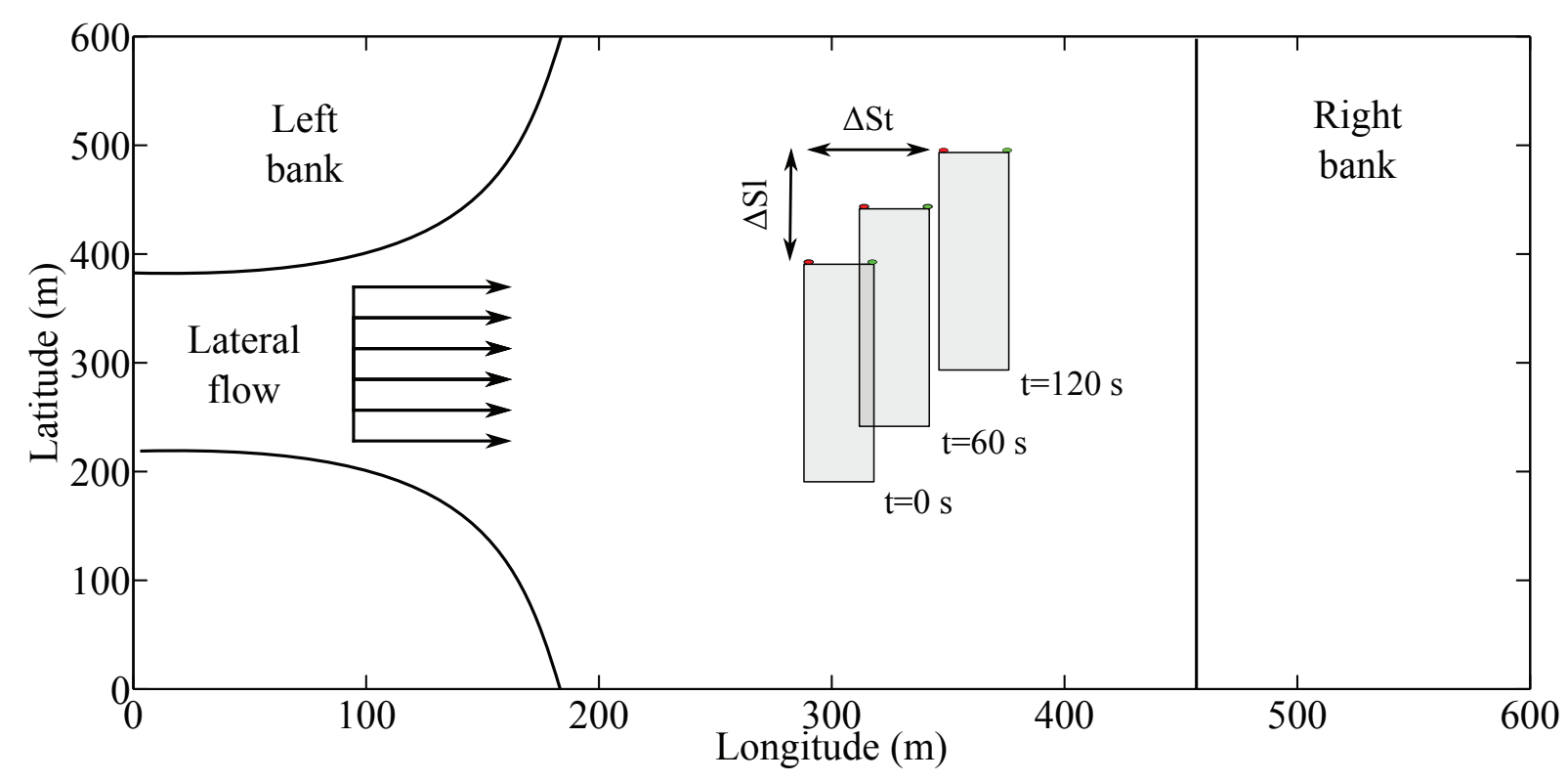

Figure 5.14: Ship motion results for scenario III for a ship moving within a $0.5 \mathrm{~m} / \mathrm{s}$ one-dimensional transversal flow

The ship velocity and force in the longitude $(x)$ and latitude $(y)$ directions are shown in Figs. 5.15 (a) and (b) respectively. For this scenario, the vessel presented transversal components, which occurred due to the lateral flow drag. One can observe that after a short simulation period (approximately 10 seconds) the ship transversal velocity converges to the flow velocity, i.e. $0.5 \mathrm{~m} / \mathrm{s}$.

Figure. 5.16 (a) shows that the maximum Froude number is subcritical, and as expected, no angular variation occurred in the ship motion, Fig. 5.16 (b). 

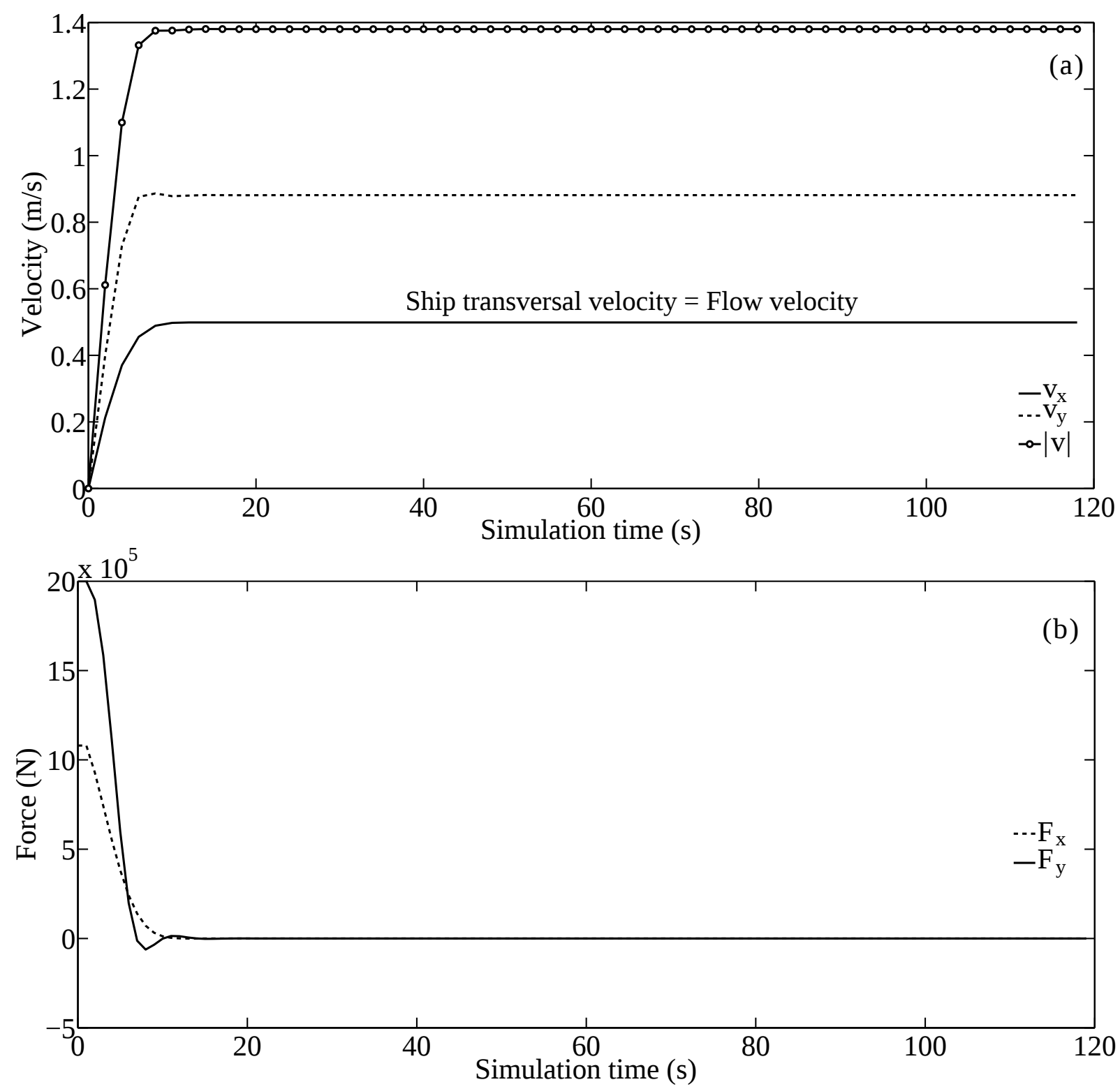

Figure 5.15: Scenario III results for velocities (a) and forces (b) of a ship navigating a 0.5 $\mathrm{m} / \mathrm{s}$ one-dimensional transversal flow. 

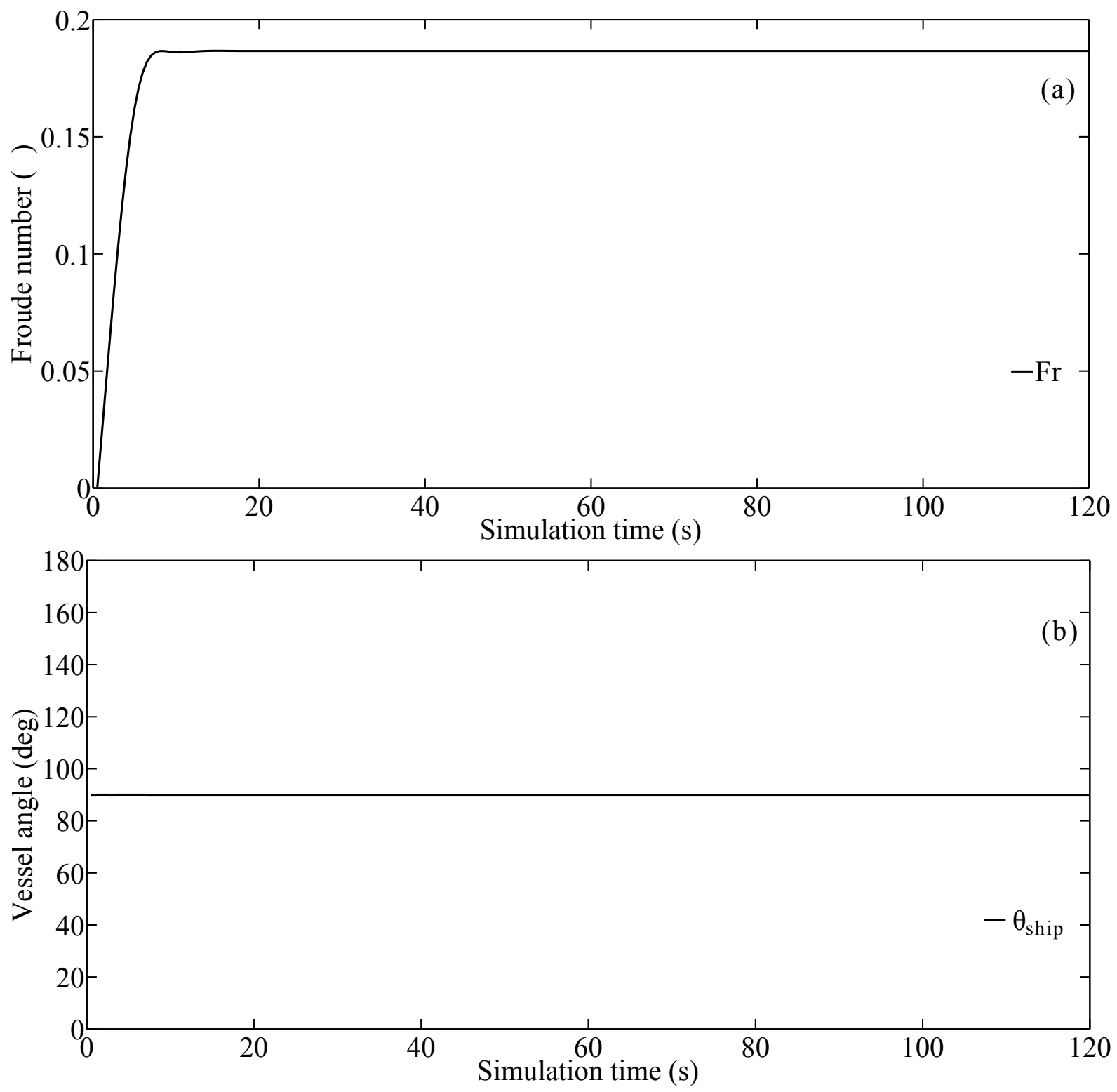

Figure 5.16: Scenario III results for the Froude number (a) and angle (b) of a ship navigating a $0.5 \mathrm{~m} / \mathrm{s}$ one-dimensional transversal flow. 


\subsubsection{Scenario IV: maneuverability analysis}

This scenario also simulates a ship navigating within a null and steady flow, analogous to the configuration presented in scenario I. However, this case considers maneuvers actions due to the auto-pilot system and azimuth thruster, where the ship seeks to navigate within the main navigation path. The adopted parameters for this simulation are described in Table C.4 in the appendix.

The vessel motion for scenario IV is presented in Fig. 5.17. For this simulation, the ship was initially 100 meters to the left of the navigation channel and at a parallel angle. Then, the auto-pilot set the target destination and the ship maneuvered to starboard, seeking the preferential navigation path.

Due to the azimuth thruster maneuver, the ship velocity and force presented components in the latitude and longitude directions, Fig. 5.18. By the analysis of Fig. 5.19 it is possible to observe that the Froude number remained subcritical (a) and that the vessel angular variation occurred only during the ship maneuver (b).

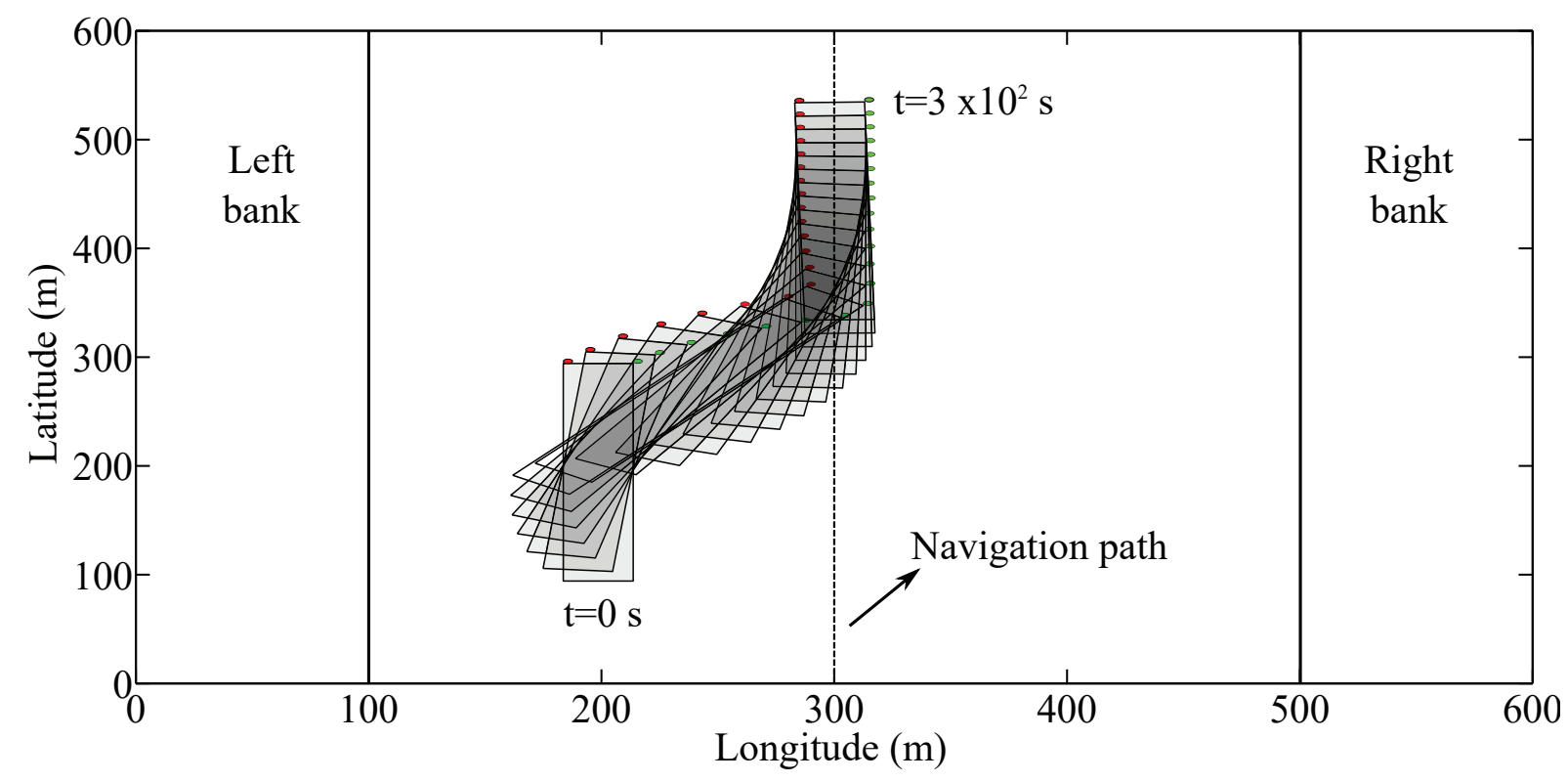

Figure 5.17: Ship motion results for scenario IV. The auto-pilot system activates the azimuth thruster in order to maintain the ship within the preferential navigation path. 

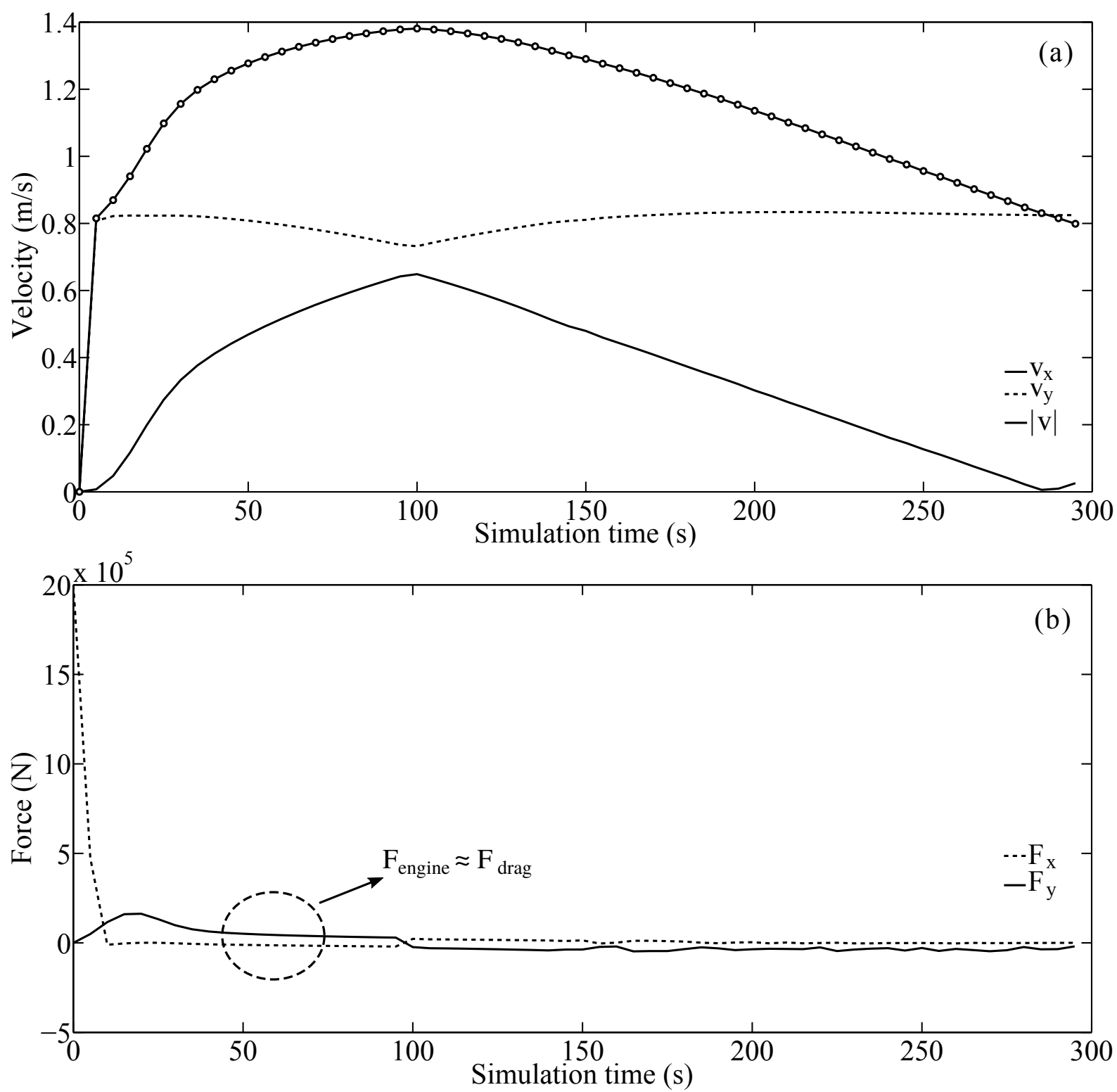

Figure 5.18: Scenario IV results for velocities (a) and forces (b) when the auto-pilot system is used. 

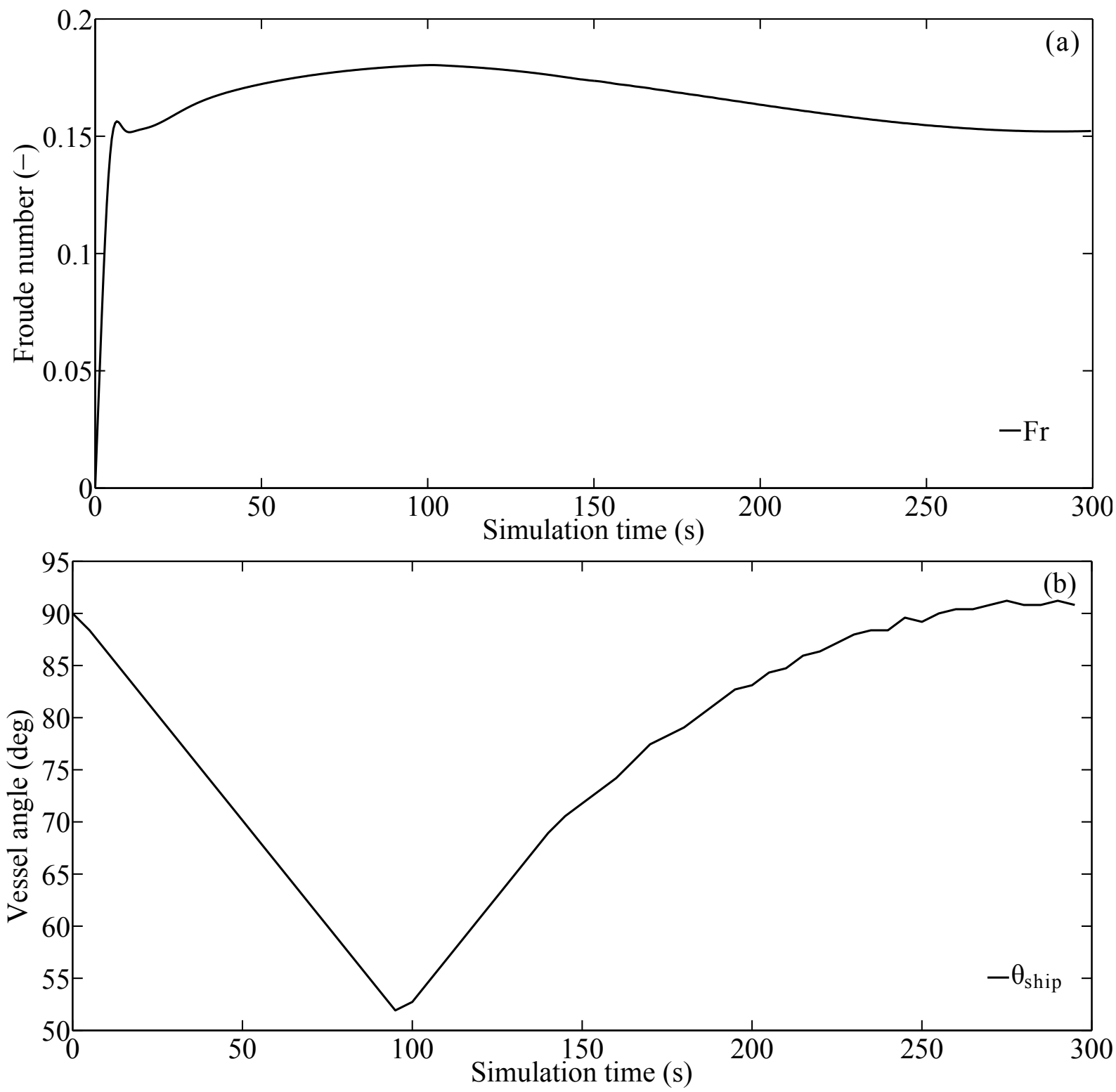

Figure 5.19: Scenario IV results for the Froude number (a) and angle (b) when the autopilot system is used. 


\subsubsection{Scenario V: auto-pilot analysis}

This scenario simulates a ship navigating a circular channel with a null and steady flow. The right margin, the navigation path, and the left margin have a curvature radius of $400 \mathrm{~m}, 500 \mathrm{~m}$, and $600 \mathrm{~m}$ respectively. This case evaluates the auto-pilot system and azimuth thruster maneuvers, keeping the vessel within the river. The adopted parameters for this simulation are described in Table C.5 in the appendix.

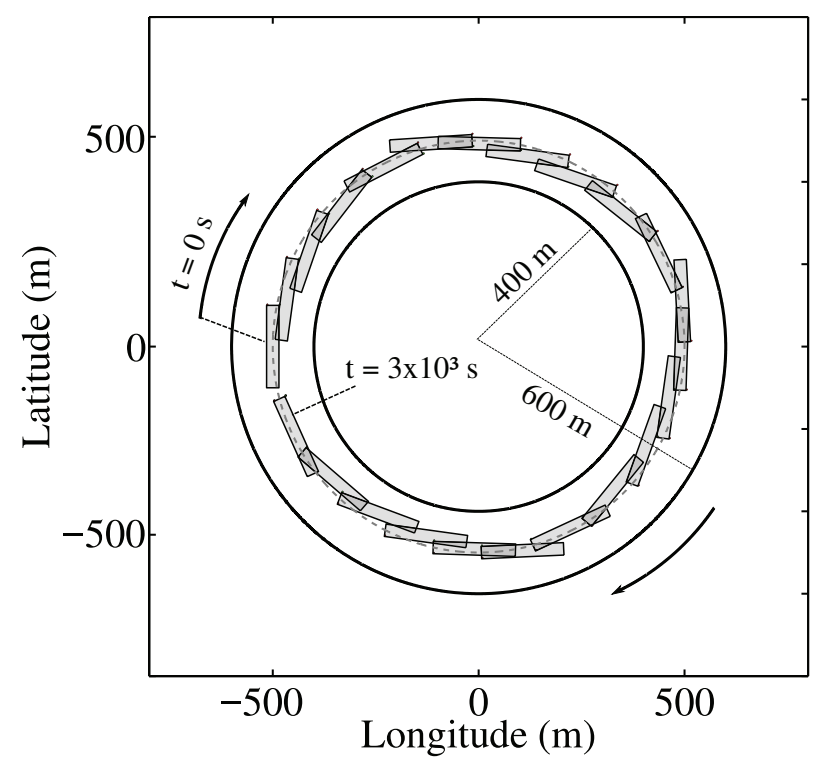

Figure 5.20: Ship motion results for scenario V, when the auto-pilot system is used in a circular hypothetical navigation channel.

Figure 5.20 presents the results for the vessel motion. One can observe that the used parameters were sufficient for the ship navigation. The auto-pilot system was able to follow the navigation channel and the vessel had no contact with margins.

The vessel velocity is presented in Fig. 5.21. The components in $x$ and $y$ direction varies according to the vessel position and angle in the circular hypothetical channel. As occurred in previous scenarios, the resultant force converges to zero when the ship velocity is approximately constant, Fig. 5.21 (b).

The Froude number is shown in Fig. 5.22 (a), the value is subcritical and its oscillation is due to the ship resultant velocity variation. Regarding the vessel yaw, Fig. 5.22 (b), the initial angle was of $90^{\circ}$. Then, the ship maneuvers to starboard side and varies its angle until a full turn in the navigation channel. 

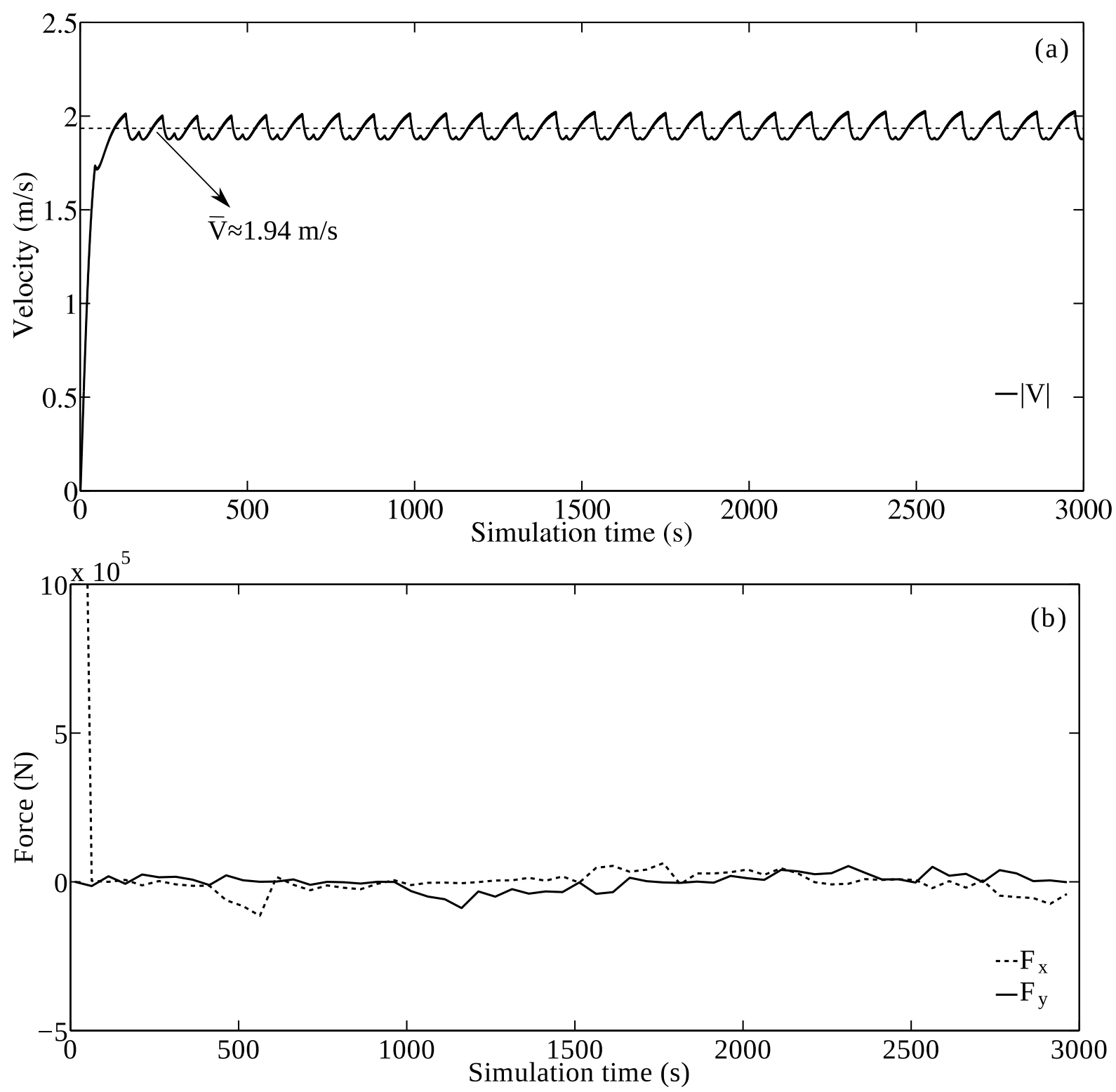

Figure 5.21: Scenario V results for velocities (a) and forces (b) when the auto-pilot system is used. 

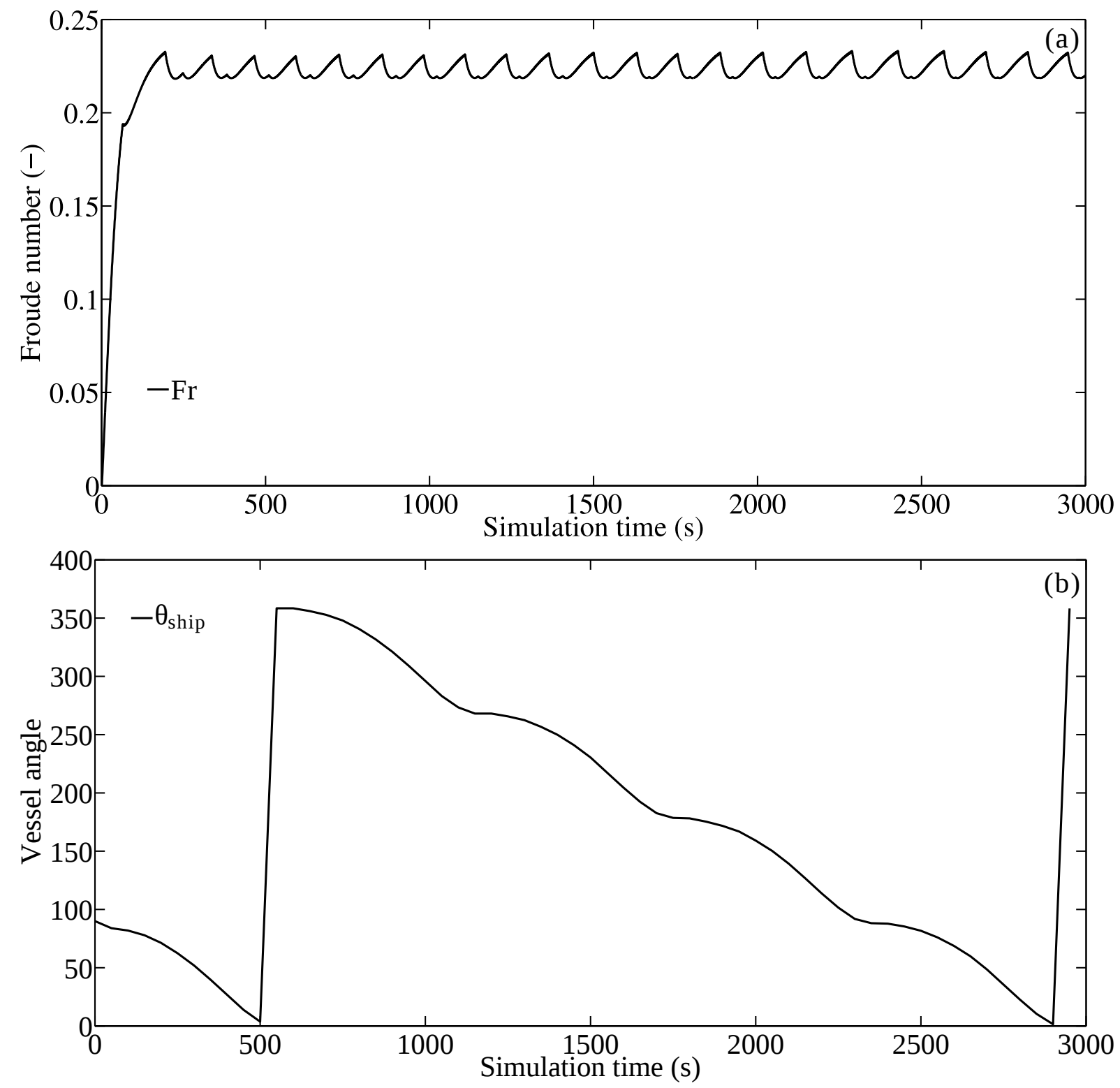

Figure 5.22: Scenario V results for the Froude number (a) and angle (b) when the autopilot system is used. 


\subsubsection{General analysis}

A stability analysis of the model was performed and is presented in Fig. 5.23. The ship resultant velocity (norm) was obtained for different values of engine force (a) and simulation time-step (b). Using the same parameters setup of scenario I, it was identified that the model remains stable for lower values of engine force. However, when this parameter was increased calculations presented oscillations, whose values may or may not converge (a). The oscillations can be reduced or eliminated by using smaller values of $\Delta t(\mathrm{~b})$, which in turn increase the computation time. Since the model uses analytical equations, numerical stability tests (e.g. Courant number) are not applicable. The instabilities are due to the quadratic relation of the drag with velocity. When greater time intervals are used, the force can reverse its direction abruptly, causing the observed results variation.

Regarding the computation time, a smaller $\Delta t$ value leads to a higher number of iterations, thus processing time and effort (e.g. vector size and memory). For $\Delta t=0.5$ seconds, the model calculated 120 iterations in 2.8 seconds. For $\Delta t=0.25$ seconds, 240 iterations were processed in 5.1 seconds. This analysis was set for a small simulation time. However, this value is greater when large stretches of waterways are being analyzed. Therefore, one must evaluate a time-step that maximize stability with the lowest possible processing time.

The drag is a major part of the vessel resultant force. As discussed in chapter 4, the drag is composed of friction and form components. For the initial stage of this study, the friction and pressure drag coefficients were set equal $\left(C_{\mathrm{D} \text {,pressure }}=C_{\mathrm{D} \text {,friction }}=1\right)$. Figure 5.24 presents the drag force distribution in the ship port and bow for a flow setup analogous to scenario I. The ship moves only in the $y$ direction and the drag force acts in the opposite direction. The drag vector is perpendicular to the vessel bow area, thus in this section, only the form component contributes to the drag (friction drag is null). On the other hand, the drag vector is parallel to the ship port area, therefore in this section, only the friction component of the drag is accounted (form drag is null). Given that the friction and drag coefficients are equal, the difference in the forces in the bow and port sections should only be due to the vessel surface wet area $\left(A_{\text {wet }}\right)$, which was the result obtained in the model.

One of the main features of the proposed model is the analysis of the ship motion response with different input parameters. Figure 5.25 presents an example of a maneuverability analysis varying azimuth thruster forces, evaluating the ship capacity to navigate in a river bend with 400 meters of curvature radius. In this simulation the parameters 

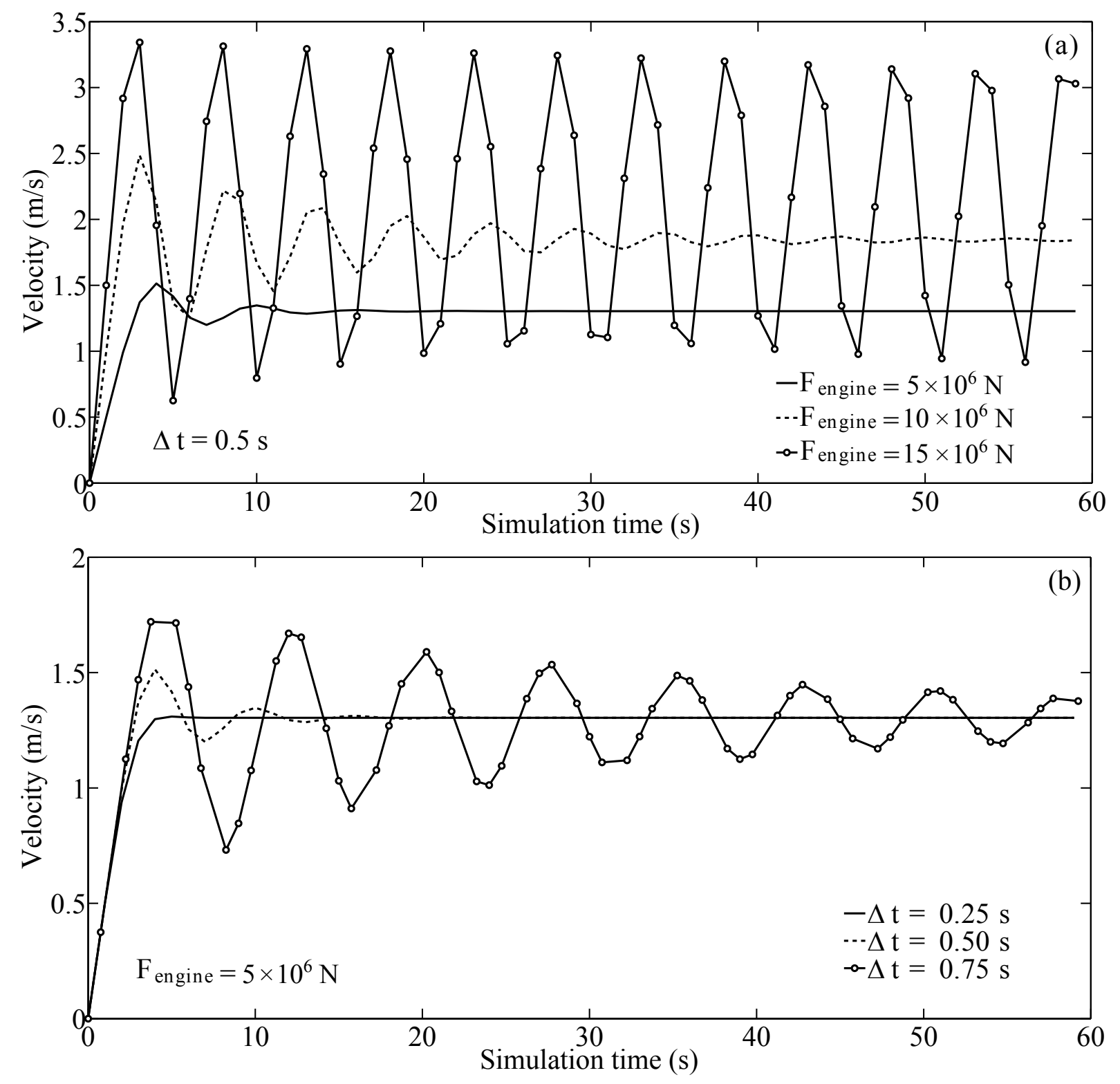

Figure 5.23: Stability analysis of the model varying the engine force with a constant time-step (a) and varying the time-step with a constant engine force (b).

were measured for $10^{3}$ seconds, using two constant azimuth thruster forces: $50 \%$ (a) and $100 \%$ (b) of the total possible force to maneuver. The remaining parameters are analogous to scenario $\mathrm{V}$. When the ship was set with $50 \%$ of azimuth thruster force (a) one can observe that it was not possible for the vessel to remain within the navigation channel, performing a turn of $82.3^{\circ}$. For the same time interval, when the ship was set with $100 \%$ of azimuth thruster force (b) the vessel remained within the navigation channel boundary, turning $97.9^{\circ}$. Thus, the latter parameter setup (b) presented a higher maneuverability capacity.

The most relevant result of the model is to determine if the vessel safely navigate 


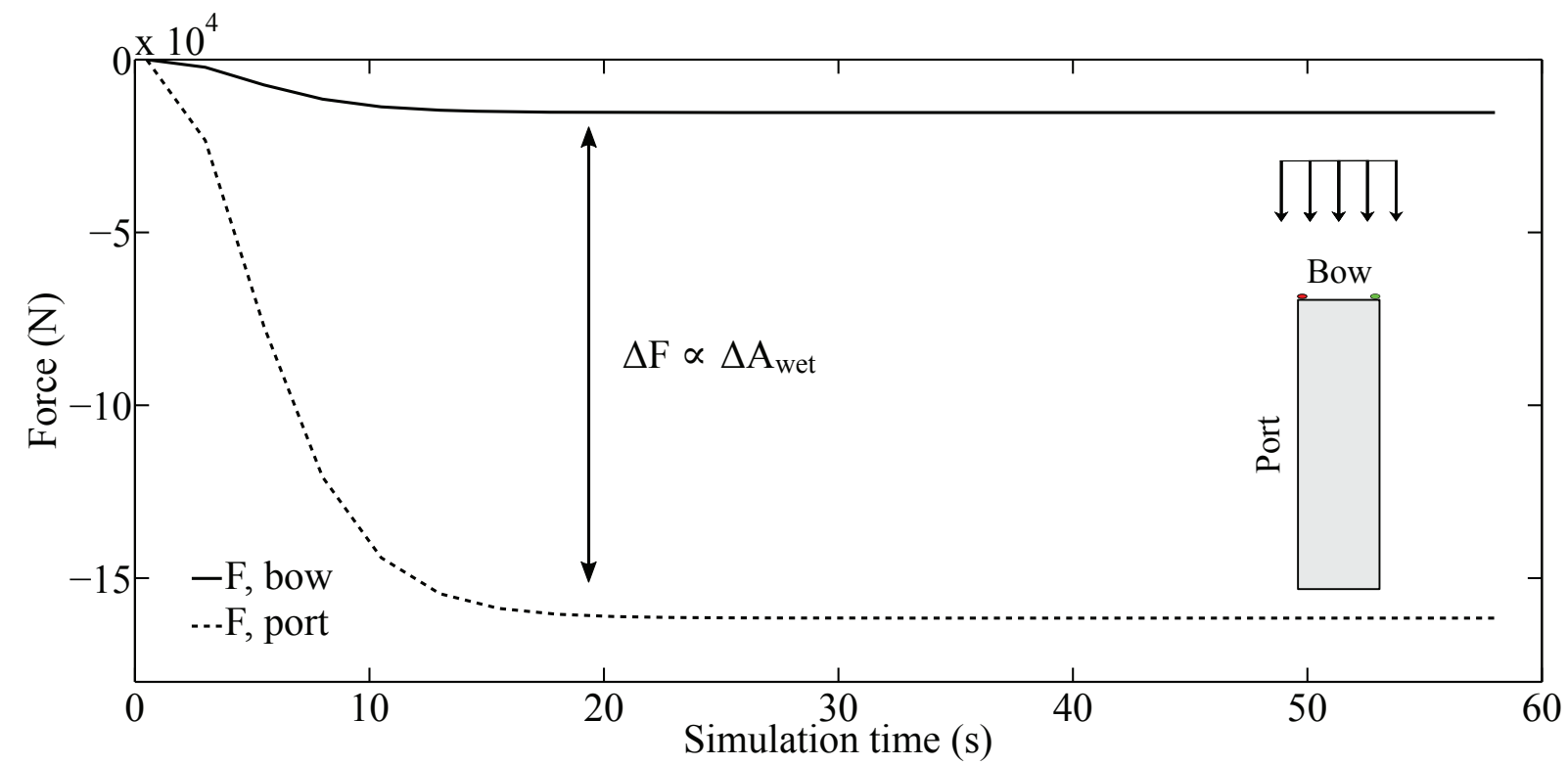

Figure 5.24: Drag force distribution in the ship port and bow sections. The wet area in the ship port under friction drag is 10.55 greater than the area of the ship bow under pressure drag, which is the same difference between the forces in the sections.

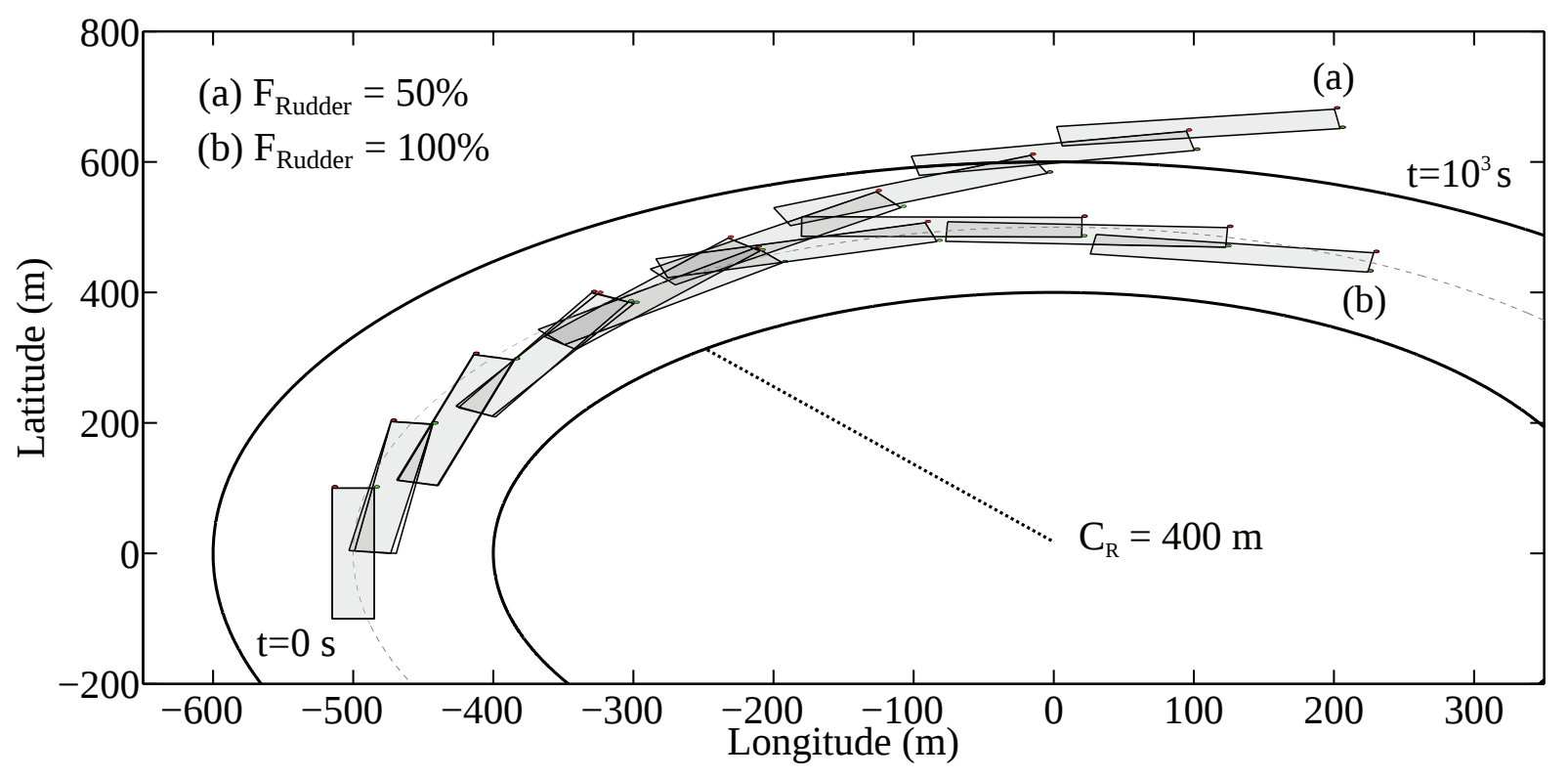

Figure 5.25: Ship maneuverability analysis example for different azimuth thruster forces.

a certain river stretch. However, there are numerous possible solutions, i.e. parameters combinations. The Method of Monte Carlo (MMC) is used to vary parameters within a defined range. This method relies on numerical simulation experiments using random values (Kalos and Whitlock, 2009; Rubinstein and Kroese, 2016) and providing suitable solutions. A calibration and verification process using field data is also necessary to verify the solutions and the model overall results and is described in the following section. 


\subsection{Model verification}

Calibration procedures are required given that even small variations of some parameters could lead the model to produce inconsistent results. This occurs mostly due to the non-linear relation between drag and velocity. The calibration is also required to optimize navigation parameters of a ship in specific waterways regions, as the maximum velocity or dimensions of a vessel to safely navigate a river bend.

Figure 5.26 presents an example of the calibration process result, comparing the model output with real data telemetry, both for the same stretch of the Rhine River. Despite the calibration process and the optimization of navigation parameters, it is possible to observe that the simulated ship may not present satisfactory characteristics (e.g. geometry, velocity) to navigate within this river stretch. This approach will also be used for the analysis of scenarios with different ships and rivers parameters for Brazilian waterways.

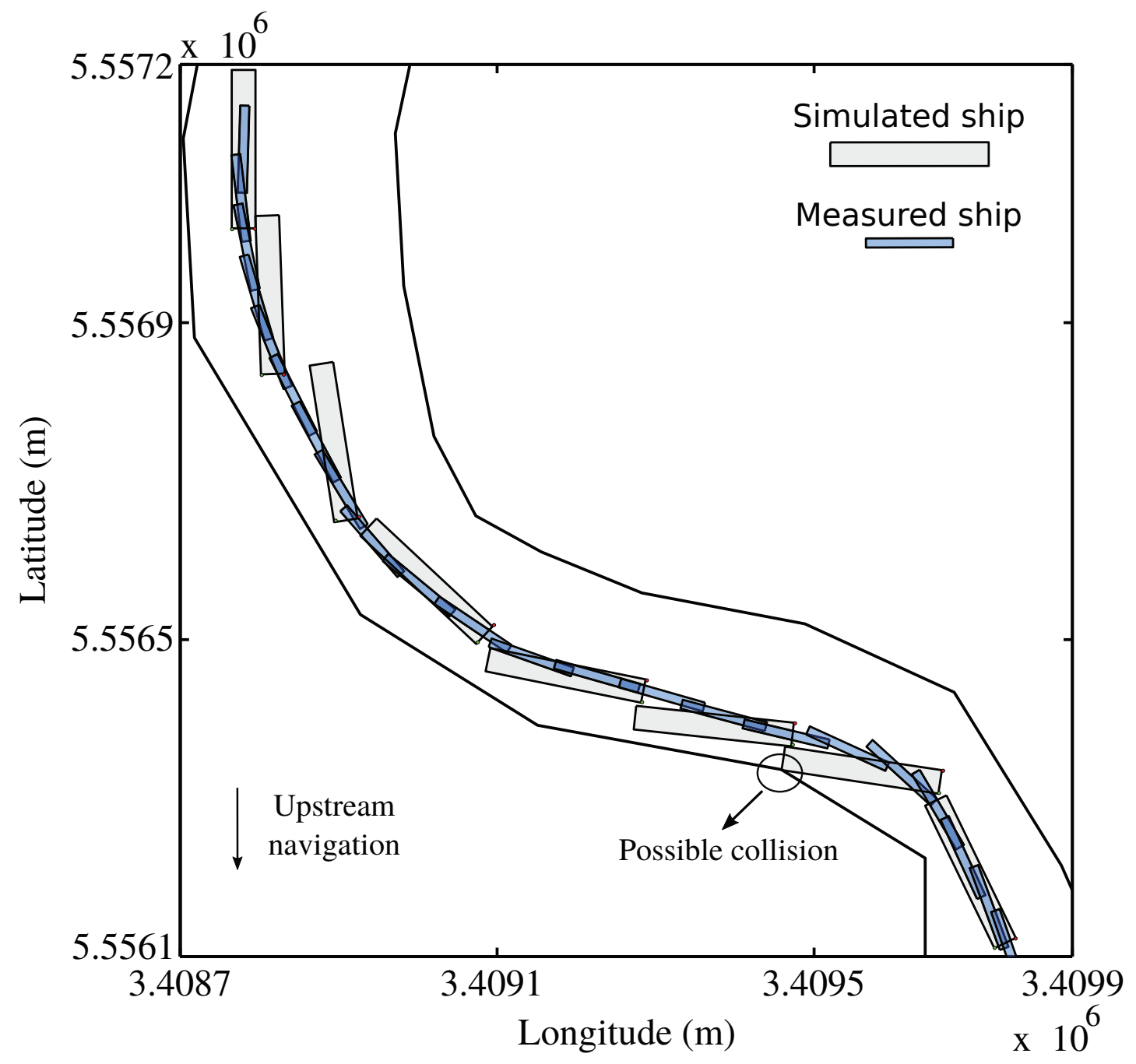

Figure 5.26: Example of the vessel-current model result. Simulated ship motion (light gray, $200 \mathrm{~m}$ long and $30 \mathrm{~m}$ wide) and real ship telemetry (light blue, $110 \mathrm{~m}$ long and $11.45 m$ wide) navigation downstream the Rhine River, Germany. 
After the setup of simulation main characteristics, it is possible to use a calibration script to determine the best set of parameters that optimize navigation, as the simulation time-step, auto-pilot instructions, azimuth thruster configuration, and engine force.

To evaluate the model results one can observe the ship motion within the waterway or graphics of parameters. However, this analysis can be considered subjective. Thus, mathematical functions are recommended to evaluate the model performance.

The Root Mean Square Error (RMSE) can be used to estimate the model performance for several parameters, e.g. path deviation, velocity or ship angle. This approach will be used to compare model results with measured data. The Root Mean Square Error estimator $(\phi)$ is given by,

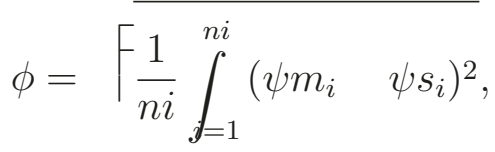

where $\psi m$ and $\psi s$ are the measured and simulated parameter respectively and $n i$ is the number of events. One must seek the minimization of this function since smaller values indicate that the model parameters results better represent the real measurements. Currently, the $\phi$ parameter is being used solely for the comparison of calibration results. However, dimensionless parameters can be estimated and be used for decision-making policies.

\subsubsection{Field data}

The Rhine River is one of the most navigated rivers in Europe and economically active in Germany. The German Federal Waterways Engineering and Research Institute (BAW) is involved in all main navigational and nautical projects on this river (Zentgraf and Dettmann, 2010). The middle section of the Rhine River has been extensively studied, not only due to natural difficulties for navigation (e.g. strong currents, narrow navigation channel, and intense traffic) but also because it was the site of a recent accident, described by Harlacher et al. (2015).

The BAW made available several data-base files, containing the position and time of different ships navigating two German section of the Rhine River. The agency also shared the river bathymetry, navigation paths and the two-dimensional velocity field, obtained by the use of hydrodynamic models. Figure 5.27 presents a data sample, where the bathymetry was interpolated using a Geographic Information System (GIS) software ${ }^{1}$.

\footnotetext{
${ }^{1}$ The open-source software QGIS was used for all GIS analysis in this research.
} 


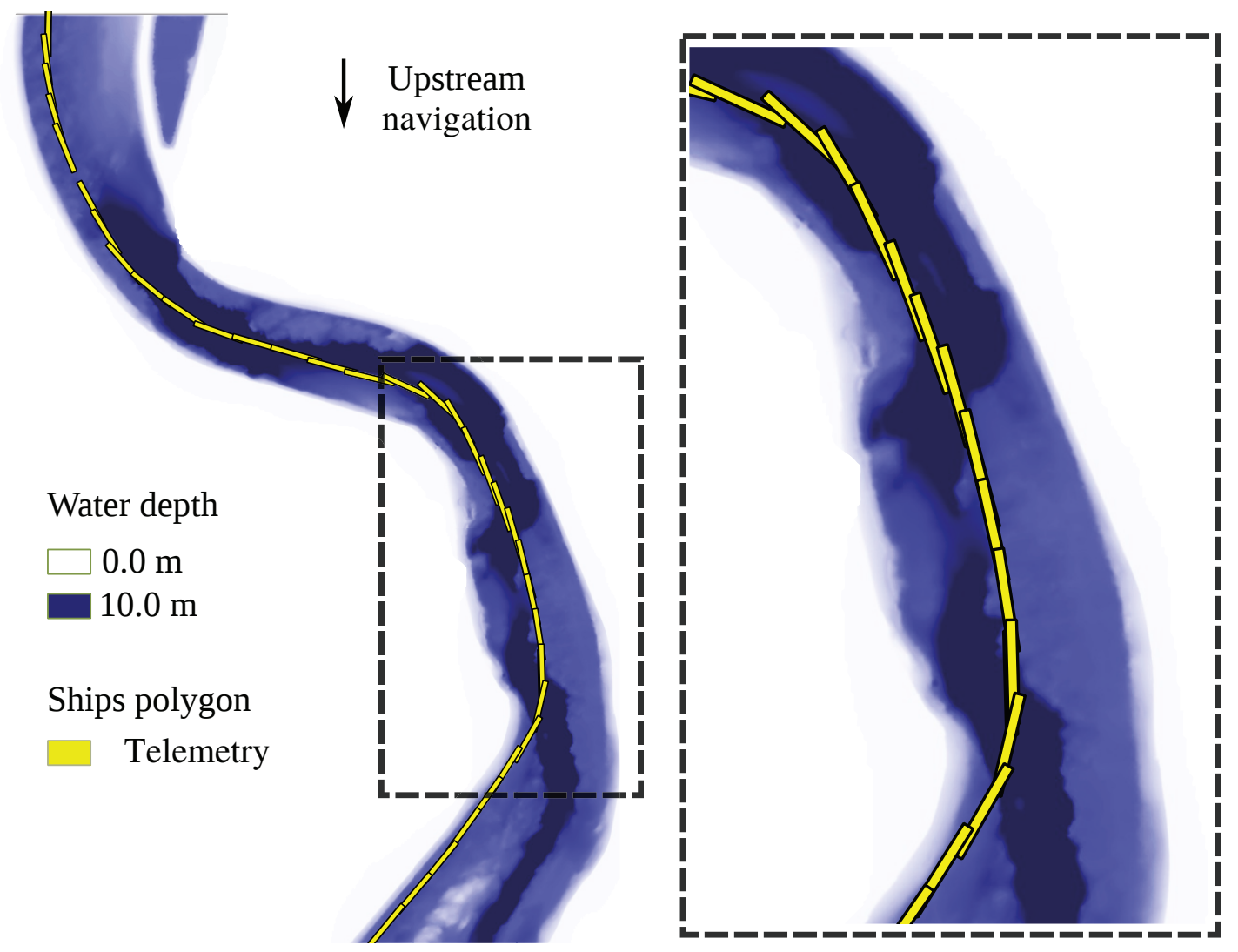

Figure 5.27: Data sample shared by the BAW, containing ship telemetry and the river bathymetry. Darker color represents a greater depth.

For the simulated Rhine section, the ship telemetry data consist of georeferenced points of 30 different vessels moving upstream and downstream the waterway, with a temporal discretization of 30 seconds. This information allows the calculation of several motion parameters, as the position, drift angle or the ship overall velocity. The flow velocity information is also distributed by georeferenced points within the river, where the data set has more than $1.5 \bullet 10^{6}$ points with the flow magnitude and direction for low, mean and high water levels. In this region the river width is approximately $650 \mathrm{~m}$ and the mean flow velocity is $1.8 \mathrm{~m} / \mathrm{s}$. The measured ships mean velocities were of 5.6 $\mathrm{m} / \mathrm{s}$ downstream and $2.7 \mathrm{~m} / \mathrm{s}$ upstream.

Three navigation paths were used in these analyses, the middle of the river, the ship passages telemetry and potential paths. The latter is a novel approach developed by the BAW to optimize vessel paths during floods, where relevant features for navigation, e.g. the flow and bathymetry data, are used to define the best possible ship trajectory (Harlacher, 2016a,b). 


\subsubsection{Verification results}

The model capacity in reproducing the motion of real ships is a necessary indication of its performance. The first scenario used real ship passages position as the navigation path reference for the auto-pilot system and the model results were compared with real telemetry. Then, the second scenario verified the feasibility of the potential paths. Finally, the third scenario measured the influence of the mass and velocity of the vessels for navigation.

Given that calibration and verification processes are an extensive task, where several parameters must range and be studied, only the most relevant analysis are presented in the following. The results were evaluated and compared to real data regarding the position, velocity, and angle of the vessels.

\section{Scenario I: ship passage verification}

The first simulation scenario is the modeling of upstream and downstream navigation of a barge ship (Schubverband) for middle water discharge level (MW), in the section between $\mathrm{km} 800-805$ of the Rhine River.

The model ship and simulation features are presented in Table 5.2. Whenever the values of total mass and engine power of a vessel is unknown, estimations of these values can be obtained by database records of the operational fleet in the region (e.g. INEA, 2016). The vessel engine power remained constant, the azimuth thruster force varied in the range of $25 \%$ to $100 \%$ of the total engine force and the overall mass for upstream simulation was higher (loaded ship).

Table 5.2: Ship parameters setup for scenario simulations.

\begin{tabular}{cc}
\hline Parameter & Description \\
\hline Ship model & Schubverband \\
Engine power & $2 \bullet 10^{3} \mathrm{~kW}$ \\
Length & $200 \mathrm{~m}$ \\
Beam & $12 \mathrm{~m}$ \\
Draft & $3 \mathrm{~m}$ \\
Maneuver setup & Azimuth thruster, 90 \\
Maneuver force & {$[25 \%-100 \%]$ Engine force } \\
Mass & $5 \bullet 10^{6} \mathrm{~kg}$ \\
Simulation time & $1000 \mathrm{~s}$ \\
Simulation time-step & $0.1 \mathrm{~s}$ \\
\hline
\end{tabular}

Figure 5.28 presents the results for position and angle of real and simulated ships 
navigating downstream (a) and upstream (b) the waterway. One can observe that greater values of azimuth thruster force are required for a safe downstream navigation, where only the ships using $75 \%$ and $100 \%$ of its total maneuver capacity were able to follow the real vessel path (red). For upstream navigation, ships that used $50 \%$ or more of its maneuver capacity moved within the channel borders. These results were expected given that downstream navigation usually is associated with greater velocities, thus requiring greater maneuverability capacity for navigation.

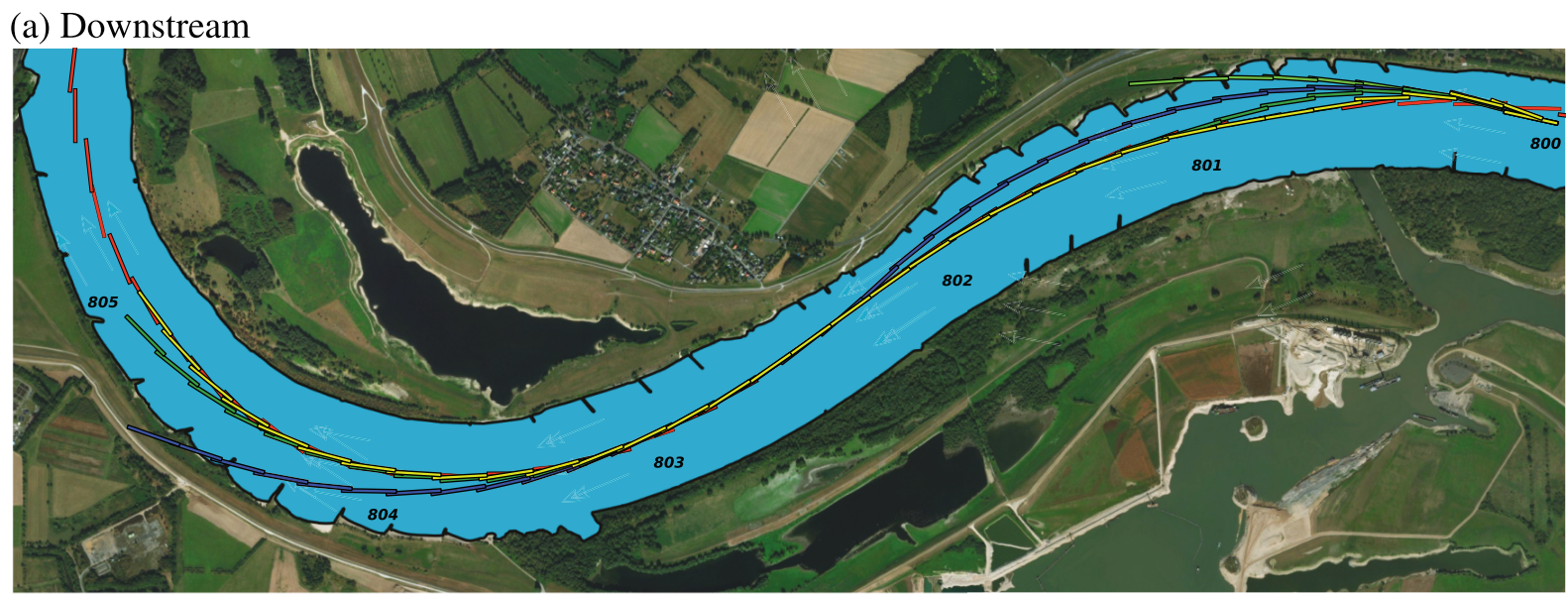

(b) Upstream

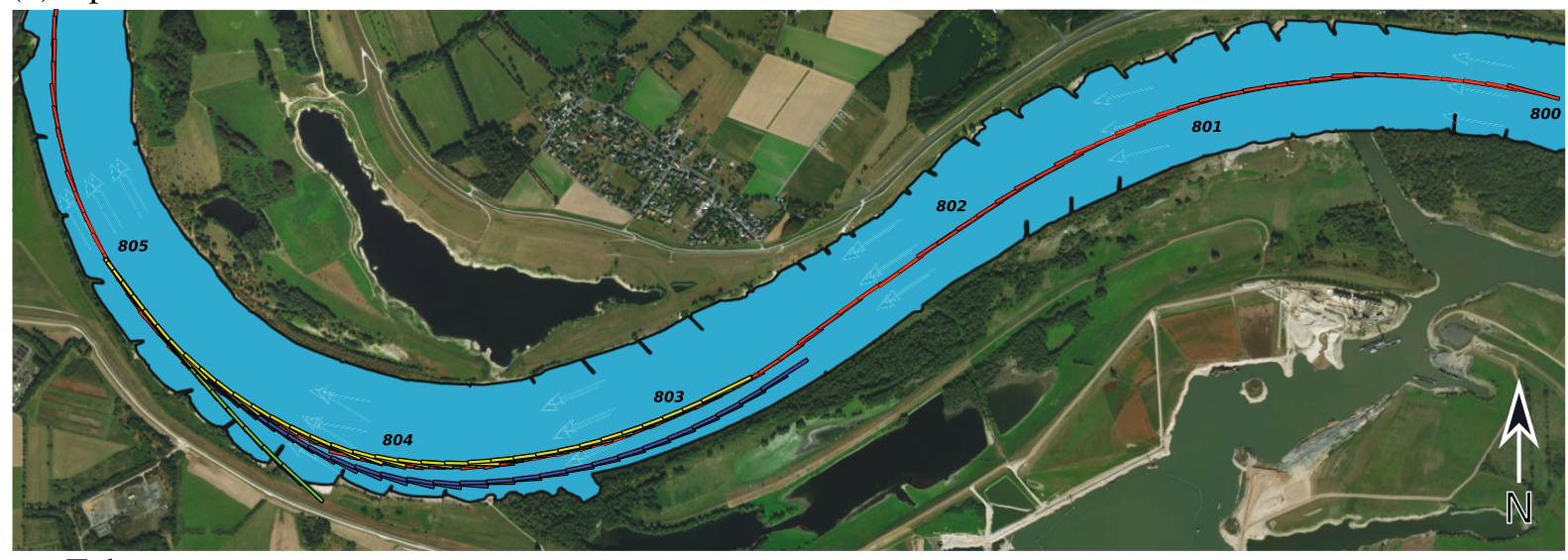

Telemetry

$100 \%$

$75 \%$

$50 \% \square 25 \%$

Lon: 737529, Lat: 6720741

Figure 5.28: Downstream (a) and upstream (b) results of a ship following real data path for different maneuver forces (red).

Table 5.3 shows the root mean square error for the results of scenario I. The values were compared to each GPS data time-step, hence every 30 seconds. The error difference reduced to greater values of maneuver force for both upstream and downstream direction, which represents a better model performance. However, possibly there is a threshold of maneuver force where if increased no advantage is obtained or even impairs the navigation.

A detailed quantitative analysis of the model results is shown in Figs. 5.29 and 5.30, where the lines are real data values and the geometrical symbols are the model results. 
Table 5.3: RMSE results of scenario I for position $\left(\phi_{L}\right)$, velocity $\left(\phi_{V}\right)$ and direction $\left(\phi_{\theta}\right)$.

\begin{tabular}{ccccccc}
\hline & \multicolumn{3}{c}{ Downstream } & \multicolumn{3}{c}{ Upstream } \\
\hline Simulation & $\phi_{L}(m)$ & $\phi_{V}(m / s)$ & $\phi_{\theta}(\mathrm{deg})$ & $\phi_{L}(m)$ & $\phi_{V}(\mathrm{~m} / \mathrm{s})$ & $\phi_{\theta}(\mathrm{deg})$ \\
\hline Ship 25\% & 160.9 & 2.1 & 16.3 & 119.1 & 0.85 & 16.9 \\
Ship 50\% & 105.3 & 1.2 & 14.5 & 54.4 & 0.60 & 8.68 \\
Ship 75\% & 79.2 & 1.1 & 11.3 & 36.1 & 0.58 & 4.5 \\
Ship 100\% & 77.1 & 1.4 & 10.3 & 36.3 & 0.58 & 4.4 \\
\hline
\end{tabular}

Sub-figures (a) present the position, (b) the absolute velocity and (c) the bow direction of the vessels. As also shown by visual inspection of Fig. 5.28 and by the RMSE analysis, the simulated vessel using 100\% of possible maneuver force presented a better performance than the vessel that used only $50 \%$. This difference was greater for downstream navigation due to the ships greater velocities. One can also observe that the upstream ship using $50 \%$ of maneuver force presented a greater resultant velocity. This is due to the fact that the vessel was further from the orientation path and closer to the river margin, where the flow velocity against the ship was lower, i.e. less drag resistance.

Figure 5.31 presents the Pearson correlation analysis for velocity (a) and angle (b) between the measured and model data for downstream simulation using 100\% maneuver force. The mean velocity for the model and for the measured ship was respectively of $5.3 \mathrm{~m} / \mathrm{s}$ and $5.5 \mathrm{~m} / \mathrm{s}$. Despite the close mean values of velocity $(\Delta \bar{v} / 3.6 \%)$, this relation presented a poor correlation index $\left(R^{2}=0.44\right)$. On the other hand, the relation obtained for the measured and model ship angles presented a greater correlation index $\left(R^{2}=0.97\right)$, that is, the model was able to perform the necessary maneuvers to maintain the ship within the preferential navigation path direction.

The correlation pattern is shown in Fig. 5.31 was expected due to the auto-pilot instruction and its degree of freedom. The auto-pilot can change the navigation course to keep the ship as close as possible to the ideal route. In fact, that was set as its main priority. However, the variation of the engine power by the auto-pilot was not configured for this simulation and the propulsion was constant. The engine power was set so that the model ship velocity reaches the reference vessel mean velocity in curves, which explain the lower correlation index for this parameter. The focus of the model is the capacity of ships to maneuver in curves, but by the use of few new instructions, it is possible to implement an auto-pilot response to variations of velocity. 

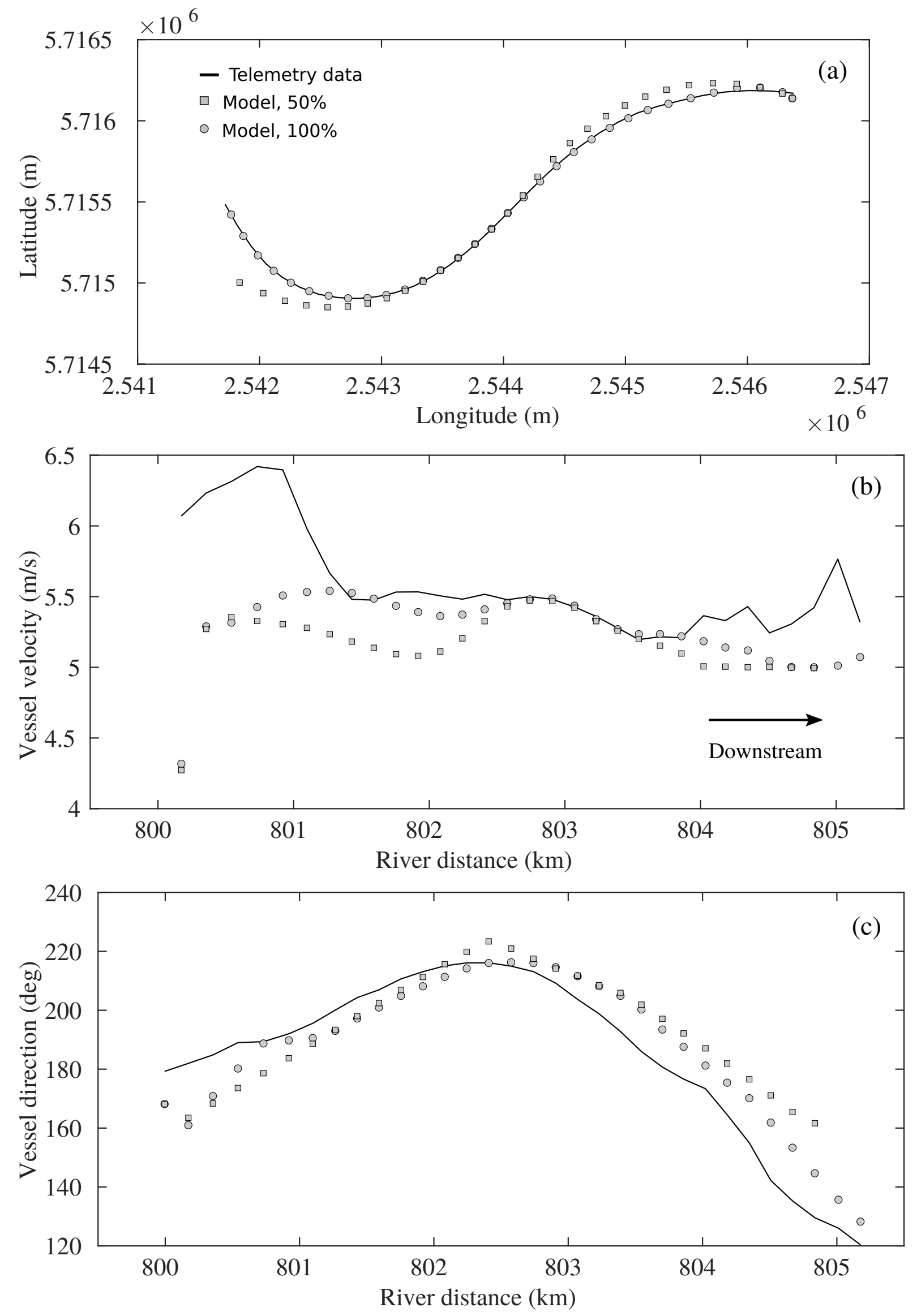

Figure 5.29: Downstream navigation telemetry (line) and simulation (points) results using $50 \%$ and $100 \%$ of possible maneuver force. 

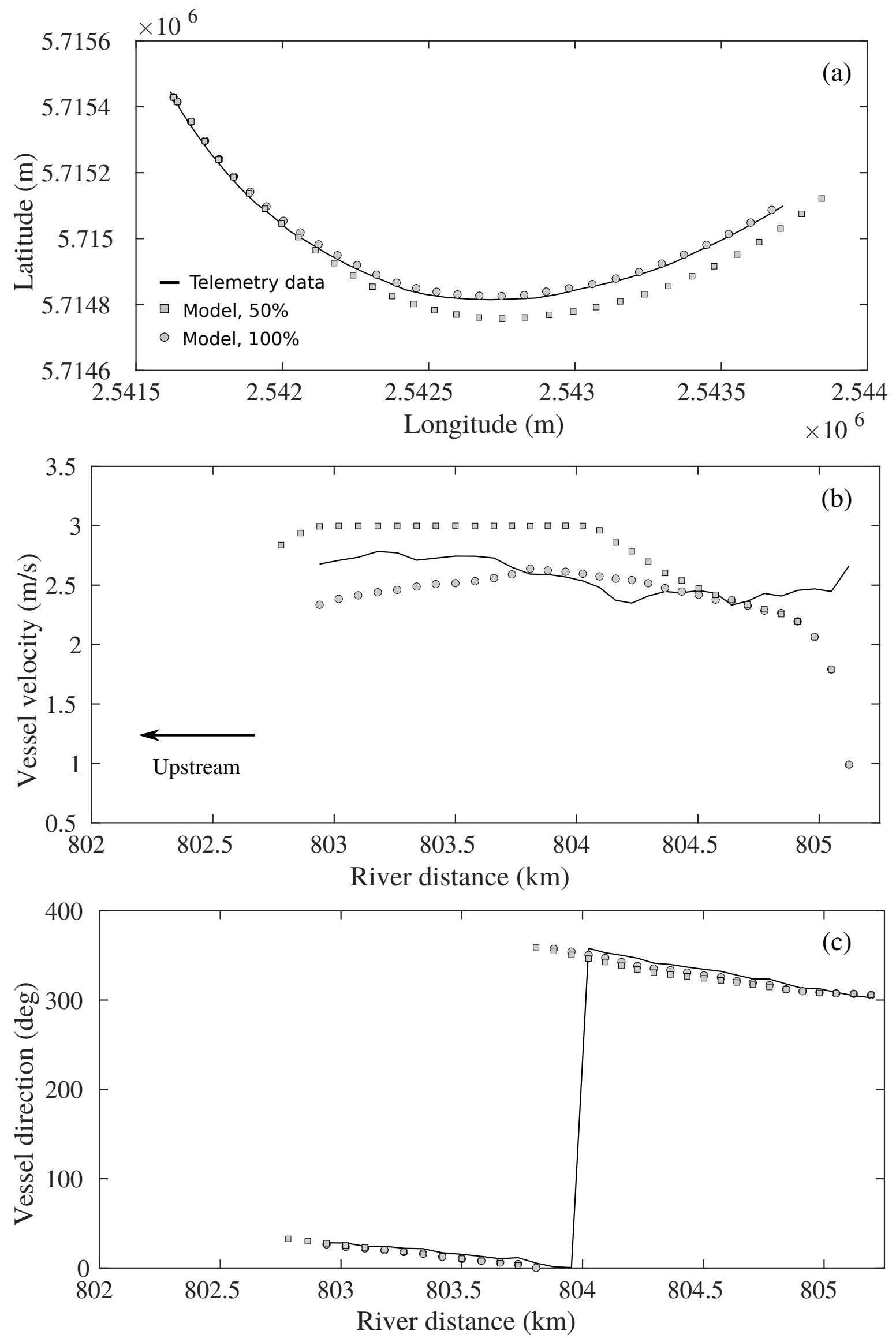

Figure 5.30: Upstream navigation telemetry (line) and simulation (points) results using $50 \%$ and $100 \%$ of possible maneuver force. 

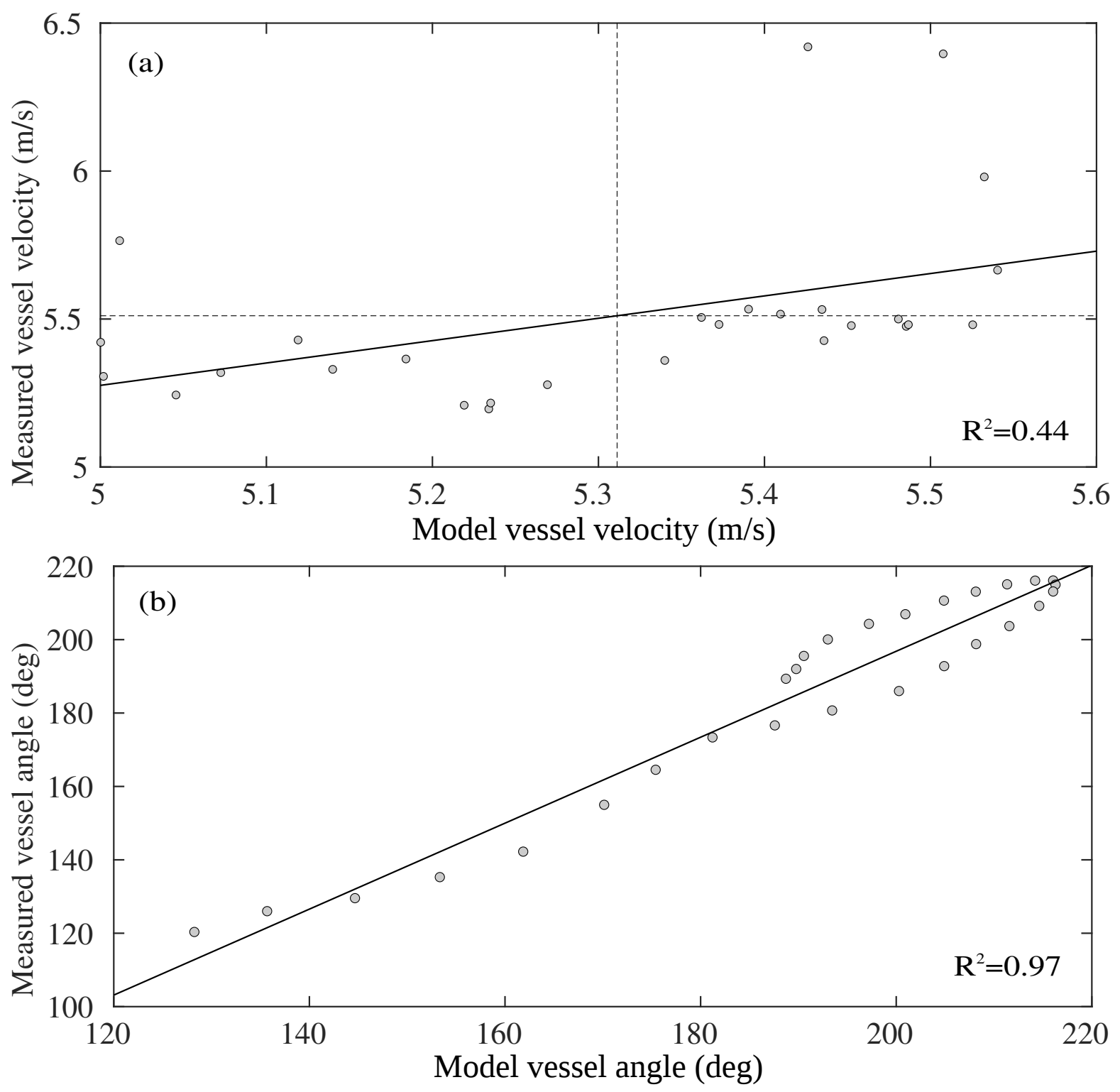

Figure 5.31: Correlation analysis for velocity and angle for downstream navigation of the model result and measured ship. The dashed lines indicate the parameters mean values.

\section{Scenario II: potential path lines}

As previously mentioned, BAW researchers developed an approach to design navigation channel paths, which mostly depend on the river bathymetry and velocity fields. For the same set of parameters presented in Table 5.2 and using full azimuth thruster force to maneuver (100\%), the model was applied to simulate upstream and downstream navigation using the potential lines as orientation for the auto-pilot. The main objective of these simulations was to evaluate the feasibility of these paths.

Figure 5.32 presents the model results for downstream (a) and upstream (b) direction. 
For the simulated stretch, the model vessel can satisfactorily navigate the river using the potential path as orientation. Furthermore, for both upstream and downstream direction, the vessels that used the ship passage path for orientation occupied mostly its right side of the waterway. When the potential paths were used, the vessels also occupied the left side of the waterway, possibly preventing ships from the opposite direction to navigate. This pattern can be increased when the flow velocity of the river is higher (downstream) and/or smaller forces are used for the maneuvers, given that the vessel tends to move tangent to curves.

(a) Downstream

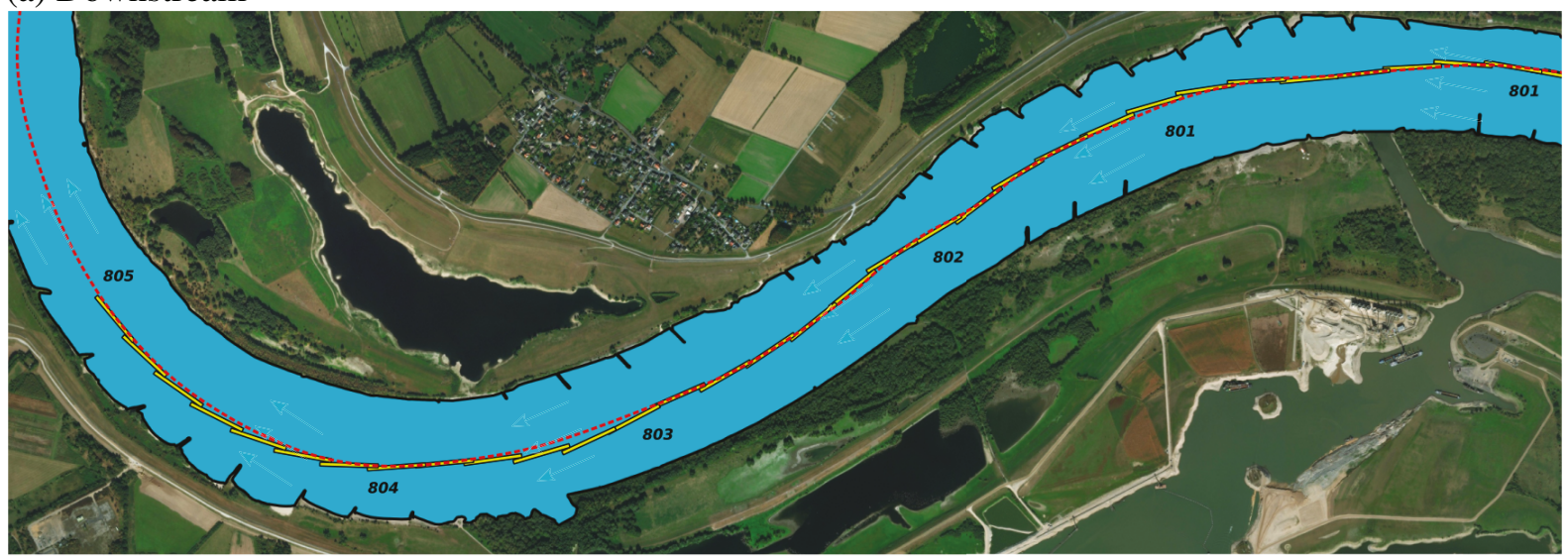

(b) Upstream

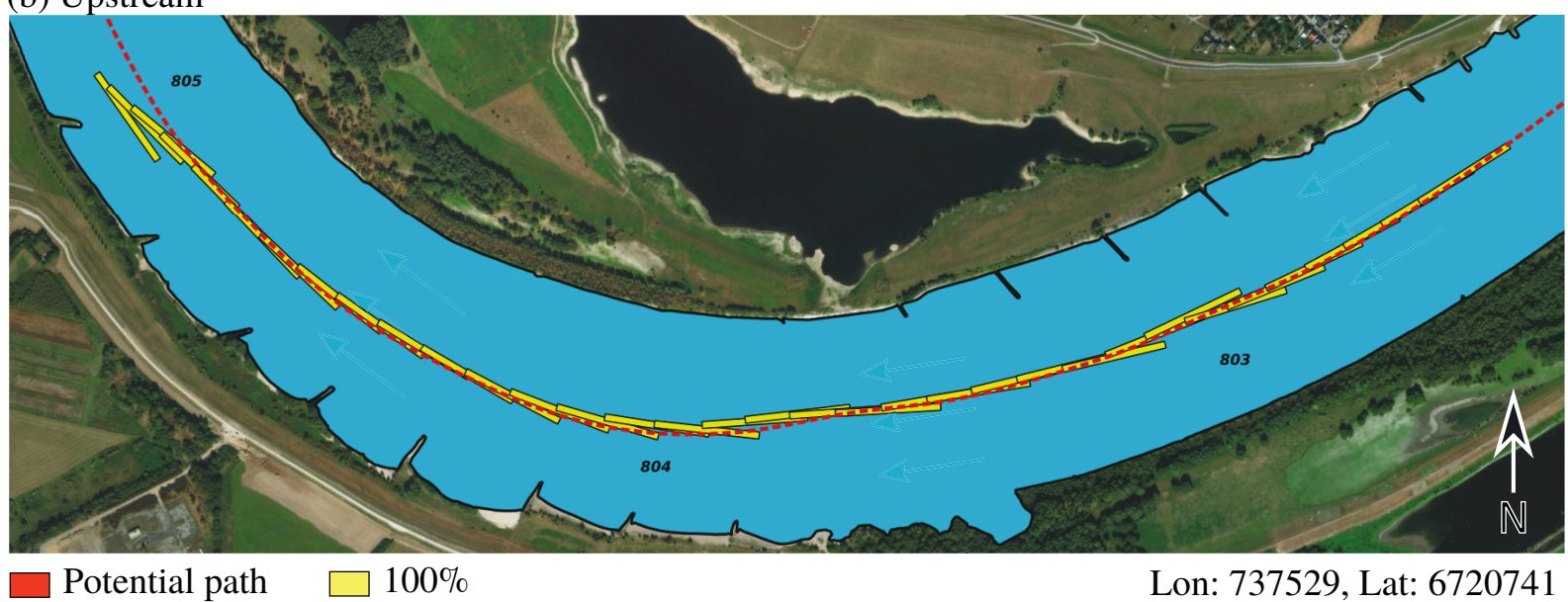

Figure 5.32: Downstream (a) and upstream (b) results of a ship using the potential path as orientation line.

This navigation route should only be used in extreme flood events where vessels should remain stationed until improvements on the navigation condition occur. The main advantage in the use of the potential paths relies on the guarantee of presenting the greatest possible values of depth and greater distance from margins. 


\section{Scenario III: mass and velocity}

This scenario presents an analysis of the relation between mass, speed and the rotational capacity of ships for downstream navigation. The simulations also used the parameters described in Table 5.2, where the mass varied from $10 \bullet 10^{6}$ to $20 \bullet 10^{6} \mathrm{~kg}$ and $100 \%$ of possible maneuver force was applied. The ship passage telemetry data were used as orientation path for the auto-pilot system.

Figure 5.33 shows the results for vessels with different values of mass. In sub-figure (a) the ship velocity was unrestrained, i.e. used the total propulsion force available to accelerate. It is possible to observe that no ship was able to perform the curve to the port side direction (left). When the velocity was restrained in $3.0 \mathrm{~m} / \mathrm{s}$, sub-figure (b), the vessel with the lowest weight (blue) remained within the channel margins. The remaining ships were not able to navigate satisfactorily with the used parameters.

The patterns observed in scenario III are due to the relation between the ship mass, the moment of inertia, the speed and the force available for maneuvers. The moment of inertia of a body is proportional to its mass. Considering a constant angular velocity, the higher the vessel mass, the greater the necessary force to rotate it. Thus, for a constant azimuth thruster force, the angular variation was lower for heavier ships. When the vessel navigates at a slower translation velocity, i.e. constrained case, it has more time to maneuver which improved the navigation condition.

\subsection{Chapter closure}

In this chapter, the model developed in this research was presented. Initial results were also shown and were used to verify the model performance. Also, the data shared by the BAW was used in the verification process of the model. One can observe that for most simulation setups the auto-pilot was able to maintain the model ship within the navigation channel. It is also possible to change the auto-pilot performance varying its parameters, as the response time and maneuver instruction. In the following chapter the vessel-current model was used to evaluate the Paraguay River waterway. 
(a) Unlimited speed

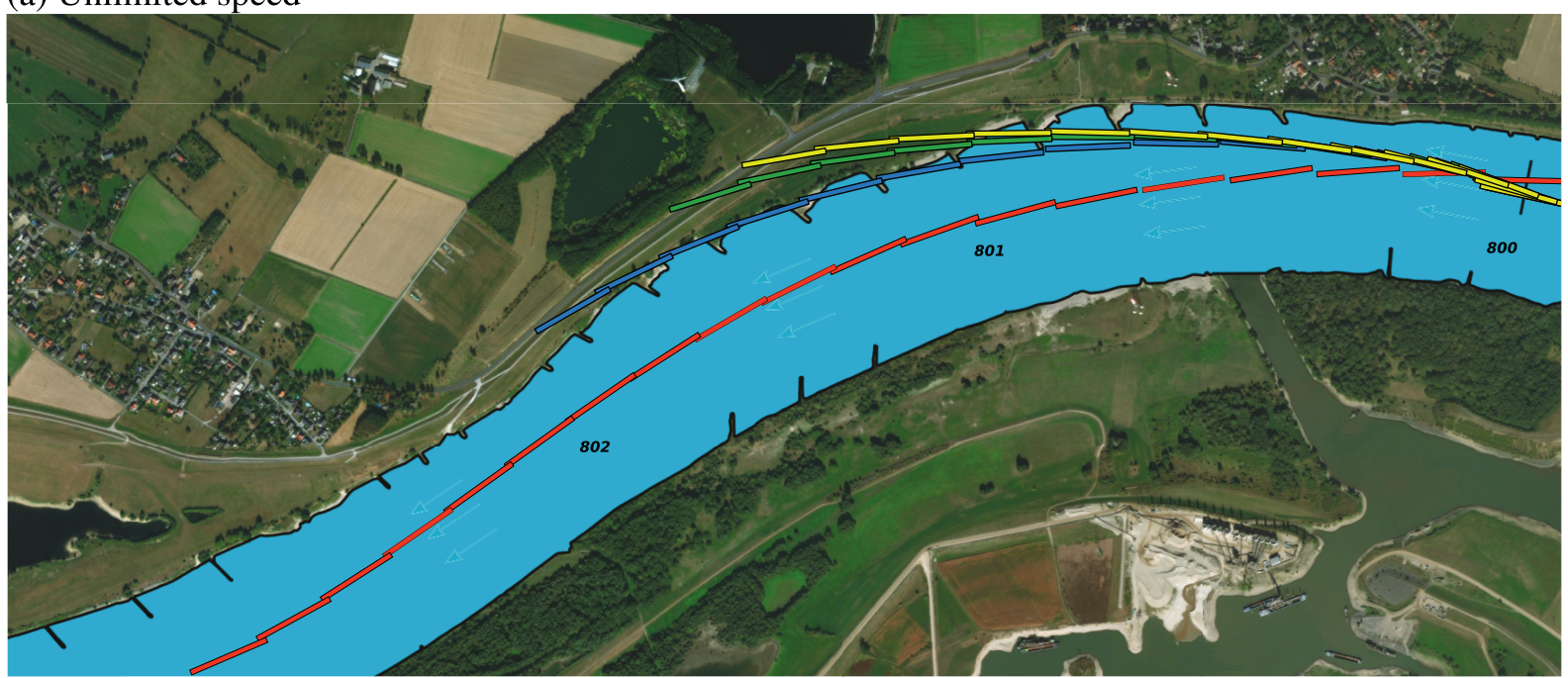

(b) Limited speed

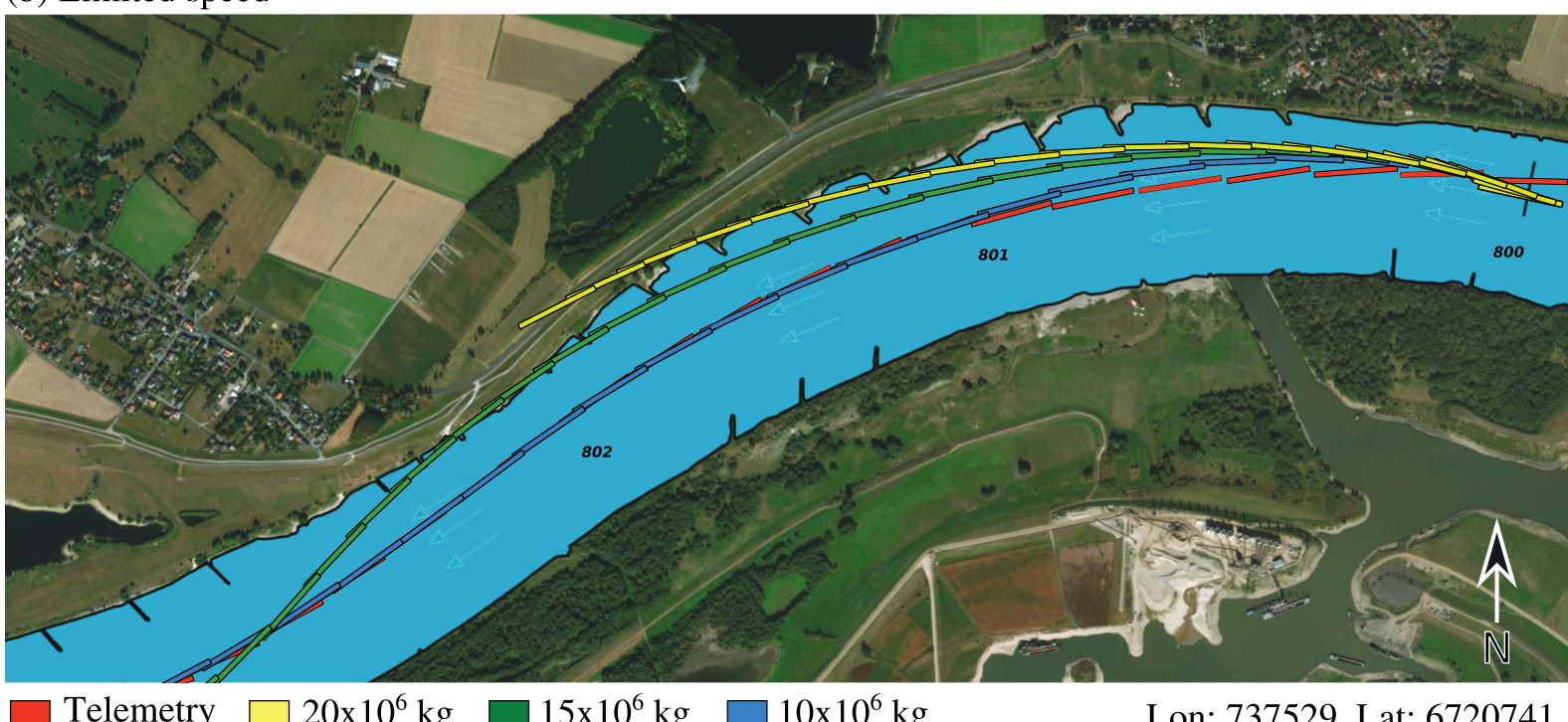

Telemetry $\square 20 \times 10^{6} \mathrm{~kg} \square 15 \times 10^{6} \mathrm{~kg} \square 10 \times 10^{6} \mathrm{~kg}$

Lon: 737529, Lat: 6720741

Figure 5.33: Unlimited (a) and limited (b) speed influence on the ship motion for different mass values. 


\section{Chapter 6}

\section{Case study - Paraguay River}

In this chapter, the developed algorithm was used for the navigation analysis of critical regions of the Paraguay River waterway. Initially, a description of the study area and data gathering during field surveys is presented. Then, the navigation modeling and results are discussed.

\subsection{Area of study}

The Paraguay River is one of the major rivers of the La Plata basin, the second largest basin in South America and the fifth largest in the world. The rivers of this basin flow from the center of the sub-continent, forming a natural corridor for the regional development. The basin can be divided into a high region, called Plateau, and a low flat area called Pantanal, which is temporally and partially flooded every year (Clarke et al., 2003).

The La Plata River basin covers part of central and northern Argentina, a vast part of Uruguay, the whole area of Paraguay, a small area in southeast Bolivia and a large part of southern Brazil. The management of the drainage basin is crucial for economic development of those countries, especially because about $70 \%$ of the total Gross national product (GNP) of the five countries is produced within the area (Tucci, 2009).

From headwaters located at the Parecis plateau in Mato Grosso State, Central-West Region of Brazil, to its confluence with the Paraná River, the Paraguay River is about 2,621 kilometers long (Innocencio, 1988). The Brazilian portion of the waterway is divided into north and south stretch. The fluvial style of the river varies significantly along the course of the upper Paraguay River, especially within the Pantanal wetland and its surrounding areas.

The north stretch, between the cities of Cáceres and Corumbá, presents some caveats 
to navigation as shoal formation, occurring by variation in the flow rates and sedimentation patterns along the channel. The south section has a broader channel to navigation and greater depth but still has some navigation restrictions. At the confluence of the Paraguay and Paraná River, near the cities of Corrientes and Resistencia in Argentina, the average flow of the Paraguay River is $2,700 \mathrm{~m}^{3} / \mathrm{s}$ (Clarke et al., 2003).

Previous studies conducted by the Brazilian Transport Ministry (2013) states that the Paraguay River can be considered quite satisfactory for navigation in the stretch between the cities of Cáceres and Corumbá, however, needs to receive maintenance dredging in specific regions during the dry season to ensure navigability.

The commercial shipping in the Brazilian portion of the Paraguay River occurs mainly between Corumbá and Porto Murtinho. The tributaries of the Paraguay River have restrictions to commercial navigation transport due to severe silting and bed changes. Therefore, it was proposed by the Brazilian Government the execution of dredging and removal of rocks on the Paraguay River and main tributaries, forming a deep channel between the cities of Cáceres, Brazil, and Nueva Palmira, Uruguay. However, given the environmental impacts involved in this proposal, the Brazilian Federal Government is studying less environmentally harmful projects.

In the Brazilian territory, the largest tributaries of the Paraguay River and also the main tributaries of the Pantanal inundation area are the Cuiabá, São Lourenço, Taquari, Miranda, and Aquidauana rivers. The Cuiaba River has approximately $850 \mathrm{~km}$ of extension and its current navigation capacity is not totally mapped due to the recent construction of a hydroelectric dam upstream the city of Cuiabá.

The need for dredging in all rivers of the region has been reinforced during the last three decades as a consequence of erosion and increased volume of sediment transported to the Paraguay River. The erosion and enhanced sediment supply, however, cannot be attributed solely to human intervention (e.g. soy crops and cattle pasture) on the surrounding plateaus. In addition, hydrological records show that rainfall and runoff have increased since 1970 (Collischonn et al., 2001).

Some authors state that the region receives great loads of sediments due to natural conditions, given the geomorphological features found in the basin, as presented by Assine (2005). In this case, to ensure the navigation conditions in some tributaries of the Paraguay River, the dredging operations would be so intense and periodic that these projects may not be economically feasible. However, understanding the dynamics of sediment transport from the basin to these rivers requires further investigation. 


\subsection{Characterization of the Paraguay River naviga- tion channel}

The Technological Institute of Transport and Infrastructure of the Federal University of Paraná (ITTI) is responsible for feasibility studies ${ }^{1}$ for the modernization of the Paraguay River waterway. This research will complement several previous studies conducted by the Brazilian Navy.

As already presented in chapter 2, the navigation channel of Brazilian waterways is determined in accordance with standards of PIANC (1995). The dimensions of the navigation channel resulted in a width of $45 \mathrm{~m}$ in the north stretch and $105 \mathrm{~m}$ in the southern stretch of the Paraguay River, with additional values of over-width in curves and varying by the local radius of curvature.

The cargo transportation in the northern stretch of the waterway is unimpressive and the maximum dimensions of the convoys are established by the Brazilian Navy (Marinha do Brasil, 2006), summarized in Fig. 6.1. Most of the northern section use a $2 \bullet 3$ barge configuration (140 $\mathrm{m}$ long and $24 \mathrm{~m}$ wide). The navigation channel designed for this stretch is $45 \mathrm{~m}$ wide and presents a minimum depth of $1.80 \mathrm{~m}$. This depth should be guaranteed in the dry season, according to the reduction levels defined for this waterway (ITTI, 2015).

The southern section of the Paraguay River presents characteristics (wider and deeper channel) that allow the $4 \mathrm{x} 4$ convoy configuration, with 16 barges of $60 \bullet 12 \mathrm{~m}$ and a pusher $50 m$ long, thus a total convoy dimensions of 290• $48 m$ (Marinha do Brasil, 2006). Due to the carrying capacity of barges, the hydro-morphological characteristics and the minimum safety depth margin $(0.30 \mathrm{~m})$ defined by the Brazilian Navy, the depth of the navigation channel was set as $3.00 \mathrm{~m}$ (ITTI, 2015).

It was established by the Brazilian Navy that convoys equipped with maneuvering facilities (e.g. azimuth propulsion) may exceed by $30 \%$ the indicated length for each sub-section, with prior approval of the Regional Maritime Authority (Marinha do Brasil, 2006). The Brazilian Navy also published a list of critical sections for navigation in the southern stretch of the River, summarized in Fig. 6.2. These regions require further attention due to the presence of obstacles for navigation, as sandbanks and curves with small radius.

Regarding the curvature radius, the Paraguay River Waterway EVTEA (ITTI, 2015) provides that the minimum bend radius of the navigation channel should not be less than

\footnotetext{
${ }^{1}$ Study of Technical, Economic and Socio-Environmental Feasibility (EVTEA).
} 


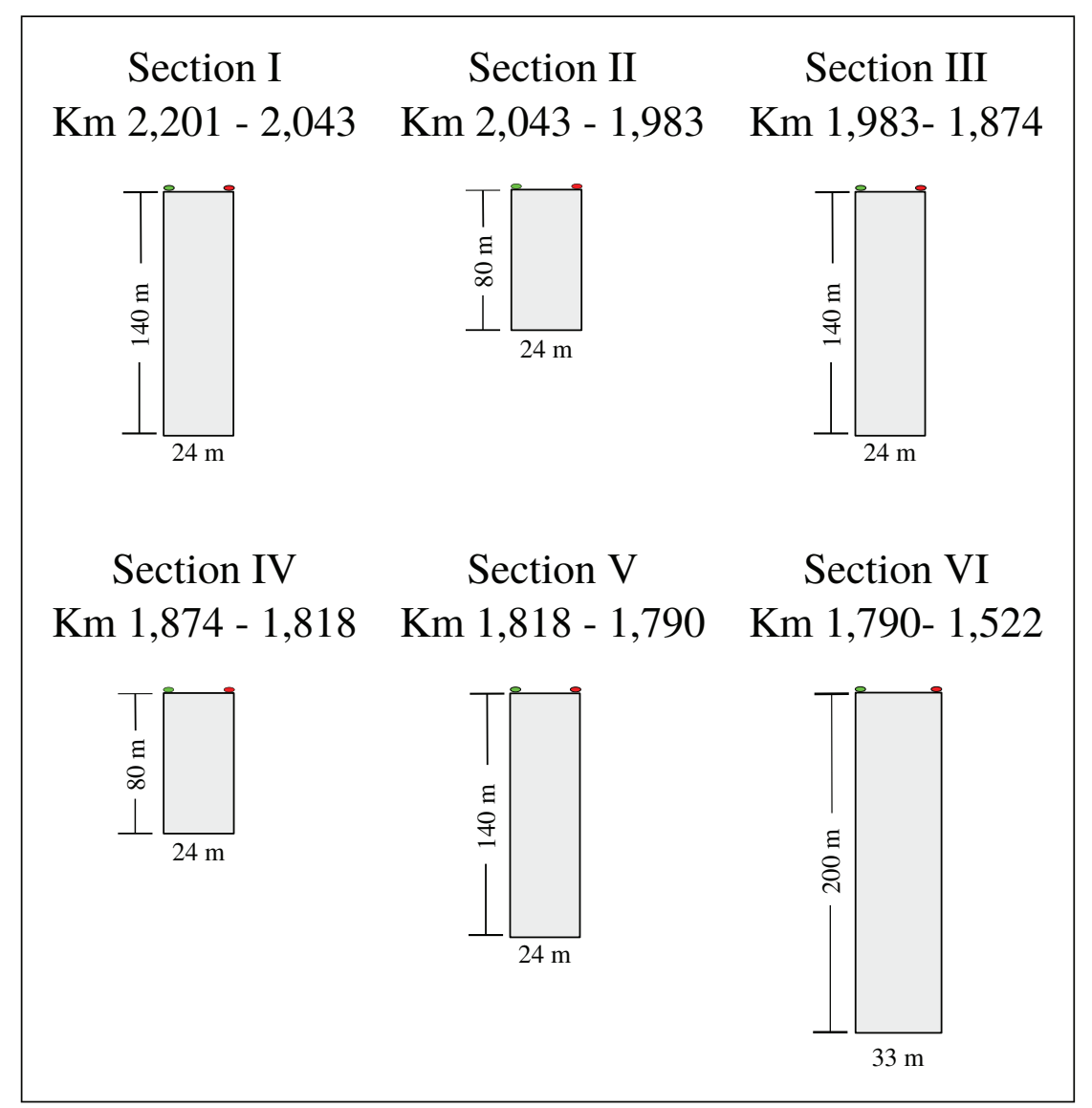

Figure 6.1: Restriction of the maximum width and length of barges composition in the northern stretch of the Paraguay River waterway. Data provided by Marinha do Brasil (2006).

10 times the length of convoys. Therefore, the minimal bending radii would be 1,350 $\mathrm{m}$ and 2,900 $\mathrm{m}$ in the northern and southern stretches respectively. In consultation with PIANC standards (PIANC, 1995), it was found that the used value of $10 \bullet L$ is overly restrictive. Therefore, it was adopted minimum values of $7 \bullet L(2,030 \mathrm{~m})$ in the south stretch and $6 \bullet L(810 \mathrm{~m})$ in the northern stretch.

The new minimum bending radius values for the waterway allowed to analyze and identify stretches with curvature radius below the recommended (Guarneri et al., 2016). This analysis estimated a total of approximately 400 critical curves in the north section and 60 in the south section (ITTI, 2015). However, it is known that full navigation in the southern region of the waterway occurs, which caused doubt about the level of rigor and conservatism of the methods suggested by PIANC to define the minimum radii (ITTI, 2015).

From the previous analysis, it was observed that the used standard of PIANC has quite conservative values, and in fact, its recommendations regard marine navigation channels. Its application for inland waterways is acceptable in compliance with specific 
characteristics of each site, meeting basic criteria of safety and vessels maneuverability. Thus, its application may be unfeasible to define inland navigation channels and specific studies are still necessary for the evaluation of the navigability capacity of Brazilian inland fairways.

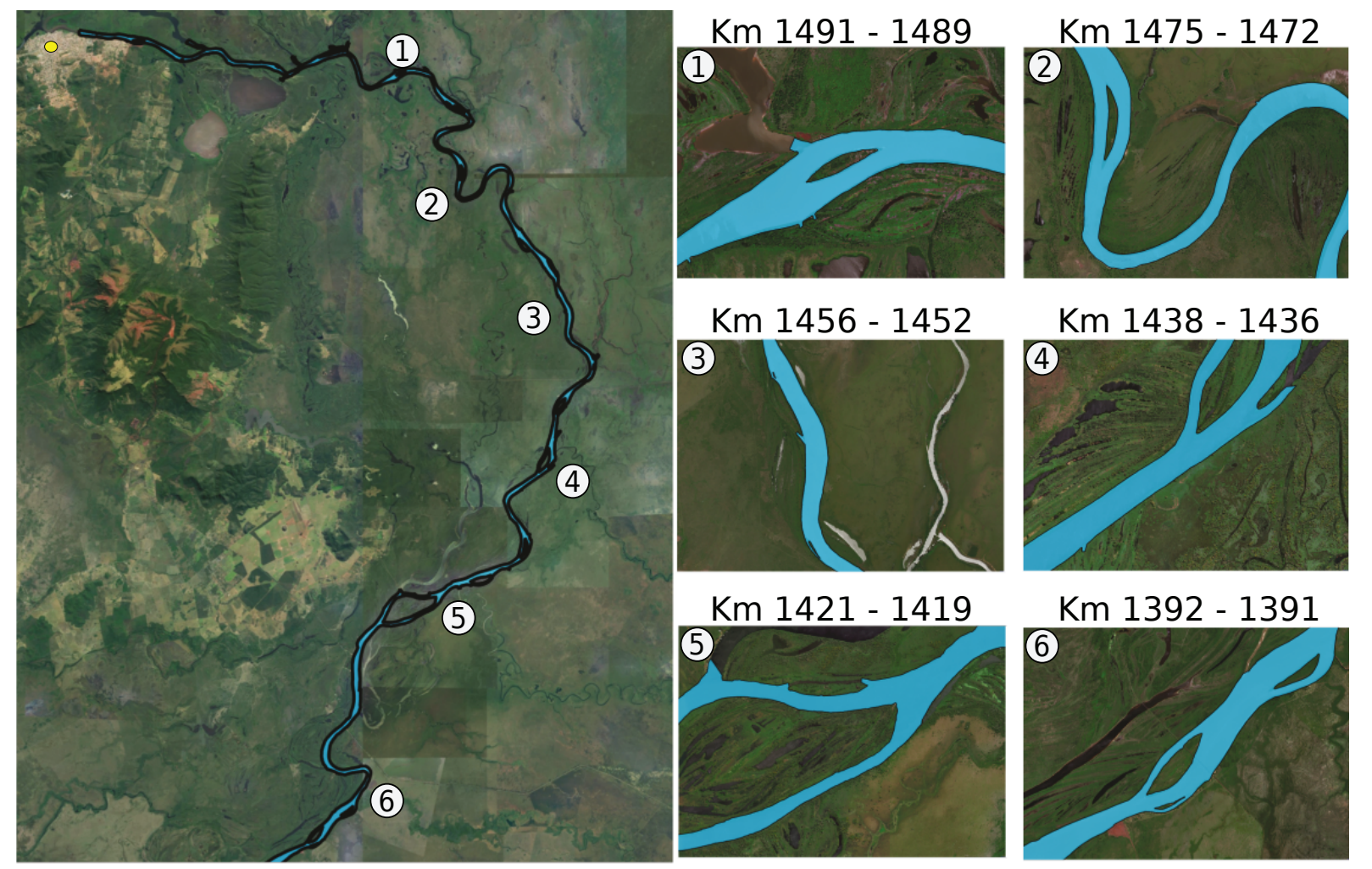

Figure 6.2: Paraguay River critical sections for navigation: 1) Santana, 2) Miguel Henrique, 3) Mucunã, 4) Abobral, 5) Caraguatá and 6) Jacaré. The yellow dot is the city of Corumbá (-19.008889, -57.652778). Data provided by Marinha do Brasil (2016).

\subsection{Field data}

Initial field investigation and measurements were conducted in the Brazilian stretch of Paraguay River and its main tributaries. The first survey was mostly performed in tributaries rivers, while the second and third field surveys were performed in the north and south stretch of the Paraguay River respectively. The field data were used to model the velocity along the waterway and also to determine the points of greater depth, used to define the navigation channel path (ITTI, 2015).

The surveys were conducted by a joint team of the Federal University of Paraná (UFPR), ITTI, DNIT and the Brazilian Navy, which provided the hydrographic vessel and logistic support. The main objective was the characterization of the rivers and deter- 
mination of their current navigability condition. Therefore, various measurements were performed, as the velocity profile, longitudinal and transversal bathymetry of the channel, sediment sampling, and measurements of the river flow. Also, the main characteristics of typical cargo vessels were assessed, as beam, length, and draft.

Due to the low water level in the Cuiabá River and the draft requirement of the research vessel, it was not possible to navigate the whole length of the river. Approximately $700 \mathrm{~km}$ were covered, remaining $150 \mathrm{~km}$ upstream.

Figure 6.3 presents the studied region, where the evaluation of the navigation condition was performed. The blue lines indicate each one of the 880 cross-section profile samples, where the river velocity, discharge, and bathymetry were measured by an acoustic profiler and a bathymetric echo sounder.
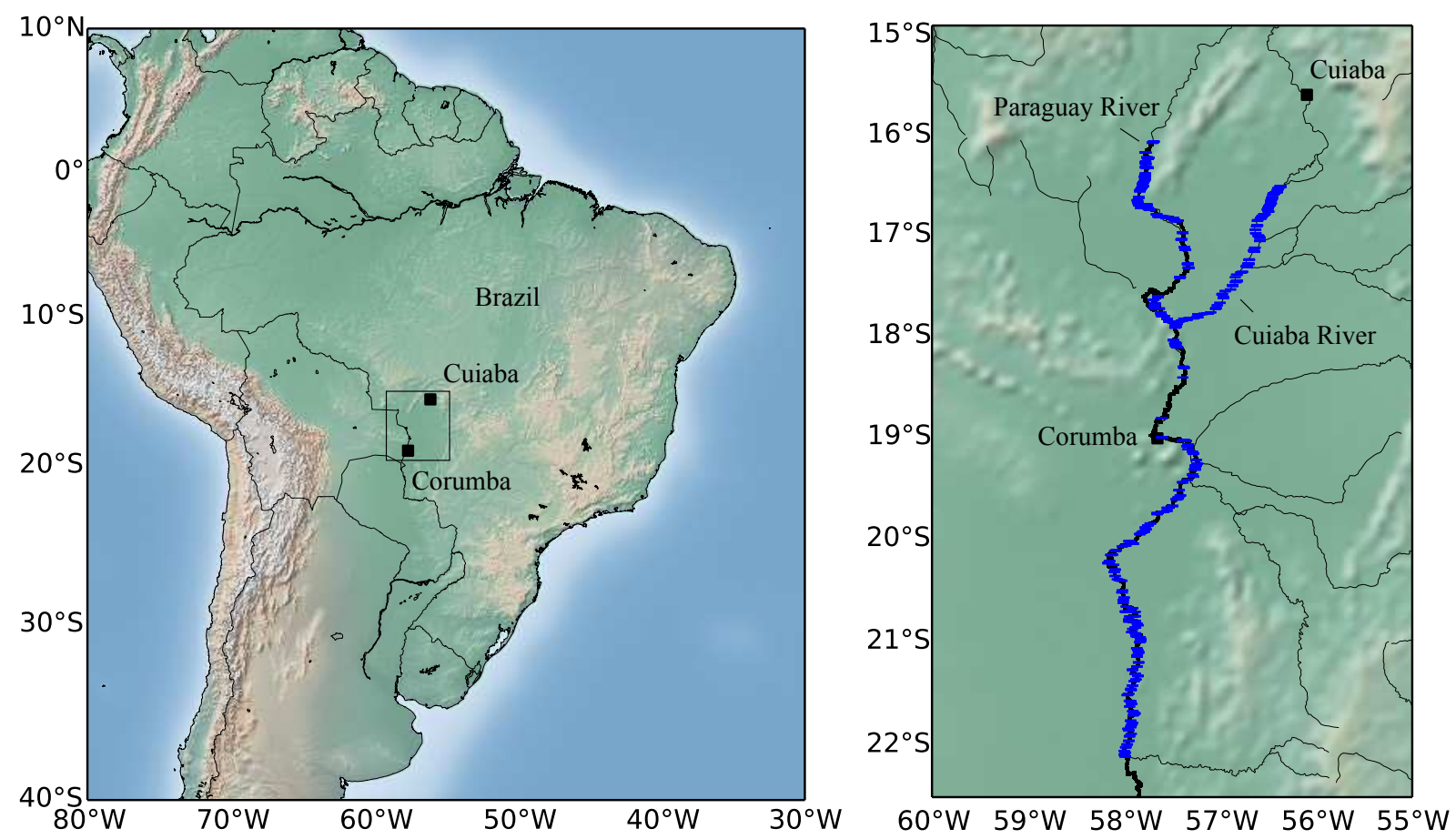

Figure 6.3: Field surveys, presenting the Pantanal region and Paraguay waterway within the rectangle area. The cross-section velocity profile and bathymetry measurements are presented by blue lines.

In the Paraguay River, 18 points were determined as the most critical for navigation. These sections require a high level of detail since they are regions with low depth, sharp bends, the formation of sand shoals, tributary entrances and strong transversal currents (ITTI, 2014). 


\subsubsection{Flow velocity}

The velocity profiles of the river were measured using a Sontek M9 Acoustic Doppler Velocimeter, whose technical specifications are described in SonTek (2010). The equipment was adjusted to a smaller vessel and measurements were performed perpendicularly to the channel flow. Both the bathymetry and the flow velocity of the sections were determined, providing the instantaneous velocity field, average flow and cross-section bathymetry for each analyzed stretch.

A total of 880 river crosses were performed, each pre-determined cross-section was covered four times, thus totaling 220 mean cross-section files. The raw data obtained is composed of several tables to be post-processed, containing three-dimensional velocity for every discrete point and its coordinate location. Previous results are also shown by graphs, as presented in Fig. 4.2.

Given the high level of details provided by acoustic profilers, the output data postprocessing requires a thorough analysis. Despite being one of the most used models, there are no open source post-processing tools for the M9 SonTek ADCP. Therefore, a software to assist the analysis of the velocity field was developed for this equipment in cooperation with researchers of the ITTI/UFPR (Tomas et al., 2016).

\subsubsection{Bathymetry}

The bathymetry of the region is carried out by the Brazilian Navy and is reevaluated approximately every two years. The data are used in the development of new charts and to update the existing ones. The hydrographic surveys follow the guidelines provided by the International Hydrographic Organization (IHO) and this information assists the determination of the river main channel.

In addition to the existing data, bathymetry was also measured in all three joint surveys. The longitudinal measurement was performed in the main navigation channel and is coincident with the path traveled by the hydrographic vessel. The used equipment was a Garmin GPSMAP 521S echo sounder, which provided the depth, latitude, and longitude at every point. As already described, the transversal bathymetry was surveyed using the ADCP equipment for every cross-section.

Detailed bathymetric surveys were concentrated at critical points since the data in those regions are fundamental for the navigability analysis. 


\subsubsection{Discharge}

The Brazilian National Agency for Water (ANA) manages a database with historical river discharge data, obtained from a network of staff gages along the main rivers of Brazil. Later, this information was used for comparative analysis with the results obtained by the ADCP equipment and to calibrate the developed river flow models (Frigo et al., 2015; Correia, 2016). Given the upstream dam construction in the Cuiabá River, the relation between water level and river flow must be reassessed for this region.

\subsubsection{Sediment transport}

Despite not being used as input data in the model, the sediment transport is important to assess long-term navigability condition of rivers. The dynamics of sand shoal formation will determine the location and movement of sediment dunes, the main navigation channel, and costs related to the areas where dredging is necessary.

The sediment sampling was performed in two ways: river bed and suspended sediment transport. The collection points were carried out every 100 kilometers and at the confluence of major tributaries rivers. The bottom sampler collects the sediment moving at the river bed. The suspended sediment sampler collects water samples loaded with sediment suspended in the water column. These samples are filtered and the sediment concentration is obtained by dividing the mass of sediment obtained in the filter and the volume of the sample. The analyzes were performed by researchers of the Federal University of Paraná (ITTI, 2015).

Researchers of the ITTI/UFPR group are researching the sedimentation pattern and morphological variation in the river bed, which may be used to vary the navigation path line and thus applied in the vessel-current model.

\subsection{Navigation modeling}

The vessel-current model was used to analyze the navigation capacity of a $100 \mathrm{~km}$ of the southern stretch of the Paraguay River (Fig. 6.2), from the section km 1500, near the city of Corumbá, to the section km 1400. The main objective of these simulations was to verify if the authorized vessel dimension safely navigate the desired channel path. First, the simulation setup is described, with the necessary input data and parameters variation. Then, the results are presented and discussed. 


\subsubsection{Simulation setup}

As presented in the previous chapter, the vessel-current model requires as input data the velocity field and a navigation path. Both datasets were developed by ITTI/UFPR for the Paraguay River analysis.

A one-dimensional river model for drought condition was modeled (Correia, 2016) using HEC-RAS software (US Army Corps of Engineers, 2006). The drought condition was used given that during this period occurs the formation of sandbanks and the narrowing of the navigation channel. The navigation path, i.e. navigation channel, was designed considering greater depths and the river curvature radius (ITTI, 2015). Furthermore, all simulated regions present lower curvature radius values than those recommended by PIANC (PIANC, 1995)

Figure 6.4 presents a sample of the Paraguay River data: the flow velocity (blue circle), the river distance (green circle) and the navigation path (green stripe). Figure. 6.5 shows the flow velocity magnitude for the study area, where the mean velocity (dashed line) is approximately $0.63 \mathrm{~m} / \mathrm{s}$ in the flow direction.

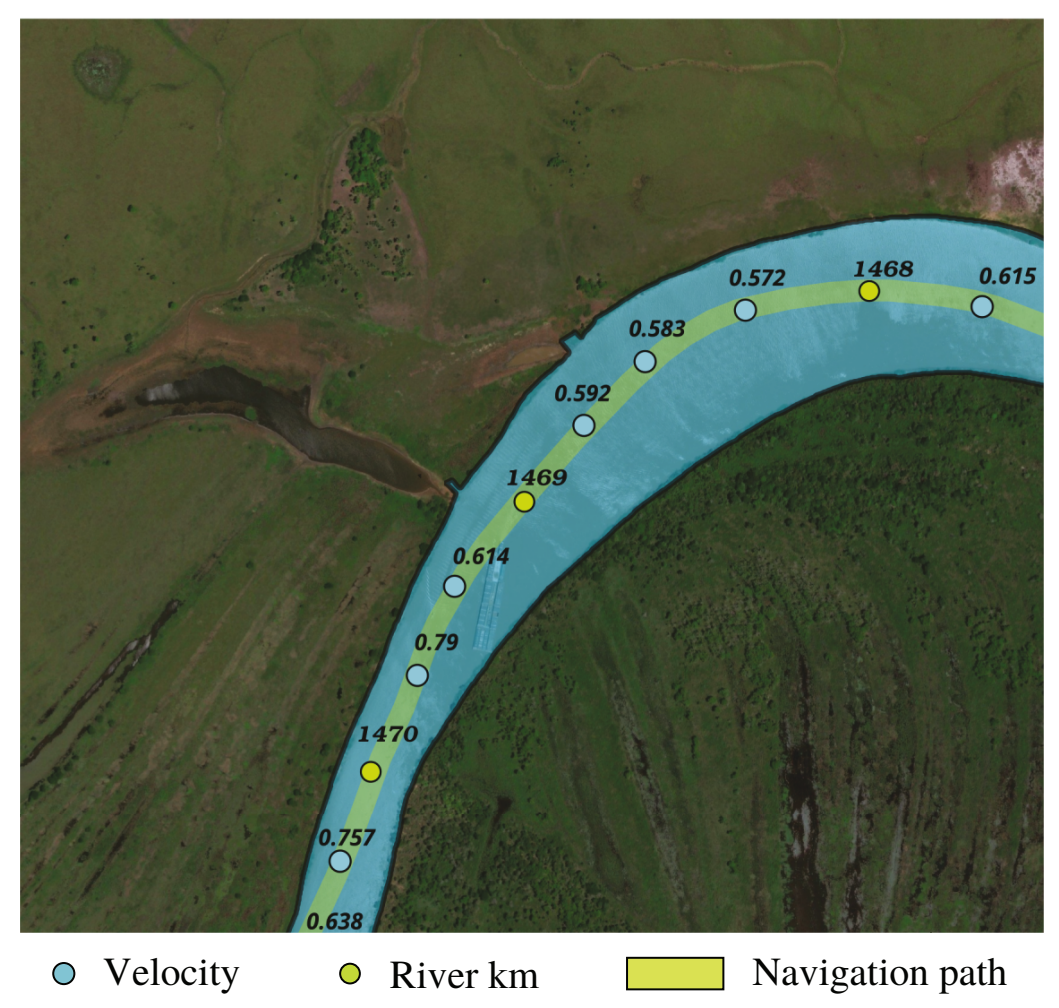

Figure 6.4: Sample of Paraguay River input data: the flow velocity (blue circle), the river distance (green circle) and the navigation path (green stripe).

The vessel characteristics are described in Table 6.1. The ship dimensions are in accordance with the proposed values by the Brazilian Navy for the southern river stretch. 


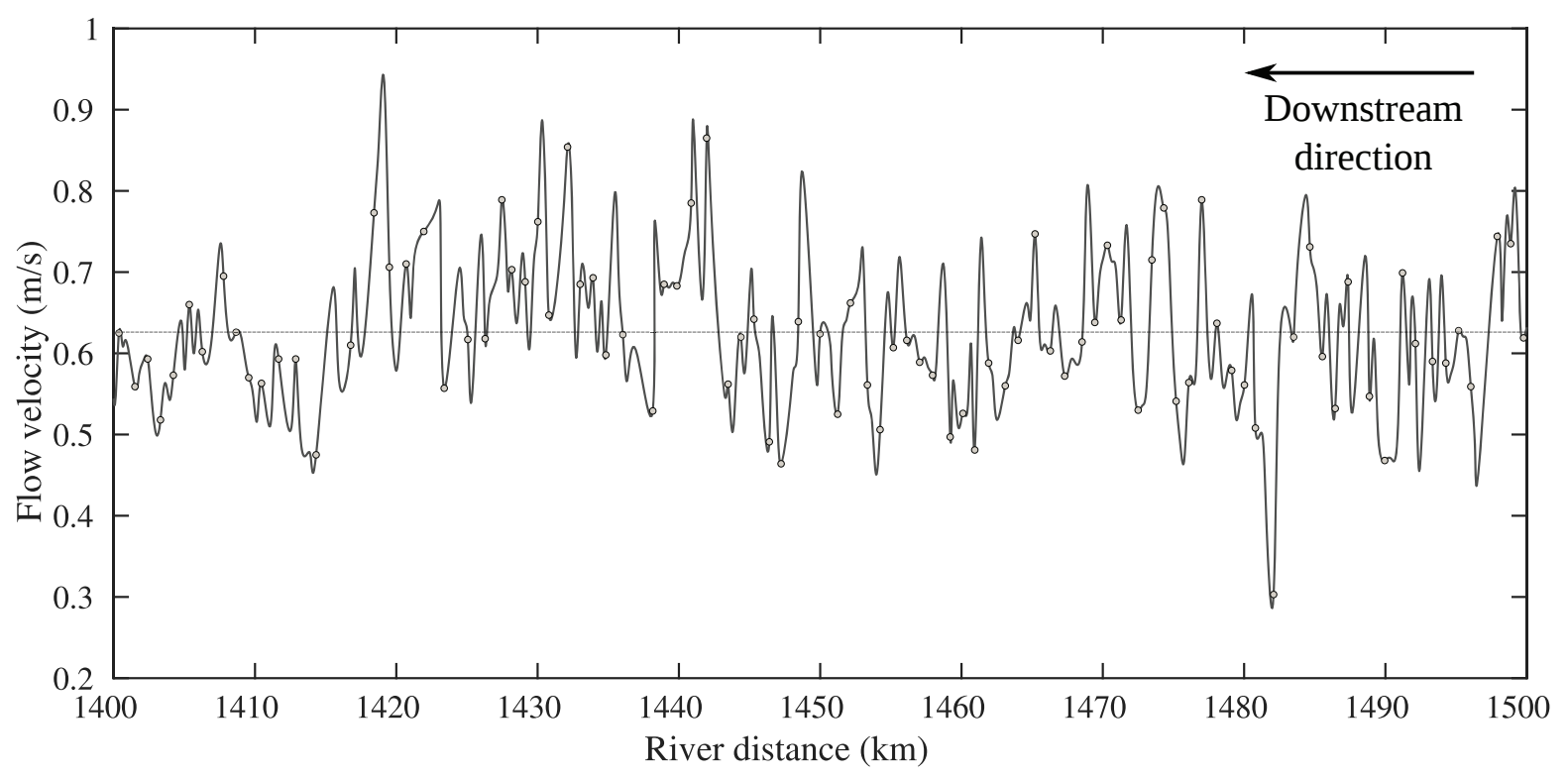

Figure 6.5: Flow velocity magnitude in the study section of the Paraguay River.

Usually, the vessel mean velocity downstream and upstream the waterway is respectively of $3.3 \mathrm{~m} / \mathrm{s}$ and $1.4 \mathrm{~m} / \mathrm{s}$. The mass and engine power were set by a survey in the fleet database. For these simulations, azimuthal thrusters were considered. Furthermore, whenever the vessel resultant velocity is higher than $3.5 \mathrm{~m} / \mathrm{s}$ the auto-pilot system reduces the propulsion so that the velocity remains below the maximum set value.

Table 6.1: Ship parameters setup for Paraguay River simulations.

\begin{tabular}{cc}
\hline Parameter & Description \\
\hline Vessel type & Barge and pushers \\
Engine power & $3 \bullet 10^{3} \mathrm{~kW}$ \\
Length & $200-300 \mathrm{~m}$ \\
Beam & $33 \mathrm{~m}$ \\
Draft & $3 \mathrm{~m}$ \\
Maneuver setup & Azimuth thruster, 90 \\
Maneuver force & {$[25 \%-100 \%]$ Engine force } \\
Mass & $5 \bullet 10^{6} \mathrm{~kg}$ \\
Simulation time & $10^{3} \mathrm{~s}$ \\
Simulation time-step & $0.1 \mathrm{~s}$ \\
\hline
\end{tabular}

The simulation scenarios are the ship modeling in critical regions for navigation in the Paraguay River (Fig. 6.2). Initially, scenario I evaluates the motion response when the vessel maneuver force was set to vary within the range of $50 \%$ to $100 \%$ of its total capacity. Then, in scenario II a ship with the maximum allowed dimension (300 $\mathrm{m} \mathrm{x}$ $33 \mathrm{~m}$ ) was simulated. Finally, scenario III features the navigation analysis of ships with different maximum velocities. 


\subsubsection{Scenario I}

Each navigation path presents plots of the position, velocity and direction of 200 meters long vessels using 50\% (green ships) and 100\% (yellow ships) of maneuver force.

Figure 6.6 presents the simulation for the Santana Pass, between km 1493-1489. This region has 1083.1 meters as the lower value of curvature radius. It was identified that the designed navigation path presented sharp directional variations (km 1490-1491), which impaired the auto-pilot, thus the model navigation. Nevertheless, the yellow vessel (100\%) was able to navigate the remaining section. The vessel that used only $50 \%$ of possible maneuver force was unable to remain within the river margins with the applied velocity.
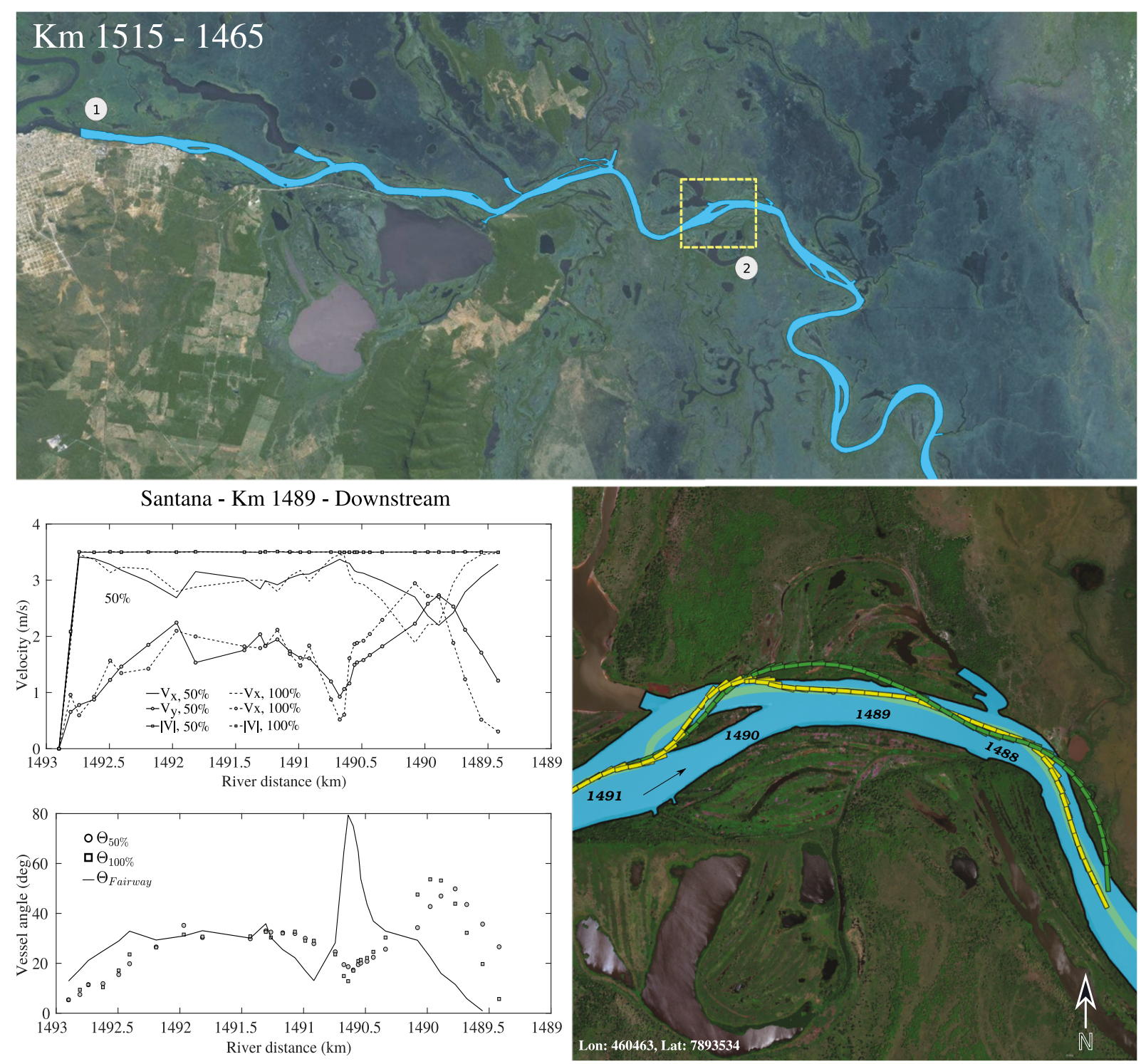

$\square$ Navigation channel

$100 \%$

$50 \%$

Figure 6.6: Scenario I results: downstream navigation at Santana Pass for ships using $50 \%$ (green) and 100\% (yellow) of total maneuver force. The city of Corumbá (1) and the simulated area (2) are also indicated. 
The results for Miguel Henrique Pass is shown in Fig. 6.7, between km 1476-1472. This region has a curve with 373.1 meters as curvature radius, a value 3.75 and 5.36 times lower than the recommended by ITTI (ITTI, 2015) and PIANC (PIANC, 1995) respectively. Although initially navigating satisfactorily, the green vessel (50\% of maneuver force) was unable to make the turn close to $\mathrm{km} \mathrm{1472.} \mathrm{The} \mathrm{vessel} \mathrm{using} \mathrm{the} \mathrm{total} \mathrm{azimuth}$ thruster force was able to maneuver with approximately the maximum speed $(3.5 \mathrm{~m} / \mathrm{s})$.
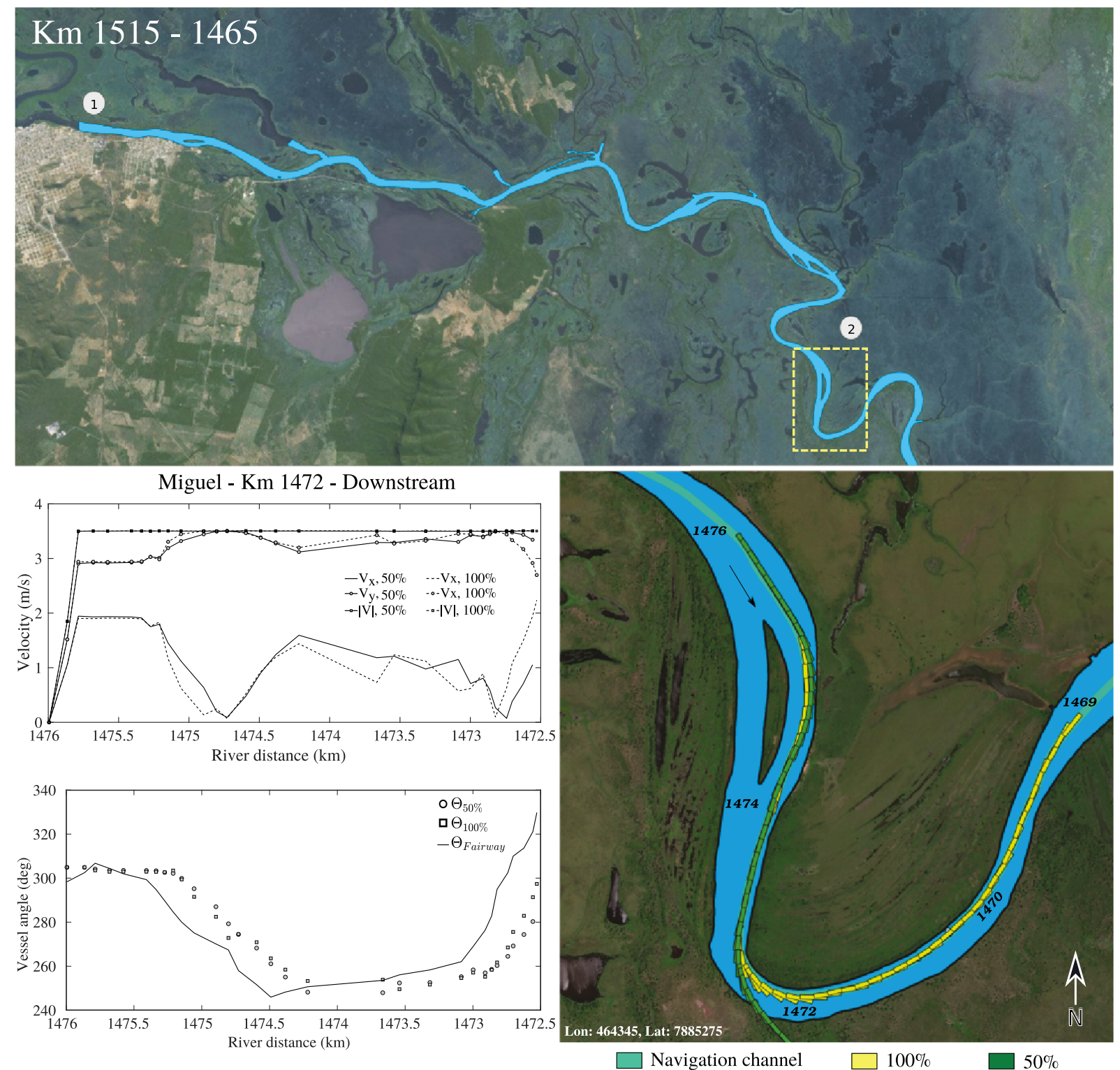

Figure 6.7: Scenario I results: downstream navigation at Miguel Henrique Pass for ships using $50 \%$ (green) and $100 \%$ (yellow) of total maneuver force. The city of Corumbá (1) and the simulated area (2) are also indicated.

The results for the remaining critical sections are shown in Figs. 6.8, 6.9, 6.10, and 6.11. Even though some sections do not meet the required minimum curvature radius (e.g. Mucunã and Abobral), all simulation results presented satisfactory navigation for both 
vessels configuration. In overall, stretches that do not feature great direction variation in curves or in the navigation path design the simulated vessel with lower maneuver capacity was able to navigate with the applied velocity.
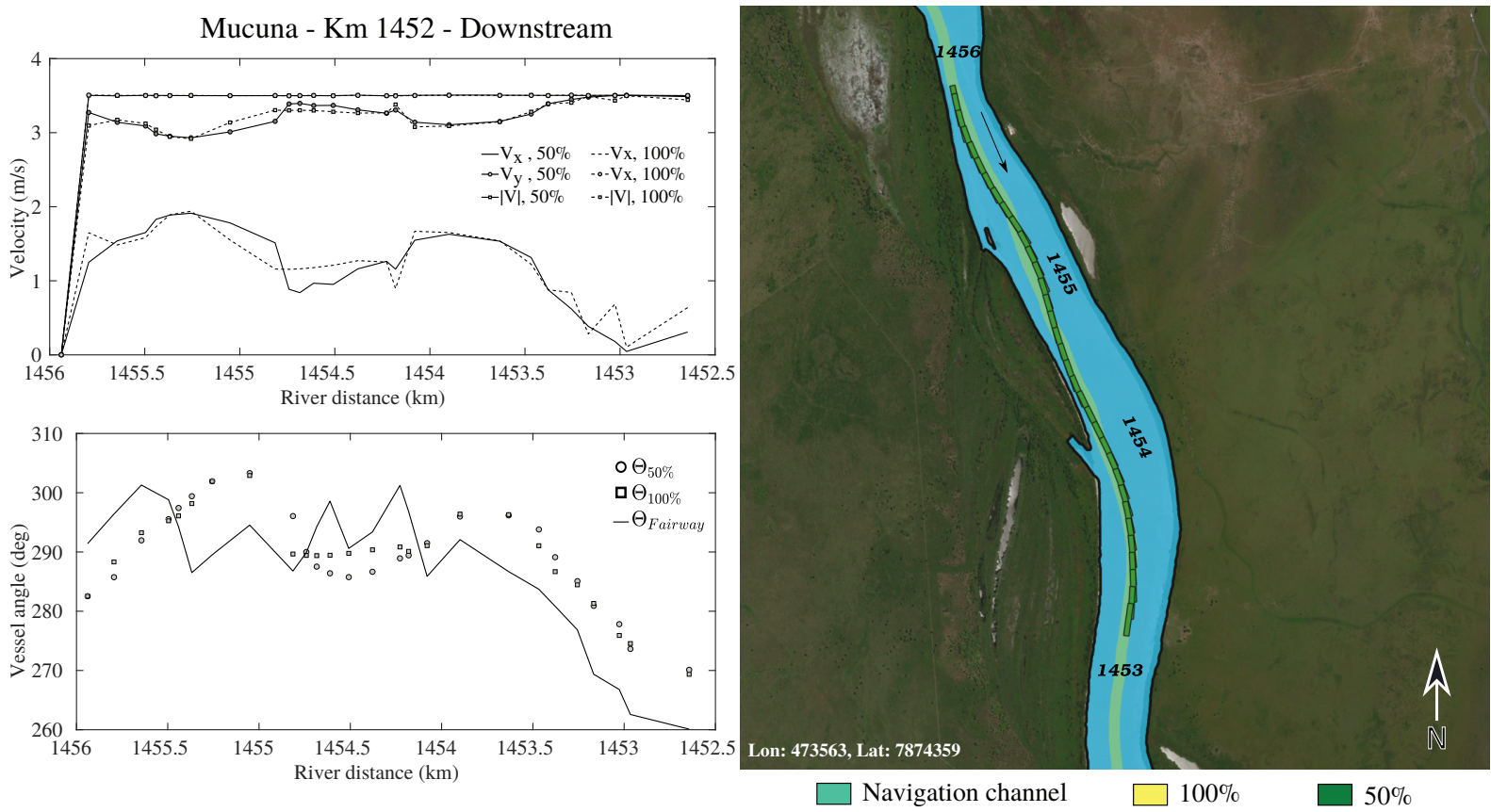

Figure 6.8: Scenario I results: downstream navigation at Mucunã Pass for ships using $50 \%$ (green) and 100\% (yellow) of total maneuver force.
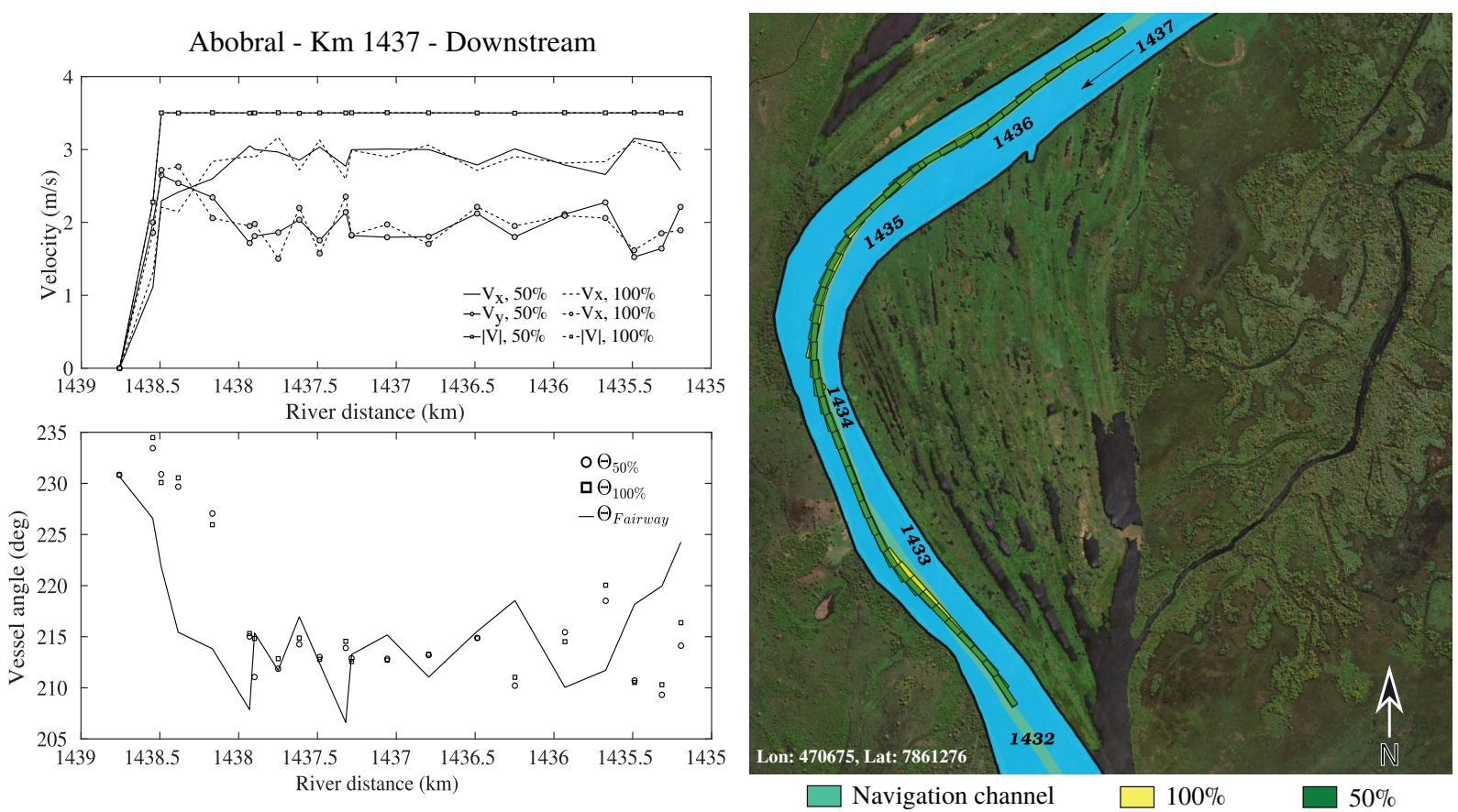

Figure 6.9: Scenario I results: downstream navigation at Abobral Pass for ships using $50 \%$ (green) and $100 \%$ (yellow) of total maneuver force. 

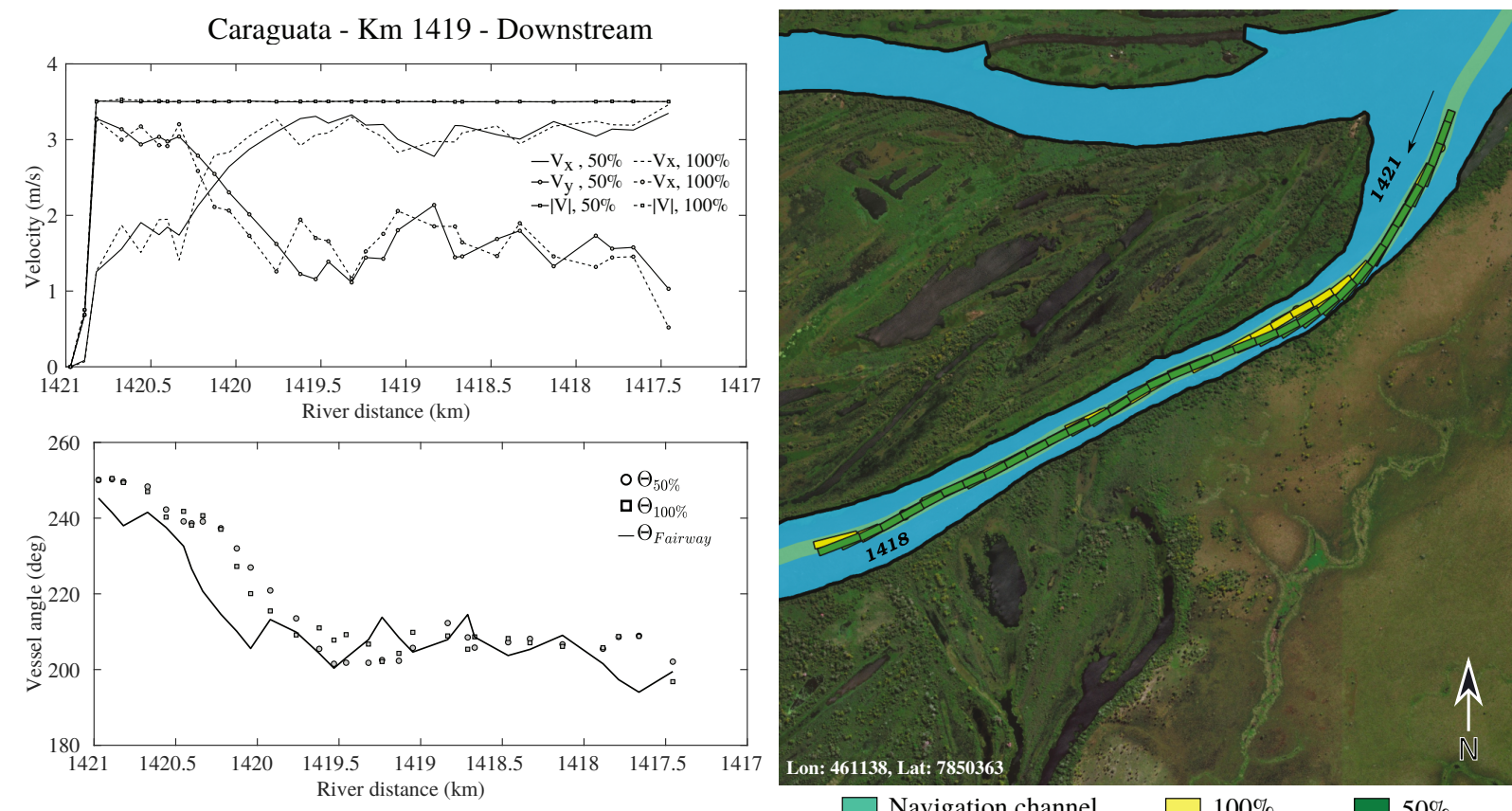

$\square$ Navigation channel

$\square 100 \%$

$50 \%$

Figure 6.10: Scenario I results: downstream navigation at Caraguatá Pass for ships using $50 \%$ (green) and 100\% (yellow) of total maneuver force.
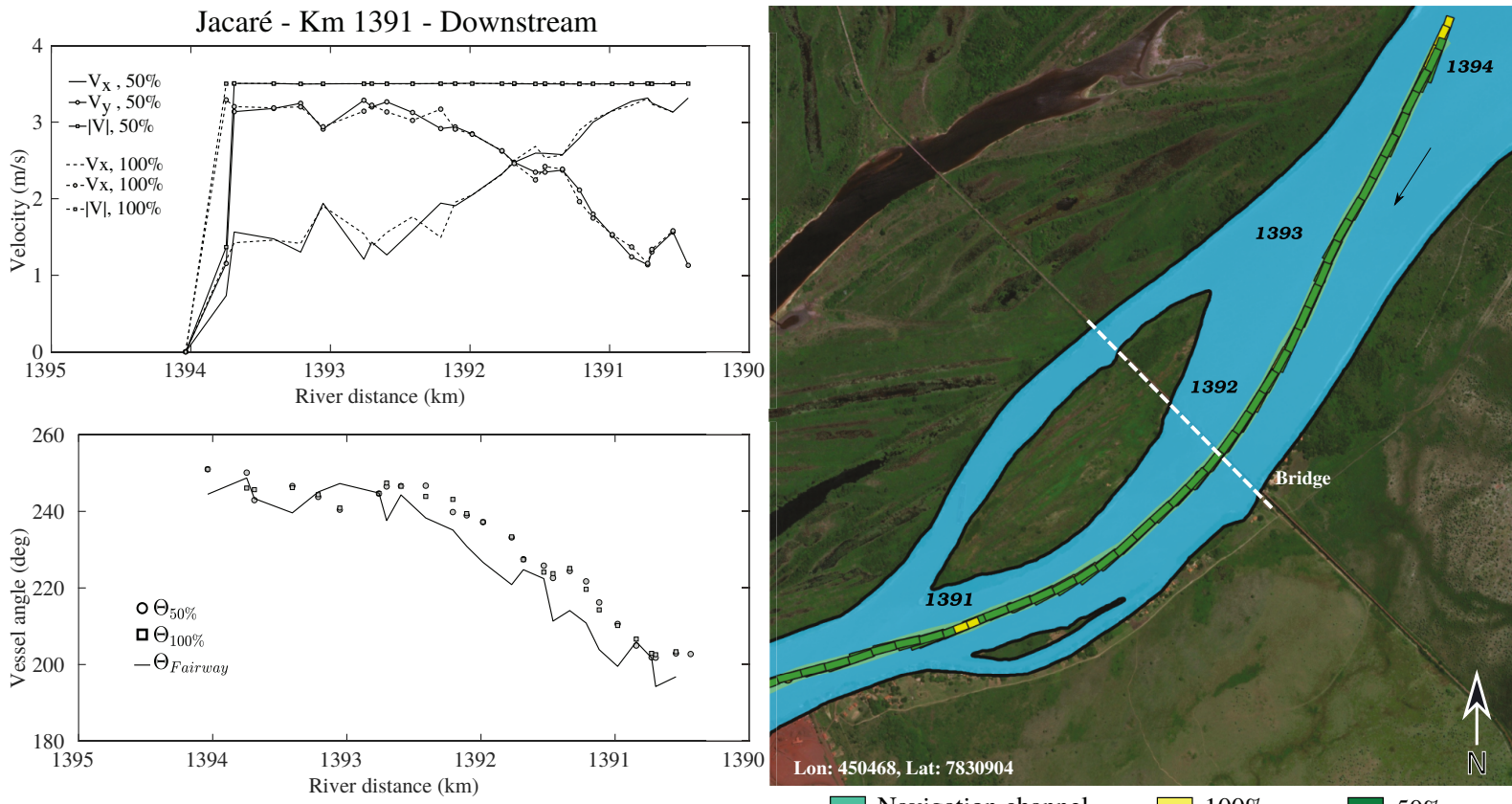

$\square$ Navigation channel

$\square 100 \%$

$50 \%$

Figure 6.11: Scenario I results: downstream navigation at Jacaré Pass for ships using 50\% (green) and 100\% (yellow) of total maneuver force. 


\subsubsection{Scenario II}

The waterways management frequently face the problem of increasing ships dimension and also maintaining the navigation safe. For Miguel Henrique pass and using 100\% of maneuver force capacity, two vessels with different dimensions were simulated. The parameters described in Table 6.1 were used and are the same except for the lengths, where the yellow and red vessel are respectively 200 and 300 meters long.
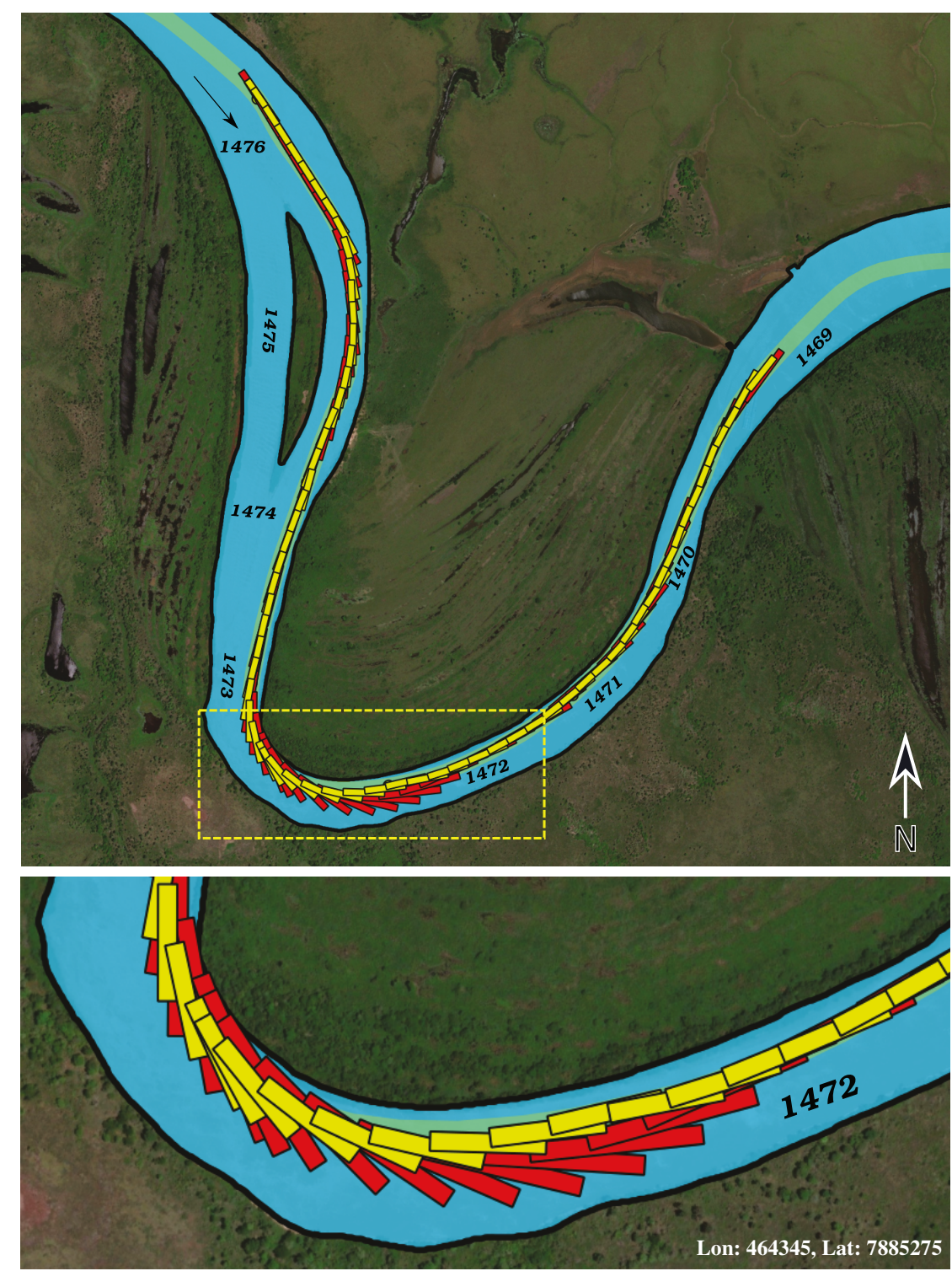

$\square$ Navigation channel

$\square 200 \mathrm{~m}$

$300 \mathrm{~m}$

Figure 6.12: Scenario II results: navigation performance comparison of vessels with different lengths: $200 \mathrm{~m}$ (yellow) and $300 \mathrm{~m}$ (red).

One can observe in Fig. 6.12 that although both vessels were able to perform the maneuver, the red ship had contact with the left bank of the channel and almost totally occupied the river transversally. Furthermore, the upstream traffic would not be possible in this stretch until the complete passage of the larger ship. 


\subsubsection{Scenario III}

This scenario evaluates other parameters that impact the ships maneuvers. Vessels with different azimuth thruster force, overall mass, and maximum velocity were simulated. The used parameters are described in Table 6.2, where the maneuver force and mass are related to the values of Table 6.1. The simulations are shown in Fig. 6.13.

Table 6.2: Summary of ship parameters for scenario III.

\begin{tabular}{lccc}
\hline Model ship & Maneuver force & Velocity & Mass \\
\hline$S_{1}$ - Dark green & $50 \%$ & $3.5 \mathrm{~m} / \mathrm{s}$ & $100 \%$ \\
$S_{2}$ - Blue & $100 \%$ & $4.5 \mathrm{~m} / \mathrm{s}$ & $100 \%$ \\
$S_{3}$ - Yellow & $50 \%$ & $2.5 \mathrm{~m} / \mathrm{s}$ & $100 \%$ \\
$S_{4}$ - Red & $50 \%$ & $3.5 \mathrm{~m} / \mathrm{s}$ & $50 \%$ \\
$S_{5}$ - Light green & $50 \%$ & $2.5 \mathrm{~m} / \mathrm{s}$ & $50 \%$ \\
\hline
\end{tabular}

The dark green ship characteristics are equivalent to scenario I, using only $50 \%$ of possible maneuver force and a mean velocity of $3.5 \mathrm{~m} / \mathrm{s}$. The blue ship used $100 \%$ of maneuver force but its mean velocity was increased to $4.5 \mathrm{~m} / \mathrm{s}$. The yellow vessel navigated with $50 \%$ of maneuver force and its mean velocity was reduced to $2.5 \mathrm{~m} / \mathrm{s}$. For the red ship, a mean velocity of $3.5 \mathrm{~m} / \mathrm{s}$ was defined with $50 \%$ of maneuver force and reduced total mass (50\% of previous ship mass). Finally, the light green vessel features the same characteristics of the red ship but its mean velocity was reduced to $2.5 \mathrm{~m} / \mathrm{s}$.

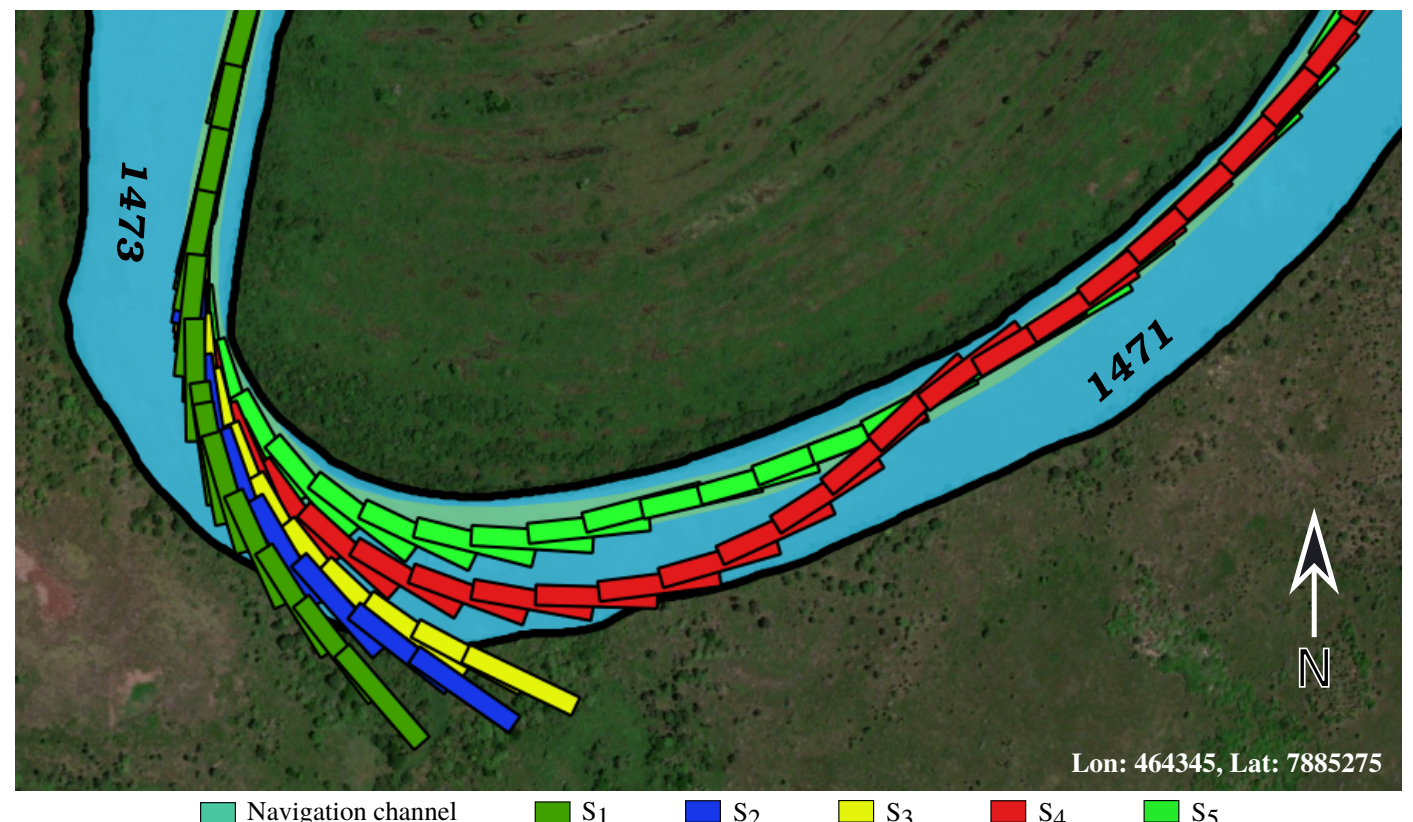

Figure 6.13: Scenario III results: navigation performance of vessels with different characteristics.

According to the results presented in Fig. 6.13, ships that achieved $4.5 \mathrm{~m} / \mathrm{s}$ are 
unfeasible to navigate this stretch, even when $100 \%$ of maneuver force was applied. The navigation using $50 \%$ of total azimuth thruster force was only successful when the vessel total mass was reduced, i.e. red and light green ships. This was also observed for the simulations of the last chapter (Rhine River analysis) and are due to the lower values of inertia moment. Given the lower ship velocity, hence more time to maneuver, $S_{5}$ performed better than $S_{4}$, the navigation occurs closer to the orientation line and did not cross the river transversely.

\subsection{Chapter closure}

Initially in this chapter, a review about the Paraguay River waterway was presented. Due to sedimentation patterns, this region features great morphological variation, which is a challenge for the navigation assessment. Brazilian authorities use excessively restrictive standards and detailed studies are required to optimize navigation.

As part of a project to improve the transportation capacity of Brazilian waterways, field studies were performed to evaluate the main characteristics of the Paraguay River. Thus, bathymetric and velocity field surveys were conducted. These data were necessary to generate computational models of the flow and to determine the navigation channel. Then, simulations using the provided data and the vessel-current model were performed in critical sections of the river. These analyzes allow a better evaluation of the influence of several parameters on the navigability condition and generate information for decision making by the waterway managers. 


\section{Chapter 7}

\section{Conclusions}

As presented in this research, the analysis of specific river parameters such as the morphology or the velocity field can provide relevant indications of its navigation capacity. Nevertheless, only by integrating these characteristics with the ship motion a complete assessment of rivers can be carried out.

The standards and guidelines are fundamental tools for the construction and operation of waterways. However, this approach may not be specific enough in order to optimize some inland navigation channels, which can lead to unnecessary adaptation works and environmental impacts in rivers. These analyzes can be complemented by computer and scale models, which usually present a complex and expensive implementation, requiring a large data set and may be unfeasible for early stages of waterways studies.

The proposed two-dimensional vessel-current model used a system of analytical equations to couple the parameters responsible for the vessel motion. This approach can be considered simpler than the use of numerical methods. Still, it allows a fast assessment using fewer data and for different scenarios of rivers and ships. Whenever data is available, one can easily vary project specifications and evaluate the impacts on navigation.

The model was verified using real telemetry data of the Rhine River. These studies allowed a thorough verification of the algorithm. Using the parameters of real ships, the model was able to satisfactorily reproduce the motion patterns. In addition, it was also used to validate new theoretical routes for navigation and evaluate the influence of different parameters.

The Paraguay River is part of a major project for the modernization of the Brazilian waterway system, where the standards being used are considered overly restrictive, nonetheless, commercial navigation is occurring. The vessel-current model was applied to the analysis of critical sections for navigation. Regarding the river features, it was 
observed that the curvature radius and the orientation path design are the factors that can limit navigation. As expected, vessels have difficulty navigating in regions with small curvature radius, i.e. sharp direction variation. In relation to the ships, due to the lower angular velocity or to the time to perform curves, heavier and faster ships require greater maneuverability capacity. Also, according to the model result, vessels with the maximum permitted dimensions are able to navigate the simulated section. However, it is necessary to observe possible restrictions that can occur for the traffic in the opposite direction, since these ships can occupy the entire channel width during maneuvers. For these cases, a traffic management system is required.

The model can be a useful tool to assist the analysis for the construction and management of internal waterways, but its application is limited to the considered hypotheses. Thus, some aspects regarding its application are emphasized in the following:

$\leq$ In relation to the considered dimensions, the two-dimensional approach is only valid for regions where the occurrence of waves can be disregarded. The presence of strong vertical components can generate instabilities for navigation that are not measured by the model.

$\leq$ The parameters that influence the navigation must be measured in a rigorous way and avoiding subjective analysis. When vessel parameters are unknown, one can use average and typical values from databases. Also, calibration processes can be used to enhance the results.

$\leq$ The bathymetry does not affect directly the model performance, however, it should be used for the determination of the navigational channel design, i.e. orientation path. One must ensure that the simulated vessel navigates as close as possible to the orientation path, which guarantees that the water level is sufficient for the passage of the ships.

$\leq$ Special attention should be given to the auto-pilot system since there is a tendency for the use of autonomous vehicles in a near future. The auto-pilot can be easily improved by the addition of new maneuvering rules.

$\leq$ Finally, the model is open source and one can edit or add new features in the user interface and even in the core algorithm. 


\section{Next steps and perspectives}

This research still has aspects that can be further discussed or investigate. The following points are highlighted as recommendations for future works following this study:

$\leq$ Research on different methods to estimate the force coefficients and compare the model results with specific small-scale studies.

$\leq$ Investigate and implement in the model the resistance effects of new forces such as wind and waves for ships navigating inland waterways.

$\leq$ Study the effects on maneuverability due to the separation distance between shipto-ship and ship-to-margins.

$\leq$ Use the model to vary the ship and river parameters and establish new safety thresholds for inland waterways navigation.

$\leq$ Using the auto-pilot system and all possible river information, develop and implement a machine-learning algorithm to define the best navigation maneuvers and routes.

$\leq$ Optimize the model algorithm to perform calculations more quickly and with less memory usage.

$\leq$ Develop a more intuitive and practical user framework to configure and evaluate simulations. 


\section{Bibliography}

Abbot, I. H. (1932). The drag of two streamline bodies as affected by protuberances and appendages. Technical Report 451, National Advisory Committee for Aeronautics NACA.

ABNT (1995). NBR 13.246: Planejamento portuário aspectos náuticos. Technical report, Associação Brasileira de Normas Técnicas.

Almeida, C. E. and Brigghetti, G. (1997). Navegação interior e portos marítimos (In Portuguese). Technical report, EPUSP.

ANEEL (2014). Banco de informações de geração (In Portuguese). Technical report, Agência Nacional de Energia Elétrica - ANEEL.

ANTAQ (2012). Anuário estatístico aquaviário (In Portuguese). Technical report, Agência Nacional dos Transportes Aquiaviários - ANTAQ.

ANTAQ (2016). Desempenho do setor aquaviário 2016 (In Portuguese). Technical report, Agência Nacional dos Transportes Aquiaviários - ANTAQ.

Assine, M. L. (2005). River avulsion on the Taquari megafan, Pantanal wetland, Brazil. Geomorphology, 70(3):357371.

BAW (2007). Competence for waterways. Technical report, Bundesanstalt für Wasserbau - BAW.

BAW (2009). Impact of climate change on waterways and navigation. Technical report, Bundesanstalt für Wasserbau - BAW.

BAW (2012). Automatisierte abfluss und stauzielregelung (in German). Technical Report 96, Bundesanstalt für Wasserbau - BAW.

Benedict, K., Fischer, S., Gluch, M., Kirchhoff, M., Schaub, M., Baldauf, M., and Müller, B. (2017). Innovative fast time simulation tools for briefing / debriefing in advanced 
ship handling simulator training and ship operation. Transactions on Maritime Science, $6(1): 24-38$.

Blaauw, H. G. and Verhey, H. J. (1983). Design of inland navigation fairways. Journal of Wateway Port, Coastal, Ocean Engineering, 109:18-30.

Brennen, C. E. (1982). A review of added mass and fluid inertial forces. Technical report, Naval Civil Engineering Laboratory.

Brevoort, M. J. and Joyner, U. T. (1935). Experimental investigation of the Robinson type cup anemometer. Technical Report 513, National Advisory Committee for Aeronautics - NACA.

Briggs, M. J., Borgman, L. E., and Bratteland, E. (2003). Probability assessment for deep-draft navigation channel design. Coastal Engineering, 48:29-50.

Brunner, G. W. and Gibson, S. (2005). Sediment transport modeling in HEC-RAS. In Impacts of Global Climate Change, pages 1-12.

Cardoso, A. H. (1998). Hidráulica fluvial. Calouste Gulbenkian, 1st edition.

Chen, Q. and Mynett, A. E. (2006). Modelling algal blooms in the dutch coastal waters by integrated numerical and fuzzy cellular automata approaches. Ecological Modelling, 199(1):73-81.

Chow, V. T., Maidment, D. R., and Mays, L. W. (1988). Applied Hydrology. McGraw-Hill, 1st edition.

Clarke, R. T., Tucci, C. E. M., and Collischonn, W. (2003). Variabilidade Temporal no Regime Hidrológico da Bacia do Rio Paraguai. Revista Brasileira de Recursos Hídricos, $8(1): 201211$.

Collischonn, W., Tucci, C. E. M., and Clarke, R. T. (2001). Further evidence of changes in hydrological regime of the River Paraguay: part of a wider phenomenon of climate change? Journal of Hydrology, 245:218-238.

Constantine, T. (1960). On the movement of ships in restricted waterways. Journal of Fluid Mechanics, 9(2):247-256.

Correia, R. (2016). Utilização de dados topo-batimétricos para a modelagem hidrodinâmica integrada a um sistema de informação geográfica - estudo de caso do rio Paraguai (In portuguese). Master's thesis, Federal University of Paraná. 
Costa, L. S. S. (2001). As hidrovias interiores no Brasil (in Portuguese). Femar, 2nd edition.

Delefortrie, G., Vantorre, M., Eloot, K., Verwilligen, J., and Lataire, E. (2010). Squat prediction in muddy navigation areas. Ocean Engineering, 37:1464-1476.

Deltares (2014). Delft3D-FLOW technical manual. Deltares.

EDF (2014). Telemac modelling system. EDF-R\&D.

Elias, E., Walstra, D., Roelvink, J., Stive, M., and Klein, M. (2001). Hydrodynamic validation of Delft3D with field measurements at Egmond. Coastal Engineering, 1:27142727.

Ellignton, C. P., van den Berg, C., Willmott, A. P., and Thomas, A. L. R. (1996). Leadingedge vortices in insect flight. Nature, 384(19/26):626-630.

EPL (2016). Transporte inter-regional de carga no Brasil, Panorama 2015 (in Portuguese). Technical report, Empresa de Planejamento e Logística - EPL.

Eurostat (2007). Inland waterways freight transport in Europe in 2006. Technical Report $132 / 2007$, Eurostat.

Fan, C., Ko, C. H., and Wang, W. S. (2009). An innovative modeling approach using Qual2K and HEC-RAS integration to assess the impact of tidal effect on river water quality simulation. Journal of Environmental Management, 90(1824-1832).

Feynman, R., Leighton, R. B., and Sands, M. (1964). The Feynman Lectures on Physics. Addison-Wesley Publishing Company, 1st edition.

Fitriadhy, A., Yasukawa, H., and Koh, K. (2013). Course stability of a ship towing system in wind. Ocean Engineering, 64:135 - 145.

Fox, R. W., McDonald, A. T., and Pritchard, P. J. (2011). Introduction to Fluid Mechanics. Wiley, 8th edition.

Freeman, H. B. (1932). Force measurement on a 1/40-scale model of the U.S.Airship Akron. Technical Report 432, NACA.

Frigo, A., Tomas, G., Golyjeswski, O., Bleninger, T., Correia, R., Ratton, P., Barsotti, H., Guarneri, H., Waydzik, F., Hoepker, R., Ratton, E., and Godoy, P. (2015). Analysis of the navigability condition of the Paraguay River waterway. In XXI Simpósio Brasileiro de Recursos Hídricos. ABRH. 
Gamaro, P. E. M. (2012). Medidores acústicos doppler de vazão. Itaipu Binacional, 1st edition.

Gerent, J. P. and Alfredini, P. (2010). A simulação não analógica de manobras não tripuladas de navios na otimização de projeto e operações portuárias (In Portuguese). Technical Report BT/PHD/209, USP.

Goett, H. J. and Bullivant, W. K. (1938). Tests of NACA 0009, 0012 and 0018 airfoils in the full-scale tunnel. Technical Report 647, National Advisory Committee for Aeronautics - NACA.

Gourlay, T. (2009). Sinkage and trim of two ships passing each other on parallel courses. Ocean Engineering, 36:1119-1127.

Graewe, H. (1971). Beitrag zur Frage der Bemessung von Fahrwasser Verbreiterungen in Kanal und Flusskrümmungen (in German). Die Bautechnick.

Graf, W. H. (1984). Hydraulic of sediment transport. Water Resources Publications.

Greenberg, M. D. (1998). Advanced engineering mathematics. Prentice-Hall, 2nd edition.

Guarneri, H., Correia, R., Ratton, P., and Bleninger, T. (2016). Avaliações preliminares referentes a caracterização de raios de curvatura de rios para o planejamento de hidrovias interiores (in Portuguese). In 26th SOBENA. SOBENA.

Harlacher, D. (2016a). Assessment procedure of the trafficability of inland waterways. Procedia Engineering, 154(Supplement C):146 - 153. 12th International Conference on Hydroinformatics (HIC 2016) - Smart Water for the Future.

Harlacher, D. (2016b). Beurteilung, Bewertung und flächige Visualisierung der Befahrbarkeit von Binnenwasserstrassen (in German). PhD thesis, Universität DuisburgEssen.

Harlacher, D., Zentgraf, R., and Dettmann, T. (2015). Investigation of the capsize of a tank motor ship by means of an inland ship handling simulator. Journal of Applied Water Engineering and Research, 3(2):95-104.

Haupt, L. M. (1890). Canals and their economic relation to transportation. American Economic Association, 5(3/4):61-85.

Haupt, L. M. (1908). The waterway problem. Journal of the Franklin Institute, $165(5): 326-344$. 
Haupt, L. M. (1909). The nation and the waterways. Proceedings of the American Philosophical Society, 48(191):51-64.

Henderson, F. M. (1966). Open channel flow. Prentice Hall PTR, 2th edition.

Henning, M., Hentschel, B., and Dettmann, T. (2007). Evaluation of river bed geometry under nautical aspects by application of a $2 \mathrm{~d}$ hn routing program. Publs. Inst. Geophys. Pol. Acad. Sc., E-7 (401).

Hoerner, S. F. (1965). Fluid-Dynamic Drag. 2nd edition.

Horritt, M. S. and Bates, P. D. (2002). Evaluation of 1D and 2D numerical models for predicting river flood inundation. Journal of Hydrology, 268:87-99.

Hu, K., Pingxing Ding and, Z. W., and Yang, S. (2009). A 2D/3D hydrodynamic and sediment transport model for the Yangtze Estuary, China. Journal of Marine Systems, $77: 114-136$.

Hüsing, A., Linke, T., and Zimmermann, C. (2000). Effects from supercritical ship operation on inland canals. Journal of Waterway, Port, Coastal and Ocean Engineering, 126:130-135.

Ince, A. N. and Topuz, E. (2004). Modelling and simulation for safe and efficient navigation in narrow waterways. The Journal of Navigation, 57:53-71.

INEA (2016). List of operational profiles and fleet families. Technical Report D1.1, Innovation and Networks Exceutive Agency.

Innocencio, N. R. (1988). Geografia do Brasil. IBGE.

International Convention on Tonnage Measurements of Ships (1969).

ITTC (1957). 8th International towing tank conference. Technical report, ITTC.

ITTI (2014). Estudo de viabilidade técnica, econômica e ambiental da hidrovia do Rio Paraguai - Levantamento batimétrico longitudinal (In Portuguese). Technical report, Instituto Tecnológico de Transportes e Infraestrutura - ITTI.

ITTI (2015). EVTEA da hidrovia do rio Paraguai. Estudos hidráulicos, hidrodinâmicos, de balizamento e sinalização (In Portuguese). Technical Report Volume 3A, Instituto Tecnológico de Transportes e Infraestrutura - ITTI.

Kalos, M. and Whitlock, P. (2009). Monte Carlo Methods. Wiley. 
Kirchhoff, G. R. (1869). Uber die Bewegung eines Rotationskörpers in einer Flüssigkeit (in German). Journal für die reine und angewandte Mathematik, 71:237-262.

Kodama, Y., Kakugawa, A., Takahashi, T., and Kawashima, H. (2000). Experimental study on microbubbles and their applicability to ships for skin-friction reduction. International Journal of Heat and Fluid Flow, 21:582-588.

Kolarov, P. (2006). Simulation von schiffsbewegungen in fliessgewässern. PhD thesis, Universität Rostock.

Kornev, N. (2013). Lectures on ship manoeuvrability. Bookboon, 1st edition.

Kume, K., Hasegawa, J., Tsukada, Y., Fujisawa, J., Fukasawa, R., and Hinatsu, M. (2006). Measurements of hydrodynamic forces, surface pressure, and wake for obliquely towed tanker model and uncertainty analysis for CFD validation. Marine Science and Technology, 11:65-75.

Kundu, P. (1990). Fluid Mechanics. Academic Press.

Lane, S. N., Biron, P. M., Bradbrook, K. F., Butler, J. B., Chandler, J. H., Crowell, M. D., Mcelland, S. J., Richards, K. S., and Roy, A. G. (1998). Three-dimensional measurements of river channel flow processes using acoustic Doppler velocimetry. Earth Surface Processes and Landforms, 23:1247-1267.

Lane, S. N., Bradbrook, K. F., Biron, K. S. R. P. A., and Roy, A. G. (1994). The application of computational fluid dynamics to natural river channels: three-dimensional versus two-dimensional approaches. Geomorphology, 29:1-20.

Lane, S. N., Parsons, D. R., Best, J. L., Kostaschuk, O. O. R. A., and Hardy, R. J. (2008). Causes of rapid mixing at a junction of two large rivers: Rio Paraná and Rio Paraguay, Argentina. Journal of Geophysical Research, 113:1-16.

Lataire, E., Vantorre, M., and Delefortrie, G. (2012). A prediction method for squat in restricted and unrestricted rectangular fairways. Ocean Engineering, 55:71-80.

Lesser, G. R., Roelvink, J. A., van Kester, J. A. T. M., and Stelling, G. S. (2004). Development and validation of a three-dimensional morphological model. Coastal Engineering, 51:883-915.

Lindsey, W. F. (1938). Drag of cylinders of simple shapes. Technical Report 619, National Advisory Committee for Aeronautics - NACA. 
Linke, T., Rauscher, D., and Söhngen, B. (2015). Recent developments in the application of shallow water ship hydrodynamics in inland waterway design. In Smart Rivers 2015.

Lissaman, P. B. S. (1983). Low Reynolds-Number airfoils. Ann. Rev. Fluid Mech., 15:223239.

Macmahan, J. and Reniers, A. (2010). River flow observations and modeling: sensitivity of Delft3D river model to bathymetric variability. Technical report, Oceanography Department, Naval Postgraduate School.

MacMillan, W. D. (1936). Dynamics of rigid bodies. McGraw-Hill, 1st edition.

Magirl, C. S. and Olsen, T. D. (2009). Navigability potential of washington rivers and streams determined with hydraulic geometry and geographic information system. Scientific investigation report 2009-5122, U.S. Geological Survey.

Marinha do Brasil (2006). Normas e procedimentos da Capitania Fluvial do Pantanal: NPCF (in Portuguese). Technical report, Marinha do Brasil.

Marinha do Brasil (2016). CHM-DHN - Avisos aos navegantes: Hidrovia Paraguai-Paraná (in Portuguese). Technical report, Marinha do Brasil.

McCartney, B. L. (1986). Inland waterway navigation project design. Journal of Waterway, Port, Coastal and Ocean Engineering, 112(6):1-13.

Merwade, V. (2009). Effect of spatial trends on interpolation of river bathymetry. Journal of Hydrology, 371:169-181.

Milgram, J. H. (1998). Fluid mechanics for sailing vessel design. Annual Review of Fluid Mechanics, 30:613-653.

Min, K.-S. and Kang, S.-H. (2010). Study on the form factor and full-scale ship resistance prediction method. Journal of marine science and technology, 15(2):108-118.

Ministério do Desenvolvimento (2015). Balança comercial Brasileira - 2015 (in Portuguese). Technical report, Ministério do Desenvolvimento, Indústria e Comércio Exterior.

Ministério dos Transportes (2013). Plano hidroviário estratégico (in Portuguese). Technical report, Ministério dos Transportes.

Moctar, O. e., Shigunov, V., and Zorn, T. (2012). Duisburg test case: Post-panamax container ship for benchmarking. Ship Technology Research, 59(3):50-64. 
Morris, W. J. and Rusak, Z. (2013). Stall onset on aerofoils at low to moderately high Reynolds number flows. Journal of Fluid Mechanics, 733:439472.

Padovezi, C. D. (2003). Conceitos de embarcações adaptadas à via aplicado à navegação fluvial no Brasil (in Portuguese). PhD thesis, Escola Politécnica de São Paulo - USP.

PIANC (1992). Capability of ship manoeuvring simulation models for approach channels and fairways in harbours. PIANC General Secretariat.

PIANC (1995). Approach Channels - Preliminary Guidelines. PIANC General Secretariat.

PIANC (1996). Standardisation of Ships and Inland Waterways for River and Sea Navigation. PIANC General Secretariat.

PIANC (2002). Vessel traffic and transport management in the inland waterways and modern information systems. PIANC General Secretariat.

PIANC (2011). Performance indicators for inland waterways transport User Guideline. PIANC General Secretariat.

PNLT (2012). Projeto de reavaliação de estimativas e metas do PNLT (in Portuguese). Technical report, Plano Nacional de Logística e Transporte - PLNT.

Prandtl, L. (1904). Über Flüssigkeitsbewegung bei sehr kleiner Reibung (in German). In Verfahren des III Internationalen Kongress für Mathematik, Heidelberg, pages 484-491.

Rijn, L. C. V. (2007). Unified view of sediment transport by currents and waves. Journal of Hydraulic Engineering, 133(6):649-667.

Roberson, J. A. and Crowe, C. T. (1993). Engineering Fluid Mechanics. Houghton Mifflin, 5th edition.

Rubinstein, R. and Kroese, D. (2016). Simulation and the Monte Carlo Method. Wiley Series in Probability and Statistics. Wiley.

Salençon, J. (2001). Handbook of continuum mechanics, volume I. Springer.

Schlichting, H. (1966). Boundary-layer theory. McGraw-Hill, 6th edition.

Sen, D. T. and Vinh, T. C. (2016). Determination of added mass and inertia moment of marine ships moving in 6 degrees of freedom. International Journal of Transportation Engineering and Technology, 2(1):8-14. 
Sequera, A. (1994). Navier-Stokes equations and related nonlinear problems. Plenum Press, 1st edition.

Skaggs, L. and Bastian, D. F. (1986). Annotated bibliography of vessel simulation studies used in channel design. Technical report, US Army Corps of Engineers.

SonTek (2010). RiverSurveyor S5/M9 system manual. SonTek.

Szupiany, R. N., Amsler, M. L., Best, J. L., and Parsons, D. R. (2007). Comparision of fixed and moving-vessel flow measurements with an aDp in a large river. Journal of Hydraulic Engineering, 133:1299-1309.

Timoshenko, S. and Young, D. H. (1948). Advanced dynamics. McGraw-Hill, 1st edition.

Tomas, G. P., Hopker, R., Frigo, A. L., and Bleninger, T. B. (2016). Velocity mapping toolbox for Sontek M9 ADCP data. In River Flow, volume 1. River Flow.

Toxopeus, S. L. (2006). Validation of slender-body method for prediction of linear manoeuvring coefficients using experiments and viscous flow calculations. In 7th International Conference on Hydrodynamics.

Tucci, C. E. M. (2009). Some scientific challenges in the development of South America's water resources. Hydrological Science Journal, 46(6):937-946.

Tucker, V. A. (1993). Gliding birds: reduction of induced drag by wings tip slots between the primary feathers. Journal of Experimental Biology, 180:285-310.

US Army Corps of Engineers (2006). HEC-RAS River Analysis System, Users Manual Version 4.0. US Army Corps of Engineers, Hydrologic Engineering Center.

Usta, O. and Korkut, E. (2013). A study for the effect of surface roughness on resistance characteristics of flat plates. In Marine Coatings. The Royal Institution of Naval Architects.

Varyani, K. S. (2006). Squat effects on high speed craft in restricted waterways. Ocean Engineering, 33(3):365-381.

Venditti, J. G., Rennie, C. D., Bomhof, J., Bradley, R. W., Little, M., and Church, M. (2014). Flow in bedrock canyons. Nature, 513:534-536.

von Graefe, A., Shigunov, V., and el Moctar, O. (2015). Rankine source method for shipship interaction problems. Journal of Offshore Mechanics and Arctic Engineering, 137(2):1-10. 
Williams, R. D., Brasington, J., Hicks, M., Measures, R., Reannie, C. D., and Vericat, D. (2013). Hydraulic validation of two-dimensional simulations of braided river flow with spatially continuous ADCP data. Water Resources Research, 49:5183-5205.

World Bank (2010). How to decrease freight logistics costs in Brazil. Technical Report 46885-BR, World Bank, Sustainable Development Department, Brazil Country Management Unit, Latin America and the Caribbean Regional Office.

WSV (2016). Elektronischer Wasserstrassen-Informationsservice - ELWIS (in German). Technical report, Wasser und Schifffahrtsverwaltung des Bundes - WSV.

Xiong, Y. F. (2011). A dam break analysis using HEC-RAS. Journal of Water Resource and Protection, 3:370-379.

Zentgraf, R. and Dettmann, T. (2010). River rhine-hydraulic and ship dynamic modelling. River Flow.

Zhao, D. H., Shen, H. W., Tabios, G. Q., Lai, J. S., and Tan, W. Y. (1994). Finitevolume two-dimensional unsteady-flow model for river basins. Journal of Hydraulic Engineering, 120(7):863883. 


\section{Appendix A}

\section{PIANC navigation channel width calculation}

As presented in chapter 2, the following tables are required in the calculation of the navigation channel width according to PIANC (1995).

Table A.1: Additional width due to the ship maneuverability capacity.

\begin{tabular}{ccc}
\hline Maneuverability & Maneuverability coefficient & Additional width \\
\hline Excellent & 1.3 & $1.3 \mathrm{~B}$ \\
Good & 1.5 & $1.5 \mathrm{~B}$ \\
Bad & 1.8 & $1.8 \mathrm{~B}$ \\
\hline
\end{tabular}

Table A.2: Additional width due to the ship velocity.

\begin{tabular}{cc}
\hline Ship mean velocity $(\mathrm{Kn})$ & Additional width \\
\hline High $(>12)$ & $0.1 \mathrm{~B}$ \\
Moderate $(8-12)$ & $0.0 \mathrm{~B}$ \\
Low $(5 \quad 8)$ & $0.0 \mathrm{~B}$ \\
\hline
\end{tabular}

Table A.3: Additional width due to the wind intensity.

\begin{tabular}{cccc}
\hline \multirow{2}{*}{ Wind intensity $(\mathrm{kn})$} & \multicolumn{3}{c}{ Ship mean velocity } \\
\cline { 2 - 4 } & High & Moderate & Low \\
\hline Low $(<15)$ & $0.0 \mathrm{~B}$ & $0.0 \mathrm{~B}$ & $0.0 \mathrm{~B}$ \\
Moderate $(15-33)$ & - & $0.4 \mathrm{~B}$ & $0.5 \mathrm{~B}$ \\
High $(>33)$ & - & $0.8 \mathrm{~B}$ & $1.0 \mathrm{~B}$ \\
\hline
\end{tabular}


Table A.4: Additional width due to the transversal current velocity.

\begin{tabular}{cccc}
\hline \multirow{2}{*}{ Current intensity $(\mathrm{Kn})$} & \multicolumn{3}{c}{ Ship mean velocity } \\
\cline { 2 - 4 } & High & Moderate & Low \\
\hline Negligible $(<0.2)$ & $0.0 \mathrm{~B}$ & $0.0 \mathrm{~B}$ & $0.0 \mathrm{~B}$ \\
Low $(0.2-0.5)$ & - & $0.1 \mathrm{~B}$ & $0.2 \mathrm{~B}$ \\
Moderate $(0.5-1.5)$ & - & $0.5 \mathrm{~B}$ & $0.8 \mathrm{~B}$ \\
High $(\approx 1.5)$ & - & - & - \\
\hline
\end{tabular}

Table A.5: Additional width due to the longitudinal current velocity.

\begin{tabular}{cccc}
\hline \multirow{2}{*}{ Current intensity $(\mathrm{Kn})$} & \multicolumn{4}{c}{ Ship mean velocity } \\
\cline { 2 - 4 } & High & Moderate & Low \\
\hline Low $(\geq 1.5)$ & $0.0 \mathrm{~B}$ & $0.0 \mathrm{~B}$ & $0.0 \mathrm{~B}$ \\
Moderate $(1.5-3.0)$ & - & $0.1 \mathrm{~B}$ & $0.2 \mathrm{~B}$ \\
High $(\approx 3.0)$ & - & $0.2 \mathrm{~B}$ & $0.4 \mathrm{~B}$ \\
\hline
\end{tabular}

Table A.6: Additional width due to aid to navigation.

\begin{tabular}{cc}
\hline Navigational aids & Additional width \\
\hline Excellent & $0.0 \mathrm{~B}$ \\
Good & $0.1 \mathrm{~B}$ \\
Moderate with moderate visibility & $0.2 \mathrm{~B}$ \\
Moderate with bad visibility & $0.5 \mathrm{~B}$ \\
\hline
\end{tabular}

Table A.7: Additional width due to cargo risk.

\begin{tabular}{cc}
\hline Cargo risk & Additional width \\
\hline Low & $0.0 \mathrm{~B}$ \\
Moderate & $\approx 0.4 \mathrm{~B}$ \\
High & $\approx 0.8 \mathrm{~B}$ \\
\hline
\end{tabular}

Table A.8: Additional width due to the channel bottom surface.

\begin{tabular}{ccc}
\hline \multirow{2}{*}{ Bottom surface } & \multicolumn{2}{c}{ Additional width } \\
\cline { 2 - 3 } & $H / d>1.50$ & $H / d<1.50$ \\
\hline Regular & $0.0 \mathrm{~B}$ & $0.1 \mathrm{~B}$ \\
Irregular & $0.0 \mathrm{~B}$ & $0.1 \mathrm{~B}$ \\
Highly irregular & $0.0 \mathrm{~B}$ & $0.2 \mathrm{~B}$ \\
\hline
\end{tabular}


Table A.9: Additional width due to the depth-draft ratio.

\begin{tabular}{cc}
\hline Draft-depth & Additional width \\
\hline $\mathrm{H} / \mathrm{d} \approx 1.5$ & $0.0 \mathrm{~B}$ \\
$1.15 \geq \mathrm{H} / \mathrm{d} \geq 1.5$ & $0.2 \mathrm{~B}$ \\
$\mathrm{H} / \mathrm{d} \geq 1.15$ & $0.4 \mathrm{~B}$ \\
\hline
\end{tabular}

Table A.10: Additional width due to effects of proximity to existing structures.

\begin{tabular}{cccc}
\hline \multirow{2}{*}{ Structure } & \multicolumn{3}{c}{ Ship mean velocity } \\
\cline { 2 - 4 } & High & Moderate & Low \\
\hline Smooth slope & - & $0.5 \mathrm{~B}$ & $0.3 \mathrm{~B}$ \\
Steep slope & - & $1.0 \mathrm{~B}$ & $0.5 \mathrm{~B}$ \\
\hline
\end{tabular}




\section{Appendix B}

\section{Model parameters}

Table B.1: Vessel-current model parameters.

\begin{tabular}{|c|c|c|}
\hline \multicolumn{3}{|r|}{ Ship features } \\
\hline Length & $m$ & Overall convoy length (pusher and barges). \\
\hline Beam & $m$ & Overall convoy width (pusher and barges). \\
\hline Draft & $m$ & Necessary water level for the ship to navigate. \\
\hline Mass & $k g$ & Overall convoy weight (pusher and barges). \\
\hline Velocity & $\mathrm{m} / \mathrm{s}$ & Vessel initial velocity. \\
\hline Angle & deg & Vessel initial angle in relation to the reference system. \\
\hline Initial position & $m$ & Ship center of mass initial position $(\mathrm{x}-\mathrm{y})$. \\
\hline Moment of inertia & $\mathrm{kg} \cdot \mathrm{m}^{2}$ & Calculated or specified overall moment of inertia. \\
\hline Engine force & $N$ & Engine propulsion constant force. \\
\hline Azimuth thruster force & $N$ & Azimuth thruster constant force. \\
\hline Auto-pilot & - & Guide the ship to the navigation preferential path. \\
\hline Drag coefficient & - & Calculated or specified overall convoy drag coefficient. \\
\hline Lift coefficient & - & Calculated or specified overall convoy lift coefficient. \\
\hline Added mass coefficient & - & Calculated or specified overall convoy added mass coefficient. \\
\hline \multicolumn{3}{|r|}{ Auto-pilot features } \\
\hline Detection radius & $m$ & Maximum distance to detect a navigation point. \\
\hline Detection angle & $\operatorname{deg}$ & Maximum angle to detect a navigation point. \\
\hline Response time & $s$ & Time-step for the auto-pilot reaction. \\
\hline \multicolumn{3}{|r|}{ River features } \\
\hline Bathymetry & $m$ & River depth for every discrete point. \\
\hline Margins & $m$ & Position of the left and right river bank. \\
\hline Navigation channel & $m$ & Position of the preferential navigation path. \\
\hline \multicolumn{3}{|r|}{ Flow features } \\
\hline Velocity & $\mathrm{m} / \mathrm{s}$ & Synthetic flow velocity for each discrete point. \\
\hline Direction & deg & Synthetic flow direction for each discrete point. \\
\hline Velocity field & $\mathrm{m} / \mathrm{s}, \mathrm{deg}$ & Velocity field exported from a two-dimensional model. \\
\hline \multicolumn{3}{|r|}{ Simulation features } \\
\hline Time & $s$ & Simulation total time. \\
\hline Time-step & $s$ & Simulation time step. \\
\hline
\end{tabular}




\section{Appendix C}

\section{Model simulation parameters}

Table C.1: Simulation I ship parameters setup.

\begin{tabular}{cc}
\hline Parameter & Description \\
\hline Length & $200 \mathrm{~m}$ \\
Beam & $30 \mathrm{~m}$ \\
Draft & $3 \mathrm{~m}$ \\
Mass & $10^{7} \mathrm{~kg}$ \\
Engine force & {$\left[10^{5}, 10^{7}\right] \mathrm{N}$} \\
Rudder force & $200 \mathrm{~N}$ \\
$C_{\text {D,pressure }}$ & 1.0 \\
$C_{\text {D,friction }}$ & 1.0 \\
Initial direction & $90^{\circ} \mathrm{deg}$ \\
Initial Velocity & $0 \mathrm{~m} / \mathrm{s}$ \\
Auto-pilot & $\mathrm{Off}$ \\
Total time & $60 \mathrm{~s}$ \\
Time-step $(\Delta t)$ & $0.5 \mathrm{~s}$ \\
Flow Velocity & $0 \mathrm{~m} / \mathrm{s}$ \\
\hline
\end{tabular}


Table C.2: Simulation II parameters setup.

\begin{tabular}{cc}
\hline Parameter & Description \\
\hline Length & $200 \mathrm{~m}$ \\
Beam & $30 \mathrm{~m}$ \\
Draft & $3 \mathrm{~m}$ \\
Mass & $10^{7} \mathrm{~kg}$ \\
Engine force & $2 \bullet 10^{6} \mathrm{~N}$ \\
Rudder force & $200 \mathrm{~N}$ \\
$C_{\text {D,pressure }}$ & 1.0 \\
$C_{\text {D,friction }}$ & 1.0 \\
Initial direction & $90^{\circ} \mathrm{deg}$ \\
Initial Velocity & $0 \mathrm{~m} / \mathrm{s}$ \\
Auto-pilot & Off \\
Total time & $120 \mathrm{~s}$ \\
Time-step $(\Delta t)$ & $0.5 \mathrm{~s}$ \\
Flow Velocity & $0.1 \mathrm{~m} / \mathrm{s}$ \\
\hline
\end{tabular}

Table C.3: Simulation III parameters setup.

\begin{tabular}{cc}
\hline Parameter & Description \\
\hline Length & $200 \mathrm{~m}$ \\
Beam & $30 \mathrm{~m}$ \\
Draft & $3 \mathrm{~m}$ \\
Mass & $10^{7} \mathrm{~kg}$ \\
Engine force & $2 \bullet 10^{6} \mathrm{~N}$ \\
Rudder force & $200 \mathrm{~N}$ \\
$C_{\mathrm{D}, \text { pressure }}$ & 1.0 \\
$C_{\mathrm{D}, \text { friction }}$ & 1.0 \\
Initial direction & $90^{\circ} \mathrm{deg}$ \\
Initial Velocity & $0 \mathrm{~m} / \mathrm{s}$ \\
Auto-pilot & $\mathrm{Off}$ \\
Total time & $120 \mathrm{~s}$ \\
Time-step $(\Delta t)$ & $0.5 \mathrm{~s}$ \\
Flow Velocity & $0.5 \mathrm{~m} / \mathrm{s}$ \\
\hline
\end{tabular}


Table C.4: Simulation IV parameters setup.

\begin{tabular}{cc}
\hline Parameter & Description \\
\hline Length & $200 \mathrm{~m}$ \\
Beam & $30 \mathrm{~m}$ \\
Draft & $3 \mathrm{~m}$ \\
Mass & $10^{7} \mathrm{~kg}$ \\
Engine force & $2 \bullet 10^{6} \mathrm{~N}$ \\
Rudder force & $200 \mathrm{~N}$ \\
$C_{\text {D,pressure }}$ & 1.0 \\
$C_{\text {D,friction }}$ & 1.0 \\
Initial direction & $90^{\circ} \mathrm{deg}$ \\
Initial Velocity & $0 \mathrm{~m} / \mathrm{s}$ \\
Auto-pilot & $\mathrm{On}$ \\
Total time & $300 \mathrm{~s}$ \\
Time-step $(\Delta t)$ & $0.5 \mathrm{~s}$ \\
Flow Velocity & $0 \mathrm{~m} / \mathrm{s}$ \\
\hline
\end{tabular}

Table C.5: Simulation V parameters setup.

\begin{tabular}{cc}
\hline Parameter & Description \\
\hline Length & $200 \mathrm{~m}$ \\
Beam & $30 \mathrm{~m}$ \\
Draft & $3 \mathrm{~m}$ \\
Mass & $10^{7} \mathrm{~kg}$ \\
Engine force & $10^{7} \mathrm{~N}$ \\
Rudder force & $200 \mathrm{~N}$ \\
$C_{\text {D,pressure }}$ & 1.0 \\
$C_{\text {D,friction }}$ & 1.0 \\
Initial direction & $90^{\circ} \mathrm{deg}$ \\
Initial Velocity & $0 \mathrm{~m} / \mathrm{s}$ \\
Auto-pilot & $\mathrm{On}$ \\
Total time & $3000 \mathrm{~s}$ \\
Time-step $(\Delta t) 0.5$ & $\mathrm{~s}$ \\
Flow Velocity & $0 \mathrm{~m} / \mathrm{s}$ \\
\hline
\end{tabular}




\section{Appendix D}

\section{Ship calibration relations}

In order to facilitate the calibration, the model response varying the vessel mass, velocity and engine force was evaluated. The results were obtained for a straight line navigation, disregarding velocity fields and auto-pilot instructions. Analysing Figs. D.1 and D.2 for a specific cargo weight, one can determine the required engine force to reach a desired velocity. These relation is only valid for the simulated ship and its parameters, described in Tables D.1 and D.2.

Table D.1: Setup parameters used to calibrate Paraguay type vessel.

\begin{tabular}{cc}
\hline Parameter & Description \\
\hline Ship model & Barge composition \\
Engine power & $3 \bullet 10^{3} \mathrm{~kW}$ \\
Engine force & {$\left[0,10^{6}\right] \mathrm{N}$} \\
Length & $300 \mathrm{~m}$ \\
Beam & $33 \mathrm{~m}$ \\
Draft & $3 \mathrm{~m}$ \\
Mass & {$\left[10^{6}, 10^{8}\right] \mathrm{kg}$} \\
\hline
\end{tabular}

Table D.2: Setup parameters used to calibrate the Rhine River vessel.

\begin{tabular}{cc}
\hline Parameter & Description \\
\hline Ship model & Schubverband \\
Engine power & $2 \bullet 10^{3} \mathrm{~kW}$ \\
Engine force & {$\left[0,10^{6}\right] \mathrm{N}$} \\
Length & $200 \mathrm{~m}$ \\
Beam & $12 \mathrm{~m}$ \\
Draft & $3 \mathrm{~m}$ \\
Mass & {$\left[10^{6}, 10^{8}\right] \mathrm{kg}$} \\
\hline
\end{tabular}




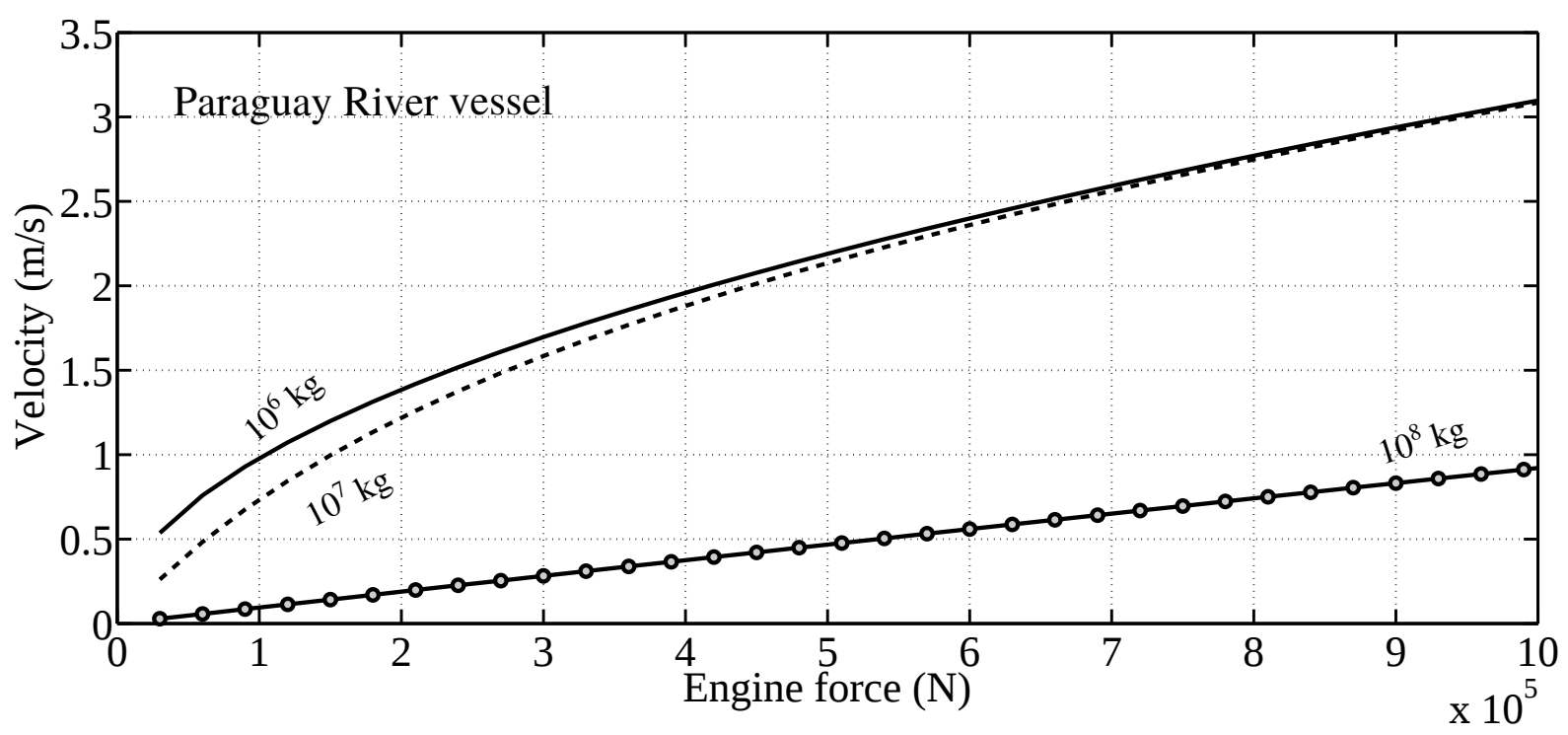

Figure D.1: Setup parameters used to calibrate the Paraguay River vessel.

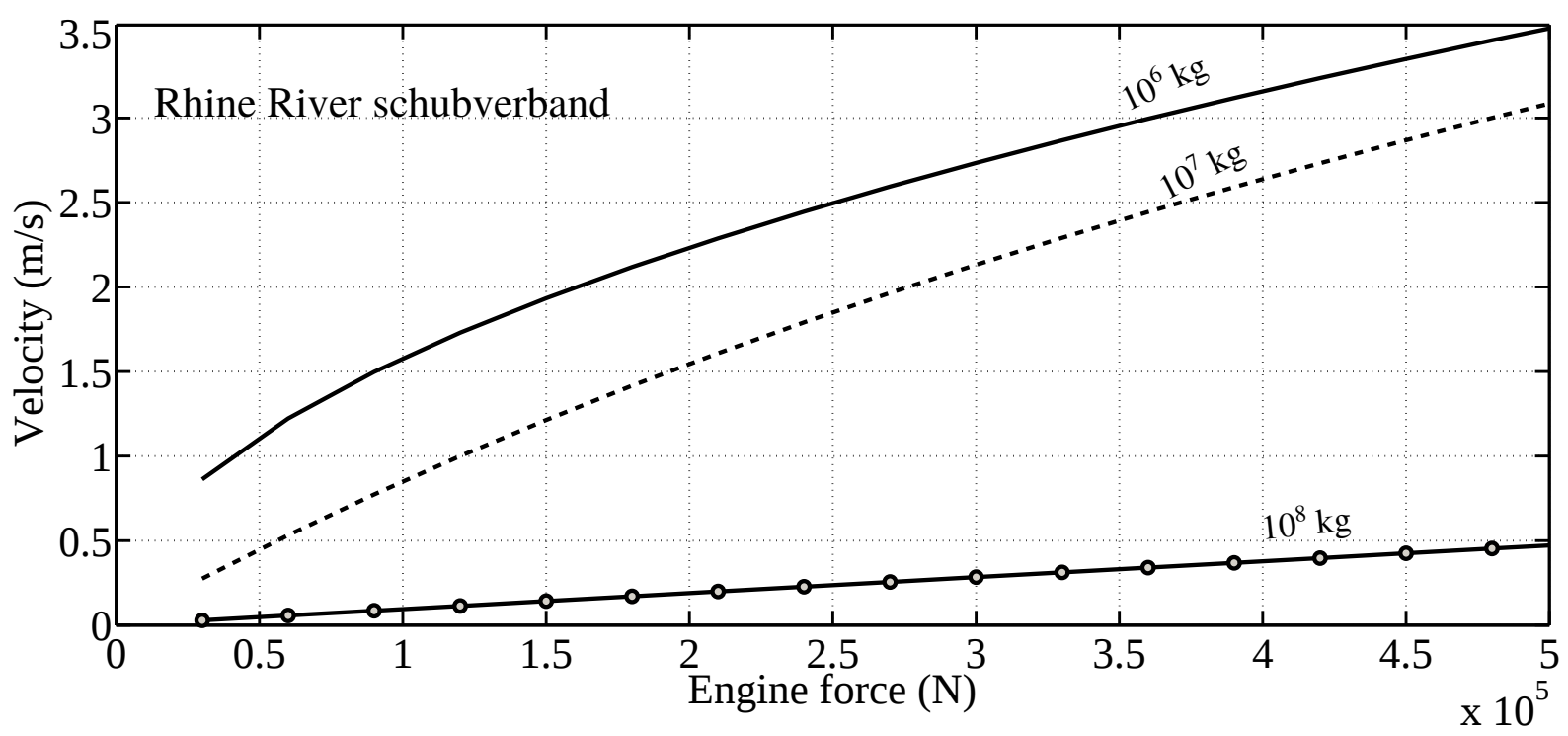

Figure D.2: Setup parameters used to calibrate the Rhine River vessel. 


\section{Appendix E}

\section{Description of developed scripts}

Table E.1 presents a brief description of the scripts necessary for the vessel-current model. The scripts were written in Matlab and Python programming languages.

Table E.1: Description of used scripts.

\begin{tabular}{cl}
\hline Script & \multicolumn{1}{c}{ Description } \\
\hline shp2mat & Read Shapefile and save data in mat format \\
\hline data_interp & Linear interpolation of missing data \\
\hline caravelas2d & Main model script - GUI, ssh and calibration version \\
\hline stat-analysis & Statistical analysis of the vessel-current model results \\
\hline mat2shp_py & Export results for a Shapefile format \\
\hline
\end{tabular}

The model tutorial and scripts are available for download at:

$\triangleright$ https://github.com/leaofrigo/caravelas2d 


\section{Appendix F}

\section{Publications}

Academic production developed within the Ph.D. period 2014-2018.

1. Errera, M. R., Frigo, A. L., and Segundo, E. V. (2014). The emergence of the constructal element in tree-shaped flow organization. International Journal of Heat and Mass Transfer.

2. Frigo, A. L., and Bleninger, T. B. (2015). A review of the navigability modeling for inland waterways. In 36th IAHR Conference.

3. Frigo, A. L., Errera, M. R., and Varassin, I. G. (2015). Numerical solution for the visitation rate of seed dispersers in forest restoration areas. In Constructal Law and Second Law Conference - CLC 2015.

4. Frigo, A. L., Tomas, G., Golyjeswski, O., Bleninger, T., Correia, R., Ratton, P., Barsotti, H., Guarneri, H., Waydzik, F., Hoepker, R., Ratton, E., and Godoy, P. (2015). Analysis of the navigability condition of the Paraguay River waterway. In XXI SBRH Conference.

5. Tomas, G. P., Hopker, R., Frigo, A. L., and Bleninger, T. B. (2016). Velocity mapping toolbox for Sontek M9 ADCP data. In River Flow Conference.

6. Errera, M. R., Frigo, A. L., Campos, R. P., and Varassin, I. G. (2017). A theoretical model of seed dispersers visitation rate in restoration areas. Journal of Theoretical Ecology (submitted).

7. Frigo, A. L., and Bleninger, T. B. (2017). Model of the movement of vessels for inland waterways assessment. In XXII SBRH Conference. 
8. Frigo, A. L., Zentgraf, R. D., and Bleninger, T. B. (2018). Two-dimensional vesselcurrent interaction model for inland waterways assessment. Journal of Waterway, Port, Coastal, and Ocean Engineering (submitted). 